$1 / 61^{3} / 1^{80}$
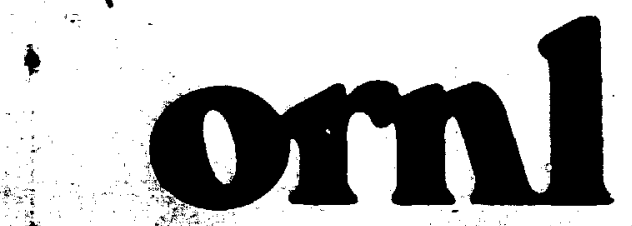

OAK RIDGE NATIONAL IABORATOES

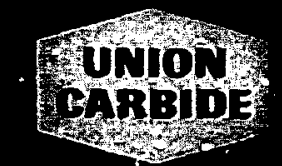

\section{Cesium Diffusion in Graphite}

\author{
R. B. Evans III
}

W. Davis, Jr.

A. L. Sutton, Jr.

\section{MASTER}

\title{
ORNL-5648
}


Contract No. W-7405-eng-26

CHEMISAL TECHNOLOGY DIVISIOA

HTGR BASE TECHNOLOGY PROGRAM

HTGR Chemistry Studies (189a 01329)

¿ESIUM DIFFUSION IN GRAPHITE

R. B. Evans $I I I^{*}$

W. Davis, Jr.

A. L. Sutton, Jr.

\section{${ }^{\star}$ Deceased.}

Dote Published: May 1980

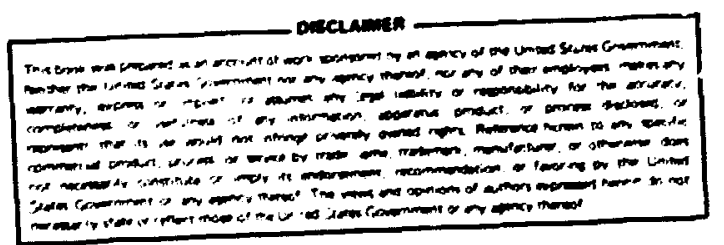

OAK RIDGE NATIONAL LABORATORY

Oak Rtdge, Tennessee 37830 operated by UNION CARBIDE CORPORATION

for the

DEPARTMENT OF ENERGY 
FOKEWORD $\ldots \ldots \ldots \ldots \ldots \ldots \ldots \ldots \ldots \ldots \ldots \ldots \ldots \ldots \ldots \ldots \ldots \ldots \ldots \ldots \ldots \ldots \ldots \ldots$

LIST OF PIGURES $\ldots \ldots \ldots \ldots \ldots \ldots \ldots \ldots \ldots \ldots \ldots \ldots \ldots \ldots \ldots \ldots \ldots \ldots$ vil

LIST OF TABLES $\ldots \ldots \ldots \ldots \ldots \ldots \ldots \ldots \ldots \ldots \ldots \ldots \ldots \ldots \ldots \ldots \ldots \ldots \ldots \ldots \ldots$ Ix

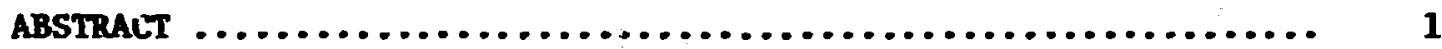

1. IMTroduction $\ldots \ldots \ldots \ldots \ldots \ldots \ldots \ldots \ldots \ldots \ldots \ldots \ldots \ldots \ldots \ldots \ldots \ldots$ 2

2. PHYSICAL PROPERTIES OF TEST GRAPHITES $\ldots \ldots \ldots \ldots \ldots \ldots \ldots \ldots \ldots$

2.1 Description of Graphites $\ldots \ldots \ldots \ldots \ldots \ldots \ldots \ldots \ldots \ldots \ldots . . . \ldots$

2.1.1 Irpregnated graphftes $\ldots \ldots \ldots \ldots \ldots \ldots \ldots \ldots \ldots \ldots .6 \ldots$

2.1.2 Structural graphites ..................... 10

2.2 Cesium Sorption by Graphites .................... 11

2.3 Nature and State of the Diffusing Cesfum ........... 15

3. EXPERIMENTAL PROCEDURES $\ldots \ldots \ldots \ldots \ldots \ldots \ldots \ldots \ldots \ldots \ldots \ldots \ldots \ldots . \ldots \ldots$

3.1 Graphite Specimen Preparation ...................... 19

3.2 Derivation and Productimn of Source Regions ........... 19

3.3 The Diffusion Anneals ......................... 21

3.4 Determination of Integral Concentration Profiles ...... 28

4. RESULTS AND DISCJSSIONS ........................ 32

4.1 Data Treatment for Ideal Diffusion ................ 33

4.2 Diffusion Coupled Hith Nonequilibriu Sorption ........ 39

4.3 Concerning Vapor-Phase rransport of Cesium .......... 51

5. SUMRLARY ART CONCLUSIONS $\ldots \ldots \ldots \ldots \ldots \ldots \ldots \ldots \ldots \ldots \ldots \ldots \ldots \ldots . \ldots$

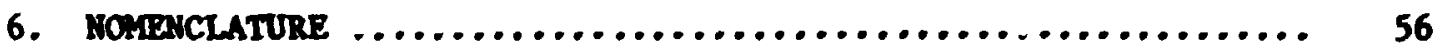

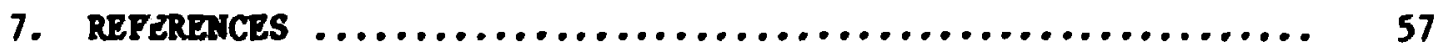

8. APPEIDIXES $\ldots \ldots \ldots \ldots \ldots \ldots \ldots \ldots \ldots \ldots \ldots \ldots \ldots \ldots \ldots \ldots \ldots \ldots, 61$

8.1 Appendix A: Experimental Data .................. 63

8.2 Appendix B: Plots of Diffust on Data ............... 83

8.3 Appendix C: Evaluation of Eqs. (16) and (17) ........ 121

8.4 Appendix D: Helium Flow During Experimente wth H-451 Graphite ............................. 125 
During the two years prior to his death in jumary $19 \%$, R. B. Evans III had performed many experikerits on the difforing of

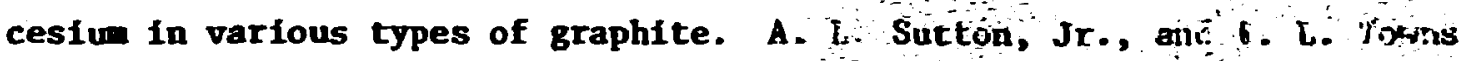
were collaborators in some of this work, wigh was a contivizinton of: that sumarfized on pp. 154-81 in Bigh Temperate Gas-forie isuctor

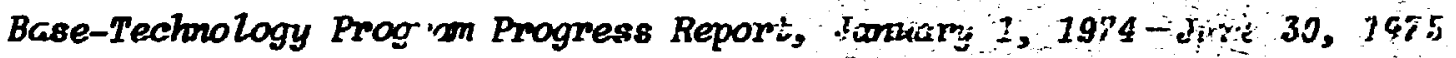
(ORIL-5108). In this report, Evans and Sieton presented a pactry juvilvIng diffusianal transport and first-order irreversible reaetion of ces in graphite. However, onls a few experfones were avajlabli, to test th theory.

At the time of his death, Evans had sitlined or written abrut halt of a report on tive cesium-diffusion experibrents. That material did not include a presertation or an analysis of the data, $\varepsilon$ task which he had. appazently only just started. His writings did include a more de: presentation of theory.

During the past year and a half, we have extracted the experimental data on cestum diffusion in graphite from various notebooks and hare completed and correrted those sections of the teport tha: Evans had started to write or had already written. This report presenti; these two items. It also presents an analysis of data on difiusion of ${ }^{37} \mathrm{Cl}_{\mathfrak{l}}$ : in HawkerSiddeley grapht te but does not contain ar. analysis of the data on other graphites in terms of theory presented by svins and sutton. As the reader will note in the Appendix $R$, there arp mary sxperimental resuite, the analyses of which should add greatly to sur knowledge of the procesides that control the transport of cestum in at lase five types of grapintes. We are not presently performing analy.zes of these data; if 18 , however, part of the purpose of this report to mals a tl:s data avaliable ro other workers so that they may be able to sest their own theories.

Wallace Dav's, Jr. Alfred L. Sutton, Jr. 
F1g. 1. Components of a Peach Botton Reactor fuel element. The fuel compact assembly is of ;rimary interest in this report .....

Fig. 2. Porostty-fore size distribuiion curves for HawkerSiddeley impregnated graphite. (Curves are based on mercuryporosimeter data.)

Fig. 3. Photogíraphs of sheazed sections of various graphites of interest. (These photrgraphs illustrate the relative sizes of the grains in the finishe? waterial, which, in turi, give sowe idea of the grain sizes in the original graphite flowers.) ..............

Fig. 4. Cesium sorpt, on isotherms for varicus graphites and coke. [The Flcwers equaticn is $\mathrm{Eq}$. (11) of ref. 18] .............

Pig. j. Stability cf :esium o ide end cesium cirbonate as a function of oxygen poten: $i_{i}$, and terperature. Isobars for cesium

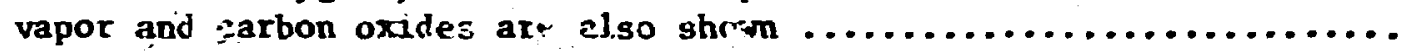

Fig. 6. Initial pezetrations rsulting from source region preparation and cesium vajurization luring conversion between $\mathbf{4 0 0}$

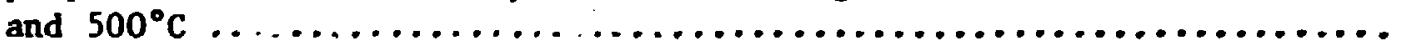

Pig. 7. Furnace cubr assembly and temperature profiles for heat treatmerzs (furnace not :hown). The arrangement of $a$ vas used for toth sestum convisich and diffuzion anneal steps; the

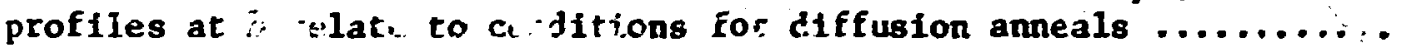

Fig. 8. 2.ails of thi sistem for sealing H-451 graphite to stainless ste:! tubing for helitm-flow experiments ..............

Fig. 9. Ren $\therefore$ sentarior $\because$ equipment used in helium-flow

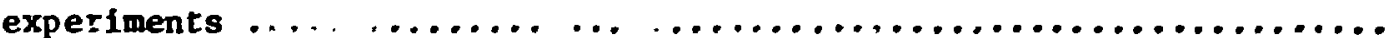

Fig. 10. jret 31 s of graph: te-stainless steel geal and of cesium concentra:-on profile:; cestum is signifiantly transported

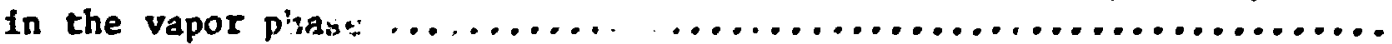

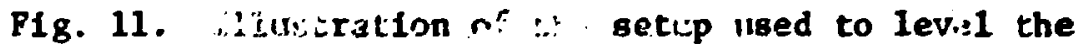
specimen prior to griniing. i!s leagtretents are referred to the bottom of the grluding irvi: which is parallel to the uppe: shoulder.) $\ldots \ldots \ldots \ldots \ldots \ldots \ldots \ldots \ldots \ldots \ldots \ldots \ldots \ldots \ldots \ldots \ldots \ldots \ldots$

Fig. 12. Major :omportrt of the lapping device laed for sectioring diffusion spectwer: $\quad 1 ;$ the anvil frame with specimen chucked into positfisi; if is the singble spindle with $\&$ polished retractable shouldir, which 2 ars ir the outer tracks of the base plate, III. A diamond iafolinp sticri. lo positioned betwes the

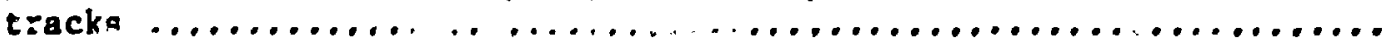


Fs.g. 13. Graphite sample mounted on optical gauge for

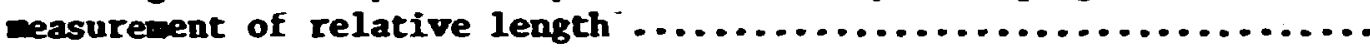

Fig. 14. Generalized integral prof 1 !.:s for cesiun diffusion

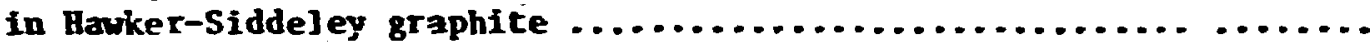

Fig. 15. Plots of two integral concentration profiles for Havker-Siddeley giaphite showing the logarith of the fraction of cesiun activity remaining as a function of the grinding or penetra-

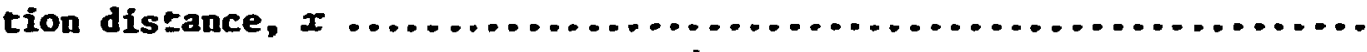

Fig. 16. Arrhenius plot ef coefficients for cesiun dfffusion in Hewker-Siddeley graphite..$\ldots \ldots \ldots \ldots \ldots \ldots \ldots \ldots \ldots \ldots \ldots \ldots \ldots \ldots$

Fig. 17. Initial appearance of integral profile data for cesiur diffusion in laige-grain H-327 graphite. (Appreciable anounts of cesfum are "held-up" near the source region; an adjusted base for $F R$ and $Q$ calculations was based on extrapolations of the bulk of the data ${ }^{0}$ base to $x=0, e . g ., I R=0.79$ and 0.82. ) $\ldots \ldots \ldots \ldots \ldots \ldots \ldots$

Fig. 18. Methods of plotting generalfzed results of the equations accounting for internal trapping in a matrix subjected to the usual thin-layer b vuda:y conditions. (Solutions of the diffusion equations with an impulse source function.) ....................

7ig. 19. Comparienn of generalized diffusion resulks obtained with an "ideal" graphite (Hawker-Siddeley curve I) and a largegrain graphite (H-327 curvc II) in which internal trapping or "plate-out" occurs. (Ali Hawker-Siddeley data tend to fall on the $\tau=0$ curve, regardless of the diffusion anneal times or temperature. Data for $t-327$ fall on different $\tau$ curves as a funct $\{$ on of time at

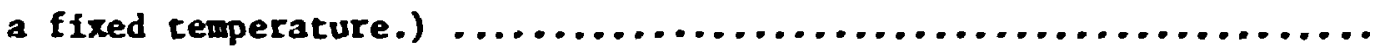

Fig. 20. Modified plozs of fraction remaining used to obtain an initfal value of $r$ for correlation pirposes $\ldots \ldots \ldots \ldots \ldots \ldots \ldots$

Fig. 21. Cesium-137 concentration profiles in experiment 1 with $H-451$ graphite. (Maximum temperature $=636^{\circ} \mathrm{C}$. ) $\ldots \ldots \ldots \ldots \ldots$

Fig. 22: Cesium-137 concentration profiles in experiment iA with H-451 graphite. (Maximu temerature $=681^{\circ} \mathrm{C}$.) $\ldots \ldots \ldots \ldots \ldots$

Fig. 23. Cestip-137 concertration profiles in experiment 3A

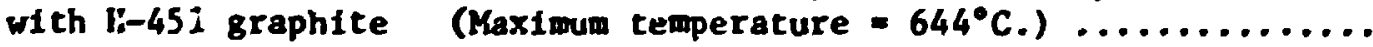

Fig. D-1. Helfum permeabilites measured with H-451 graphite

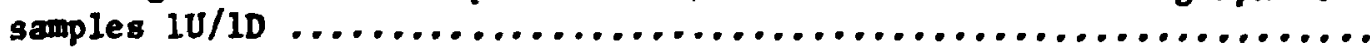

Fig. ע-2. Hellum permeabilicies measured with H-451 graphite

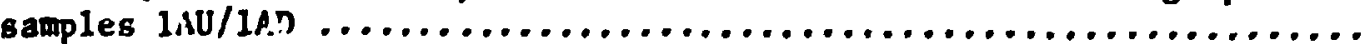

Fig. : - : Hel..um prormeabilicles measured with H-451 graphite

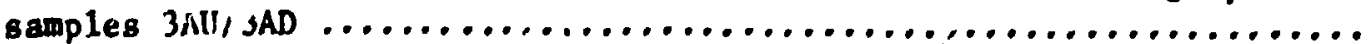


Table 1. Characterization of the bulk properties of graphite related to cesiu diffusion studies ..................

Table 2. Characterization of the gas transport properties of graphites used in cesiu-diffusion studies (noninal values based on measurements at $24^{\circ} \mathrm{C}$ : ..........................

Table 3. Anaiysis of dita on ${ }^{137} \mathrm{Cs}$ df ffusion in HawkerSiddeley graphite...$\ldots \ldots \ldots \ldots \ldots \ldots \ldots \ldots \ldots \ldots \ldots \ldots \ldots \ldots \ldots \ldots$

Table C.1. Computed values of the concentration-ratio function for diffust on with first-order plate-out in an infinitely long mediu with an instantaneous-plane (impulse) source .........

Table C.2. Computed values of the fraction-renaining function for diffusion with first-order plate-out in an infinitely Iong pedium with an instantaneous-plane (impulse) source ......... 


\title{
CESIUR aRFUSION IN GRAPHITE
}

\author{
R. B. Evans III \\ H. Davis, Jr. \\ A. L. Sutton, Jr.
}

\section{ABSTRACT}

Duriag the two years prior co his dzath in iojury 1977, R. B. Evars III, in part-rime collaboration with i, i. Sntton, Jr., performed experiments on diffusion of 137 : s it 1 ie types of graphite, namely, Hankex-Siddeley HS-1-1, Grat La'ios Carbon Company H-327, H--451, HIH-85, and Nationdl Cartor Cumpany ATJ. At the time of his death, Evans had writren abcur, half of a topiczJ report; he had not yet analyzed or sumarized the data. The present document provicics a completiun of the report that Evans in. $J$ started and inciudes a presentacion of ail of the diffusion data, previously unpublished, ottained by Evans and Sutton.

Except for data on mass transfer of ${ }^{137} \mathrm{Cs}$ in the: HawkerSiddeley graphite, analyses of experimentai resilits were initiated but not completed. The mass transter process of cesium in HS-1-1 graphite at 600 to $1000^{\circ} \mathrm{C}$ in inelfum atmosphere is essentially pure diffusion wherein v: iues of $(J / \varepsilon)_{0}$ and $\Delta E$ of the equation

$$
D / \varepsilon=(D ; \varepsilon)_{0} \exp [-\Delta E / R T]
$$

are about $4 \times 10^{-2} \mathrm{~cm}^{2} / \mathrm{s}$ and $3 \mathrm{kcal} /$ mole, respectively.

Evans has presented a modril of diffusion coupled with irreversible first-order fixafion of cestum to explain data on mass transfer of ${ }^{37} \mathrm{Cs}$ in some of the other graphices. We tested this model by use of nonlinear least sijuares to estimate diffusion and reaction rate parameters of three ots of data, one on ATJ and two on H-327 graphites. Although th. cinputer program did calculate these parameters, the $f(t)$ of dat,s :0 model was not good. The inadequacy of the model is its inability to ascount for a very steep ${ }^{137} \mathrm{Cs}$ concentration gradient at ver; smal $\perp$ penetration distances. Further anaiyses of the data will clfarly require the use of numerical techniques that permi a ms:e complicated mechanism for cesium trapping than that $e$ :yor. by irreverstble first-order kinetics.

Three experiments were performed to test for vaid-phase transport of cesfum in H-451 graphite at 635 to $680^{\circ}:$ In each case, such transport was less than the limits of weasurement. 


\section{INTRODUCTION}

It has been weII-established that wost $c_{i}$ the fission product gana activity present in HTGR heliu cooling circuits results from cesium that escaped fueled regions and then migrated into and through surrounding containment and support structures. A large portion of the available information concerning cesium migration in reactors has been generated through the auspices of the BTGR Surveillance Program, 1,2 which directs and executes examination of Peach Botton Experimental Reactor ${ }^{3}$ components. A schematic cutäway drawing of a Peach button fuel-element assembly is shom in Fig. 1. All components of this assewl.ly are composed of graphite, with the exception of the fuel kernels in $t$. coated particles which are bonded together to form the fuel compacts. Considerable interest has been shown in the past in the nature of cesium release from fuel particles; "however, current research attention has shifted to cesfum migration in porous graphites as represented by the nonfueled components in Fig. 1. Thus, one facet of our program concerns the determination and interpretation of cesium distribution patterns as they exist in fuel elements retrieved from the Peach Bot tom Reactor - particularly in spines and sleeves next to compacts. Another facet concerns an auxiliary investigation, which includes benchscale experiments designed to support the survetllance effort. Raactor component data reflect long-term migration behdvior; bench-scale results can readily be arranged to reflect short-tern (transient) behavior. The primary purpose of this report is to present results of investigations of cestum diffusion performed since our previous studies. $5-7$

The basic relationships for the transport of volatile metals, such as cesium, through graphite matrices are predicated on the reasonable assumptions that the two primary paths for diffusion are: (1) the free volumes associated with open connection pores in the matrix; (2) the graphite surfaces that delineate the pore boundaries. The first are possible regtons for gas or vapor phasc transport; the second are regtons for adsorbed phase transport. Vapor phase transport of cesfum at the temperatures and bu!k concentrations prevalling in a reactor core w11l be vanishingly small when vapor and adsorbed phases are in equilibrium. The 


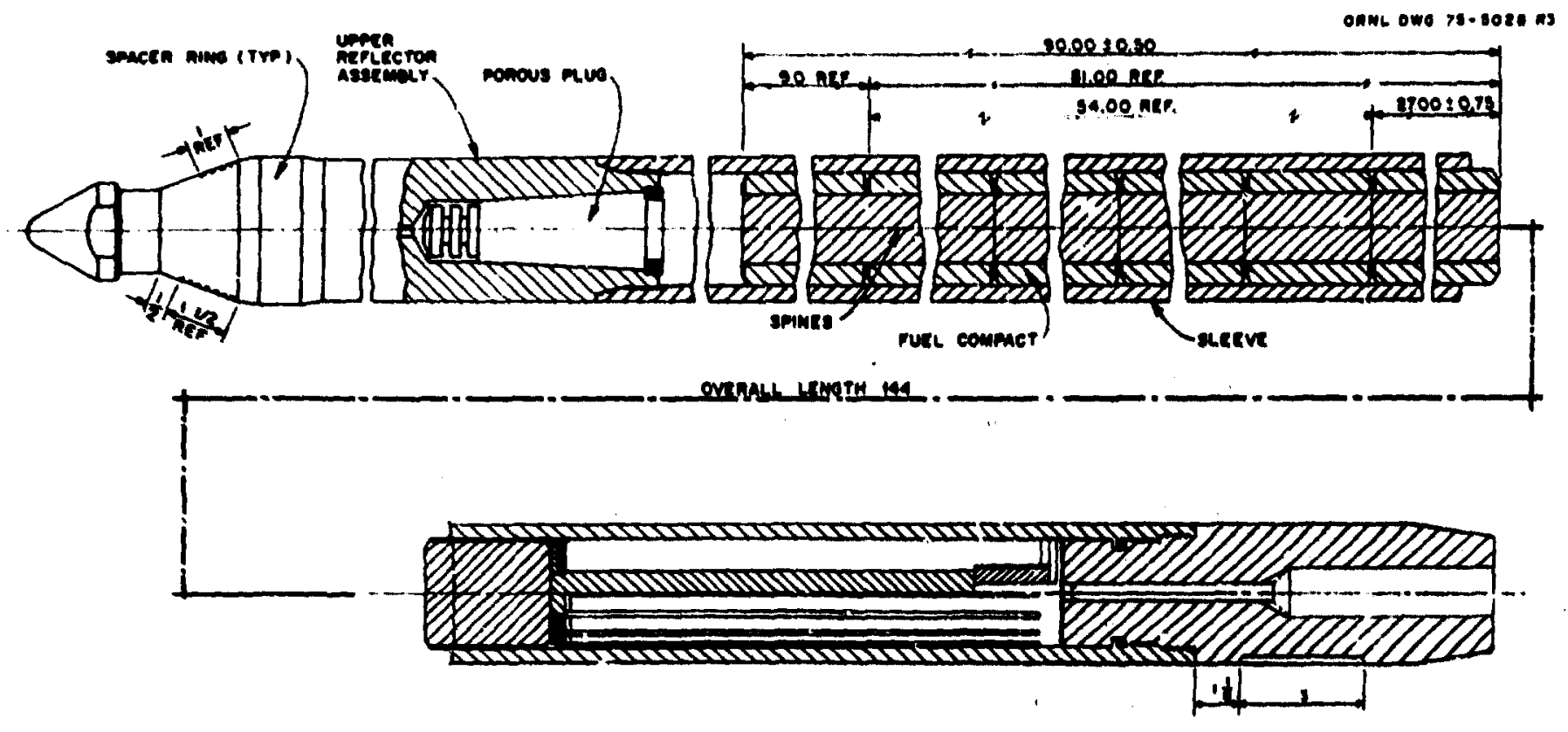

alt amensoows in newes

ASSEMBLY

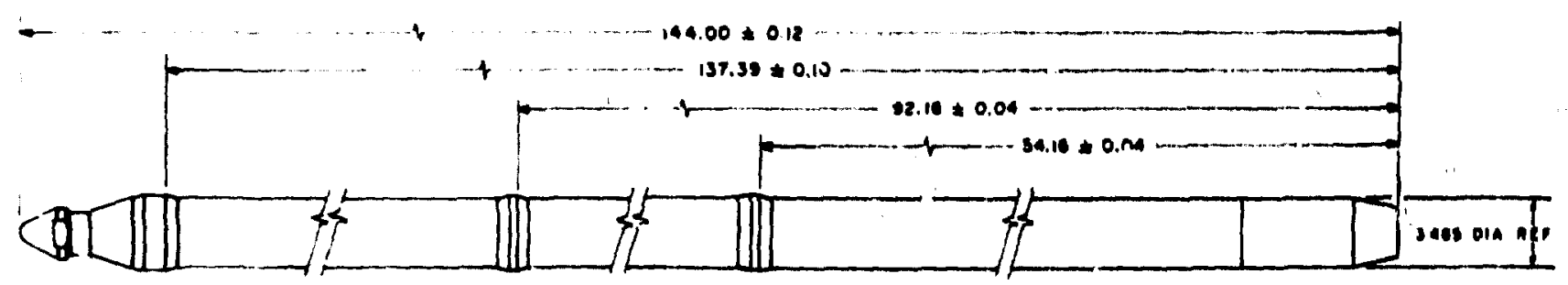

FUEL ELEMENT OUTLINE

F18. 1. Components of a Peach Bottom Reactor fuel element. The fuel compact assembly is of primary interest in this report. 
only regions and conditions wherein cesium vapor transport appears to be important are the free volumes adjacent to highly aturated strfaces (forced flow dow spine-compact-sleeve gaps) or volumes about bulk graphite surfaces prior to equilibration with respect to the adsorbed phase. Thus, it would seem that surface diffusion is the dominant cesiun migration mechanism. However, we present the results of chree experimer:s to test for the relative magnitudes of surface and vapor transport mechanisms. A combined mechanism of surface- and vapor-phase transfort has been proposed by Özisik and Silvorman ${ }^{8}$ for highly saturated systems at steady-state flow conditions and by Rodiffe ${ }^{9}$ for transient flow conditions. The latter treatment indicated that transverse flow effects are negligible at $10 \mathrm{w}$ cesium concentrations or loadings which correspond to the Henry's law region of. the sorftion isotherms.

In an effort to ubtain some correspondence with results of other investigations and the U.S. development program, we chose to conside:r at least two impregnated graphites and two high-permeability graphites. Two of these are impregnated graphites, with questionable pedigree tut pertaining to the Peach Botton Reactor; one porous graphite was chosen for its relation to the Fort St. Vrain HTGR; ${ }^{10}$ and yet another porous graphite for the new "reference design" advanced HTGR. 11

The work plan for this investigation comprised two major parts or phases: (1) a series of cesium-diffusion experiments at uniform blanket heli:m pressure within the matrix, and (2) some cesium diffusion experiments with a helium pressure drop across the specimens to induce and superpose a forced carrier flow on the cesium diffustion system.

After preliminary experiments in phase 1 , It became obvicus that the best approach would be to employ the tlassical thin-layer technique wherein cestum is placed on adjacent faces of graphite specimens which are subsequertly presised together to frrm a diffusion couple. The source region can then be described as a spike or impulse function; iffusion times and specimen dimensions can be arrangeri so that the specjmens represent semi-infinite media. With this technique, we could characterize the diffusion process by determining concentration profiles with the same grinding techniques and equipment used in earlier urantum-graphite diffugion studies. 12 
Except with Havicer-Siddéley graphite, cesium moved relatively rapidly out of the source region, then slowed down and assumed a quasi s' adystate profile, similar to profiles for imobilized daughters of mobile precursors $^{13}$ (e.g., $\mathrm{Xe} \rightarrow \mathrm{Cs}$, or $\mathrm{Kr} \rightarrow \mathrm{Sr}$ ). Something other thar simple diffuston was apparenty controlling the cesium migration in these other graphites.

\section{PHVSTCAL PROPERTIES OF TEST GRAPHITES}

\subsection{Description of Graphites}

This graphites studied in this investigation fall into two rather broad categories: those which might be classified as structural materials, and chose subjected to impregnation treatments for the express purpose of reducing the porosity and/or permeability of a given base stock. Inftial conceptual designs of nTGRs demanded impregnated graphite envelopes around fueled regions simply because the technology of coating individual fuel particles did not exist. Impregnated graphtie envelopes coupled with a back purge of helfum were the unly fission-product-migration barrier available to minimize coolant contamination in the early days. As coating techniques improved, the need for impregnated graphites diminished. The emphasis then shifted toward the utilization of nearly isotropic materials with specific structural properties and resistance to radiation damage.

Nearly all arrificial graphites are impregnated at leas: once in order to arhieve an acceptable structure. Accordingly, we note that the term "impregnated grapinite" In this report is used in reference to those materials that have undergone special and additional impregnation treatments primarily to attain permeability reduction. Typical impregnation treatments usually involve injection of pitch or an organic liquid, followed by a low-viscosity resin former, which are carbonized and rinally partially graphitized to open pores; this is followed by a careful carbonization step to produce a char residue which sirves to plug or redice the diameters of the larger pores. Resins are composed of furfuryl alcohol or furfurajdehyde catalyzed to enhance pclymer formation. 


\subsubsection{Impregnated 3raphites}

Two impregnated graphites, HS-1-1 and HIM-85, we re studied.

Howker-Siddeieu HS-1-1 is one of the remants of the experimental batches produced by the now defunct Hawker-Siddeley Power Company in conjunction with an OEEC Dragon Project development program for the preparation of HTGR core components. The ferticular specimen used in our investigarion was probably fabricated by subjecting a piece of Morgan EYX-50, a member of the EY9 family manufactured by Morganite Carbon Ltd., Battersea, London, to a single permeability-reduction treatwent with condensation of furfuraldehyde with aniline. Use if this particular impregmant elfminates water-vapor evolution iuring bakeout. This material was recefved in the form of 7.6-cm-OD cylinders. Results of the single treatment were not very Iramatic; the helium permeability at 1 atm was raduced from $1.0 \times 10^{-2}$ to $4.4 \times 10^{-3} \mathrm{~cm}^{2} / \mathrm{s}$ while the open porosity was reduced from 18 to 9 vo? \%. A pcre-size distribution curve: obtained by mercury perosimetry, for the treated waterial is shown in Fig. 2 . The - pore structure is bimodal with a primary peak at $\langle\mathbf{r}\rangle=0.55 \mu \mathrm{m}$ and a secondary peak at $\langle r\rangle=0.01 \mu \mathrm{m}$. Treatment always attacks the primary peak. The impregnation must have fivolved a flow process of some type because flow tests indicated very uniform properties. It is interesting to note that pore radius is $0.4 \mathrm{\mu m}$ as seen by permeability alone. Perhaps the most significant feature of this material, insofar as cesium diffusion is concerned, relates to the EYX-60 basa stock. The latter is manufa-tured from a finer-grained flour (not petroleum coke) mf: ith w30\% carbon hlack. ' he small grain sizes are svident in the photomicrograph show in Fig. 3. The presence of carbon black is reflected in the relatively high electrical resistivity of the treated product. The BET surface area of this material is unusually high, as :1oted in Table 1. This table Includes data presented by Bromley and Large for comparison. ${ }^{14}$

Great Lakes Carbon Company HLM-85 came to use through General Atomics in the form of a full-size nonirradiated fuel element sleeve as iself in the Peach Bottom HTGR (see Fig. 1). The base stock was fabricated from a moderate grain size "Y" coke (840- $\mu$ m maximus on edge), mixed with 


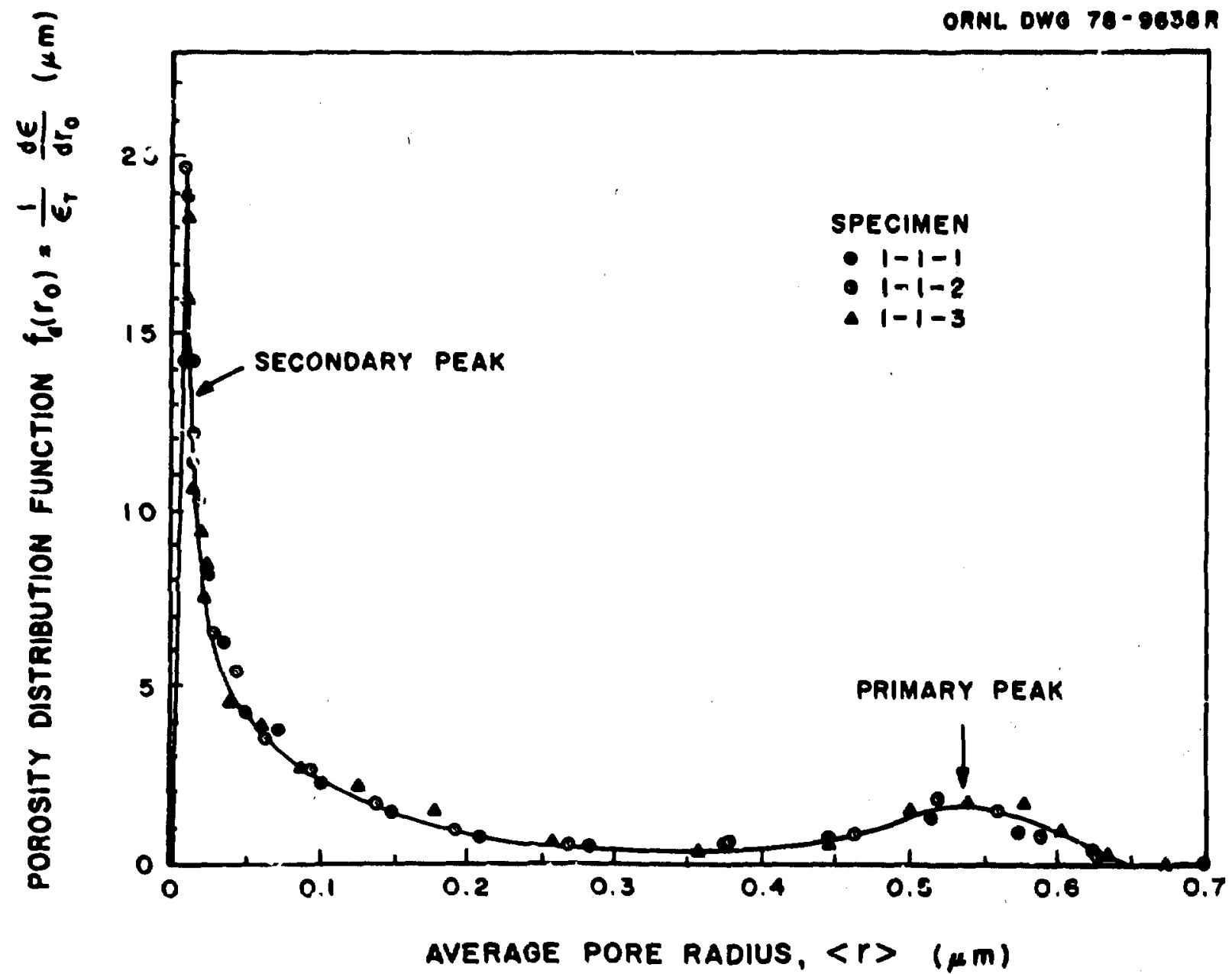

Fig. 2. Porosity-pore size distribution curves for Hawker-Siddeley impregnated graphite. (Curves are based un mercury-porosimeter data.) 


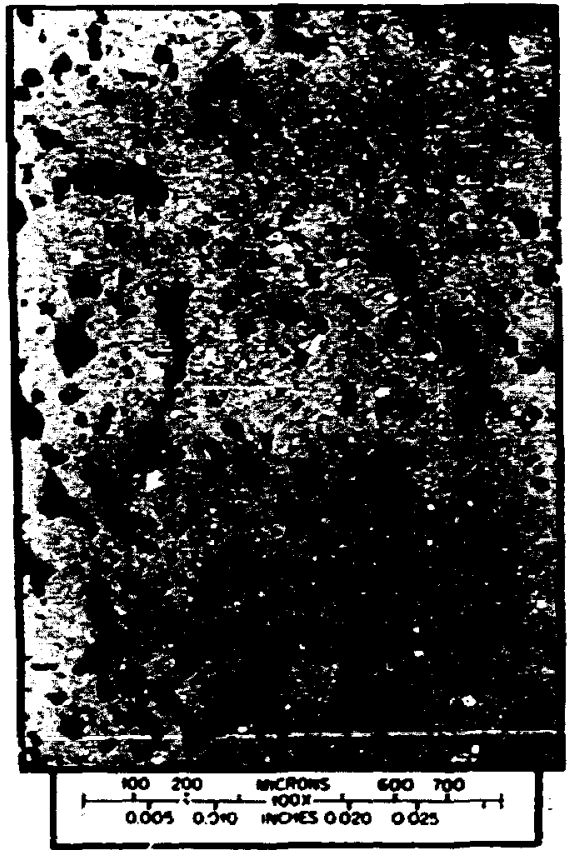

4 neceind

ats - mationa camos cemarar

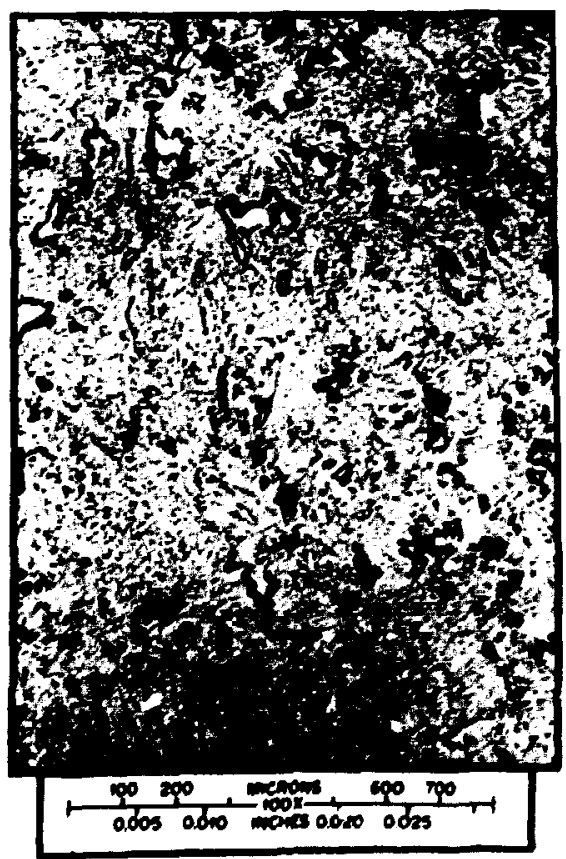

As recelived

my-ls - eneat und canon comant $r-153597$

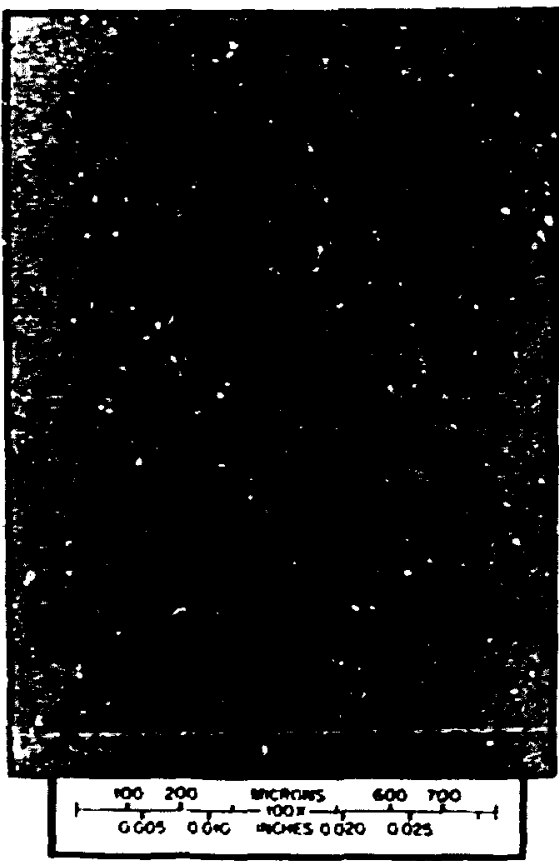

As aceative

15-1-1 - marca-sieceltr

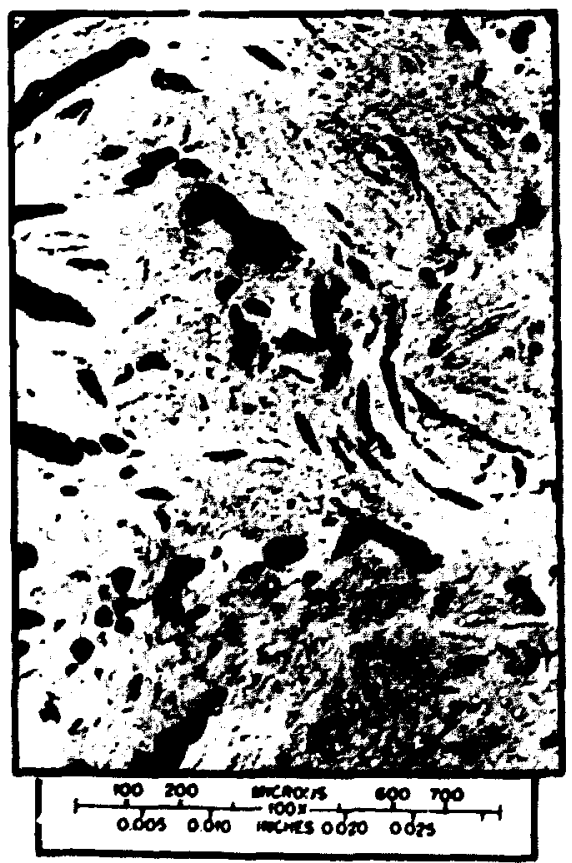

Ao Recelved

-327 - eneat uars canoon comanr

P1g. 3. Photographs of sheared sections of various graphites of interest. (These photographs illustrate the relacive sizes of the grains in the finished material, which, in turn, give some idea of the grain sizes in the original graphite flowers.) 
Table 1. Characterization of the bulk properties of graphite related to cesium diffusion studies

\begin{tabular}{|c|c|c|c|c|c|}
\hline Graphite & $\begin{array}{c}\text { Bulk } \\
\text { density } \\
\left(\mathrm{g} / \mathrm{cm}^{3}\right)\end{array}$ & $\begin{array}{l}\text { Optn } \\
\text { porosity } \\
\text { (vol } z)\end{array}$ & $\begin{array}{l}\text { Radius of } \\
\text { prinary } \\
\text { peak, <r>a } \\
\text { (um) }\end{array}$ & $\begin{array}{c}\text { BET surface } \\
\text { area } \\
\left(\mathrm{n}^{2} / \mathrm{g}\right)\end{array}$ & $\begin{array}{c}\text { Perweability to } \\
\text { helfum at } 1 \text { atm } \\
\qquad\left(\mathrm{cm}^{2} / \mathrm{s}\right)\end{array}$ \\
\hline HS-1-1 & 1.80 & 7.8 & 0.55 & $21.5^{b}$ & $4.4 E-3^{C}$ \\
\hline FLM-85 & 1.9 .1 & 10.1 & - & 0.08 & $1.3 E-3$ \\
\hline Speer 711 & 1.84 & 12.0 & - & - & 1. $0 \mathrm{E}-1$ \\
\hline ATJ & 1.77 & 13.4 & 3.0 & 0.14 & $1.0 \mathrm{E}+0$ \\
\hline$i-327$ & 1.76 & 16.7 & $2.0^{d}$ & 0.16 & $1.0 E+0$ \\
\hline$H-451$ & 1.73 & 17.2 & $4.0^{d}$ & 0.63 & $3.4 \mathrm{E}-1$ \\
\hline EY9 ${ }^{e}$ & 1.70 & 18.0 & e & 0.68 & $1.2 \mathrm{E}-1$ \\
\hline $\operatorname{tx} 12^{e}$ & 1.83 & 10.0 & $\mathbf{e}$ & 0.63 & $2.2 \mathrm{E}-3$ \\
\hline
\end{tabular}

"Based on merzury porosimetry; all graphites have a secondary peak at $0.01 \mathrm{\mu m}$.

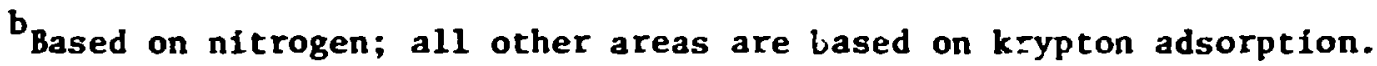

$c_{4.0 E-3}$ means $4.3 \times 10^{-3}$.

Rough estimates; results uncertain due to the presence of isolated voids ( $0.20 \mathrm{~mm} \mathrm{df} \mathrm{am})$.

Eata from J. Bromley and N. R. Large, ref. 14. Based on $K_{0}$ and $B_{0}$, $\langle r>$ values are 0.2 and $0.6 \mu \mathrm{m}$ for EY9 and $\mathrm{HX12}$, respectively. 
pitch, formed by extrusion, then graphitized and baked. Hext, two or three impregnations with pitch were performed followed by additional furan-based resin impregnations and a firal regraphitization at $2800^{\circ} \mathrm{C}$. We speculate that at least some of these treatments were performed while the structure was in the form of a holl w cylinder to perait a radial flos impregnation. In any event, the helium permeability of the final naterial was reduced to $1.4 \times 10^{-3} \mathrm{~cm}^{2} / \mathrm{s}$. Hercury porosinetry results did not indicate a definitive prinary peak pore radius. The average flow radius, $\langle r\rangle$, based on permeability measurements, was $0.5 \mathrm{~mm}$. The effective diffusion coefficient was lower than the HS-1-1 values by a factor of about 50. One wight expect this since Hil-85 was subjected to more impregnations $t$ ! an HS-1-1. The BET surface area of the treated eaterial was relatively $10 \mathrm{w},{ }^{14}$ as show in Table 1; thus we concluded that the resin char, after a final $2800^{\circ} \mathrm{C}$ treatment, will not enhance cesium absorptive capacity.

\subsubsection{Structural graphites}

National Carbon Company. ATJ graphite is employed as core support material in the Fort St. Vrain Reactor. Tois material contains finegrain-size (150- $\mu m)$ needle coke, and it appears to be fairly uniform in a given orientation direction (Fig. 3). He used this material in develop. ing techniques for placing tracer on coupons and the development of grinding techniques. Althcugh it had been impregnated with pitch wore than once during fabrication, the nominal helium permeability is somewhat high, nemely $1 \mathrm{~cm}^{2} / \mathrm{s}$ at 1 atm.

Great Lakes Carbon Company $B-327$ is the material used to fabricate the large hexagonal fuel blocks, as well as the reflector blocks, used in the Yort St. Vrain. HTGR. The starting materials were petroleum-based needle coke mixed with a coal-tar binder. After extrusion and baking, the material was purified during graphitization. Somewhere in this scheme the bodies were subjected to coal tar pitch impregnations. Sheared specimeng of the finished material reveal the presence of very large cryetalline agslomerates; polished sections (see Pig. 3) revcal frequent large pores which we mitht classify as vugs. This very coarse structure might have resulted from the utilization of very large coke grains, up to $6.0 \mathrm{~mm}$ on 
edge, in the starting materisls. If is not sutprising that this is one of the ost permeable graphites we liave ea cutered. As suown in Table 1, the helium permeability is $1.3 \mathrm{~cm}^{2}$ is at $24^{\circ} \mathrm{C}$ and 1 atm. Foctunately, the large rugs with radif up to 20 in do not ovily infinence the average bulk values. The average racius fitimited t:on frosimetry data is

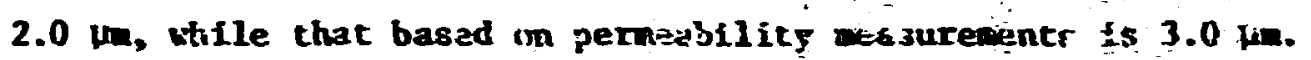

Great Lakes Carbon Cunany 4-453. The tabrication athods used for this graphite are qufte sinllar to ihose rsed for 127 . The impregant was petroleu zather than coal ta: picch. Of. grez_significance is the fact that the starting coke grafins vere nerrly isctropic, petmlemderfved particles as cor.cristed t: the niedle coice used t.n H-32i. Inspection of sheared specimens suggests $\equiv$ iner prain giructure than in H-327 (see Table 2). Miis materjal was to have been used in the advanced "large HrrRs"; its nost attractive feature is a relatively low degree of anisotrupy (imparcer oy the improved coke), with inhances radiation stability.

\subsection{Cesfum Sorptic:- by Graphites}

Some typical results or cesium-graphite equilibrium studies ar. shown in Fig. 4 In the furm of sorption isotherms; all these data were generated at che General Atomic Company. 15-17 Included are data for several different graphites of current interest, namely: TS-688, whtch is Nation:l Carbon Company block ACOT; Great Lakes Carbon Company H-327 and $\mathrm{H}-451$; and a high-surface-area coke, which is representative of a fur:l bushing watrix binder and possibly of HS-1-1. The values sought from these fsotherms are the $\alpha$ values as defined by $\mathrm{Eq}$. (1) with $n=1$,

$$
c_{8}^{n}=\alpha c_{8}
$$

These way be extracted, graphically or by use of Flowers' equation, ${ }^{18}$ from the lower left-hand segments of the 1sotherms that have a unt slope, namely the Hencian region of the 180 therm. For example at $900^{\circ} \mathrm{C}$ loee P1g. 4(a)] graphite IS-688, which has a density of $1.7 \mathrm{~g} / \mathrm{cm}^{3}$ and a eurtace area of $0.585 \mathrm{~m}^{2} / 8$, loads to $10^{-0.35} \mu \mathrm{mole} / \mathrm{m}^{2}$ at a vapor density of $10^{-10}$ umole $/ \mathrm{cm}^{3}\left(1 . e .,{ }^{-11} \mathrm{~atm}\right)$. Thus 
Table 2. Characterization of the gas transport properties of graphites used in cestum-diffuston studies ${ }^{a}$

(Nominal values based on merturements at $24^{\circ} \mathrm{C}$ )

\begin{tabular}{|c|c|c|c|c|}
\hline \multirow[b]{2}{*}{ Parameter } & \multicolumn{4}{|c|}{ Craph te } \\
\hline & HIAt-85 & HS-1-1 & E-327 & a-451 \\
\hline$\langle\mathrm{Lx} / \Delta<\mathrm{p}\rangle, \quad \mathrm{cm}^{2} / \mathrm{s} \cdot \mathrm{atm}$ & $5.36 \mathrm{E}-4^{\mathrm{b}}$ & $1.51 \mathrm{E}-1$ & $1.05 \mathrm{E}-\mathrm{C}$ & $2.16 E-1$ \\
\hline $\mathrm{B}_{v} \cdot \mathrm{cm}^{2}$ & $1.04 \mathrm{E}-13$ & $2.96 \mathrm{E}-13$ & $2.06 \mathrm{~B}-10$ & 4. $22 E-11$ \\
\hline $\mathrm{L}_{\mathrm{HeK}}, \mathrm{cm}^{2} / \mathrm{s}$ & $8.06 E-4$ & $2.84 E-\bar{s}$ & $2.75 E-1$ & $1.2 \mathrm{~B}-1$ \\
\hline $\mathrm{x}_{0}^{\mathrm{d}}, \approx$ & $4.82 E-9$ & $.70 E-8$ & $1.6 \mathrm{JE}-6$ & $7.18 \mathrm{E}-7$ \\
\hline$D_{\text {He-air }}, \mathrm{cm}^{2} / \mathrm{s}$ & $1.98 \mathrm{~B}-5$ & $.53 \mathrm{E}-3$ & $2.723-3$ & - \\
\hline$E^{\prime} / q$ (dimensionless) & $2.76 \mathrm{E}-5$ & $2.14 \mathrm{E}-3$ & $2.05:-3$ & - \\
\hline
\end{tabular}

${ }^{a}$ The bases for the values in this rable at: ns inlows:

$\eta=1.98 \times 10^{-4} \mathrm{~g} /(\mathrm{cm} \cdot \mathrm{s})$ and the inversion fact.r $1.013 \times 10^{6}$ $\mathrm{g} / \mathrm{cm} \cdot \mathrm{s} \cdot \mathrm{atm}$,

$\mathrm{v}_{\mathrm{He}}=1.254 \times 10^{5} \mathrm{~cm} / \mathrm{s}$,

$D_{\text {He-afr }}=0.717 \mathrm{~cm}^{2} / \mathrm{s}$ at experimental $t=24^{\circ} \mathrm{C}$ and $p=0.941 \mathrm{~atm}$.

See Sect. 6 for Jefinitions and refs. 6 and 13 for detailed discussion of these parameters.

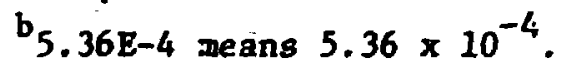



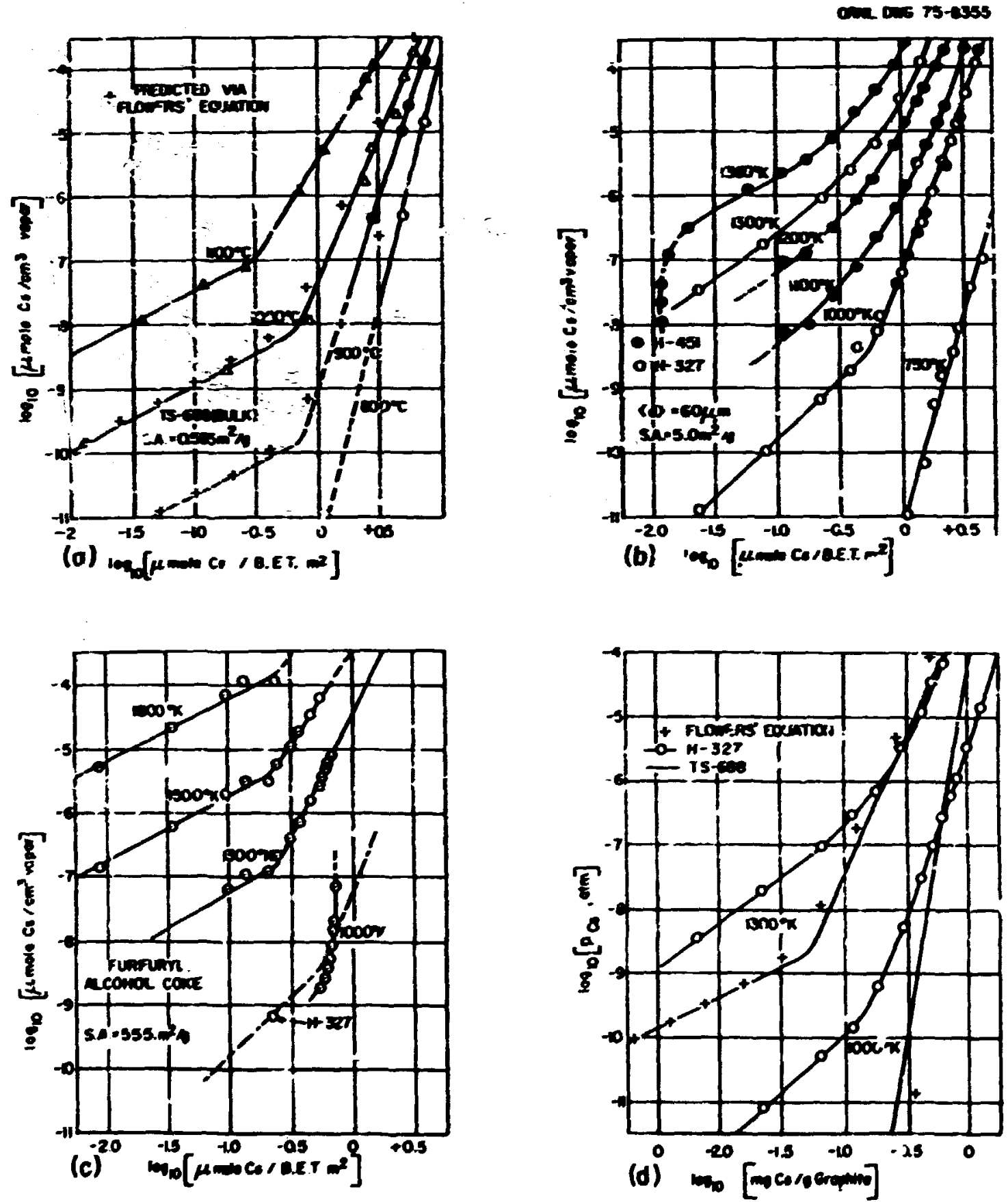

Fig. 4. Cesium sorption 1sotherws for various graphites and coke. [The rlowers equition $18 \mathrm{Eq}$. (11) of ref. 18.] 


$$
\alpha=\frac{c_{g}}{c_{s}}=2.2 \times 10^{-10} \frac{\text { bulk } c m^{2}}{\text { bulk } c m^{3}},
$$

this value being constant along the $900^{\circ} \mathrm{C}$ isotherm (within the Henry's lad regirsn) up to a loading break point at $2 \cdot 10^{-0.2} \mu m o l e / m^{2}$. Values of a for isctherms at other temperatures reveal that a varies with absolute temperature according to the equation

$$
\alpha=\alpha_{0} \exp \left(-\Delta E_{\text {sorb }} / R T\right),
$$

where $\Delta E_{\text {sorb }}$ represents: the internal sorption energy.

Regions to the right of the breakover loading are sometimes called Freundlich regions; above and to the right of these, the slopes of the isotherms cend to decrease again, suggesting the saturation of Lenrian sites and sorption by other mechanisms. In any event, present interests focus on the Henrian region.

Cesium adsorption fsotherms have been determined both by static and by dynamic methods. ${ }^{16,17}$ Each method involves a considerable number of measurements concezned with the rate of approach to equilibrim. For example, in the sciption studies of: hLM-85 graphites, the timis required to reach equilibrium in the Freundlich reginn at $1000^{\circ} \mathrm{C}$ ranged from 3 to 8 days. To keep iquilibration times within this range, and a lso to enhance sorptivity of convenfently small specimens, most of the data (TS-688 and coke excepted) ware obtained with specimens comprising small graphite particles produced by grinding and screening bulk specimens. The twodimensional features of the coke allow direct conversion of loading values of H-327 and TS-688 charcoals from a surface-area basis [Figs. 4 (a) and 4(b)] to bulk values [Fig. 4(d)]. Some queslions arise concerning the conversion of particle data to bulk values for $H-327$ and $H-451$, and it has been recommended that a particle size correction (ratio of surface areas) of $1 / 2.5$, from particle to bulk, be employed for both materials. However, the validity of this factor seems questionable in view of the different bulk surface areas cited in Table 1 . Replots of the data, in units frequently used by the General Atomic Company [shown in Fig. 4(d)], 
are based on use of the appropriate and/or recoumended conversions from particle to bulk areas. Loci of points frow an equation reported by Flowers, ${ }^{18}$ as fitted to TS-688 data, appear in Figs. $4(a)$ and $4(d)$ : Cross plots of $\log \left(\mathrm{p}_{\mathrm{Cs}}\right)$ vs $\left(\mathrm{T},{ }^{\circ} \mathrm{K}\right)^{-1}$ at a fixed loading from plots such as Fig. 4 (d) permit computation of $\Delta E_{\text {sorb }}$ from slopes corresfonaing iv the Henrian region. In this regicn, the sorption energies jo: $\mathrm{B}-327$, H-451, and the coke material all range about $67 \mathrm{k}=1 / \mathrm{mol}$. Thus, frmm the standpoint of adsorption, the only distinguishing feature of hese structures seems to be the different effective surface areas, wis. respect to cesium, and the different loading values at the breakovir point.

\subsection{Nature and State of the Diffusing Cesium}

The cesium used in our laboratory experiments was a purifled fraction extracted from a mixture of fission products. We received th as cesium chloride dissolved in hydrochloric acid. Since the extraction was performed 12 years before the present studies were initiated, tise ${ }^{134} \mathrm{Cs}$ activity had effectively decayed, leaving caly ${ }^{137} \mathrm{Cs}$ as the radioactive tracer. This considerably simplified counting procedures to assay cesium values in diffusion specimens referred to ${ }^{137} \mathrm{Cs}$ standards. Based on calculations with the ORIGEN code, ${ }^{19-21}$ it was estimated that ${ }^{137}$ Cs constituted about $40 \%$ of the total cesium; stable barium, from cesium decay was present to the extent of about $12.5 \%$ of total cesium.

Before the cesium solution was placed on graphite to form source regions, iliquots of the chloride mixture were diluted with nitric acid and evaporated to dryness twice, then redissolved in distilled water. This was done to eliminate the chloride (as volatile nitrosylchloride and chlorine) and to convert cesium chloride to cesium nitrate. Appropriate volumes of the converted solution were then placed on graphite surfaces. After drying, the cesium-bearing graphite was placed in a quartz furnace tube which could be either evacuated or continuously purged with helium. The furnace temperature was ralsed to $450^{\circ} \mathrm{C}$ while the specimens were under a helfum blanket. At this point, the system was evacuated to $22 \times 10^{-5}$ atm. Next, the helium blanket was reapplied and the 
temperature was increased to $500^{\circ} \mathrm{C}$; then the furnace was shut down to permit exanination of the graphite specinen for unifornity of cesium placement. Tests with specimens before and after this heat treatment strongly suggested that the cesiu had been converted from the nitrate to a strongly adsorbed state, probably through the internediate oxide and metallic forms.

Under the assumption that trace amounts of cesiun nitrate will decompose to cesium oxide at $450^{\circ} \mathrm{C}$, we consider the equilibrium

$$
4 \mathrm{Cs}^{\circ}(l)+\mathrm{O}_{2}(\mathrm{~g})+2 \mathrm{Cs}_{2} \mathrm{O}(\mathrm{s}) \text {, }
$$

which shifts as a function of temperature at various levels of oxygen chenical potential, as illustrated by the solid line on Fig. 5. The dot-dashed curves reflect the temperature dependence of the oxygen potential for the carbon - carbon moncxide - carbon dioxide - oxygen equilibrium and the dashed curves show the same sort of relationships for the equilibrium

$$
2 \mathrm{Cs}_{2} \mathrm{P}(\mathrm{s}) \neq 4 \mathrm{Cs}^{\circ}(\mathrm{g})+\mathrm{O}_{2}(\mathrm{~g}) \text {. }
$$

The lat:er indicates that cestum vapor pressures over the oxides are relatively high.

Consider point $A$ on $F^{\prime} \cdot 8.5$, which is near the experimental conditions where we belfeve that the oxide decomposition takes place, namely $450^{\circ} \mathrm{C}$ at $22 \times 10^{-5}$ atm (we ignore the residual helfum pressire). Since this point falls on the curve, elemental cesfum and cesium oxide could coexist on or in the graphite spectmens. We also find that carbon monoxide is the dominant oxide of carbon in the ragion of point $A$. Thus we invoke the auxiliary equilibrium

$$
\mathrm{Cs}_{2} \mathrm{O}(\mathrm{s})+\mathrm{C}(\mathrm{s}) \ddagger \mathrm{CO}(\mathrm{g})+2 \mathrm{Cs}^{\mathrm{O}}(\mathrm{g}) \text {. }
$$

with

$$
\Delta G=[-41.47+2 \times 4.37-(-60.38)]-3.203 \log _{10}\left(p_{C O}\right)\left(p_{C_{8}}\right)^{2}
$$

at $700^{\circ} \mathrm{K}$, using standard Gibbs' free energies. 


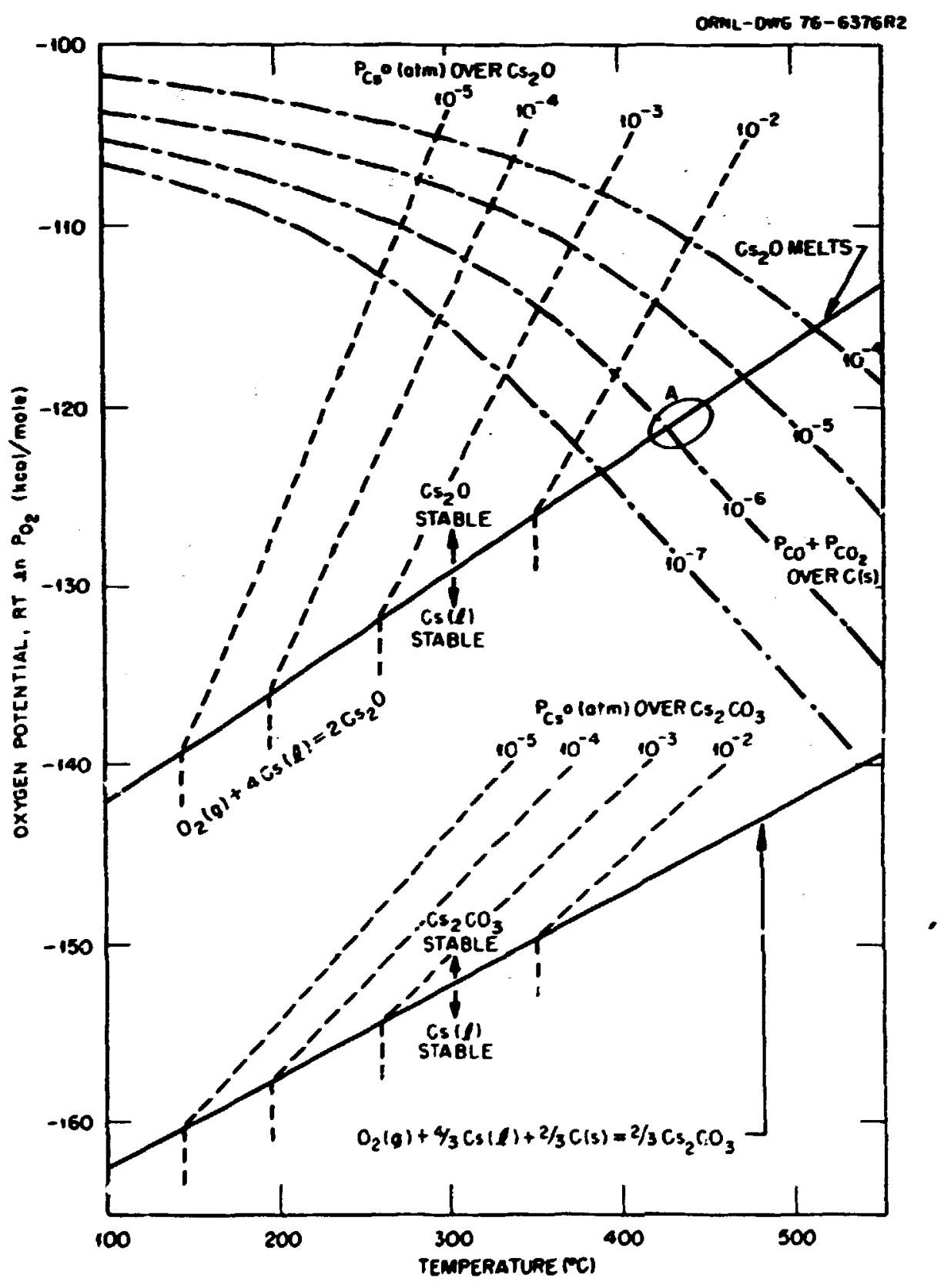

Fig. 5. Stability of cesium oxide and cesium cartonate as a function of oxygen potential and temperature. I sobars for cestum vapor and carbon oxides are also shown. 
If the rotal pressure is $2 \times 10^{-5}$ atw (pure carbon monoxide), the cesium vapor pressure at equilibrium is given by

$$
\log _{10}\left(p_{C_{s}}\right) \leq 1 / 2[-8.6+4.7] \sim-2
$$

furtherwore, the equilibrium graphite loading, from H-327 sorption isotherms, for example, would be greater than $0.5 \mathrm{mg} \mathrm{Cs} / \mathrm{g}$ graphite. Actual experimental loadings obtained with the subject procedures, conditions, and aterfals turned out to be $20.1 \mathrm{mg} / \mathrm{g}$, well within the uncertainties of theoretical calculations. We conclude that all the ces,um placed on the graphite (as nitrate) reacted to form adsorbed cesiun. Also, the adsorbed cesium at diffusion-anneal temperatures probably coexisted with small quantities of cesium in the vapor state.

\section{EXPERIMENTAL PROCEDURES}

Ciassical thin-layer techniques frequently eaployed for selfdiffusion measurements in solid-state systems were used in this investigation. Briefly, a layer of cesium nitrate was placed on the inner faces of two identical cylindrical graphite specimens to form diffusion couples such that the diffuston would proceed axially from (normal to) a coumon plane source when subjected tó diffusion anneal temperatures ranging from 600 to $1000^{\circ} \mathrm{C}$. Annealing times and specimen lengths were adjusted to ensure that semi-infinite solutions to the diffusion equation would apply. After the diffusion anneals, the specimens were sectioned and analyzed to establish the nature and extent of cesium transport. Utilization of the thin-layer technique has special advantages: It allows some controi of cesium corcentrations; it obviates the need for complicated flux measurements; and all the characteristics of the cesium-transfer process are reflected by the shape of the section profiles.

The thin-layer technique was used in its simplest form in all experiments with ATJ and H-327 graphites and in four experiments with HS graphite. static helium formed the atmosphere in each of these experiments. Experiments with $\mathrm{H}-451$ graphite were all perforwed with helium flowing through the pair of samples to test the significance of vapor-phase transport of 
cesium. Finally, experiments with HIM-85 graphite were performed with samples in the form of approximately 0.76-cm-dian cylinders pressed into annular cylinders of HS graphite of approxinately 1.8-ce outside dianeter.

\subsection{Graphite Specimen Preparation}

The diffusion specimens for experimerts with ATJ, B-327, and $\mathrm{B}-451$ graphites and for four experiments with HS graphite were fabricated by cutting and carefully achining stock material into indiriduai cylindrical shapes with diameters ranging about $1.4 \mathrm{~cm}$ and lengths ranging between 1.0 and $1.4 \mathrm{~cm}$. In the beginning, the circular surfaces normal to the axes rere ground flat and parallel within very close tolerances after machining. This step was eliminated, however, when we became concerned about charging debris into surface pures, and it became obvious that the unexpectedly deep penetrations of cesium relaxed the need for close surface dimensions. To remove debris created by machining, finished specimens were heated to $2250^{\circ} \mathrm{C}$ on a hot plate and then dropped into cool 1sopropanol. A vigorous inhalation-ejection of alcohol was thus obtained; this expelled most of the debris present (ultrasonic cleaning appeared to us to be somewhat drastic). Finally, the specimens were outgassed under vacuum at $i s 0 \Omega^{\circ} \mathrm{C}$.

Specimens of HLM-85 graphtite were obtained by cutting sections of approximately 1-cin width parallel to the axis of Peach Bottom sleeve No. 1010. This concentric-cylindez sleeve had an inner diameter of $5.7 \mathrm{~cm}$ and ail outer diameter of $7.6 \mathrm{~cm}$. The cut sections, of roughly trapezoidal cross section, were machined into $0.792-\mathrm{cm}-\mathrm{d}$ iam cylinders. Each of four samples of HLM-85 graphite was pressed into a sleeve of HS graphite that had been bored to provide a tight fit of the two graphites. 0.ter diameters of the HS sleeves were about $1.8 \mathrm{~cm}$.

\subsection{Derivation and Production of Source Regions}

One of the more difficult laboratory exercises was the development of an acceptable cesium source configuration for the diffusion experiments. Based on the initial assumption that the experiments might best be conducted 
under constant source potential conditions, the possibility of using rather large (1.4-cri-diam $\times 0.5-\mathrm{cm})$ sources, in the form of cesium im, regnated graphite, was explored. This approach was abandoned since ii was nearly :-mpossible to guarantee uniform cesium concent rations in suck. sources. furthermore, with most graphites, the sorbed cesium seemed to be permatrent ly attached to the graphite grains after an initial movement thrisugh the watrix. This meant that a high level of activity would have io be carried throughout the diffusion anneals to obtain measurable levels in the specimers. The second approach involved attempts to generate a thin-layer boundary condition using thin impregnated wafers: Untortunately, the problems mentioned abrve remained to some degree. Also the wafers were very fragiie and difficult to handle.

Finally, we decided to plate the cesium tracer (in aqueous form) directly on one face of the diffusion specimens after treating the face with a temporary pore-blocking agent such as paraffin wax, mineral oil, kerosene, and/or naphthalene. The paraffin and oil were difficult to remove; kerosene had a tendency to evaporate before the aqueoug solution dried up. Naphthalene gave the most satisfactory results, since judicious aprlication of mild hea: and vaccum to the treated specimens permitted solution drying before naphthalene removal via sublimination.

After trac:r placement, specimen pairs were inserted in a quartz sleeve, which, in rurn, was placed in a quartz furnace tube such that latoled ends of the specimens were in intimate contact. Then the entire assembly was heated to $500^{\circ}$ r for nitrate to adsorbed-state conversion. The total activity on each specimen was checked before and after the conversion step to make sure that the activities were nearly the same on each source surface.

During one source-region preparation, the two H-327 specimens drifted apart when the vacuum was applied at $450^{\circ} \mathrm{C}$; thus the iaces were not in conuact during the conversion siep (between 400 and $500^{\circ} \mathrm{C}$ ). When the array was cooled down, we found that $25 \%$ of the tracer orfginilly placed on the s:pecimen surfaces had plated out all $a^{\prime}$ ng the quartz sleeve. A similar cest wth two intentionally separated $\mathrm{H}-327$ specimens exposed to $700^{\circ} \mathrm{C}$ 
revealed that 507 of the cesium present deposited on the quartz sleeve. The results strongly suggested that elemental cesium vapor was present during conversions and inftial stages of diffusion anneals. They also demonstrated how all of the specimens picked up various quantities of cesium during heat treatments even though the clearances between the sleeve walls and graphite surfaces were very small.

Exemplary integral concentration profiles for source regions (fraction activity remaining after grinding away ax axial $N$ :stance, $x$ ) are shown in Fig. 6. The curves resulted from procedure evaluation lests with H-327 (the most pcrous and nonuniform graphite); naphthalene was clearly the best nore-blocking agent, but sone penetration via diffusion took place during conversion. Since the penetrations indicated on Fig. 6 at $500^{\circ} \mathrm{C}$ - plus those induced on the trip to higher diffusion anneals must sometimes be accounted for through a dumy run, several specimen pairs were set aside for this purpose.

\subsection{The Diffusion Anneals}

Diffusion couples, except those involving HLM-85 cylinders in HS sleeves, with acceptable source regions were again placed in a tightficting quartz sleeve which, in turn, was slipped into a quartz furnace tube as shown in Fig. $7(a)$. Since we found that specimens could shift about, the couple was held in contact by graphite keys wedged into the inner sleeve $a^{t}$ the ends of each specimen. Annealing was carried out in a small resistance furnace connected to a temperature controller with a sensor in contact with the outer quartz tube. Temperature measurements during annealing were made with a calibrated Chromel-Alumel thermocouple positioned as in Fig. 7 (a). Suparate temperature surveys [Pig. 7(b)] along tine length of the inner tube were made with a thermocouple with the end attached to a close-fitting graphite plug to ensure that the diffusion couple resided in an isothermal region.

When an anneal was inftiated, the system was held under vacuum until timperature-pressure conditions of $250^{\circ} \mathrm{C}$ and $20 \mathrm{im} \mathrm{Hg}$ were attained, at which point helfum was admitted to a pressure of 20 torr above atmospheric. 


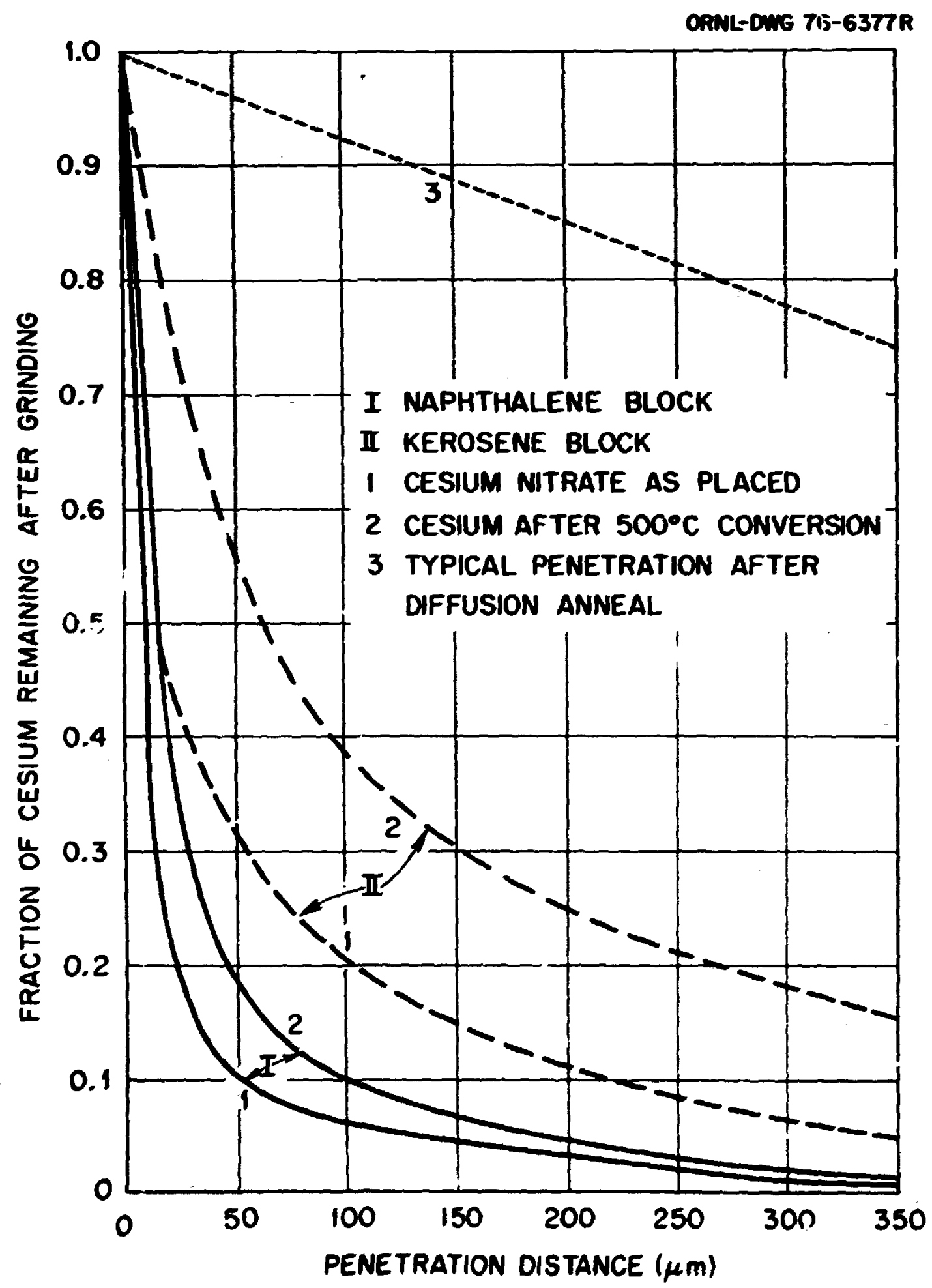

Fig. 6. Inttial penetrations resulting from source region prepisatio. and cesfum vaporization during conversion between 400 and $500^{\circ} \mathrm{C}$. 


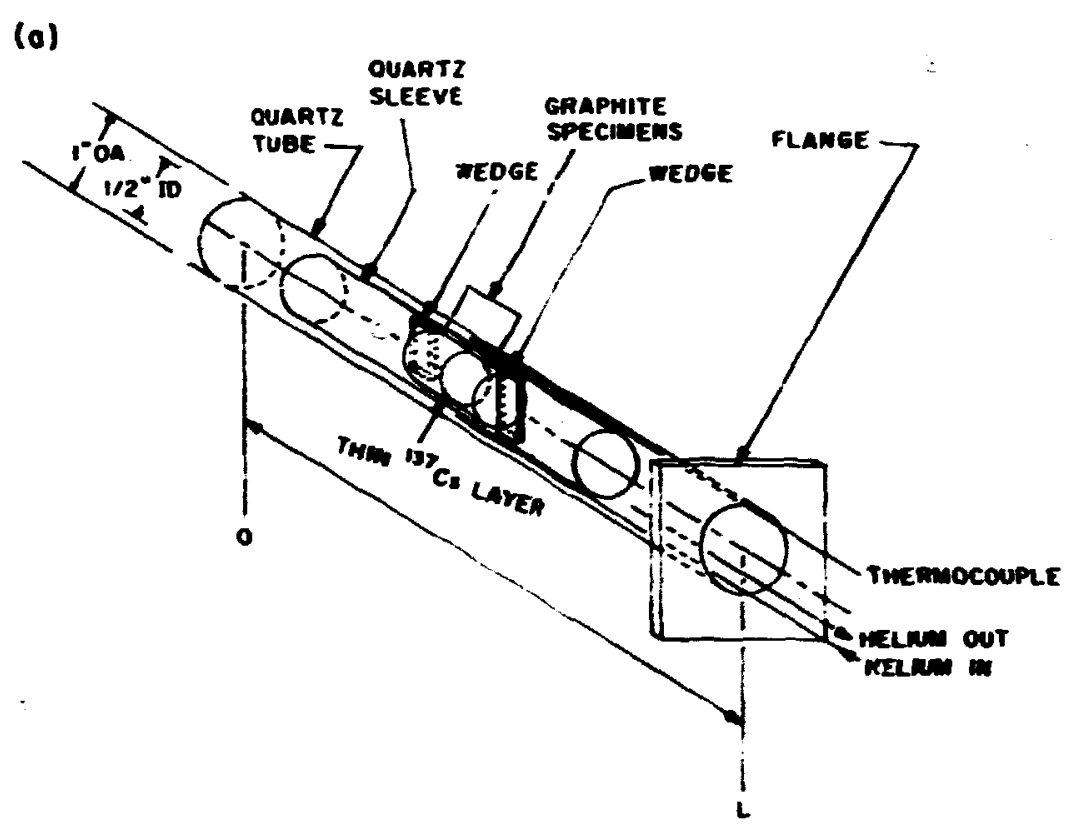

(b)

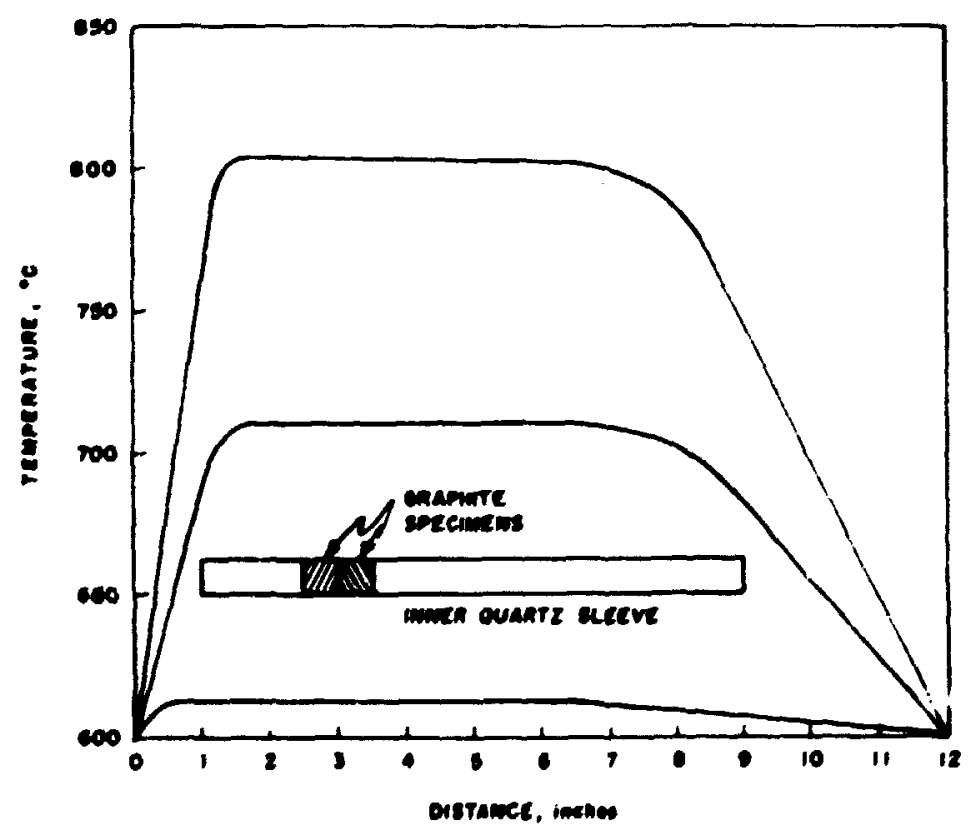

remenatunc calimation oata

Fig. 7. Purnace tube assembly and temperature proftles for hest treatments (furnace not shown). The arrangement of a was used for both cesium conversion and difusion anneal steps; the profiles at $b$ relate to corditions for dif fusion anneals. 
The helfur blanket, with a $:-\mathrm{cm}^{3} / \mathrm{s}$ sweep, was maintained during the rest of the operation which included (1) the renainder of the approach to annealing temperature, (2) the anneal at temperature, and (3) the coolfing to roon temperature. The heliw inlet and outlet were arranged so that the region about the diffusion couple was at uniform pressure (no helium flow through the specinens except in experinents with B-451 graphite).

Blank or dung runs were performed in exactly the sane way as described above with the exception that the specimen was held at the annealing temperature for only 1 an. Times required to increase teperatures from $500^{\circ} \mathrm{C}$ to 600,800 , and $1000^{\circ} \mathrm{C}$ were 4,18 , and 70 an respectively.

As wentioned above, experiments with H-451 graphite were performed partly for evaluating the magnitude of vapor-phase transport of cesium. Equipment used in these experiments was more complicated than that used in all others because of the need to eliminate leakage flow of heliu between graphite and its container and to measure helfum flow rates. The apparatus used for annealing is shown in P1g. 8, while a line drawing of the flow-measuring apparatus is shown in Fig. 9. The setup for sample holding consisted of a hydraulic jack and associated compression sleeves and rings. In srief, axial pressure from the jack was trangntted radially through a silver sleeve to the internally copper-plated, thin-walled $(0.015-$ cw or 0.006-in.) stainless-steel tube that contained the graphite specimens.

Extensive tests were made to ensure a good seal of the copper-plated stainless-steel tube to the graphite specimens. In fact, the setal tube had to be torn from the graphite specimens before we could reasure radioactivity count rate versus penetration.

Pigure 10 contains a wore detalled drawing of the graphite sample and stainless-8teel tube. Also shown in this drawing is a conceptugl representation of the skemess in cesi w penetration expected to be caused by flow of hellum throngh the back face of the upstream graphite sample, through the region of contact of the two samples, and, finally through the back face of the downstream sample. 


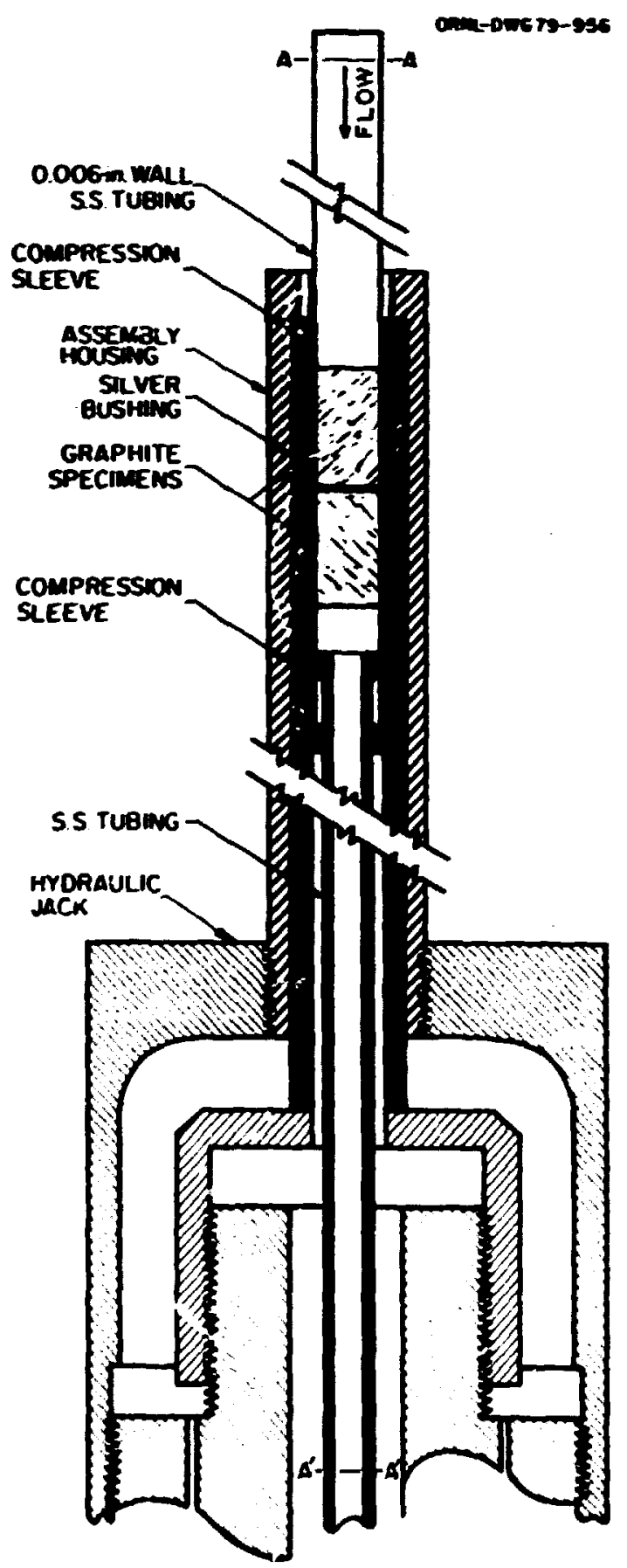

P1g. 8. Detalls of the system for sealing H-451 graphite to stainless steel tubing for hellum-flow experiments. 


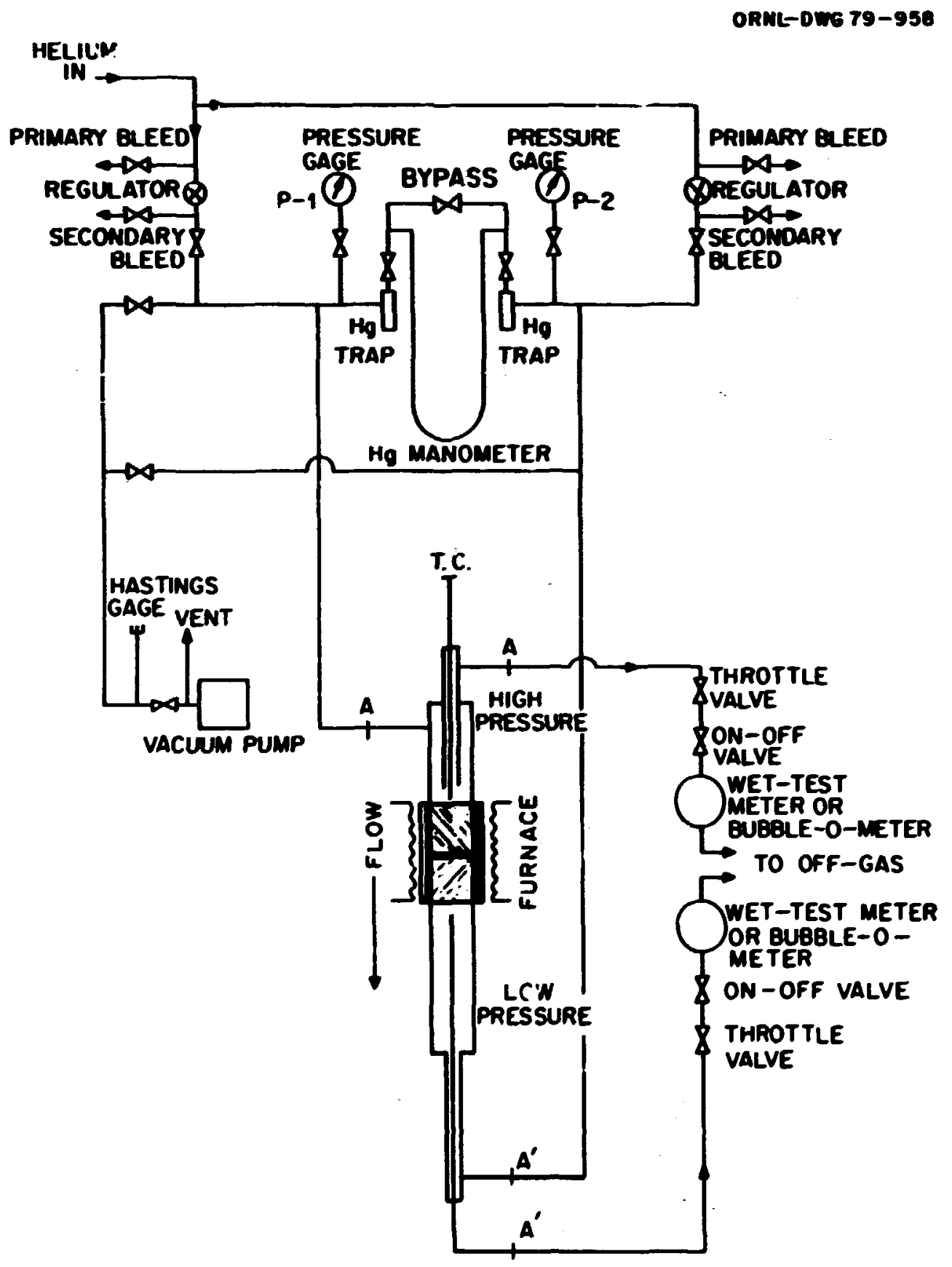

F1g. 9. Representation of equipment used in helium-flow experiments. 


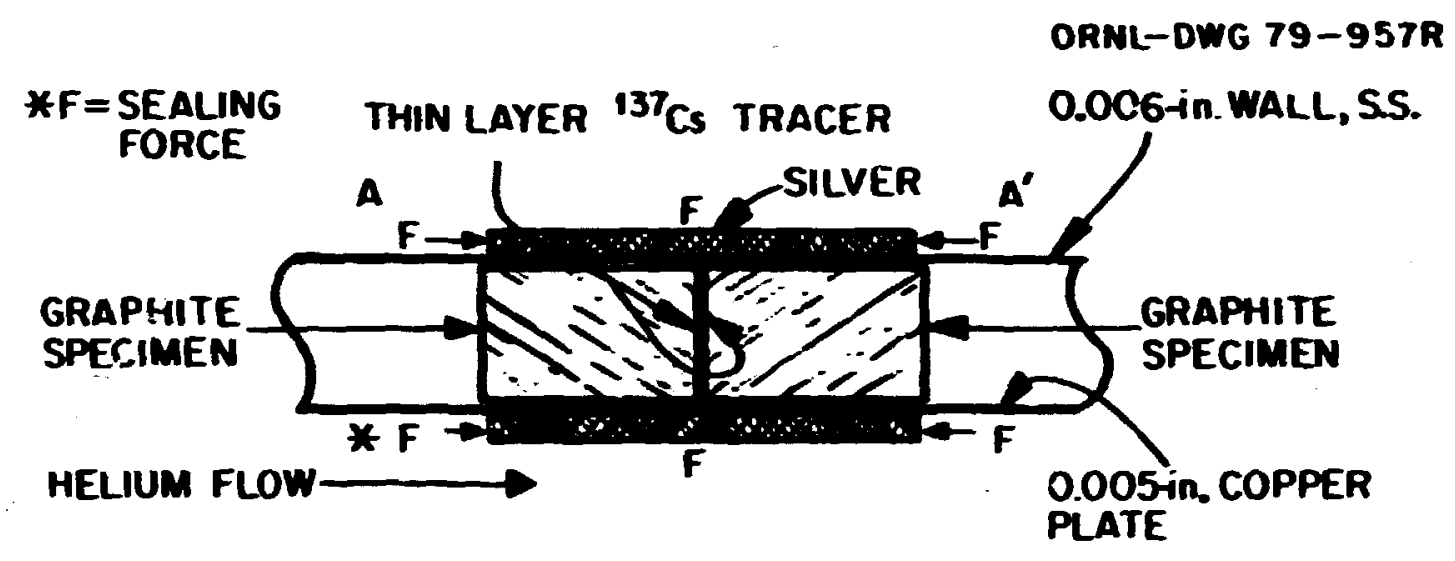

COUPLE ENCLOSED FOR DIFFUSION ANNEAL

CESIUM CONCENTRATION PROFILES ANTICIPATED AT $t_{1}$ AND $t_{2}\left(t_{1}<t_{2}\right)$

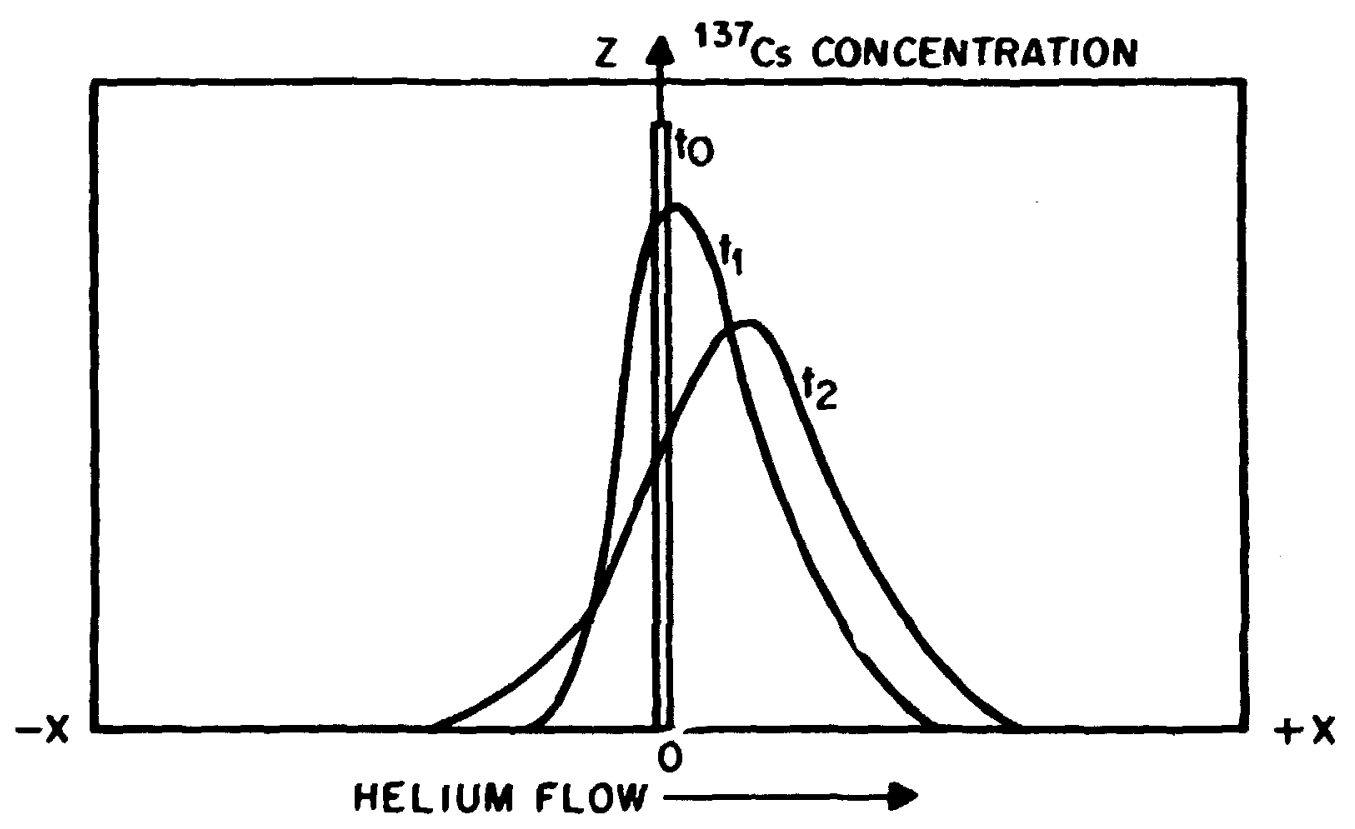

71g. 10. Detalls of graphite-statnless steel seal and of cesium concentration profiles if cesium is significantly transported in the vapor phase. 


\subsection{Determination of Integral Concentration Profiles}

After removal from the annealing furnace, individual. diffusion specimens were counted and then trimmed, in sections, over the sides and back using a small lathe enclosed in a glove box. This was done to elfminate spurious contributions of contamination over these surfaces and to obtain dimensions suitable for the lapping device; pieces were collected and counted to estimate the extent of contamination or to determine whether the specimen was acceptable for sectioning.

Trimed specimens were cemented to a metal cylinder, and the latter was chucked into the lapping device shown in Fig. 11, using a height gage and surface plate (not shown). This was a critical step because accurate grinding required that the plane of the outer shoulder of the device be perfectly aligned with the specimen surface. The grinder is actually a modified micrometer, some detalls of which are shown in Fig. 12. In cumponent $I$, a nylon collet surrounds the mounting cylinder and the back of the cylinder presses against a small-diameter anvil (not shown). Alignment or leveling was performed by tapping the cylinder at appropriate points while tightening the collet with a small spanner. The ground back surface of $I$ served as a reference plane for leveling, lapping or grinding, and measurements of grinding distances. This surface was parallel with the shoulder on II and the plane of lapping.

During use, parts $I$ and II were engaged as in Fig. 11, and the shoulder of II was fitted into the tracks of the base plate III (specimen down). For the first cut, considerable care was required for the height adjustment of the specimen surface with respect to the diamond lapping stone. Retraction of the shoulder advanced the specimen toward the stone. The calibrated markings and verniers were used to "set-up" a lapping distance of grinding interval. However, the final depth measurements were made with a direct-reading optical gage, as shown in F1g. 13, before and after each grinding operation. Grinding was carried out by moving the grinder back and forth over the grinding stone with a rotary motion.

All activity determinations, grinding operations, and height measurements were performed with the specimen chucked in the grinder; 1 ts 


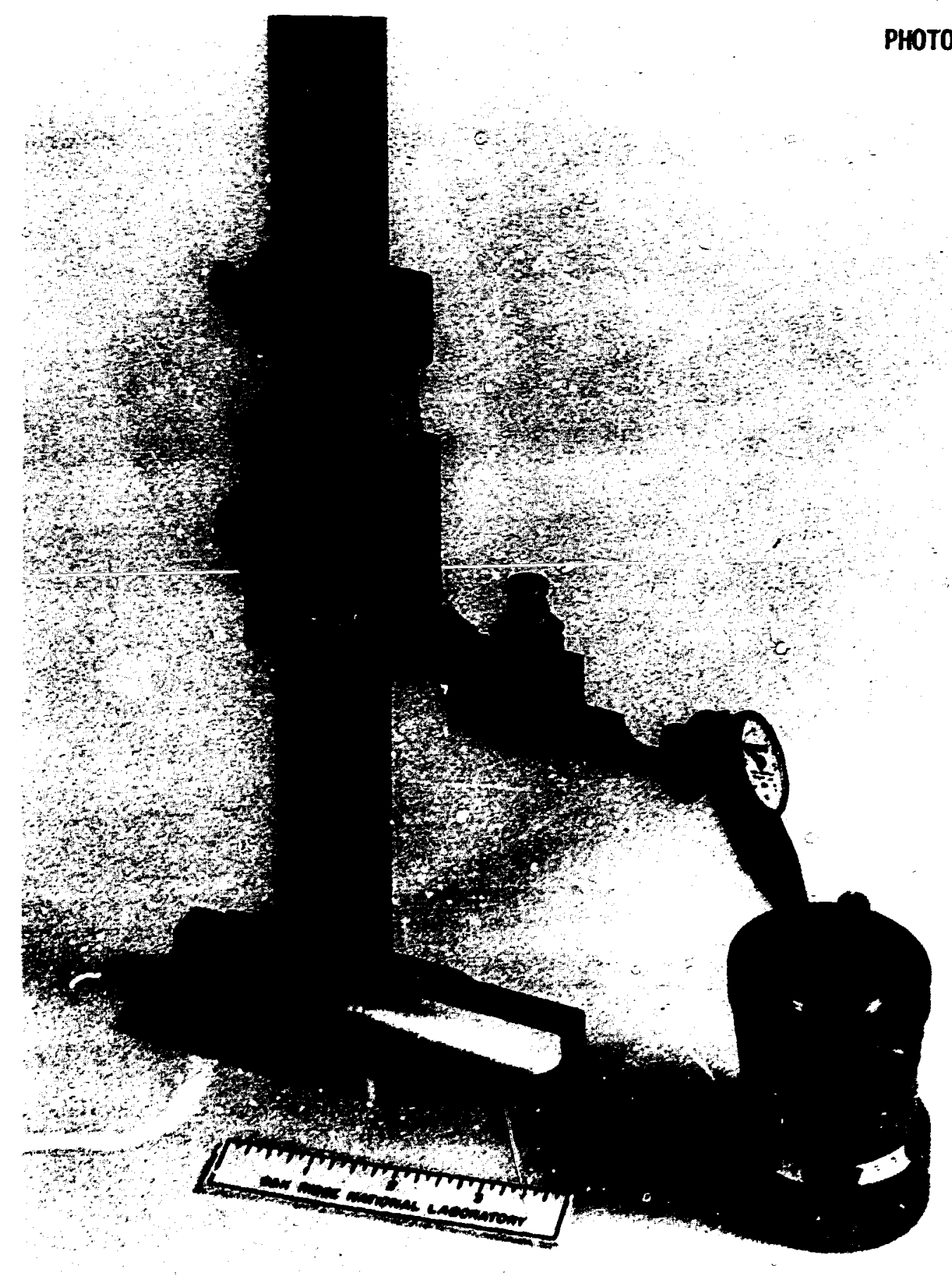

P18. 11. Illustration of the setup used to level the specimen prior to grinding. (All measurements are referred to the bottom of the grinding device, which is parallel to the upper shoulder.) 


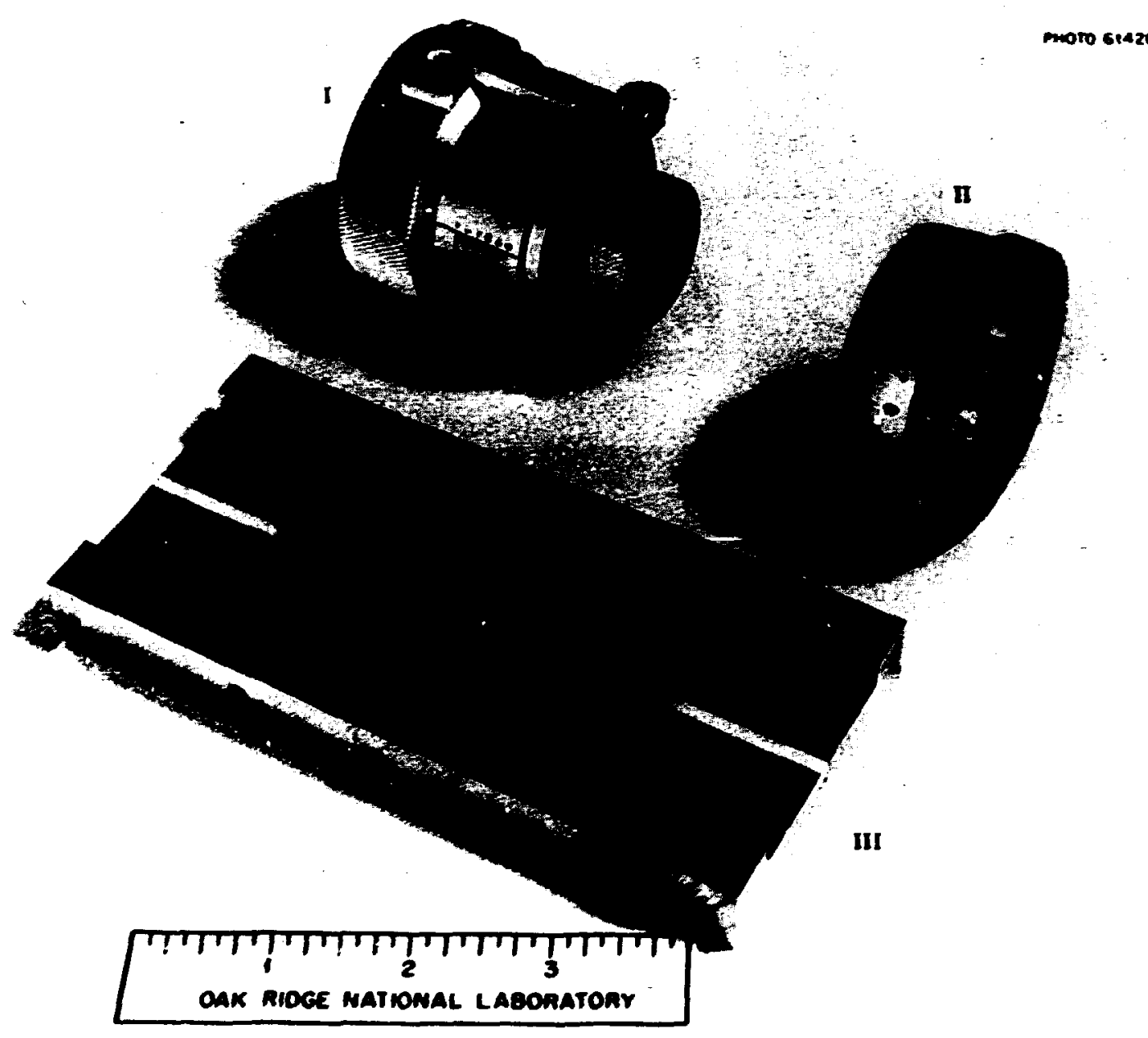

Fig. 12. Major component of the lapping device used for sectioning diffusion specimen. I is the anvil frame with specimen chucked into position; II is the thimble spindle with a polished retractable shoulder, wh.ich bears on the outer tracks of the base plate, III. A diamond lapping stone is positioned between the tracks. 


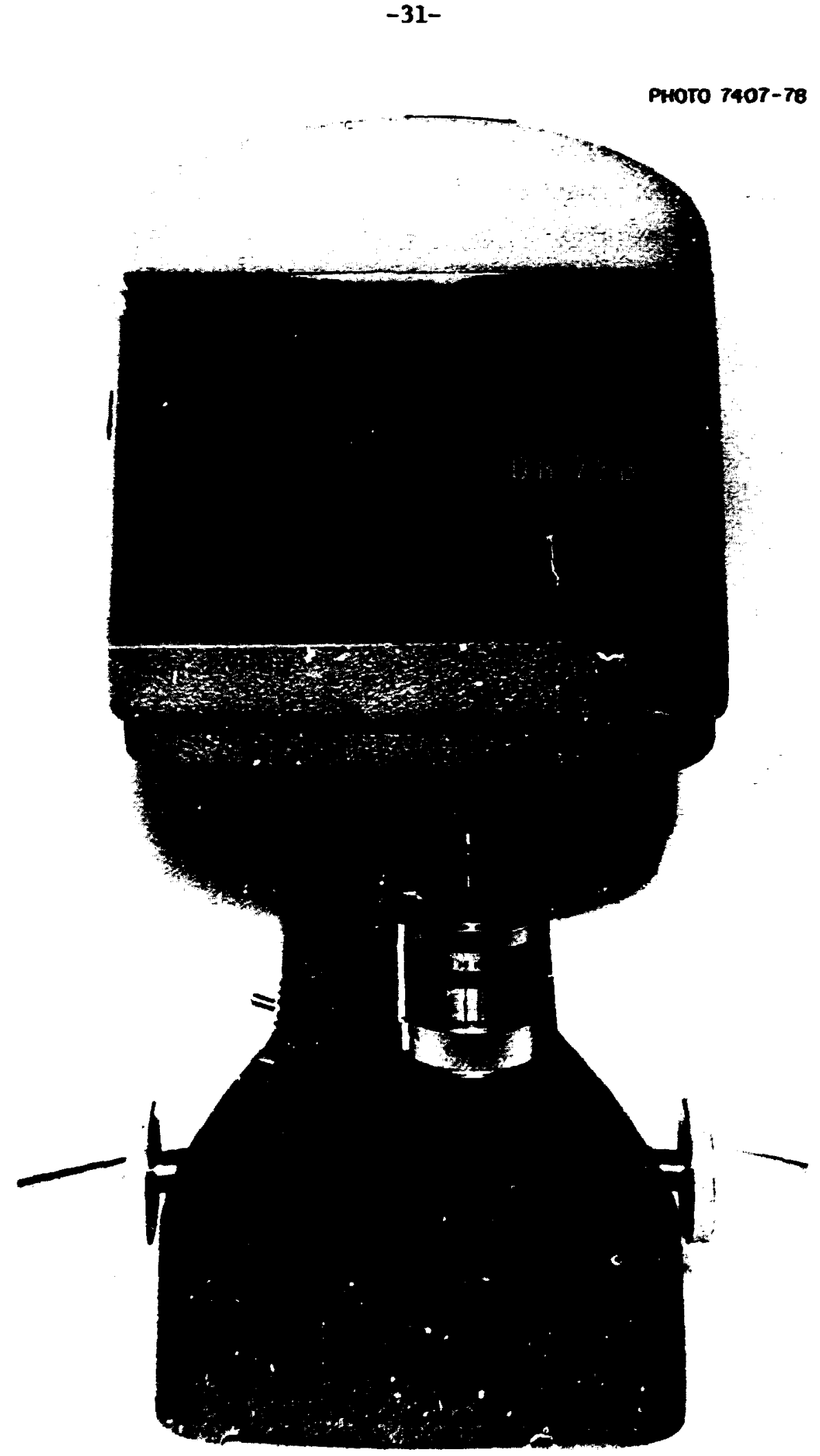

P1g. 13. Graphtte sample mounted on opt1cal gauge for measurement of relative length. 
position was never altered. The sequence consisted of counting, grinding, measurewent, and so on, until the gama activity approached zero or a constant value (background contanination). The data involved measurements of the activity remaining in the specimen vs measurements of the total grinding distance. The stone was always saturated with kerosene, and the grindings were wopped up in the form of a slurry which was imediately discarded and never counted. Since this procedure elininated dangers associated with handing dry contantinated dust, the operation could be performed in a hood. Count rate measurements were made with a singlechannel analyzer system in conjunction with a 7.6-ce $\times 7.6-\mathrm{cm}$ sodium lodide crystal. Whenever specinens were counted, a standard containing a known amount of cesium was also counted at the same distance from the crystal.

\section{RESULTS AND DISCUSSIONS}

As noted in the Foreword, a primary purpose of this report is to present essentially raw data from 36 experiments on the diffusion of cesium in five different graphites. These data are shown in tabular form in Appendix A; they are also presented in plots of relative concentration vs both penetration distance and the square of penetration distance in Appendix B. The relative concentration is the difference between two successive count rates, in counts/s, divided by the volume of graphite, in $\mathrm{cm}^{3}$, removed between the counting operations. The penetration distance in these plots is the distance to the midpoint between successive penetrations; it should be contrasted with several reduced (normalized) distances used in some figures of this section. Inserts in the data plots show the variation of specimen temperature, above $400^{\circ} \mathrm{C}$, with time.

For the purpose of obtaining approxinate concentration of cesium, in, for example, units of nanomoles $/ \mathrm{cm}^{3}$, in any graphite sample, the following product can be formed:

$$
\begin{aligned}
C\left(\mathrm{nmoles} / \mathrm{cm}^{3}\right)= & {\left[\mathrm{f}_{1} \mathrm{f}_{2} /\left(\mathrm{f}_{3} \mathrm{f}_{4}\right)\right] \times \mathrm{CR}=6.69 \times 10^{-4} } \\
& {\left.\left[\text { nmole } \mathrm{CB}_{8} \text { counts }^{-1} \text { \& } \times \mathrm{CR} \text { (counts } 8^{-1} \mathrm{~cm}^{-3}\right)\right] . }
\end{aligned}
$$


Here

$\mathrm{f}_{1}=2.275 \times 10^{-6} \mathrm{nmole}{ }^{137} \mathrm{Cs} /(\mathrm{dis} / \mathrm{s}) ;$

$f_{2}=2.5$ nmole.s Cs/nmole ${ }^{137} \mathrm{Cs}$;

$\mathrm{f}_{3}=0.85$ photopeak photon $/{ }^{137} \mathrm{Cs}$ disintegration;

$f_{4}=0.01$, the counting-system efficiency with the sample $12 \mathrm{~cm}$ above the 3-in. $\times$ 3-in. LiF(Ge) crystal, counts $/{ }^{137} \mathrm{Cs}$ photon;

CR = counting rate, cuurits $\mathrm{s}^{-1} \mathrm{~cm}^{-3}$.

Counting rates near the surface $x=0$ in many of the experiments were in the range $10^{4}$ to $10^{5}$ counts $\mathrm{s}^{-1} \mathrm{~cm}^{-3}$; thus, concentrations of cesfum vere in the range 7 to $70 \mathrm{nmoles} / \mathrm{cm}^{3}$.

\subsection{Data Treatment for Ideal Tiffusion}

Use of the term "ideal" for diffusion of sorbed cesium through graphite implies the absence of all rate terms other than the usual accumulation term in the diffusion equation. The equation that describes our transient experiments for these idealized conditions is

$$
\text { D } \frac{\partial^{2} c}{\partial x^{2}}=E \frac{\partial C}{\partial t}
$$

for the impulse or thin-layer (combined initial-boundary) condition at $x=0$, with $c(x,+0)=0$ and $c(\infty, t)=0$. C is the vapor-phase concentration of cesium in the pores, and $D$ is an effective free-space diffusion coefficient. In reality, diffusion is primarily due to transport of cesium along pore surfaces. The solution is

$$
\varepsilon C_{p}(x, t)=C_{b}(x, t)=\left(Q_{0} \sqrt{\frac{\varepsilon}{\pi D t}}\right) \exp \left(\frac{-\varepsilon x^{2}}{4 D t}\right) .
$$

The pre-exponential term is the surface concentration, $c_{b}(0, t)$. Subscripts $p$ and $b$ refer to pore and bulk, respectiveiy. The symbol $Q_{0}$ represents the amount of cesfum placed, at $x=0$, on a single specimen per square centineter of geometifical area normal to the linear diffusion path $x$. wheras the total amount per couple is $2 Q_{0}$; and $t$ is the diffusion time. 
Of the five graphites considered in this report, only Havker-Siddeley graphite exhibits the craracteristics of simple diffusion. This is shown by tne plot'. in Appendix B, wherein logarithms of relaiive concentrations of ${ }^{137} \mathrm{Cs}$, in counts $\mathrm{s}^{-1} \mathrm{~cm}^{-3}$, appear to be linear functions os the square of the penetration distance, as required by Eq. (3). Extraction of diffu:ion coefficient, from four of the experiments with Hawker-Siddeley graphite (HS-3-I samples I1, I4, 3, and 5) by the graphic:l co.parison method have been presented previously, ${ }^{6}$ as shown in Fig 14. This figure is bized on the reduced-fonetration $u=(x / 2) \sqrt{\varepsilon / D t} ;$ Fig. 15 shows data from two of the experiments based on the penetratica distauce, $x$.

All of the data pertaining to the diffusion of ${ }^{137} \mathrm{Cs}$ in HawkerSiddeley graphite have now been analyzed in terms of Eq. (3) by use of the Marquardt nonlinear least-squares program. ${ }^{22,23}$ Results of this analysis of seven experients are summarized in Table 3 . It should be noted that there are swall differences between reaction times and diffusion coefficiercs, $D / \varepsilon$, of Table 3 and Fig. 14 for experiments $I 1, I 4,3$, and 5. Difference: in diffusion coefficients reflect differences between graphical and numericai methors of analysis.

An examination of the piuts of ${ }^{137} \mathrm{Cs}$ concentration vs penzcration dis:-ance in Hawker-Siddeley graphite (Appendix B) reveals that the first point is higher than expected by a factor of abnit 2 in experiment $I 1$ and by a $\varepsilon_{i=t}=t$ of about 5 in experiment 12 ; in all other "periments, the first point appears to be lower than expected. Parameters listed in Table 3 are based on analysis of all of the data; however, an analysis based on the exclusion of the first point in all experfments produces results that are not much different. Figure 16 displays data from Table 3 in a reciprocal-temperature plot. Numerical analyses of the data in terms of thr equation

$$
D / \varepsilon=(L / \varepsilon)_{0} \exp [-\Delta E / R T]
$$

are summarized as follows: 
ORNL DWG. 75-822IR3

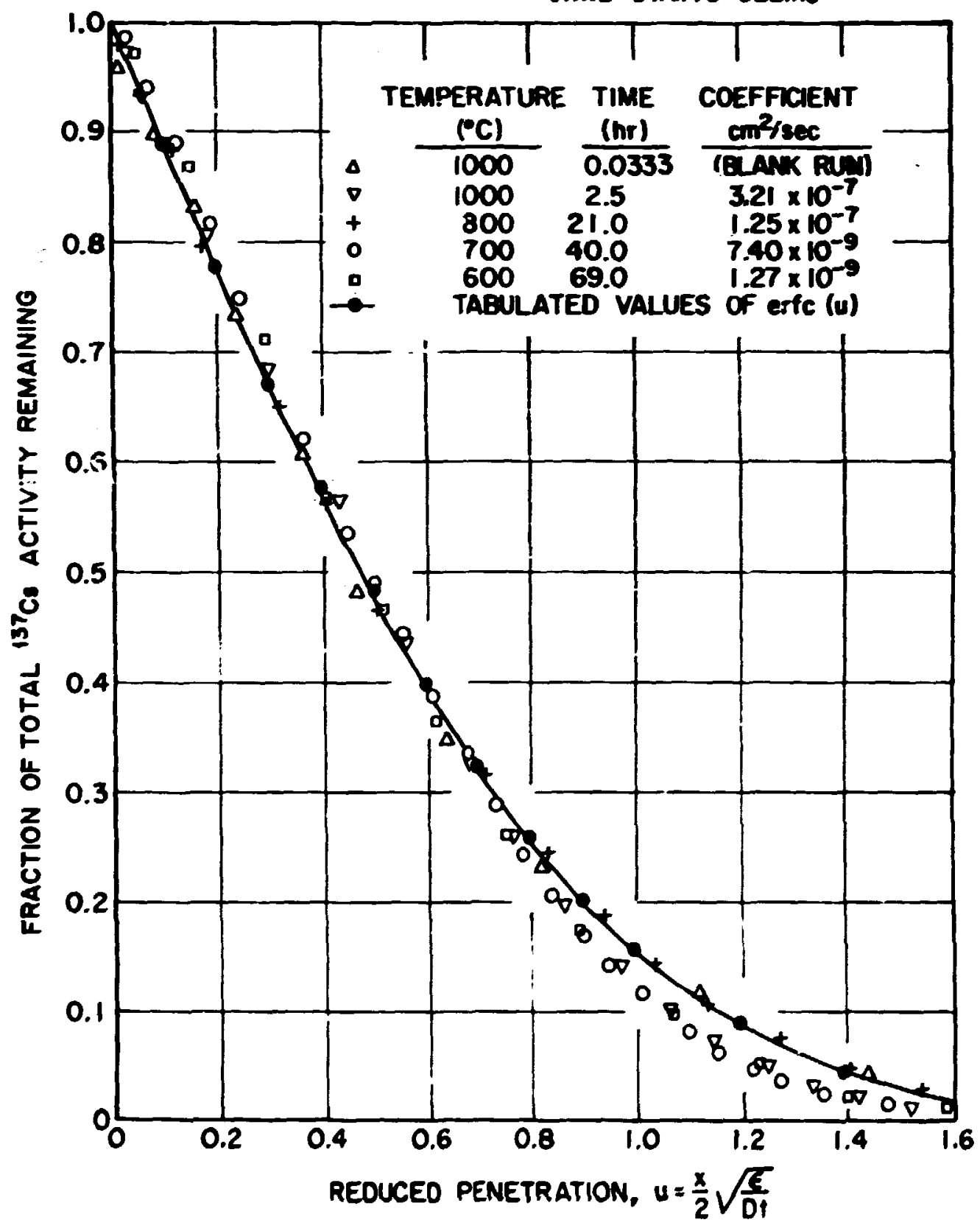

Pig. 14. Generalized integral profiles for cesium diffusion in Hawk, r-Siddeley graphite. 
COML OW' 75-8220R2

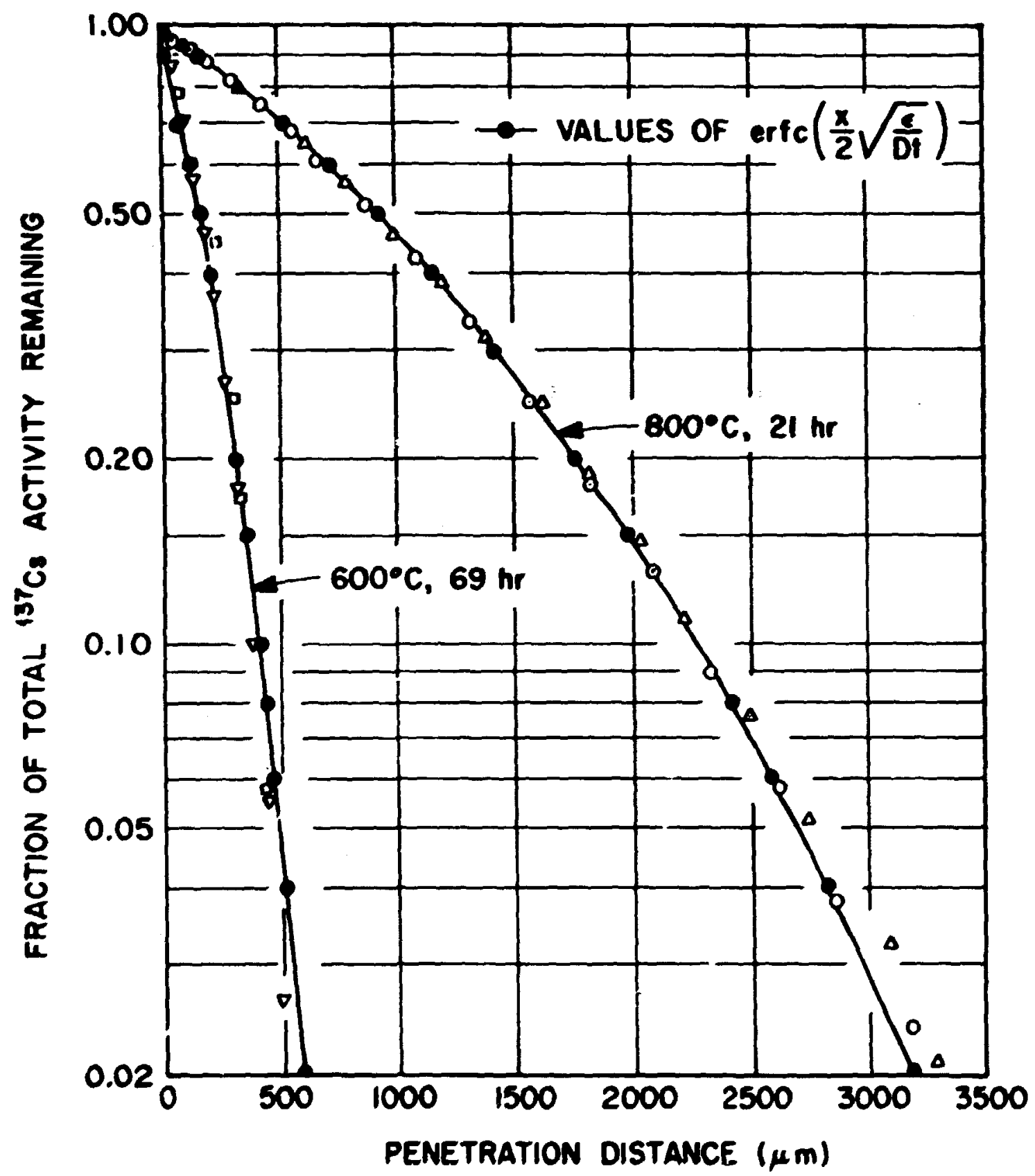

Fig. 15. Plots of two integral concentration profiles for HawkerS1ddeley graphite showing the logarithm of the fraction of cestum activity remaining as a function of the grinding or penetration distance, $x$. 
Table 3. Analysis of data on ${ }^{137} \mathrm{Cs}$ diffusion in Hawker-Siddeley graphite

\begin{tabular}{|c|c|c|c|c|c|c|c|c|c|c|}
\hline \multirow[b]{3}{*}{$\begin{array}{l}\text { Run } \\
\text { No. } a\end{array}$} & \multirow{2}{*}{\multicolumn{2}{|c|}{ Approximate run }} & \multirow[b]{3}{*}{$\begin{array}{l}\text { No, of } \\
\text { points }\end{array}$} & \multicolumn{7}{|c|}{ Parnmeters and standard devlations $b$} \\
\hline & & & & \multirow{2}{*}{$\underset{x}{s(f 1 t)}$} & \multirow{2}{*}{$\frac{B(1)}{(\operatorname{counts}}$} & $\hat{s}[B(1)]$ & $B(2)$ & \multirow[t]{2}{*}{$\hat{S}[B(2)]$} & \multirow[t]{2}{*}{$D / \varepsilon$} & \multirow[t]{2}{*}{$\hat{\mathbf{s}}(D / \varepsilon)$} \\
\hline & $\left({ }^{\circ} \mathrm{c}\right)$ & $(m \mid n)$ & & & & $\mathrm{s}^{-1}\left(\mathrm{~m}^{-3}\right)$ & & & & \\
\hline II & 800 & 1250 & 21 & 17.5 & $1.536 \mathrm{E}+4$ & $0.078 \mathrm{E}+4$ & 10.238 & 0.162 & $1.27 \mathrm{E}-07$ & $0.048-07$ \\
\hline I 2 & 800 & 1250 & 24 & 28.6 & $1.240 \mathrm{E}+4$ & $0.108 \mathrm{E}+4$ & 9.840 & 0.219 & $1.38 \mathrm{E}-07$ & $0.06 \mathrm{E}-07$ \\
\hline I3 & 600 & 4150 & 15 & 15.6 & $1.143 \mathrm{k}+5$ & $0.062 E+5$ & 63.538 & 0.664 & $9.95 \mathrm{E}-10$ & $0.21 \mathrm{E}-10$ \\
\hline 14 & 600 & 4150 & 10 & 32.1 & $1.144 \mathrm{E}+5$ & $0.165 E+5$ & 59.451 & 1.363 & $1.14 \mathrm{E}-09$ & $0.05 \mathrm{E}-09$ \\
\hline 1 & $>900^{c}$ & 47 & 13 & 25.0 & $1.513 E+5$ & $0.132 E+5$ & 48.572 & 1.081 & $1.508-07$ & $0.07 \mathrm{E}-07$ \\
\hline 3 & 700 & 2090 & 33 & 43.0 & $5.879 E+4$ & $0.677 \mathrm{E}+4$ & 34.678 & 0.786 & $6.63 \mathrm{E}-09$ & $0.30 \mathrm{E}-09$ \\
\hline 5 & 1000 & 175 & 24 & 18.4 & $3.558 E+4$ & $0.186 \mathrm{E}+4$ & 19.443 & 0.205 & $2.52 \mathrm{E}-07$ & $0.05 \mathrm{E}-07$ \\
\hline
\end{tabular}

a Runs $: 1,12,13$, and 14 Involved the HS graphite as gleeves around HLM 85 graphite. Runs 1, 3, and 5 involved separate HS cylinders.

"B(1) corresponds to the tirm $Q_{0} \sqrt{r / \pi D t}$ of Fq. $(20) ; B(2)$ corresponds to $\sqrt{E / D t}$. $\hat{s}(f 1 t) 18$ the estimated standard deviation of $f i t$ of the data to F.q. (20). $\hat{s}[B(1)], \hat{s}[B(2)]$, and $\hat{s}(D / E)$ similarly are estimated standard devlat lons of $B(1), B(2)$, and $D / \varepsilon$. We calrulate $D / E=1 \cdot /[t \star B(2) \star B(2)]$ and $\hat{s}(D / \varepsilon)=2$. $\hat{s}[B(2)] \star(D / E) / B(2)$.

$C^{C}$ The time-averaged temperalure of this experiment was assumed to be $950^{\circ} \mathrm{C}$ for the purpose of plotting in Fig. 16 and of calculating the activation energy of diffugion. 


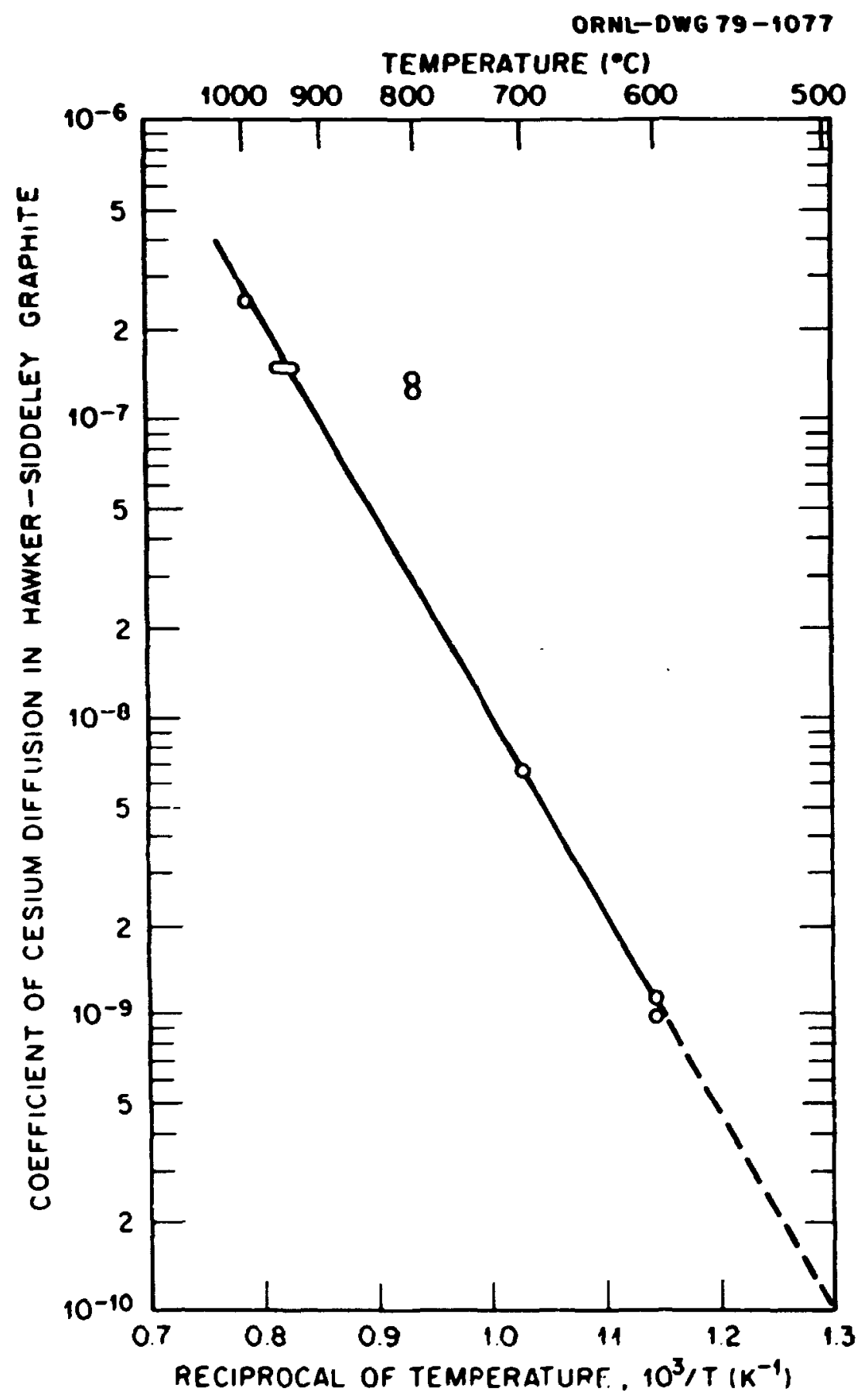

Fig. 16. Arrhentus plot of coefficient.s for cesium diffusion in Hawker-Siddeley graphite. 


\begin{tabular}{|c|c|c|c|c|c|}
\hline \multirow[b]{2}{*}{ All data used } & \multicolumn{2}{|c|}{$\begin{array}{c}{\left[(D / \varepsilon)_{0} \text { and } \hat{s}(D / \varepsilon)_{0}\right] \times 10^{2},} \\
\mathrm{~cm}^{2} / \mathrm{s}\end{array}$} & \multicolumn{2}{|c|}{$\begin{array}{l}{[\Delta E \text { and } \hat{s}(\Delta E)],} \\
\text { kcil/mole }{ }^{137} \mathrm{Cs}\end{array}$} & \multirow{2}{*}{$\begin{array}{c}\hat{s} \text { (fit), } \\
\frac{z}{50}\end{array}$} \\
\hline & 4.44 & 5.87 & 30.4 & 2.7 & \\
\hline $\begin{array}{l}\text { xclude runs I1 } \\
\text { and I2 }\end{array}$ & 3.71 & 0.64 & 30.1 & 0.35 & 6.1 \\
\hline
\end{tabular}

It is apparent from this sumary, or from Fig. 16, that wost of the uncertainty in $(D / E)_{0}$ is due to runs $I 1$ and.I2; the calculated energy of activation is not changed much by their exclusion.

\subsection{Diffusion Coupled Witi: Nonequilfbrium Sorption}

When the sama type of thin-layer cesium experiments are performed with materials such as H-327 graphites, which contain three-dime- sional grains, one obtains penetration profiles that are significantly different frow those indicative of an idealized diffusion process. The first deviation from ideal behavior becare apparent in the early stages of the grinding procedures; the cesium activity that remained dropped sharply in the first series of sections, then more slowly with distance as the grinding depths increased. It appeared that only part of the cesium initially placed on the surfaces diffused into the specimens. A residual amount seemed to be imobijized near the source, which resulted in abnormally high cesium concentrations at the $x=0$ surface.

Illustrations of chis effect, in terms of typical fraction remaining versus grinding distance plots, are shown on Fig. 17. This same characteristic applies to all data on ATJ, H-327, and HLM-85 graphites, as may be seen in the plots of Appendix $B$. We should also stress the point that such results were never obtained with Hawker-Siddeley graphite.

Surface effects of this kind were first reported for cesium-graphite (and barfum-graphite) systems in $i 961$ by Bromiey and l.arge ${ }^{14}$ with the following explanation:

The high activities (in out-of-plle diffusion specimens) near the source disc have been attributed to the fact that creation of a (machined) surface has opencd up a number of otherwis? blind pores which do not provide a through path for the diffusion process. The surfaces of these blind pores become cusered 


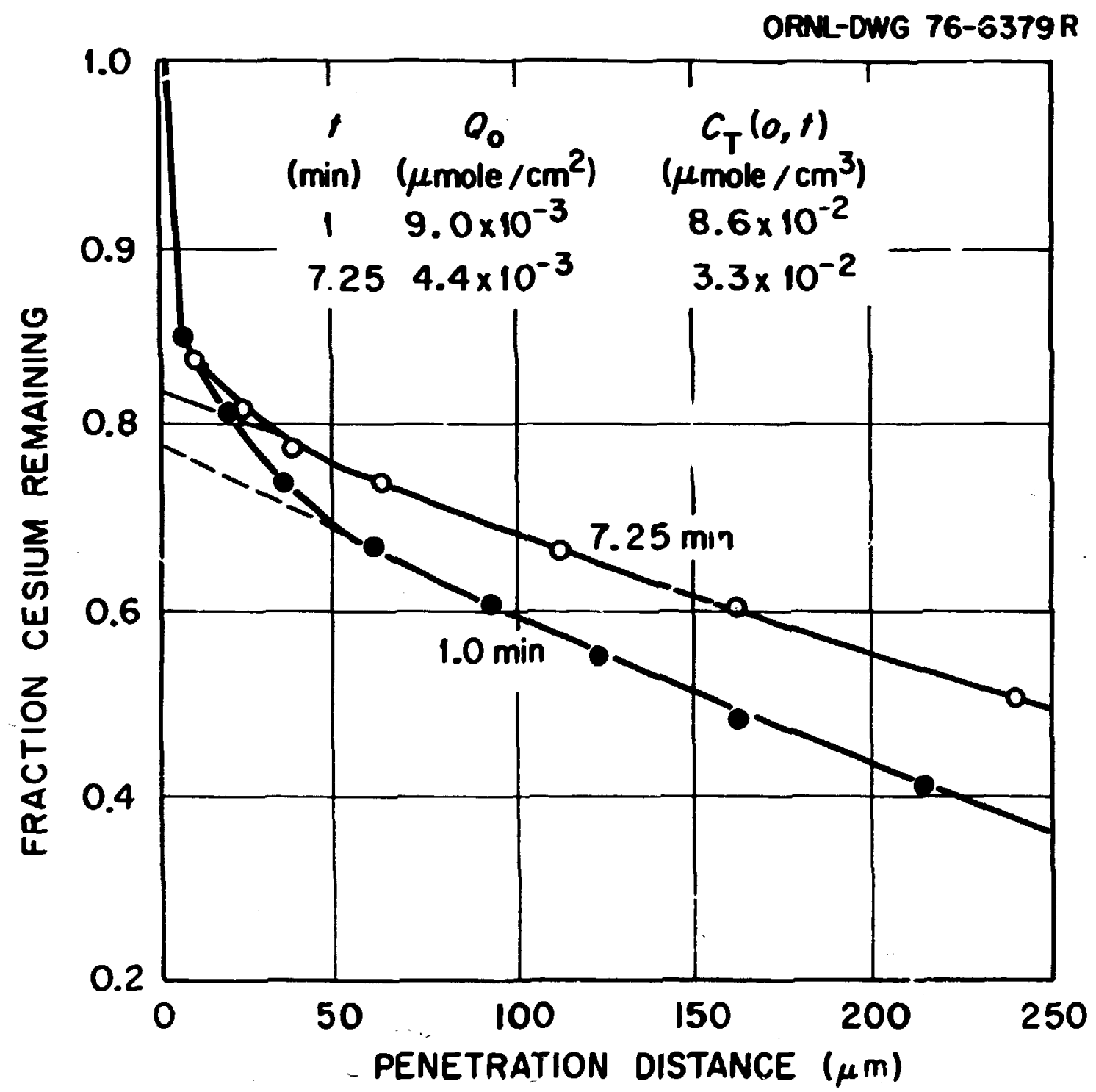

Pig. 17. Intial appearance of interal profile data for cestum diffuston in large-grain H-327 graplite. (Appreciable amounts of cestum are "held-up" near the source region; an adjusted base for $F R$ and $Q_{0}$ calculations was based on extrapolations of the bulk of the data back to $x=0$, e.g., $E R=0.79$ and 0.82 .) 
with an adsorbed layer of diffusing species which is unable to aigrate further into the graphite.

If this explanation had included exposure of an unusually high number of active chenisorption sites, its plausibility would have been considerably enhanced. Nonetheless, Bromey's ideas do seen to for a nucleus for an extended cxplanation of holdup effects (over superficial surfaces) when possible sorption mechanisus are also included.

We envisfon that the nature of achined surfaces truncating threedimensional grains in structural graphite is quite complex, and, in theory, one must consider all forms of sorbed states as they relate to a cesium vapor pressure: a physically adsorbed state (P), an internediate chemisorbed state (A), and a final chemisorbed state (B). A representation given by Hayward and Trapnel1 ${ }^{24}$ is

$$
[\mathrm{Cs}]_{\mathrm{V}} \rightleftharpoons[\mathrm{Cs}]_{\mathrm{P}} \rightleftarrows[\mathrm{Cs}]_{\mathrm{A}} \neq[\mathrm{Cs}]_{\mathrm{B}} \text {. }
$$

For the special case of Hawker-Siddeley graphite, wherein holdup was never detected, the above serms to reduce to

$$
\begin{aligned}
& \mathrm{Ke} \\
& {[\mathrm{Cs}]_{\mathbf{v}} \rightleftarrows[\mathrm{Cs}]_{\mathrm{A}} \text {, }}
\end{aligned}
$$

where contribucions of the $(P)$ and $(B)$ states are negligible. The system appears always to be in equilibrium even though the concentrations shift about markedly as a result of diffusion. Perhaps the absence of $(P)$ and (B) state contributions results from the dominance of the two-dimensional materials (coke and lamp black) in this particular struccure.

For more typical graphites, 1 the $\mathrm{H}-327$, with three-dimensional grains, we suspect that Eq. (5) reduces to

$$
\begin{aligned}
& k_{\mathrm{e}} \quad \mathrm{k}_{3} \\
& {[\mathrm{Cs}]_{\mathrm{v}} \rightleftarrows[\mathrm{Cs}]_{\mathrm{A}_{\mathrm{k}}} \underset{\mathrm{CSs}]_{\mathrm{B}}}{\rightleftarrows}}
\end{aligned}
$$

since ( $P$ ) coverage is small compared with (A) coverage and (V-P-A) equilfbrium is rapidly attained. Consider now a possible sequence of events which might occur near the source surfare of a structure wherein 
the (B) state can exist [and Eq. (6) applies] under conditions related to a thin-layer experiment. Initially, the cesium coverage suddenly becomes relative!y high, which ensures significant $B$ coverage if the rate constant $k_{3}$ is high. Immediately after this buildup, the cesium concentration starts to fall as the mobile cesium, under the $K$ regime, drains or diffuses out into the specimen. If $k_{4}[\mathrm{Cs}]_{B}$ is smaller than $k_{3}[\mathrm{Cs}]_{A}$, considerable cesium can be left behind in an immobilized (B) state. A disprof rtionate amount of this immobilization or holdup occurs at the surface since this is a region of unusually high concentration of (B)state sites (artificially formed) and high initial cesium concentratinns.

The model is predicated on the assumption that the surface (coupled with gas) phase diffusion rates are equal to, or greater than, the equilfbration rates associated with ultimate sorption saturation; thus, the mobile fraction will not "wait around" for a slow sorption proc. to achieve equilibrium. With this in mind, we invoke a system similar to that described by Eqs. (5) and (6). Whether a P-A system without B, or and $A-B$ system without $P$, controls the sorption rate is of little concern since we do not know enough about the sorption kinetics of cesium in "H-327-1ike" graphites to make such a distinction.

A new hypothetical system, namely a coupled mobile gas-surface phase which tends to become trapped or occupy strungly chemisorbed sites and to diffuse as well, is visualized at this point. The subscript $I$ refers to inmobilization sites or states; subscript $\underline{M}$ means mobile. For example, $C_{M}(x, t)$ and $C_{\tau}(x, t)$ designate mobile and immcbile concentrations, respectively, which are referred to the pore volume; if a prime appears, the concentrations are referred to the bulk volume. We seek a reaction or sorption-rate expression, $r_{\text {ads' }}$ which is to be added to the $\partial c / \partial t$ term of the transient diffusion relationship $\mathrm{Eq}$. (2). In the absence of diffusion, the rate refers to the following system:

$$
[\mathrm{Cs}]_{v} \neq[\mathrm{Cs}]_{M} \underset{k_{2}}{\stackrel{k_{1}}{\ddagger}[C s]_{T}} \text {, }
$$

where 


$$
\begin{aligned}
& r_{\text {ads }}=\frac{d C_{\tau}(t)}{d t}, \\
& r_{\text {ads }}=k_{1} C_{M}(t)\left[C_{\tau}(\infty)-C_{\tau}(t)\right]-k_{2} C_{\tau}(t),
\end{aligned}
$$

oir

$$
r_{\text {ads }}=k_{1} C_{M}(t) \cdot C_{\tau}(\infty)-\left[k_{1} C_{M}(t)+k_{2}\right] C_{\tau}(t)
$$

The symbol $C_{\tau}(\infty)$ means the maximum number of available chemisorption sites, and the :ast term on the right within the brackets represents a combined fill-up an I reversing back-pressure term. In view of the nature of the thin-layer cxperiments, we anticipate that the fraction of available $\tau$-sites actuilly occupied will be swall; furthermore, the $k_{2}$ desorption rate will be 1 egligible. Thus, $r_{\text {ads }}=k c_{M}(t)$, where $k=k_{1} c_{\tau}(\sigma)$ with units $s^{-1}$.

The equation For transient diffusion of the mobile cesium species subject to an irreversible first-order sorption rate is

$$
\frac{\partial^{2} C_{M}}{\partial x^{2}}=\frac{\varepsilon}{D} \frac{\partial C_{M}}{\partial t}+\frac{\varepsilon k}{D} C_{M},(x>0, t>0),
$$

where $C_{M}$ is the mobile concentration as a function of position and time, $c_{M}(x, t)$. The initial and boundary conditions corresponding to the experimental procedures are:

$$
C_{M}(x, 0)=0,(x>0),
$$

and

$$
\lim _{x \rightarrow \infty} c_{M}(x, t)=0,(t>0),
$$

when

$$
\begin{aligned}
& J(t)=J_{0^{\prime}},\left(x=0, t<t_{0}\right) \\
& J(t)=0, \quad\left(x=0, t>t_{0}\right),
\end{aligned}
$$

where we hold $J_{0} t_{0}=Q_{0}$, while $t_{0} \rightarrow 0$ and $J_{0} \rightarrow \infty$. Thls flux condition at the $x=0$ boundary may be written as 


$$
J_{x=0}=Q_{0} \delta(t),
$$

where $\delta(t)$ is the Dirac delta function whose Laplace transform is unity.

The Laplace transformed version of this system is

$$
\frac{d^{2}}{d x^{2}}\left[\bar{c}_{M}(x, s)\right]=\frac{\varepsilon}{D}\left[s \bar{C}_{M}(x, s)-C_{M}(x, 0)\right]+\frac{\varepsilon}{D} k \bar{c}_{M}(x, z ;,
$$

where transformation of $\mathrm{Eq}$. (10a): is not required. Also

$$
\bar{c}_{\boldsymbol{H}}(\infty, s)=0 \text {, }
$$

with

$$
(\bar{j})_{X=0}=Q_{0}=-D \frac{d}{d x}\left[\bar{c}_{M}(0, s)\right] .
$$

The solution in transformed coordinates under the conditions stated is:

$$
\bar{c}_{M}(x, s)=Q_{0}[(E D)(k+s)]^{-1 / 2} \exp \left\{-x[(E / D)(k+s)]^{1 / 2}\right\} .
$$

With the aid of the translation properties and Eq. (7), Appendix $V$ of Carslaw and Jaeger, ${ }^{25}$ the inverted form of Eq. (11s) and the solution for the mobile fraction based on the bulk volume is:

$$
\varepsilon C_{M}(x, t)=C_{M}^{\prime}(x, t)=Q_{0} \sqrt{\frac{\varepsilon}{\pi D t}} \exp \left[-\left(\frac{\varepsilon x^{2}}{4 D t}+k t\right)\right] .
$$

The prime here means the same as subscript b in $\mathrm{Eq}$. (3).

The same form would have been obtained if we had derived a solution for a species undergoing radioactive decay during the diffusion anneal; the result here is merely $\mathrm{Eq}$. (3) multiplied by an attenuation factor $e^{-k t}$, with $k$ representing the decay factor. However, ${ }^{137} \mathrm{Cs}$ does not decay significantly during an anneal; it is simply immobilized, yet continues to be counted. This mea:is that the total count rate in an experiment is the cumulative value for both mobile and immobile fractions. In other words, if we integrate $\mathrm{Eq}$. (12) from zero to infinity with respect to $x$, we find that the total amount of mobile cesium in the graphite specimen is $Q_{0} e^{-k t}$ erfc $(u=1)$ or $Q_{0} e^{-k t}$; the 1mmobilized fraction (still counting) $18 Q_{0}\left(1-e^{-k t}\right)$. 
Thus we must compute the distribution of the imobilized cesium along $x$ and add this to the amount given by Eq. (12) in order to obtain the total concentration detected by grinding. We seek an expression such as

$$
C_{T}^{\prime}(x, t)=C_{M}^{\prime}(x, t)+C_{\tau}^{\prime}(x, t),
$$

where the subscript $T$ means total. In particular, we seek the term

$$
C_{i}^{\prime}(x, t)=\int_{0}^{t} \varepsilon k C_{M}(x, t) d t .
$$

In view of Eqs. (14) and (11s), we write the transform of $c_{\tau}^{\prime}(x, t)$ as follows:

$$
\bar{c}_{\tau}^{\prime}(x, s)=(\varepsilon k / s) \bar{c}_{M}(x, s)=Q_{0} s \sqrt{\frac{\varepsilon(k+s)}{D}} \exp \left\{-x\left[(\varepsilon / D)(k+s)^{1 / 2}\right]\right\} .
$$

Inversion of $\mathrm{Eq}$. (14s) to obtain $\mathrm{C}_{\tau}^{\prime}(x, t)$ is accomplished by using the translation property of Eq. (31), Appendix VI of Carslaw and Jaeger. 25 The result, in terms of the new independent variables, $u=(x / 2)(\sqrt{\varepsilon / D t})$ and $\tau=\sqrt{\mathrm{kt}}$, is:

$$
C_{\tau}^{\prime}(x, t)=Q_{0} \frac{u \tau}{x}\left[e^{-2 u \tau} \operatorname{erfc}(u-\tau)-e^{+2 u \tau} \operatorname{erfc}(u+\tau)\right]
$$

Next, we add Eq. (15) to Eq. (12), in terms of $u$ and $\tau$, to obtain $C_{T}^{\prime}(x, t)$, evaluate this at $x=0$, and form the ratio

$$
\frac{C_{T}^{\prime}(x, t)}{C_{T}^{\prime}(0, t)}=\frac{e^{-\left(u^{2}+\tau^{2}\right)}+(\tau \sqrt{\pi} / 2)\left[e^{-2 u \tau} \operatorname{erfc}(u-\tau)-e^{+2 u \tau} \operatorname{erfc}(u+\tau)\right]}{e^{-\tau^{2}}+(\tau \sqrt{\pi})[1-\operatorname{erfc}(\tau)]} .
$$

This is the expression for the reduced concentration profile that is applicable to many studies wherein concentrations, as opposed to FR, are determined.

By using the dimensionless groups $u$ and $\tau$, one can readily compute approprtate values for generalized curves which, In turn, can be used to evaluate $D$ from experimental concentration profiles after the applicable $\tau$ value has been established. We mention here that another chofce of a 
dimensionless penetration can be used in lieu of $u$, namely $z$, where $z=2 u \tau$ or $u=z / 2 \tau$. Plots of the concentration ratio as a function of either $u$ or $z$, for fixed $\tau$ values, are presented in the top half of Fig. 18; tabulations of the values used to prepare these plots appear in Appendix C. While the "u plots" are more usoful for correlation purposes, the "z plots" give a more realistic interpretation of the way the profiles move ont as the diffusion anneal times increase. Inspection of the curves on Fig. 18 show that the logarithm of the concentration ratios become linear with $u$ or $z$ as $\tau$ approaches 2.2 or greater. This can be verified through $\mathrm{Eq}$. (16) by using the identity erfc(-u) $=2-\operatorname{erfc}(+u)$. In other words, the slope of a plot of the natural logarithm of concentration ratio vs $x$ approaches the group $\sqrt{\varepsilon k / D}$ as $\tau$ approaches 2.2 or greater. Finally, we note that the ideal relationship, Eq. (3), is reccsered when $\tau \rightarrow 0$.

As mentioned before, the nature of $\ldots$. grinding and ${ }^{137} \mathrm{Cs}$ counting procedures makes it convenient to use an integral form of the concentration function that will give a "working equation" in terms of $u$ and $\tau$ so that values of $D / 5$ and $k$ can be extracted from experimental FR-vs-x plots. Integration of the penetration distance is from $x$ to infinity, which corresponds to measuring the ${ }^{137}$ Cs remaining ir. the cylinder, not that which has been removed by grinding. The result of integrating the first term in Eq. (16), which represents the mobile fraction, is $e^{-\tau} \operatorname{erfc}(u)$. Integration of the last two terms, which represent the imnobile fraction, can be readily accomplished using the parts formula. The complete result for the tolal fraction of cesium remaining (FR) in the cylinder, at the penetration distance $x$ and in cerms of $u$ and $\tau$, is:

$$
F R=(1 / 2)\left[e^{+2 u \tau} \operatorname{erfc}(u+\tau)+e^{-2 u \tau} \operatorname{erfc}(u-\tau)\right]
$$

For the evnerimental plots of FR us $x$, we note that the fraction reinaining will $L$ an adjusted value based on an extrapolation to $x=0$ as indicated in Fig. 17.

Plots of the FR function according to Eq. (17) as a function of $u$ and $z$ at fixed $\tau$ values are presented in the hottom half of Fig. 18; corresponding tabulations appear in Appendix $C$. When $T \rightarrow 2.2$ or greater, 

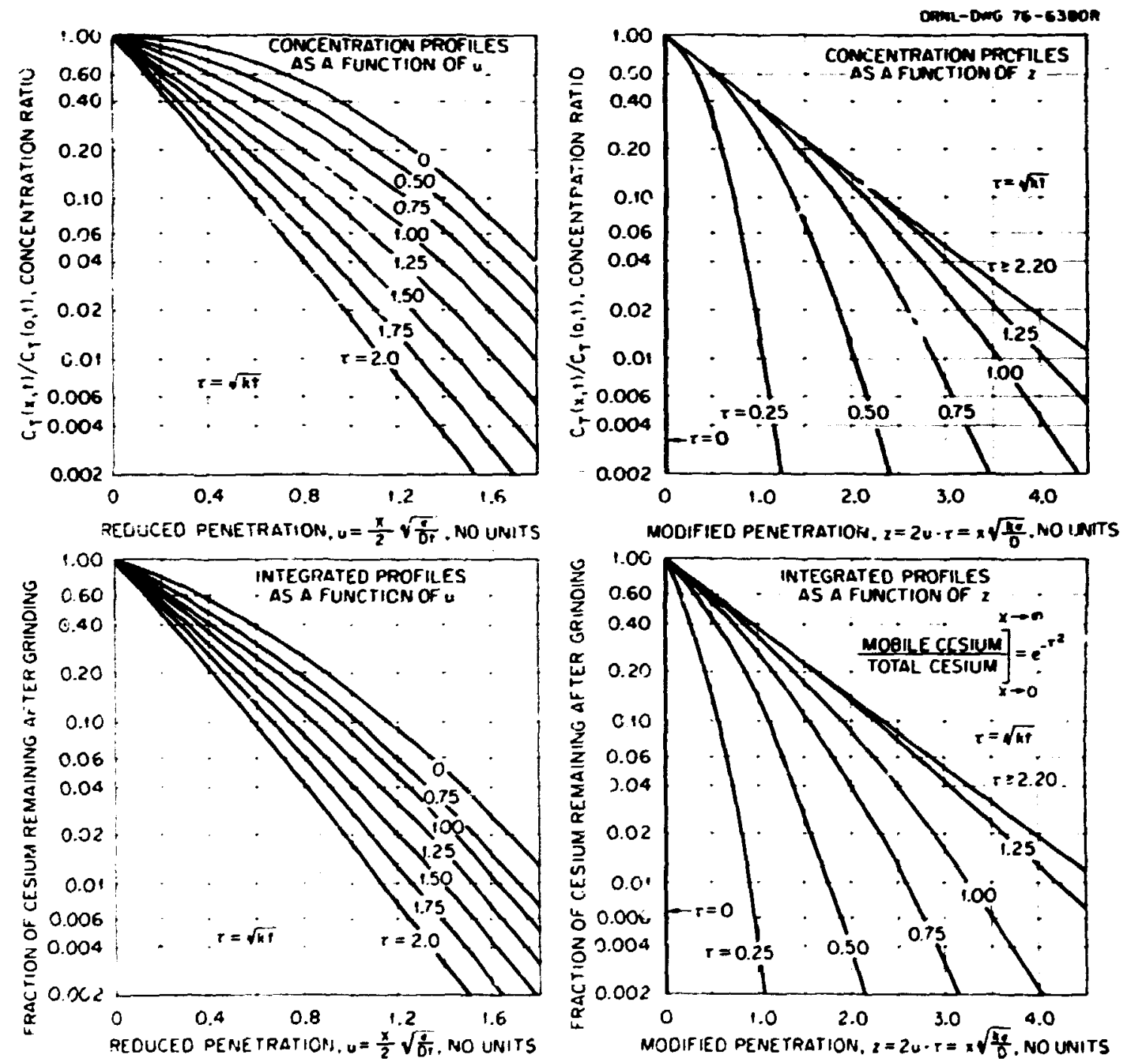

Fig. 18. Methods of plotting generalized results of the equations accounting for internal trapping in a matrix subjected to the us'jal thinlayer boundary conditions. (Solutions of the diffusion equations with an impulse source function.) 
the FR function approaches $e x_{2}(-x \sqrt{\varepsilon k / D})$, as in the case of Eq. (16). Wher $T \rightarrow 0$, the "ideal" relationship Eq. (3) is recovered. Comparison of the concentration and FR functions in Fig. 18 reveals a : criking degree of similaricy; the only difference is that the spread of the curves with respect to fixed $\tau$ values is less pronounced on $t$ ie $\%$ plots.

It seems reasonable to expect that the same phenomenon giving rise to holdup at external graphite surfaces siould also take place along the internal surfaces of the same graphite, albeit with fewer dramatic effects. This seems to be the case in an experiment with H-327 graphite, the results of whici are shown in a comparative plot with 3 Hawker-Siddeley graphite in Fig. 19. When $\tau=0$ on this plot, ideal behavior is indicated since the solid curve represents computed values based on an integrated form of Eq. (3), naisely,

$$
\mathrm{FR}=(2 \sqrt{\pi}) \operatorname{erfc}(v) \text {. }
$$

When $\tau \neq 0$, the diffusion equations (and $H-327$ data) reflect the effects of an irreversible sorption rate, which acts in competition with the transient diffusion rates. The data and the computed values at $\tau=1.25$ show iair agreement. The assumptions and resultant diffusion equations appear to have some merit.

Use of the $t \mathrm{l}$-ical FR-vs-u plots to extrart $k t$ rom $\tau$, and $D / \varepsilon$ from $u$, by compariso.s with experimenta FR-vs-x plots can result in laborious iterative procedures unles: one can arrange to isolate or sepazate $\tau$ or $u$ so that one does not depend directly on the other. We have found that a satisfactory way of doing this is to divide all penetraifons beyond the FR $=0.5$ value by the penetration for this particl:lar value. Then $311 \mathrm{u}, z$, and $x$ ratios are equivalent for a itxed $\tau$ since groups $\varepsilon$ uch as $\sqrt{\varepsilon / D t}$ or $\sqrt{\varepsilon k / D}$ will cancel out. We selected the $F R=0.5$ penetration as the base since most of the diffuston-vs-trapping ra:e action occurs beyrnd this point. This produced a set of theoreicical curves, based on ET. (16). on which experimental data could be placed directly withouc modification other than forming the $x$ ratio on the basis of an interpolated $F R=0.5$ penerlation. Pjots of theoretical ratio curves, with data superposed as described, are shown in Fig. 20. By trearing the 


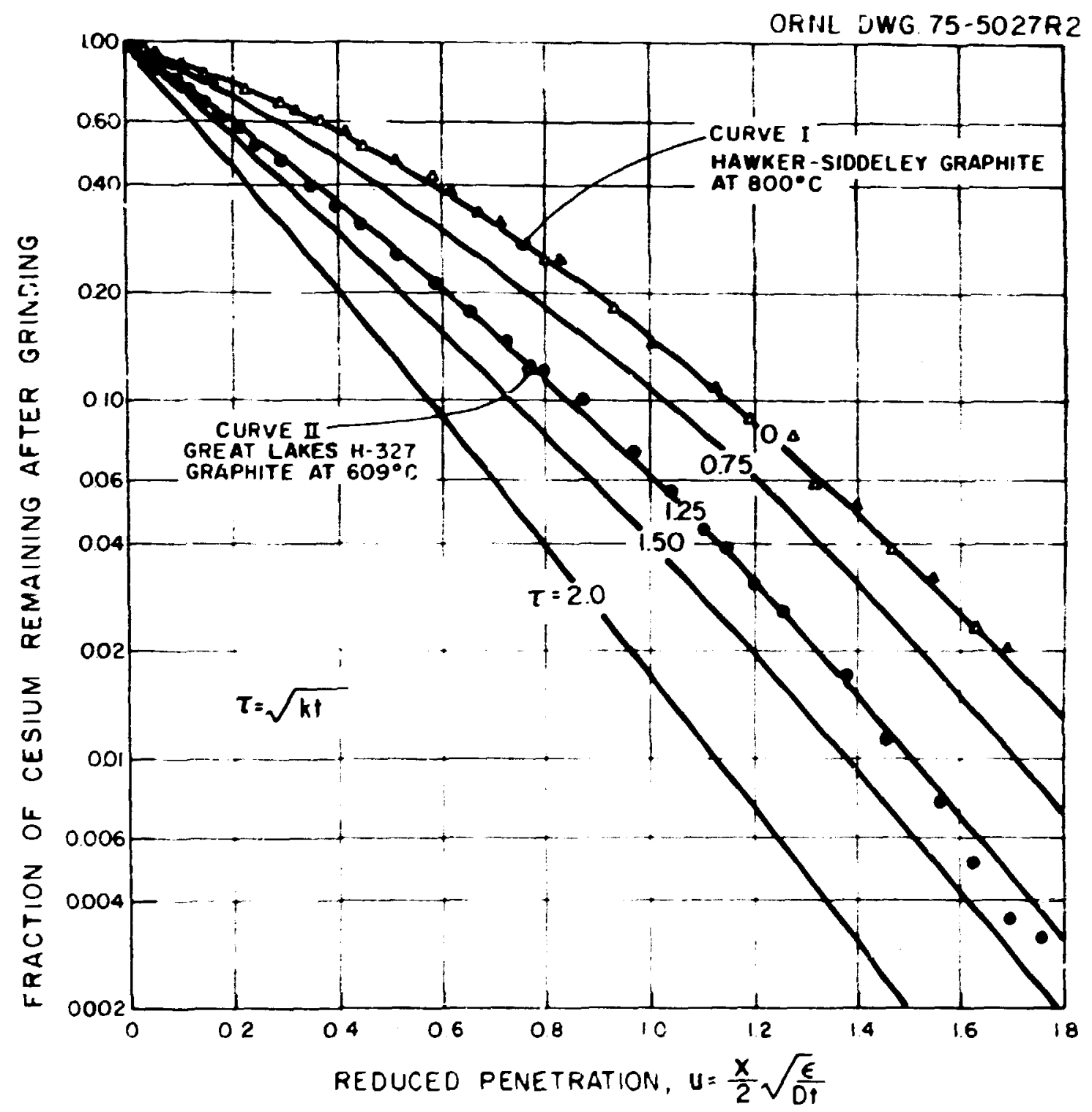

Fig. 19. :omparison of generalized diffusion results obtained with an "ideal" graphale (Hawker-Sfddeley curve I) and a large-grain graphite (H-327 curve II) in which internal trapping or "plate-out" occurs. (All HawkerSiddeley data tend to fall on the $T=0$ curve, regardless of the dfffuston anneal times or temperature. Data for H-327 fall on different $T$ curves as a function of time at a fixed temperature.) 
OPNL-DWG 76-6381

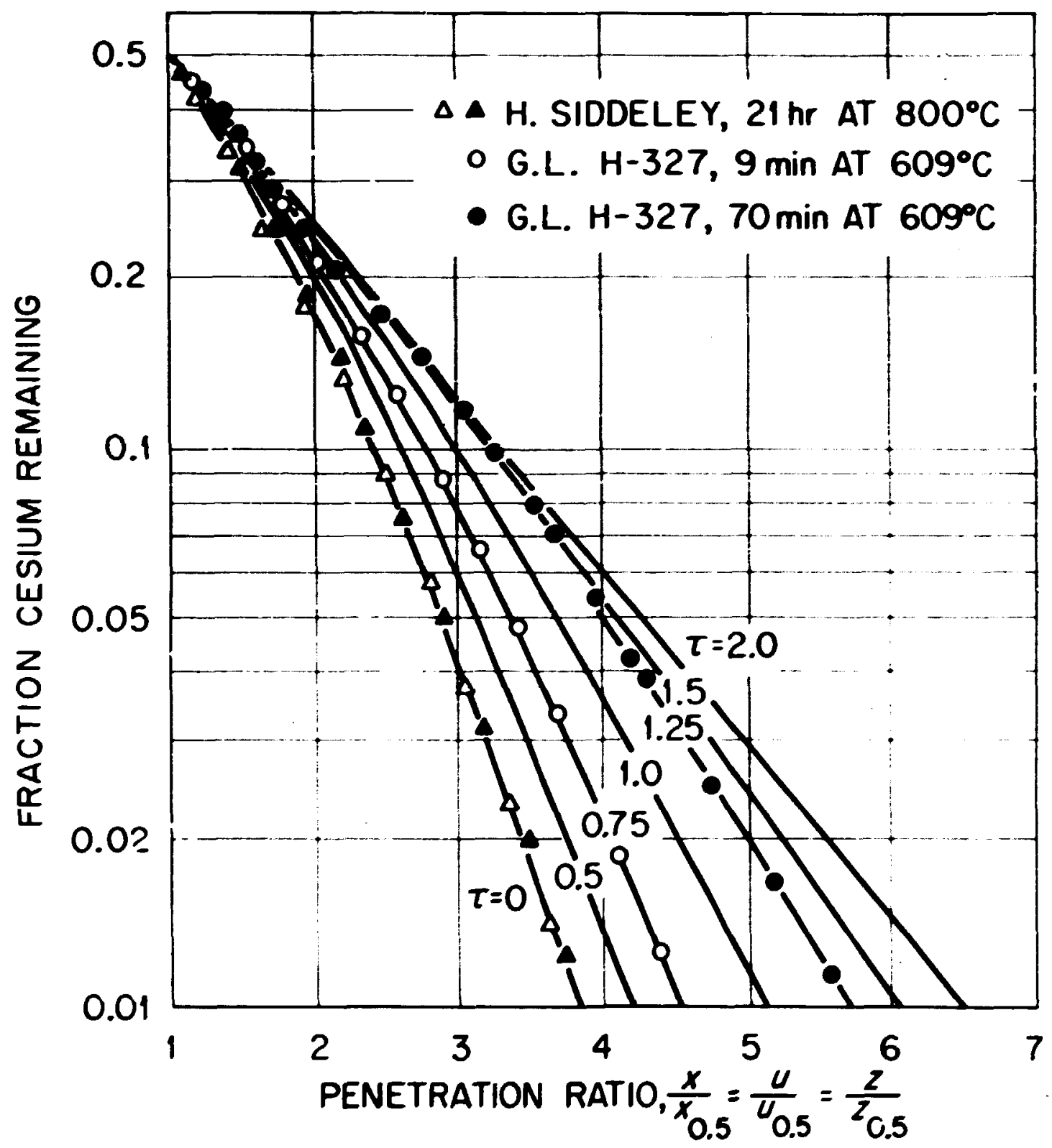

Fig. 20. Modified plots of fraction remaining used to obtain an initial value of $T$ for correlation purposes. 
data in this fashion, gnnd initial es:imates of the applicable $\tau$ could be obtained without prior knowledge of the $D / \varepsilon$.

Some efforts have been devoted to checking the model of cesium transport as presented in Eq. (16) by use of nonlinear least-squares methods. An examination of the data plots in Appendix B shows that the following experiments would appear susceptible to such resting: (1) experiment $7 U$ with ATJ graphite; (2) experiments 1U, 2, 2U, 5C, 7UU, 8, 8UU, and 9UU with H-327 graphite. We have fitted data of the first three of these experiments to Eq. (16); unfortunately, the fitting procedure does not lead to acceptahle agreement between calculated and observed concentrations of ${ }^{137} \mathrm{Cs}$ in the regions of small penetration, where the concentrations are changing rapidly. From these tests of the model of Eq. (16), it would appear that better agrefment between observed and calculated concentrations near the initin: surface 411 require some explanation other than that of first-order irreverible reaction. At present, no effort has been devoted to devising or te:ting other models.

\subsection{Concerning 'apor-Phase Transport of Cesium}

Three tests for a helium-sweep effect were performed with H-451 graphite; temperatures of two of the tests were about $635^{\circ} \mathrm{C}$, while the third was performed at about $680^{\circ} \mathrm{C}$. In addition to the usual data on count rate vs penetration and sample temperature vs time (Appendixes A and $B)$, Append $x$ D lists the flow-related data of flow rate, fore pressure, back pressure, the more accurately measured pressure differential, temperature, and time for these experiments. Relative concentration data from these experiments are plotted in Figs. 21-23 vs the square root of penetration distance frow the sample-pair interface. The square root was used to expand the data at small values of penetration. It 18 apparent, from symmetry about the 0-penetration distance, that there is no effect of the hellum sweep used in these experiments.

Tile magnitudes of the hellum flow rates are presentec in Appendix D in terms of volumetric flow in $10 \mathrm{~s}$. In experiment 1 (samples $1 \mathrm{D}$ and $1 \mathrm{IJ}$, where $D$ repiesents the dowistream sample and $U$ the upstream sample), the 


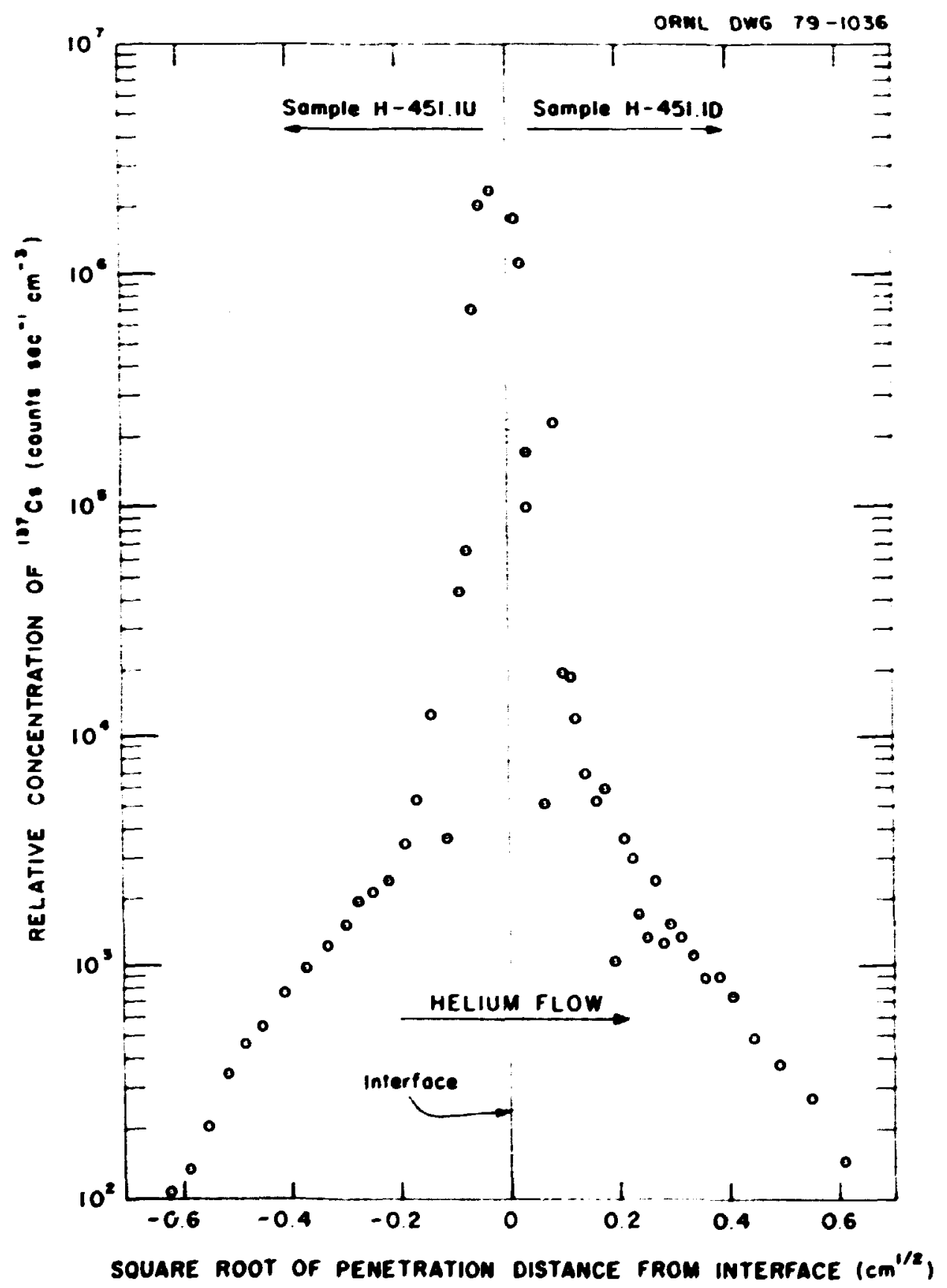

Fig. 21. Cesium-137 concentration profiles in experiment 1 with H-451 graphite, (Maximum temperature $=h 36^{\circ} \mathrm{C}$.) 


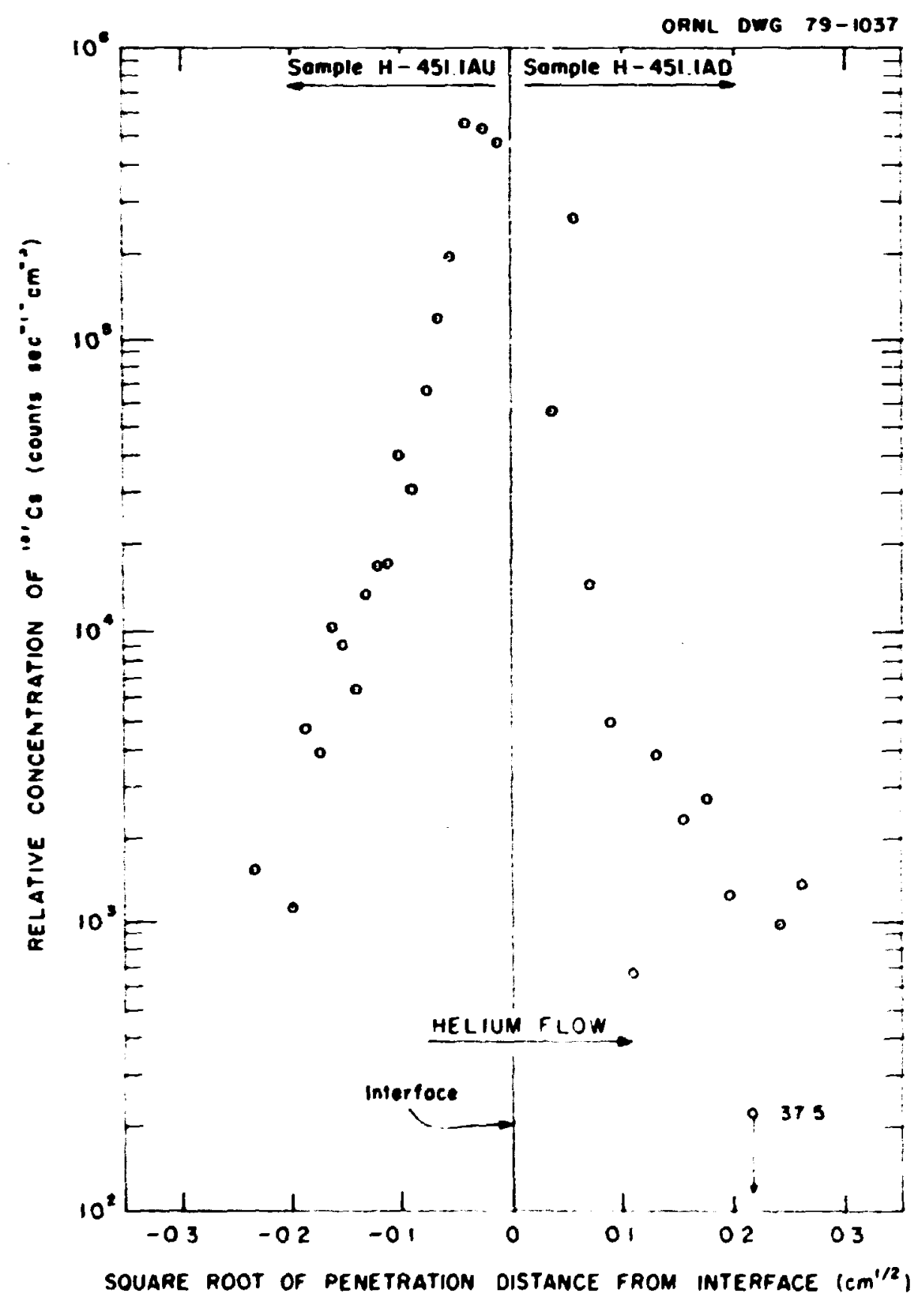

Fig. 22. Cesium-137 concentration profiles in experiment lA with H-451 graphite. (Maxinum temperature $=681^{\circ} \mathrm{C}$.) 


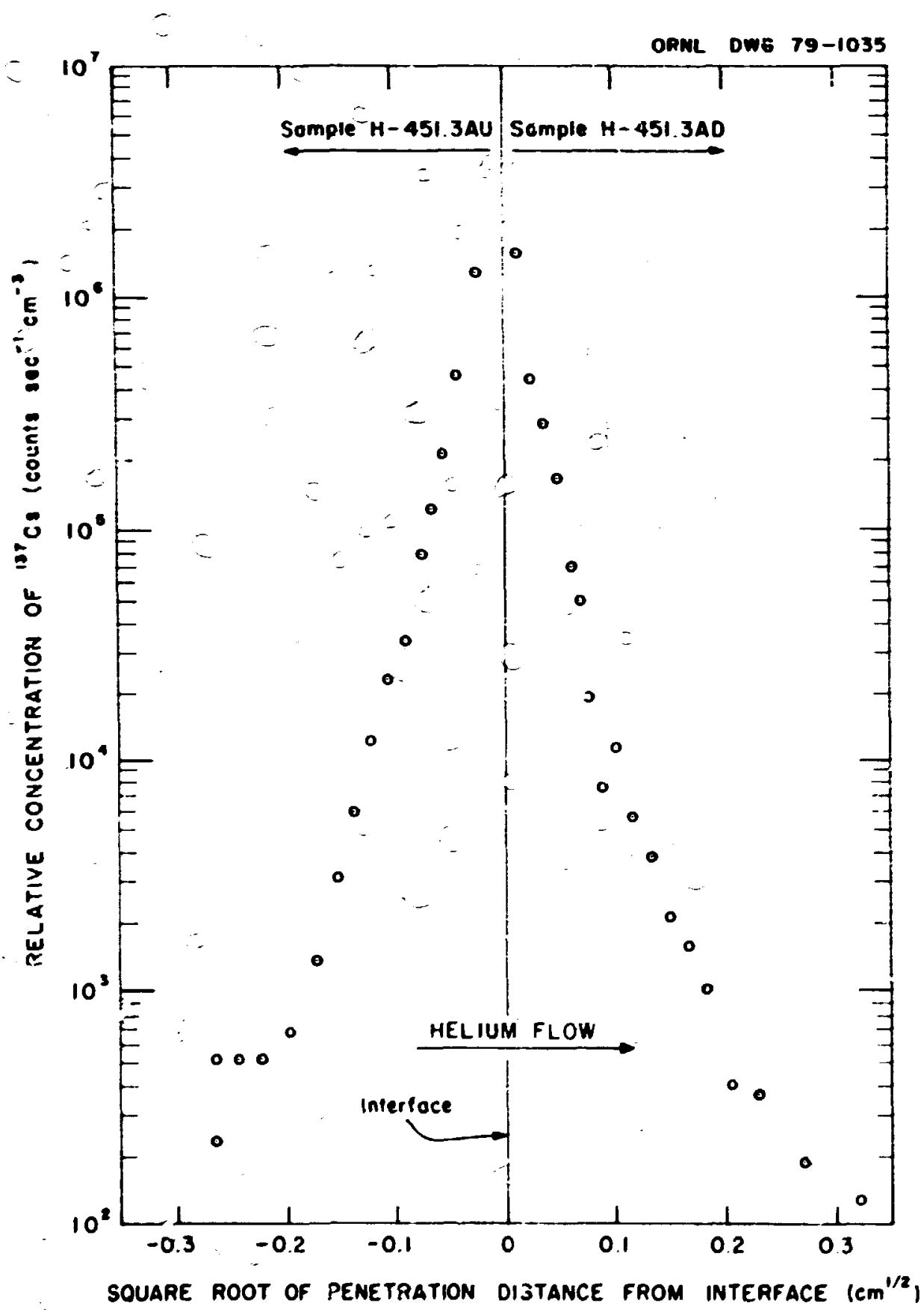

F1g. 23. Cesium-137 concentration profiles in experiment $3 \mathrm{~A}$ with H-451 graphite. (Maximum temperature $=644^{\circ} \mathrm{C}$.) 
flow-rate range of 34 to $92 \mathrm{~cm}^{3} / 10 \mathrm{~s}$ corresponds to 3.4 to $9.2 \mathrm{~cm}^{3} / \mathrm{s}$ or a superficial velocity of 2.86 to $7.75 \mathrm{~cm} / \mathrm{s}$ on the basis of the graphite area. Similarly, helium flow rares in the second experiment at $635^{\circ} \mathrm{C}$ (experiment $3 \mathrm{~A}$ with samples $3 \mathrm{AD}$ and $3 \mathrm{AU}$ ) were 2.4 to $10 \mathrm{~cm} / \mathrm{s}$ (2.06 to $8.46 \mathrm{~cm} /-$ ); those of experiment IA (samples $1 \mathrm{AD}$ and $1 \mathrm{AU}$ ) at $680^{\circ} \mathrm{C}$ ranged from 0.82 to $8.0 \mathrm{~cm}^{3} / \mathrm{s}(0.69$ to $6.74 \mathrm{~cm} / \mathrm{s})$. Also, as may be seen in the tabulations of Appendix $D$, pressure differentials across a pair of H-451 samples were in the range 500 to 800 corr.

\section{SUMMARY AND CONCLUSIONS}

Data are presented on the transport of ${ }^{137} \mathrm{Cs}$ into and in five difierent graphites, namely ATJ, H-327, H-451, HLM-85, and HS-1-1. Femperatures of the experiments ranged from 600 to $>1000^{\circ} \mathrm{C}$. Also presented are flow measurements made in an effort to determine whether vapor-phase transport could be observed. Transport of ${ }^{137} \mathrm{Cs}$ appears to follow a simple diffusion process only in the case of the Hawker-Siddeley graphite liS-1-1. For this graphite, the following equation and paraneters apply:

$$
\begin{aligned}
\mathrm{D} / \mathrm{E} & =\left(\mathrm{D} / \mathrm{C}_{0} \exp [-[\mathrm{E} / \mathrm{RT}],\right. \\
(\mathrm{D} / \mathrm{E})_{\mathrm{o}} & \simeq 4 \times 10^{-2} \mathrm{~cm}^{2} / \mathrm{s}, \\
\lambda \mathrm{E} & \simeq 30 \mathrm{kcal} / \mathrm{mole} .
\end{aligned}
$$

Transport of ${ }^{137} \mathrm{Cs}$ into the other four graphices cannot be described by a simple diffusion process since, after the diffusion anneal, there $i=$ a very steep concentration gradicat near the surface to which the cesis:was applied. Only at penetration distances beyond the end of this steep gradient does simple diffusion appear, from some of the data plots, to become the dominant mass cransport mechanism. We used norlinear leastsquares techniques and some of the Jata appearing most susceptible to analysis to test a mechanism involving diffusion plus an irreversible, first-order removal of cesium. The three parameters of this model, namely surface concentration, diffusion coefficient, and chemical (or physical) reaction rate constant, werr evaluated. However, the fit of data to the model was very poor, Indlcating that the model is unlficely to he correct. 
Measurements made to test for transport of ${ }^{137} \mathrm{Cs}$ via the vapor phase within H-451 graphite showed such transport to be undetectable under the experimental conditions. These conditions involved flowing helium through a pair of samples whose contacting surfaces had been coated with ${ }^{137} \mathrm{Cs}$. Fore pressures on the upstream sample ranged up to $100 \mathrm{psi}$, while pressure drops across the two samples were about $1 \mathrm{~atm}$.

\section{NOMENCLATURE}

$b$ = subscript referring to bulk phase

$B_{0}=$ viscous flow parameter for a porous medium, $\mathrm{cm}^{2}$

$c_{i}=$ concentration of component $i$ in free space

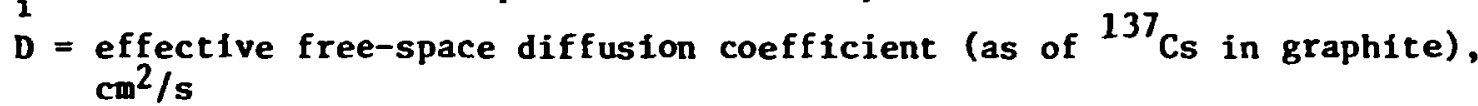

$D_{i j}=\underset{c m^{2} / \mathrm{s}}{(1)}$ diffusion coefficient for an $i-j$ biıary mixture in fres space,

$D_{1 K}=$ Knudsen diffusion coefficient for component $i, \mathrm{~cm}^{2} / \mathrm{s}$

$F R=$ fraction remaining

$B$ = subscript referring to gas

$k=$ reaction rate constant, usually used with a subscript

$K=$ combined Knudsen-viscous flow permeability coefficient for porous medium, $\mathrm{cm}^{2} / \mathrm{s}$

$K_{0}=$ Knudsen flow coefficient

$n=$ an exponent in the Freundlich sorption equation

$p=$ total gas pressure, dynes $/ \mathrm{cm}^{2}$ or atm

$\langle p\rangle=$ arithmetic mean pressure, dynes $/ \mathrm{r}^{2}$ or atm

$\Delta p=$ pressure drop across specimen, dynes $/ \mathrm{cm}^{2}$ or atm

$q$ = effective tortuosity factor for porous medium

$Q_{0}=$ the amount of cesium placed on the end of one cylinder of graphite

$r_{0}=$ average flow radius, $\mathrm{cm}$

$\langle r\rangle=$ mean pore radius, $\mathrm{cm}$

$\mathbf{r}_{\text {ads }}=$ rate of adsorption

8 = subscript referring to a surface

$t=$ time coordinate

$T$ - absolute cemperature, ${ }^{\circ} \mathrm{K}$

$u=$ reduced dimension $=(x / 2) \sqrt{\varepsilon / D t}$ 


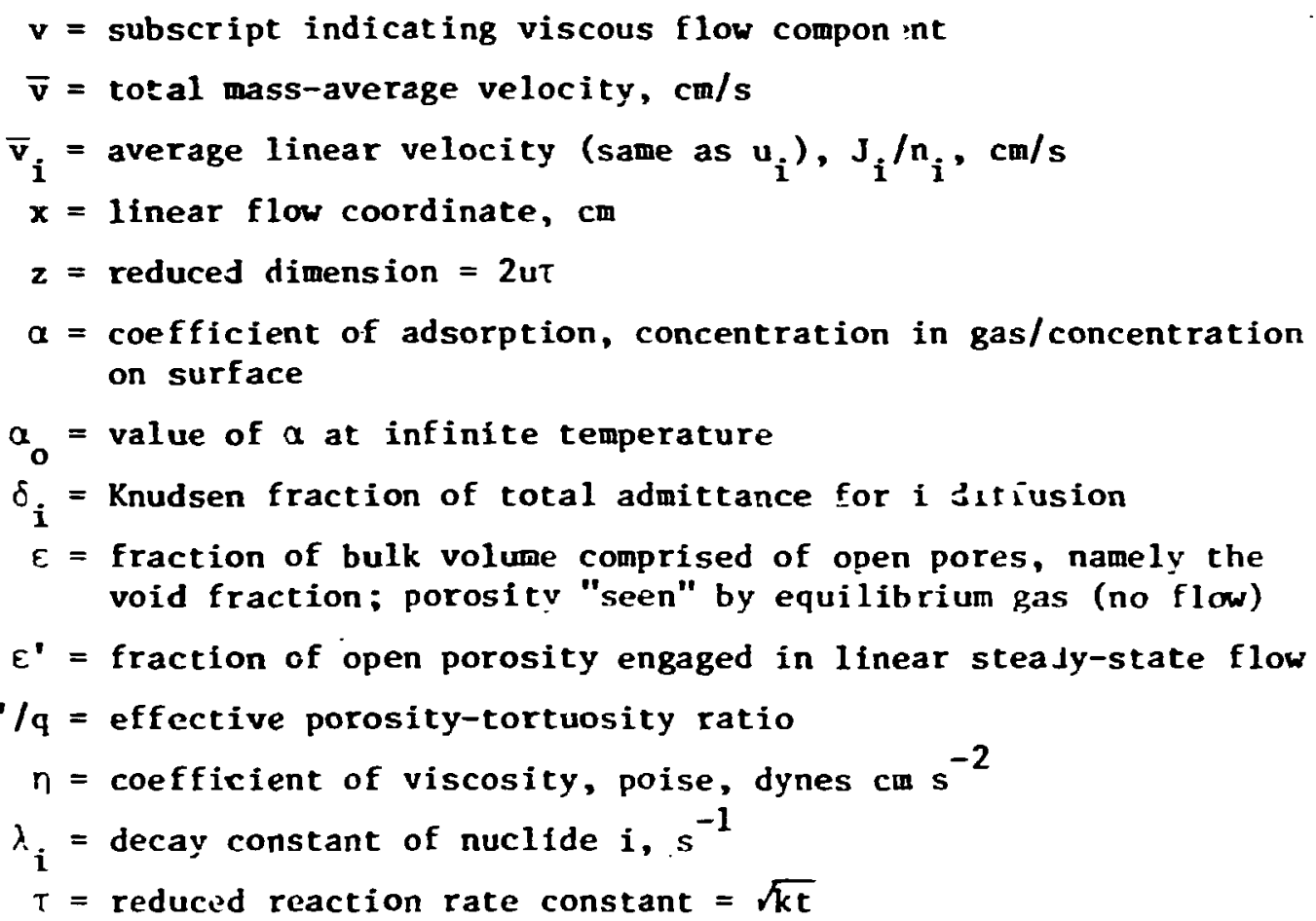

\section{REFERENCES}

1. F. F. Dyer, R. P. Wichner, W. J. Martin, L. L. Fairchild, R. J. Kedl, and $H$. J. de Nordwall, Postirradiation Examination of Peach Bottom Driver Fuel E.lement E06-01, ORNL-5216 (April 1976).

2. R. P. Wichner, F. F. Dyer, W. J. Martin, and L. C. Bate, Distribution of Fission Products in Peach Bottom HTCR Fuel Element E11-07, ORNL-5214 (Apri1 1977).

3. F. F. Dyer, R. P. Wichner, W. J. Martin, and H. I. de Nordwal1, Distribution of Radionuclides in the Peach Bottom HTGR Primary Coolant Circuit During Core 2 Operatirn, ORNL-5188 (March 1977).

4. R. B. Evans III and M. T. Morgan, Mathematical Description of Fisston Product Transport in Coated Particles During Postirradiation Anneals, ORNL-4969 (suace 1974).

5. "Diffusion of Adsorbed Species in Porous Media," p. 93 in Chem. Techno1. Div. Annu. Prog. Rep. Mar. 31, 1975, ORNI-5050 (October 1975). 
6. R. B. Evans III and A. L. Sutton, Jr., "Transport of Stroagly Adsorbed Species In Porous Media," pp. 154-81 in High-Temperature Gas-Cooled Reactor Base-Technology Program Progress Report for January 1, 1974, Through June 30, 1975, ed. by J. H. Coobs and P. R. Kasten, ORNL-5108 (November 1976); R. G. Evans III, A. L. Sutton, Jr., and R. L. Towns, "Gas Transport Properties of HTGR Graphite," pp. 190-98 in High-Temperature Gas-Cooled Reactor BaseTechnology Program Progress Report for July 1, 1975-December 31, 1975, ed. by F. J. Homan and P. R. Rasten, ORNL-5274 (wovember 1977).

7. "Diffusion of Adsorbed Species in Porous Media,". p. 118 in Chem. Technol. DIv. Annu. Prog. Rep. Mar. 31, 1976, ORNL-5172 (September 1976).

8. M. N. Özisik and M. D. Silverman, "The Effects of Transverse Plow Through Graphite on Fission Product Movement in HTGR-Type Systems," Nuc1. Techno1. 41, 240 (1972).

9. R. S. Rodliffe, The Effect of Flow on Mass Transport of an Absorbing Ea

10. A. L. Habush and A. M. Harris, "330 MW(e) Fort Saint Vrain HighTemperature Gas-Cooled Reactor," Trans. Am. Nucl. Soc. 10, 320-21 (June 1967); CONF-670602.

11. (a) Final Environmental Statement Relative to Operation of the Fort St. Vrain Nuclear Generating Station of the Public Service Company of Colorado (Docket No. 50-267), pp. III. 23-33 (August 1972). (b) Final Safety Analysis Report for Fort St. Vrain, Vol. I, Sect. III, p. 3.4-1, Public Service Company of Colorado (Docket No. 50-267).

12. R. B. Evans III, J. 0. Stiegler, and G. M. Watson, "Diffusion of Actinides in Pyrocarbons: Thin Layer Experiments," J. Appl. Phys. 41. 4808 (1970).

13. R. B. Evans III, J. I. Rutherford, and A. P. Malinauskas, Gas Transport in MSRE Moderator Graphite. II. Ef fects of Impregnation. III. Vartation of Flow Propertles, ORNL-4389, PP. 28, 31, 38, 39 (May 1979). 
14. J. Bromley and N. R. Large, "The Migration of Fission Products in Artificial Graphite," p. 365 in Vol. 1, Proceedings of the Fifth Conference on Carbon, held at the Pennsylvania State University, 1961, Pergamon, Macmillan, New York (1962).

15. C. E. Milstead, A. B. Riedinger, and L. R. Zumwalt, "CesiumGraphite Sorption Isotherms Determined by a Static Method," Carbon 4 , 99 (1966).

16. J. H. Norman, L. R. Zumwalt, and H. G. Staley, "Thermodynamics of Adsorption of Mixed Metal'ic Elements on Graphite at High Temperature," in Proceedings of the Thermodynamik Symposium V, vol. 3, Heidelburg, Germany (Sept. 12-14, 1967).

17. C. E. Milstead, "Sorption Characteristics of the Cesium-Graphite System at Elevated Temperatures and Low Cesium Pressures," Carbon $\underline{7}$, 199 (1969).

18. R. H. Flowers, "The Relation of Fission Product Release Limitations to the Design and Operation of a Large H.T.R. Station," paper 2/118, pp. 311-60 in Proceedings of Gas-Cooled Reactor Information Meeting at the Oak Ridge National Laboratory, Apri1 27-30, 1970, CONF-700401.

19. M. J. Bell, ORIGEN - The ORNL Isotope Generation and Depletion Code, ORNL-4638 (May 1973).

20. C. W. Kee, A Revised Light Element Library for the ORIGEN Code, ORNL-TM-4896 (May 1975).

21. A. G. Croff, M. A. Bjerke, G. W. Morrison, and L. M. Petrie, Revised Uranium-Plutonium Cycle PWR and BWR Models for the ORIGEN Computer Code, ORNL/TM-6051 (September 1978).

22. D. W. Marquardt, "An Algorithm for Least-Squares Estimation of Nonlinear Parameters," J. Soc. Ind. Appl. Math. 11, 431 (1963).

23. D. W. Marquardt, Least-Squares Estimation of Nonlinear Parameters (NLIN), SHARE Program Library, SDA 309401.

24. D. O. Hayward and B. M. W. Trapne11, Chemisorption (2nd ed.), pp. 131-35, Butterworths, Washington, 1964.

25. H. S. Carslaw and J. C. Jaeger, Conduction of Heat in Solids, 2nd ed., Clarendon Press, Oxford, 1359. 
$-61-$

8. APPENDIXES 


\subsection{Appendix A: Experimental Data}

Some details of experimental procedures were given in Sect. 3. In Appendix A, we present the data from each experiment. Data are entered in a standard rormat in anticipation of compiter-assisted manipulation and analysis. The ruccessive entries are as follows:

1. Listing of the particular gaphite (such as ATJ), the sample number (such as $4 \mathrm{C}$ ), and the date on which the experiment was performed.

2. Two row entries listing nominal run temperatures and heating times: Two rows are used because Evans listed two halt-temperatures in some experiments (such as run $7 U$ with ATJ graphite). However, actual experimental temperature-time data are listed in entry 12 , below.

3. Original length of graphite sample.

4. Original diameter of graphite sample.

5. The length to which the graphite sample was reduced after the diffusion anneal. The sample iength was reduced by machining some of the graphite from the end of the cylinder opposite that to which ${ }^{137} \mathrm{Cs}$ had been applied. $\mathrm{No}{ }^{137} \mathrm{Cs}$ was asscciated with the graphite removed in this manner.

6. The diameter to which the graphite sample was reduced aftar the diffusion anneal. The sample diameter ras reduced by machining the full length. In this case, ${ }^{137} \mathrm{Cs}$ was removed.

7. The distance from sample to crystal detector aid the duration of counting.

8. The courit rate of the specimen mounted as shown in Fig. 13. This is, of course, the count rate corresponding to zero penetration distance.

9. The count rate of a standard ${ }^{137} \mathrm{Cs}$ source, such as 145,200 counis/ min due to standard 3 used with sample $4 \mathrm{C}$ of the AT.J grapinite. 
10. The next entries are variable in number and each row consists of 1,2 , or 3 sets $c$ the following three data:

(1) the count rate of the sample,

(2) the count rate of the standard,

(3) the length by which the sample length had been shortened by abrasion, in inches.

11. A commentary ( $\$$ in column 1 ) indicating the start of temperaturetime disa.

12. The next entries are variable in number, and each row consists of one to eight sers of temperature-vs-time data. The computerprogramming t.EAD format is $8(F 5.0,13,12)$. The first number in each field of 10 is temperature, in ${ }^{\circ} \mathrm{C}$; the next two digits are hours of the day; and the last wo digits are minutes of the hour. For example, the first complete entry for sample $4 \mathrm{C}$, ATJ graphite, lists $c$ temperature of $105^{\circ} \mathrm{C}$ at $8: 17$ AM on 8-25-74. If an experiment ixcended overnight, the hours of the day exceeded 24 . Thus, sample 3 of graphite HS-1-1 (Hawker-Siddeley) has an entry of $700^{\circ} \mathrm{C}$ at $5019 \mathrm{~h}$ on $4-30-75$. The entry of $5019 \mathrm{~h}$ corresponds to $0219 \mathrm{~h}$ (2:19 AM) on $5-2-75$.

T.bulations of data from exyeriments wits HS graphite contain additiund entries, as collows: in iour experiments, namely HS-1-1.I1, -I2, $-\mathrm{I3}$, and $-\mathrm{T4}$, the HS graphite was used as a sleeve around HLM85 graphite simples HLM85-I1, $-12,-13$, and $-I 4$. After separating the two types of graphile, the HS sleeves yere machined to increase the inner diameters as well as to reduce outer diameters. Thus, in addition to the original (outer) diameter listed according to 4 , above, there is listed an original inner diameter, which is the same $(0.3 i 2$ in.) in all cases as the original (outer) diameter of the HLM85 samples that were pressed into the HS sleeves. Finally, the diameter to which this inner diameter was increased is 1isted on the same line as item 6 , above. 


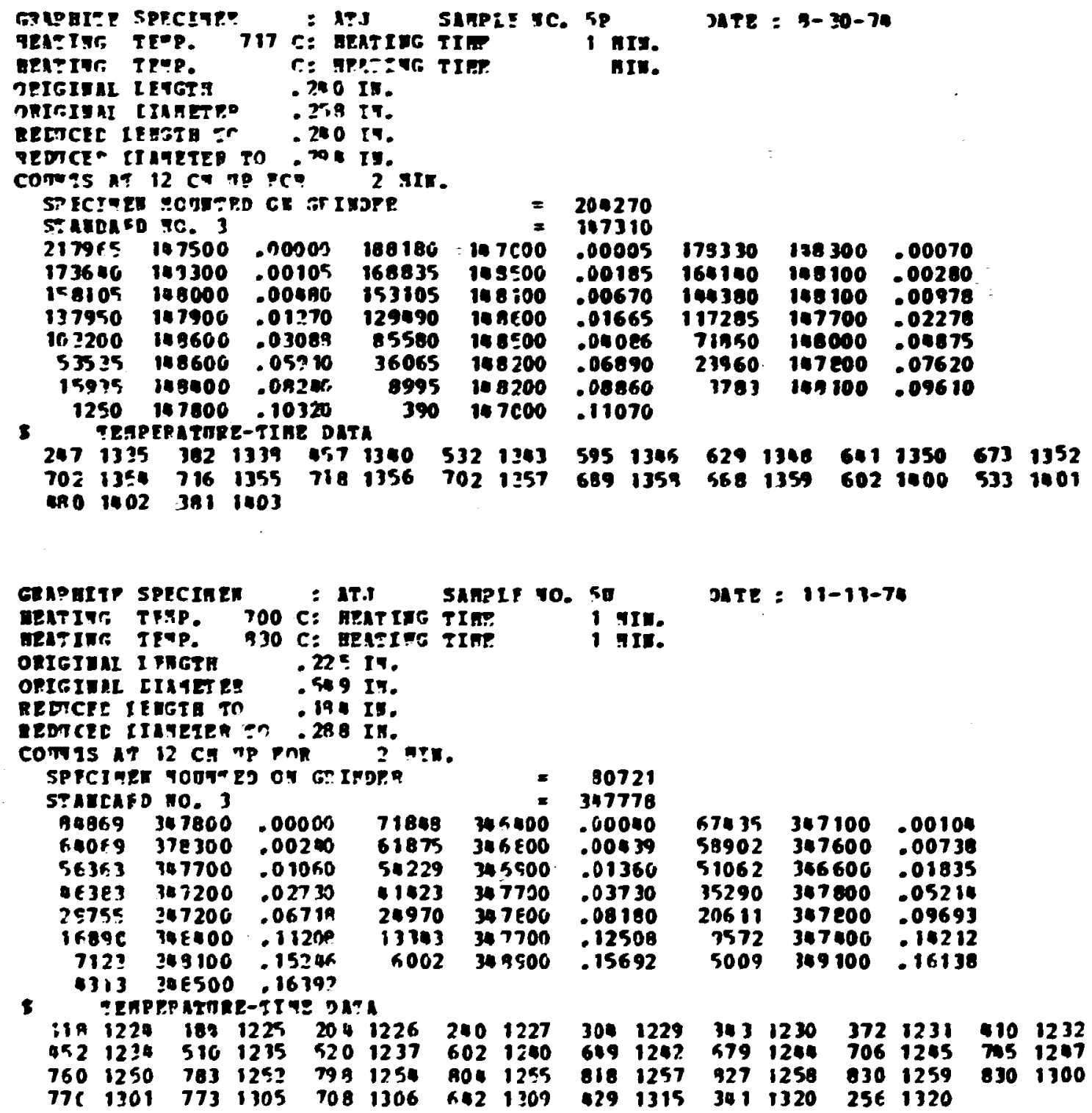




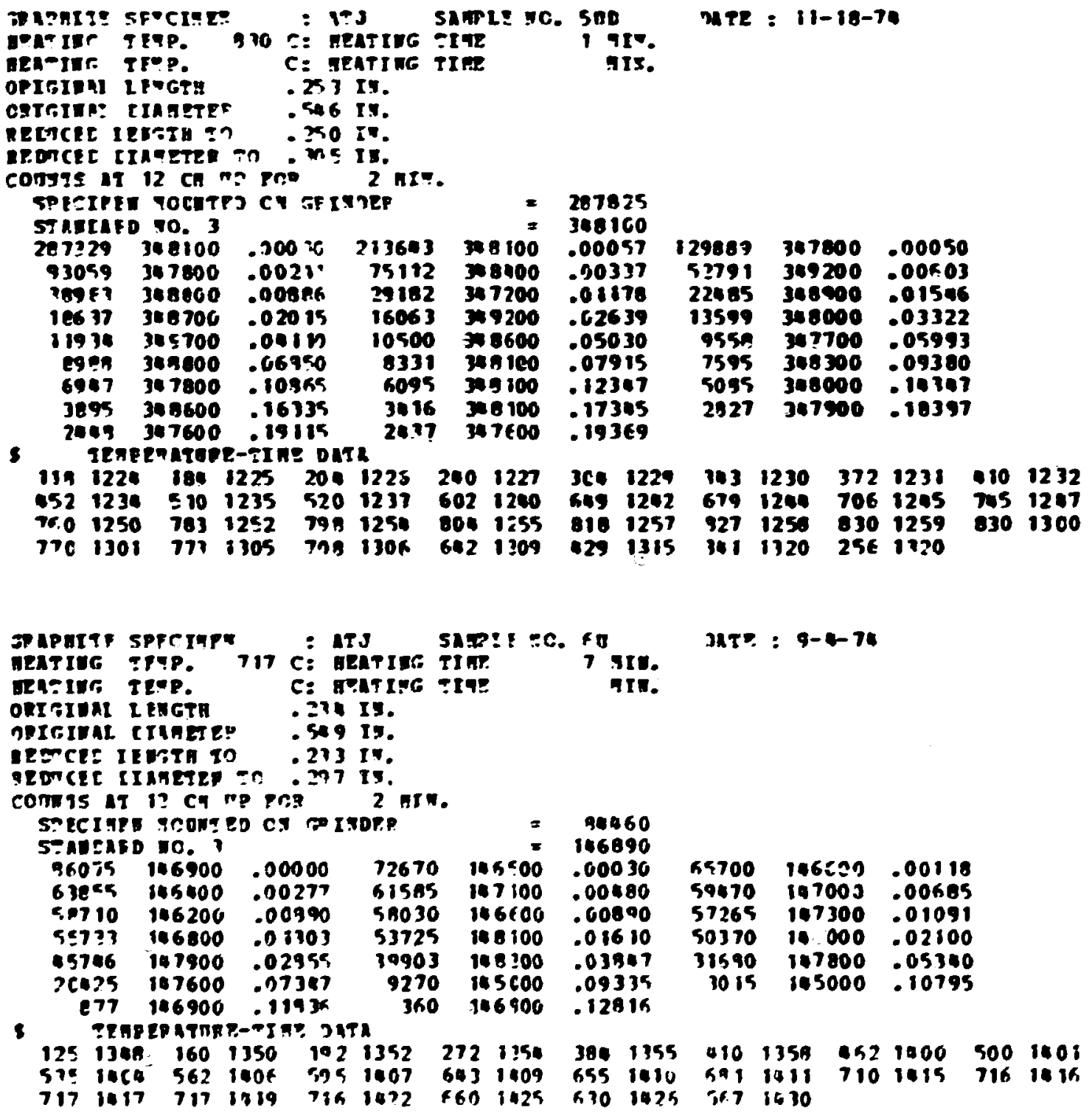




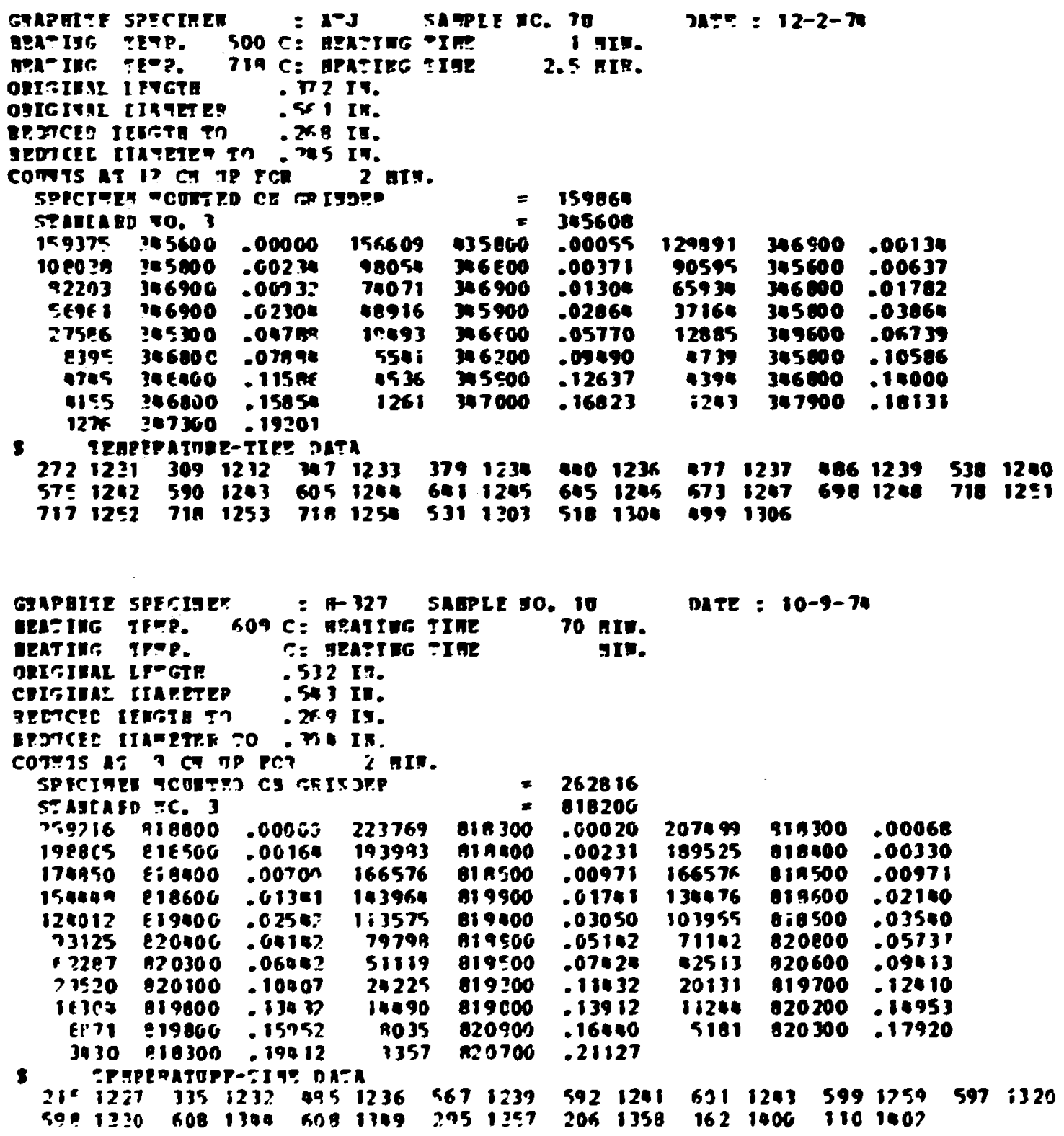




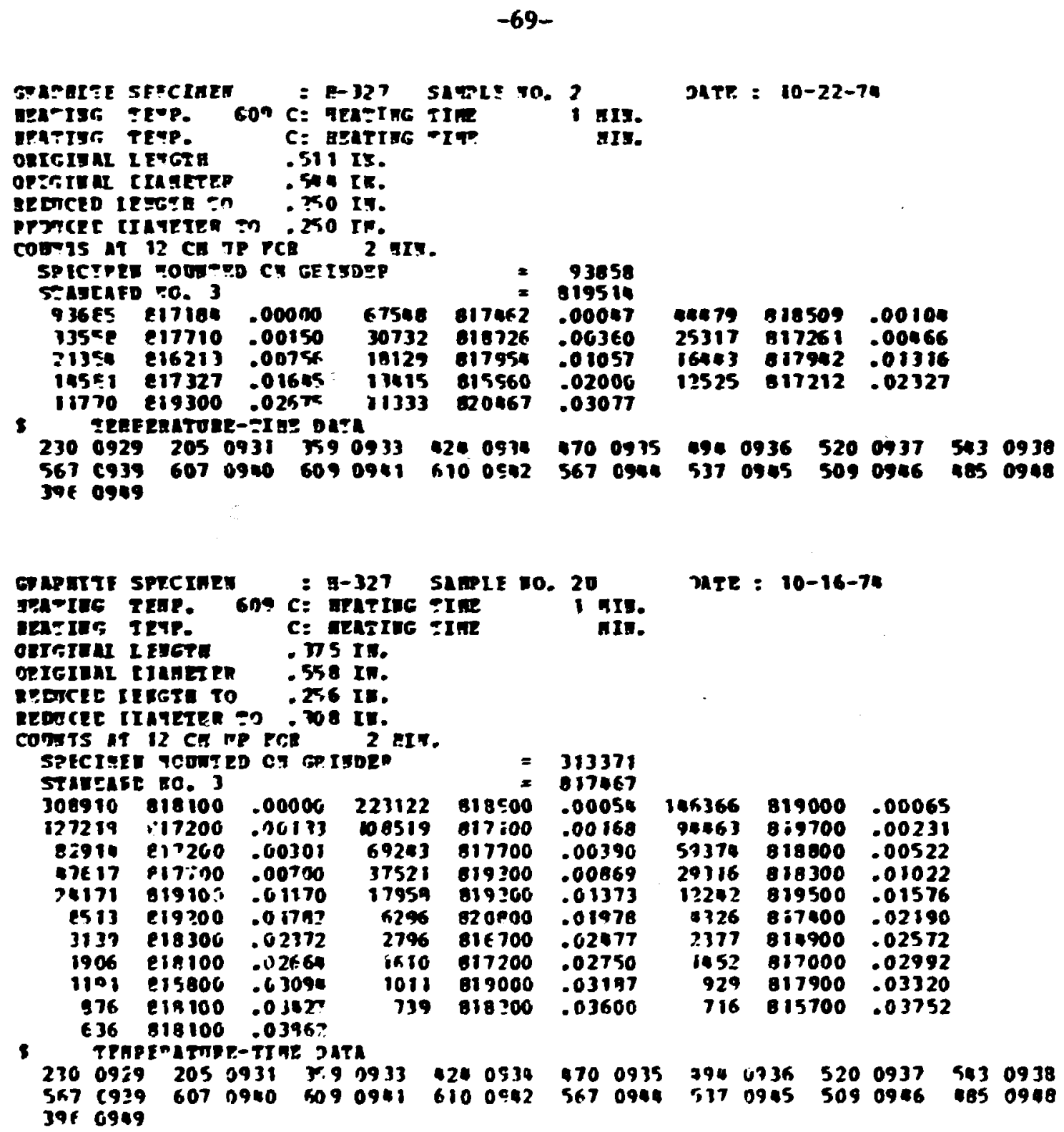




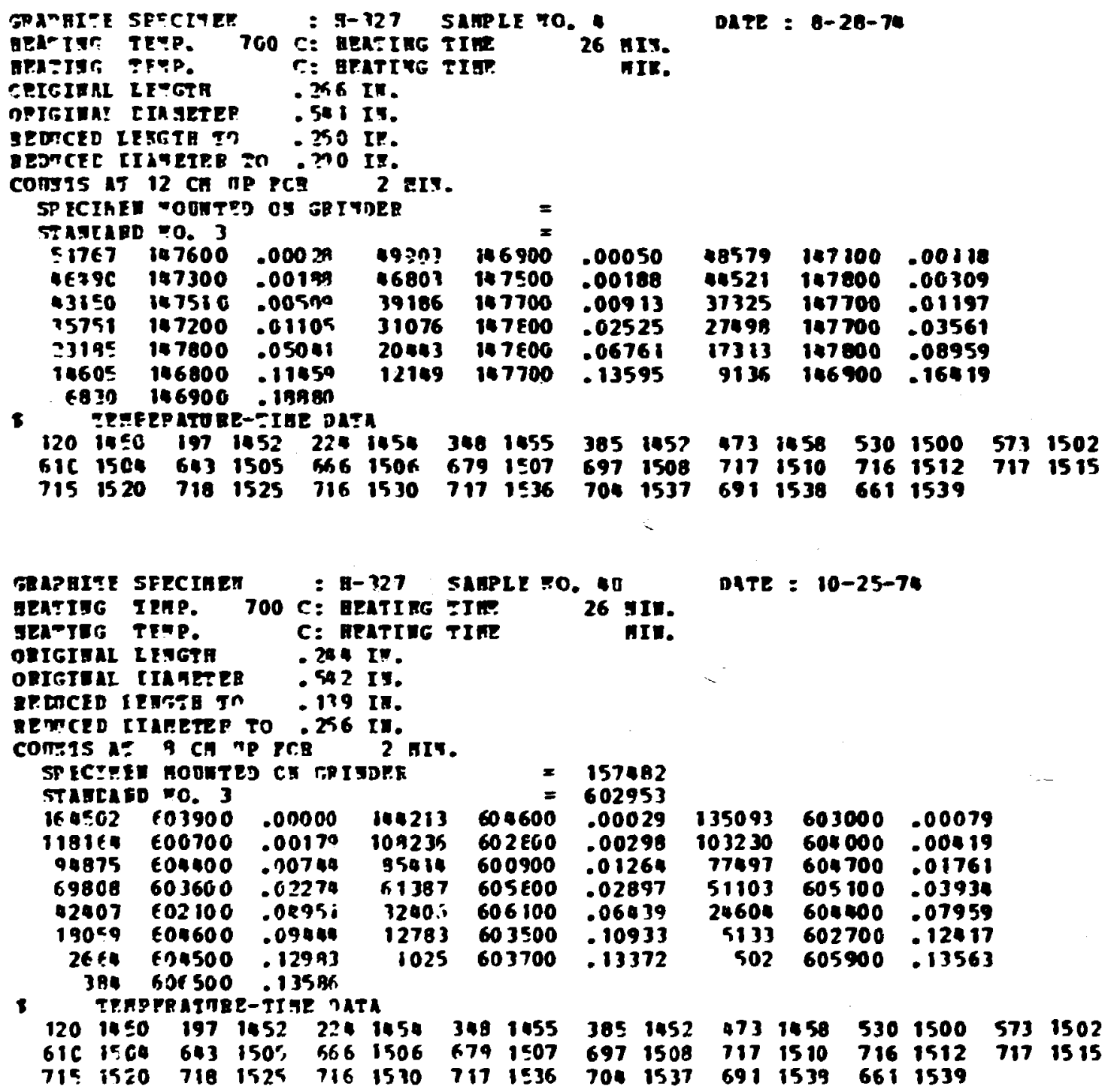




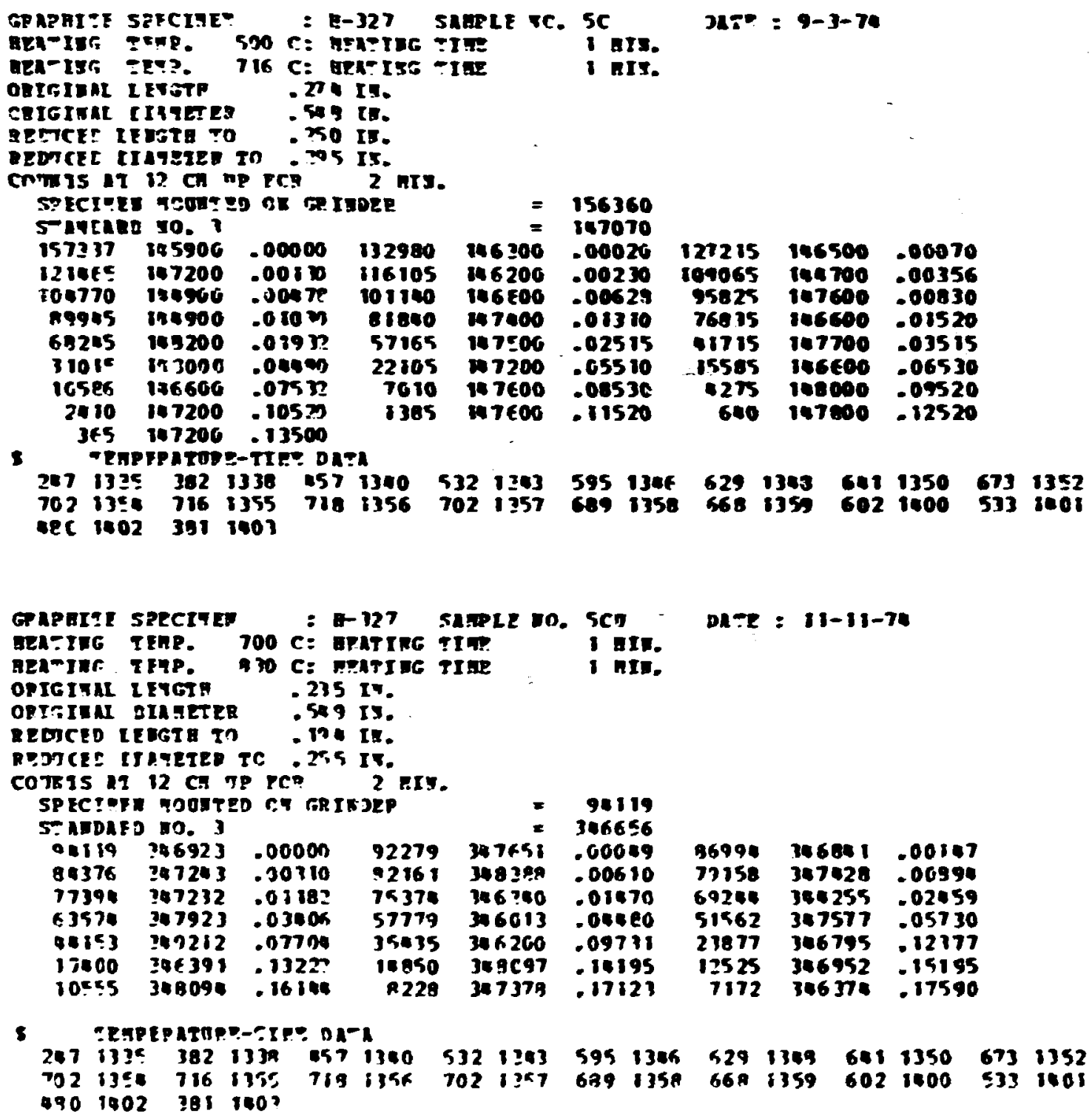




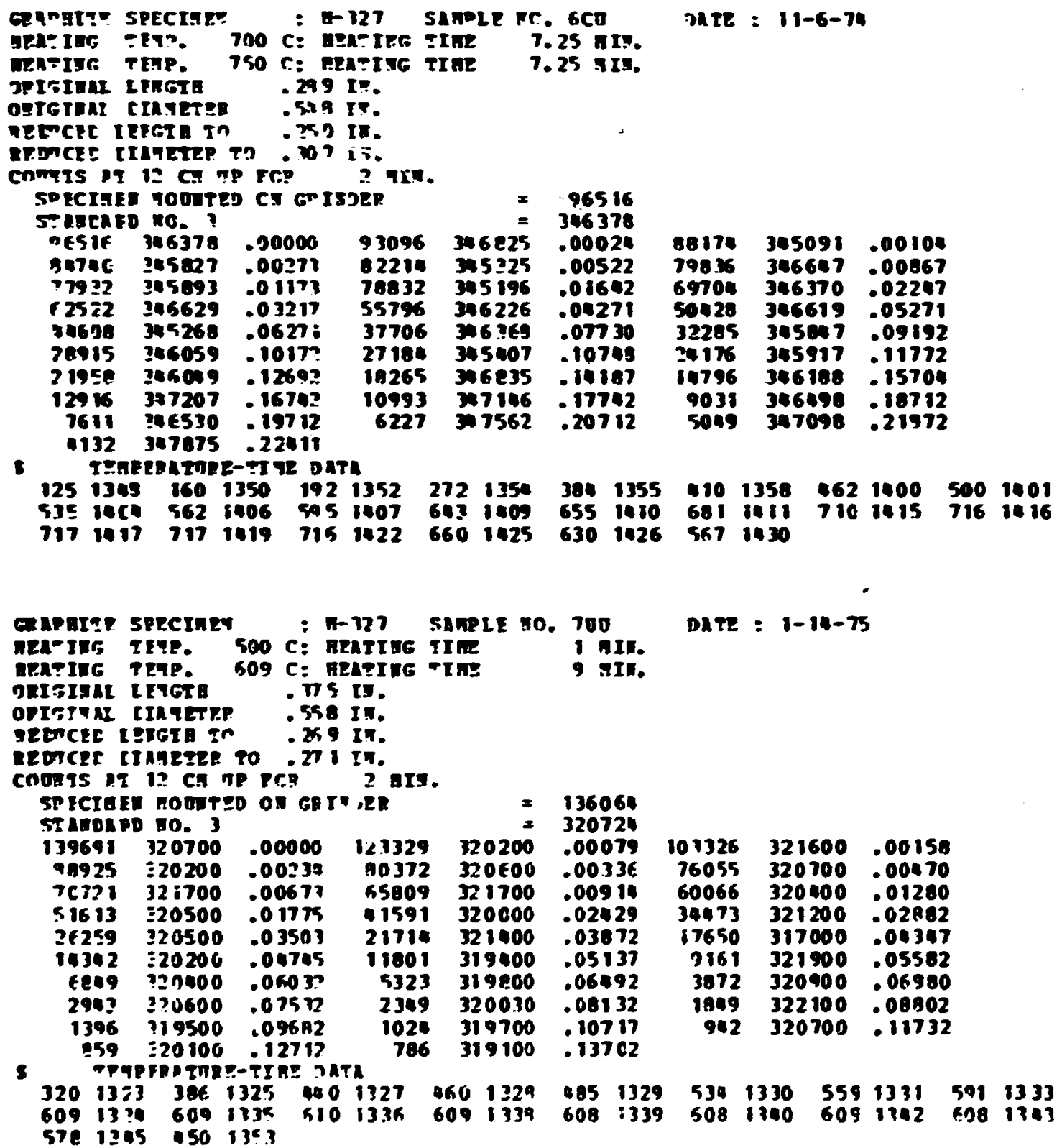




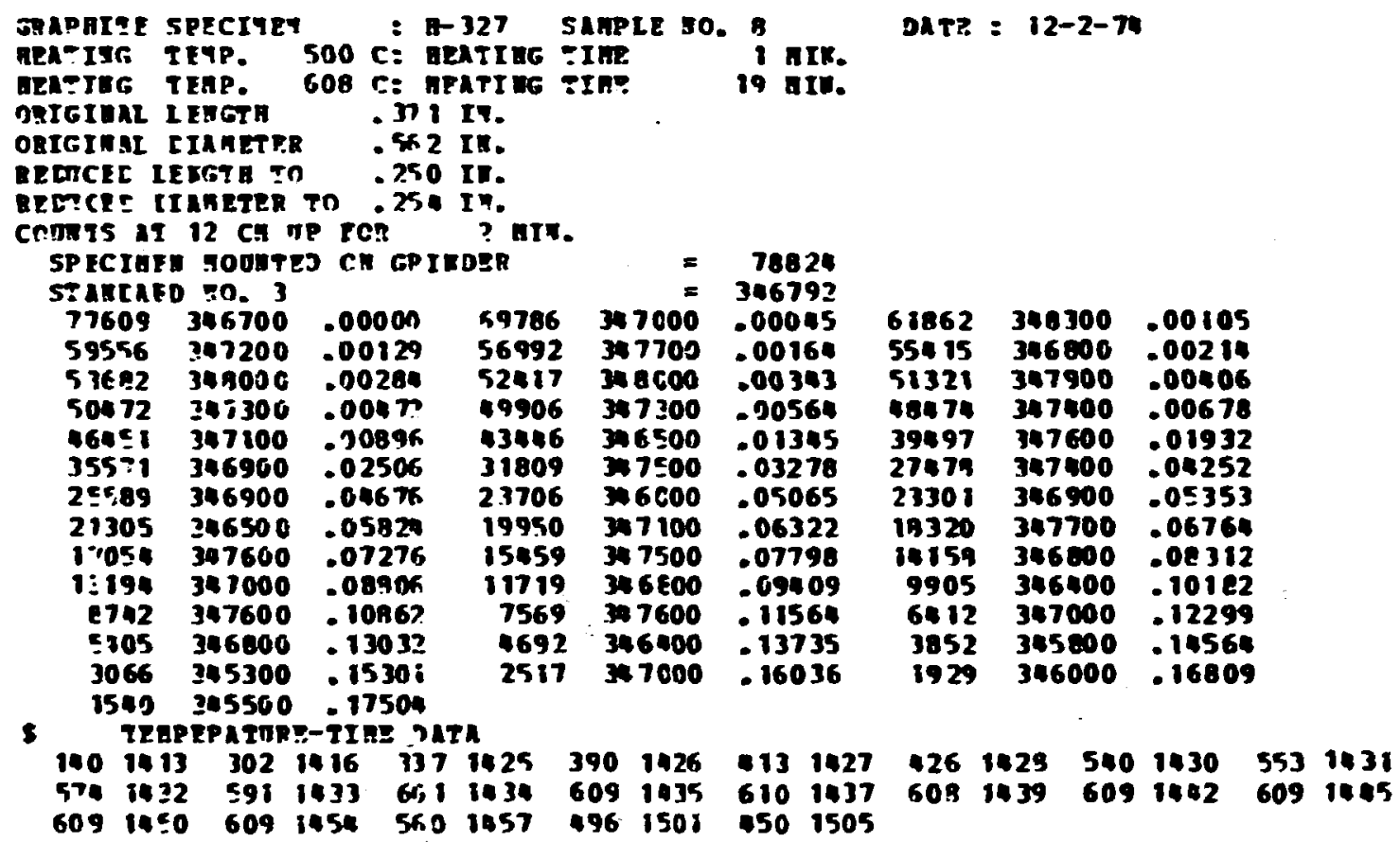

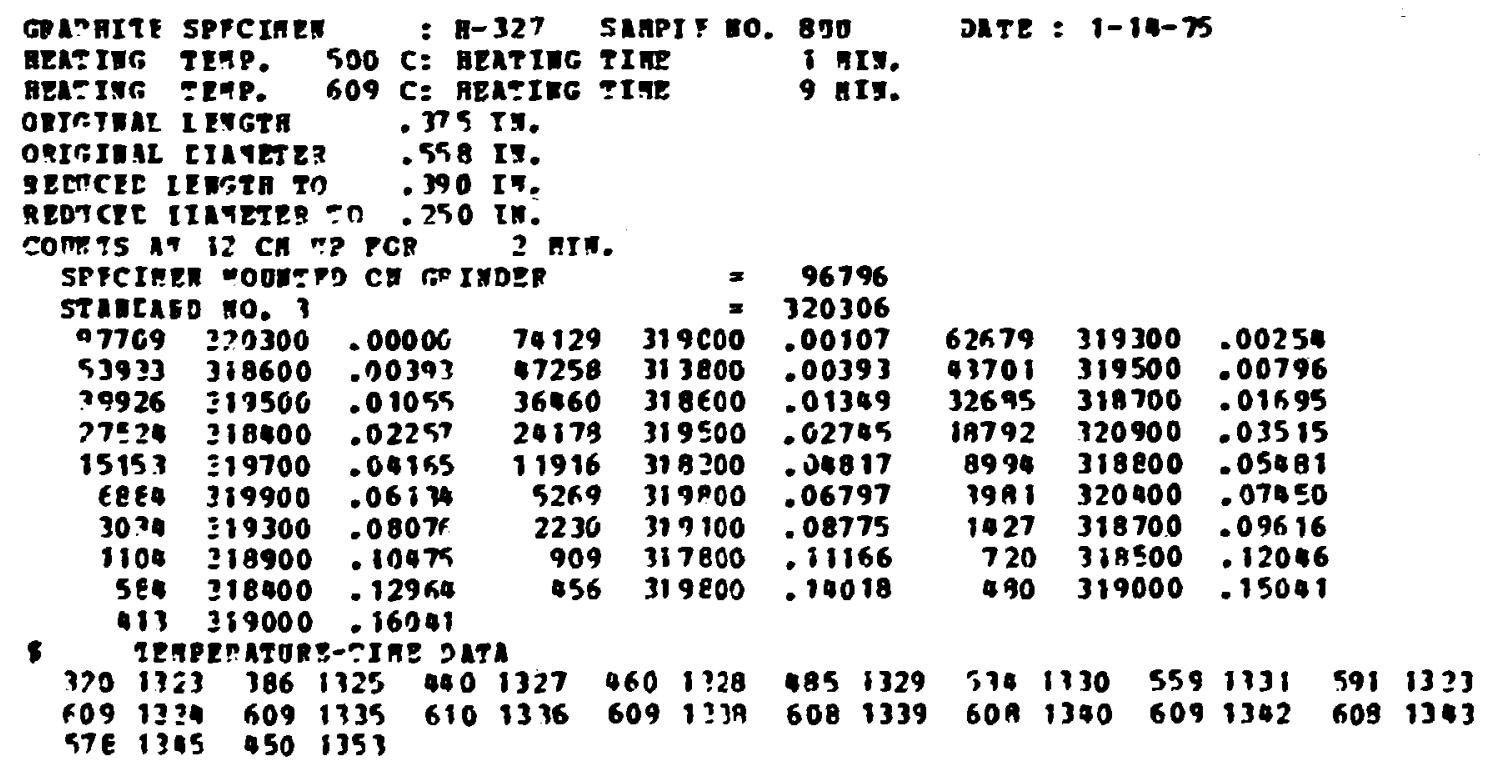




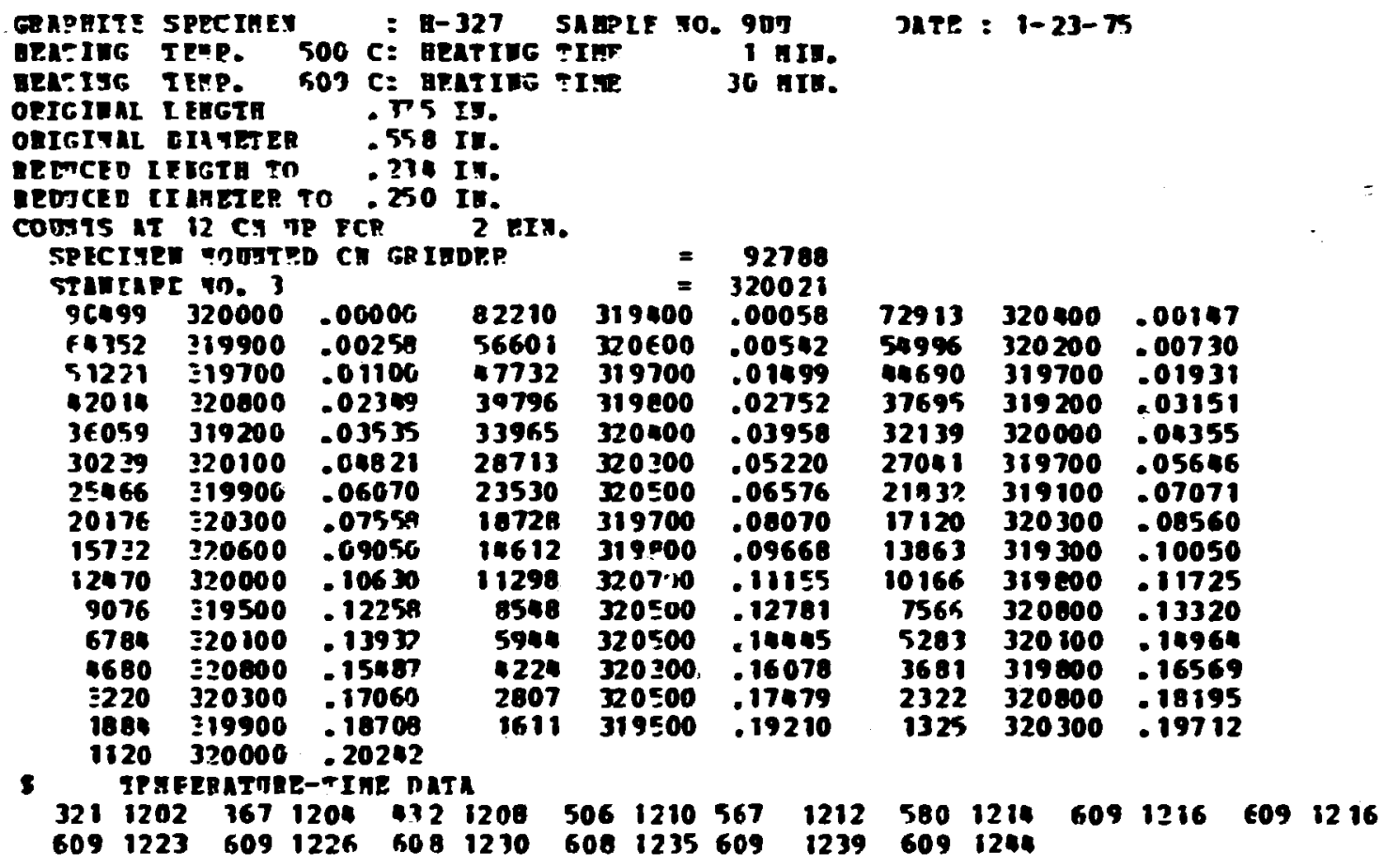

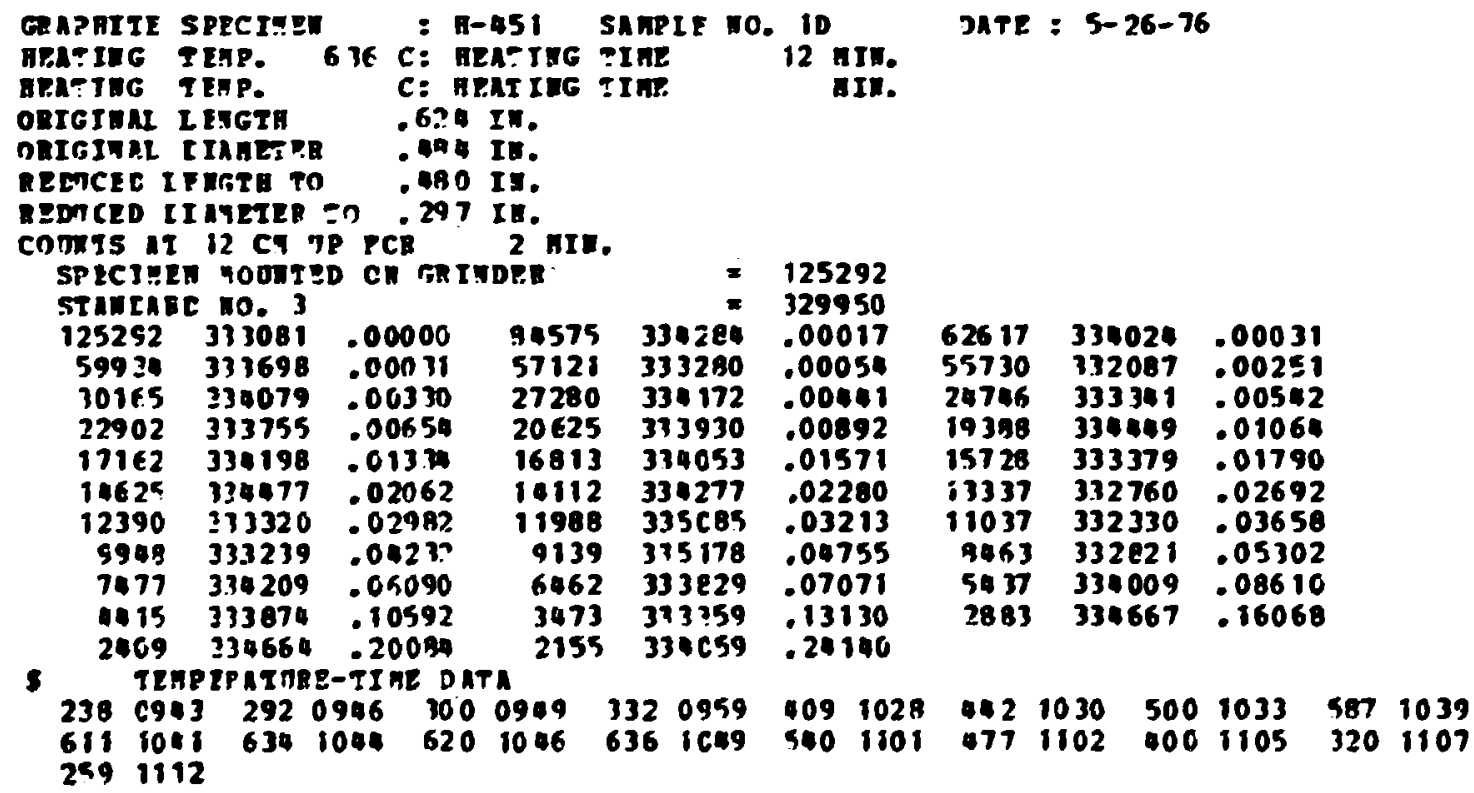




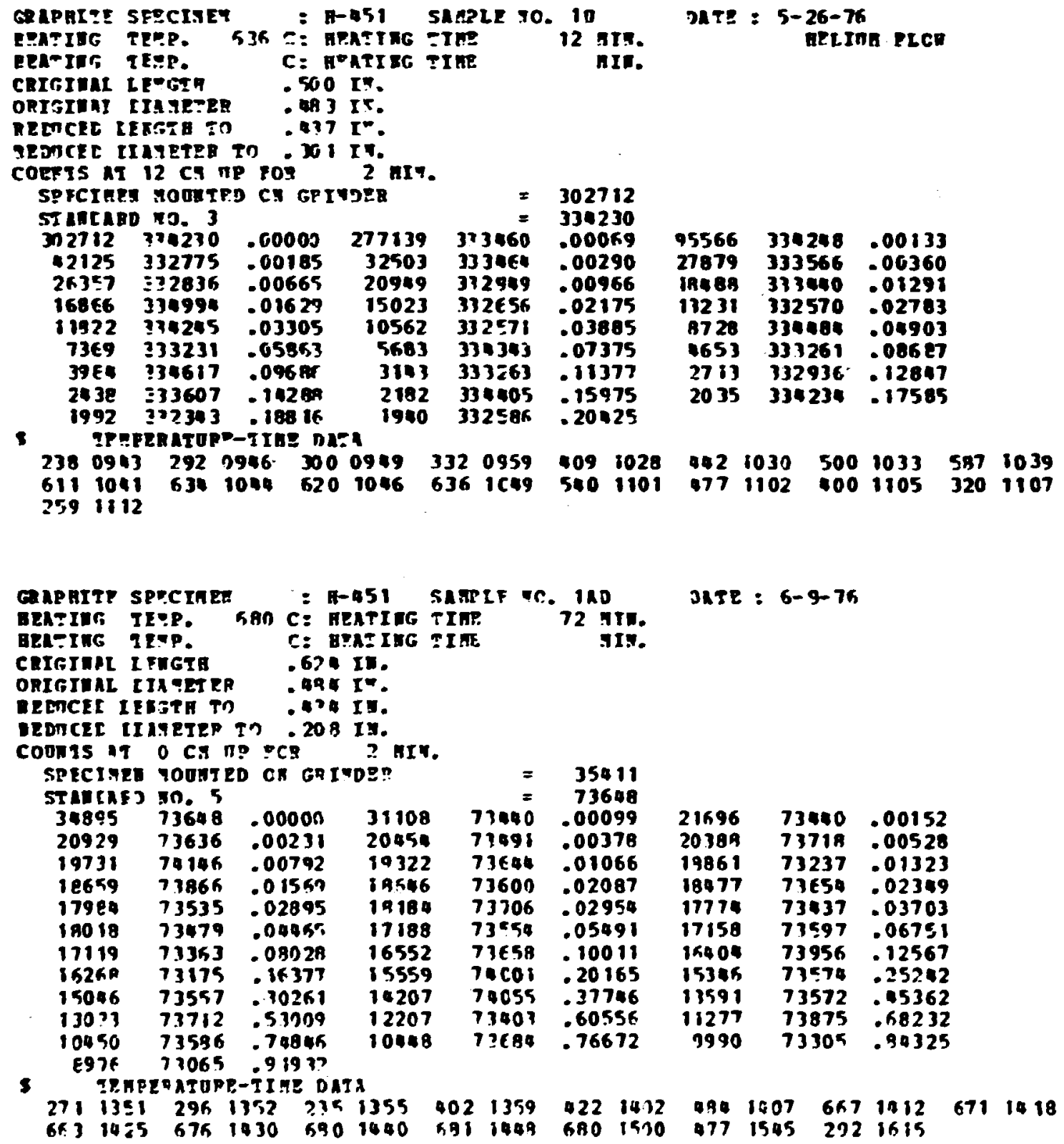




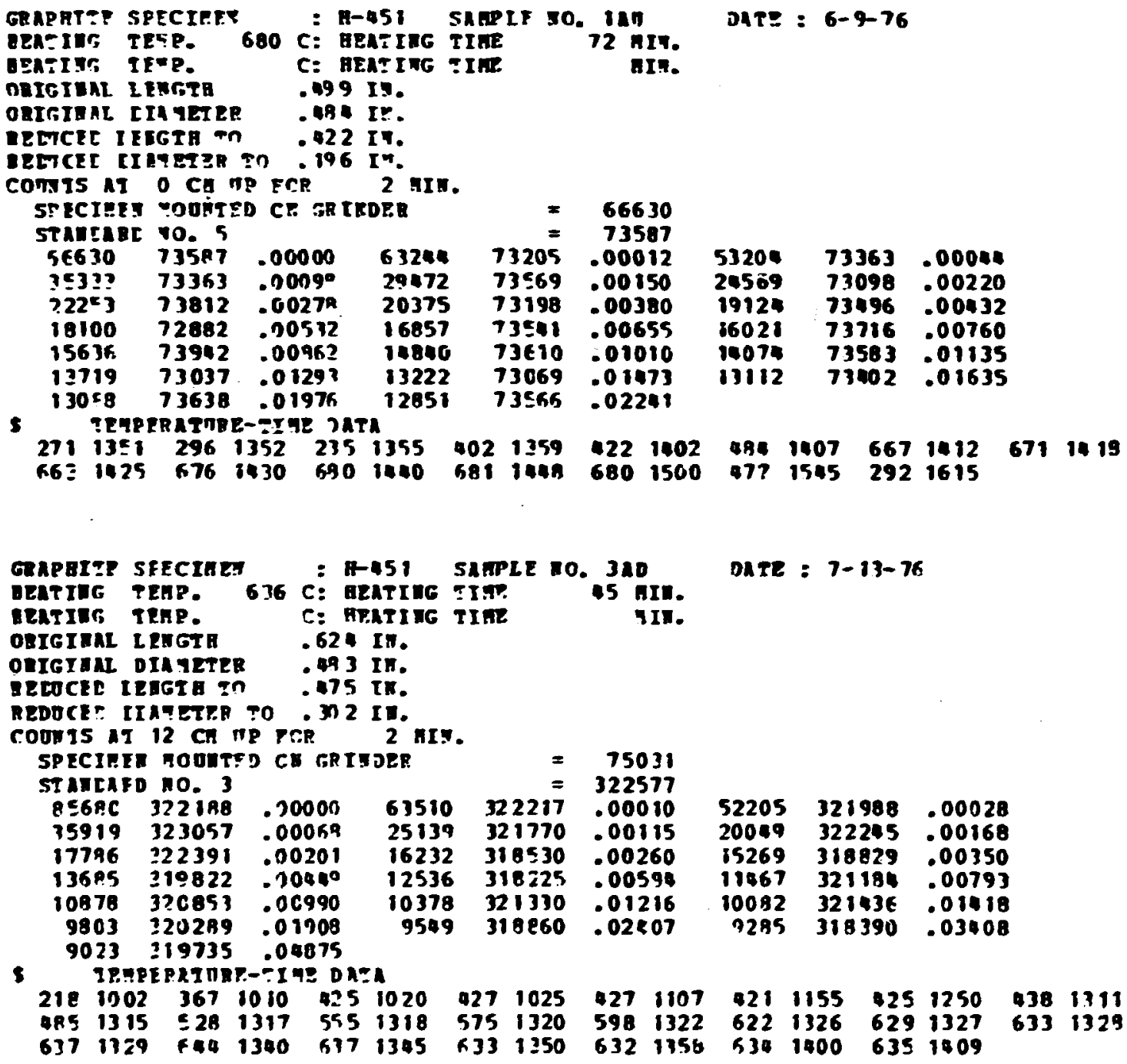




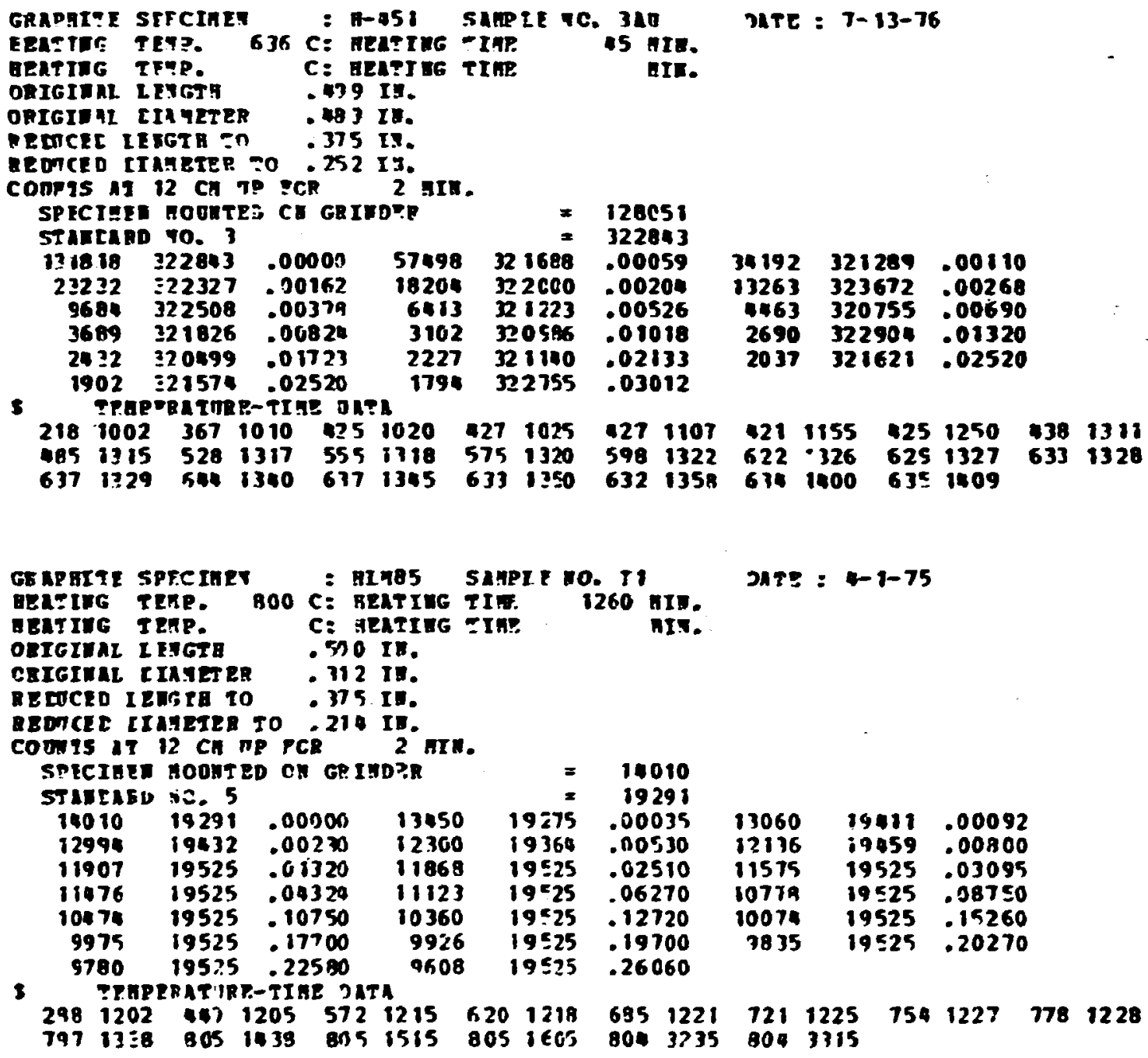




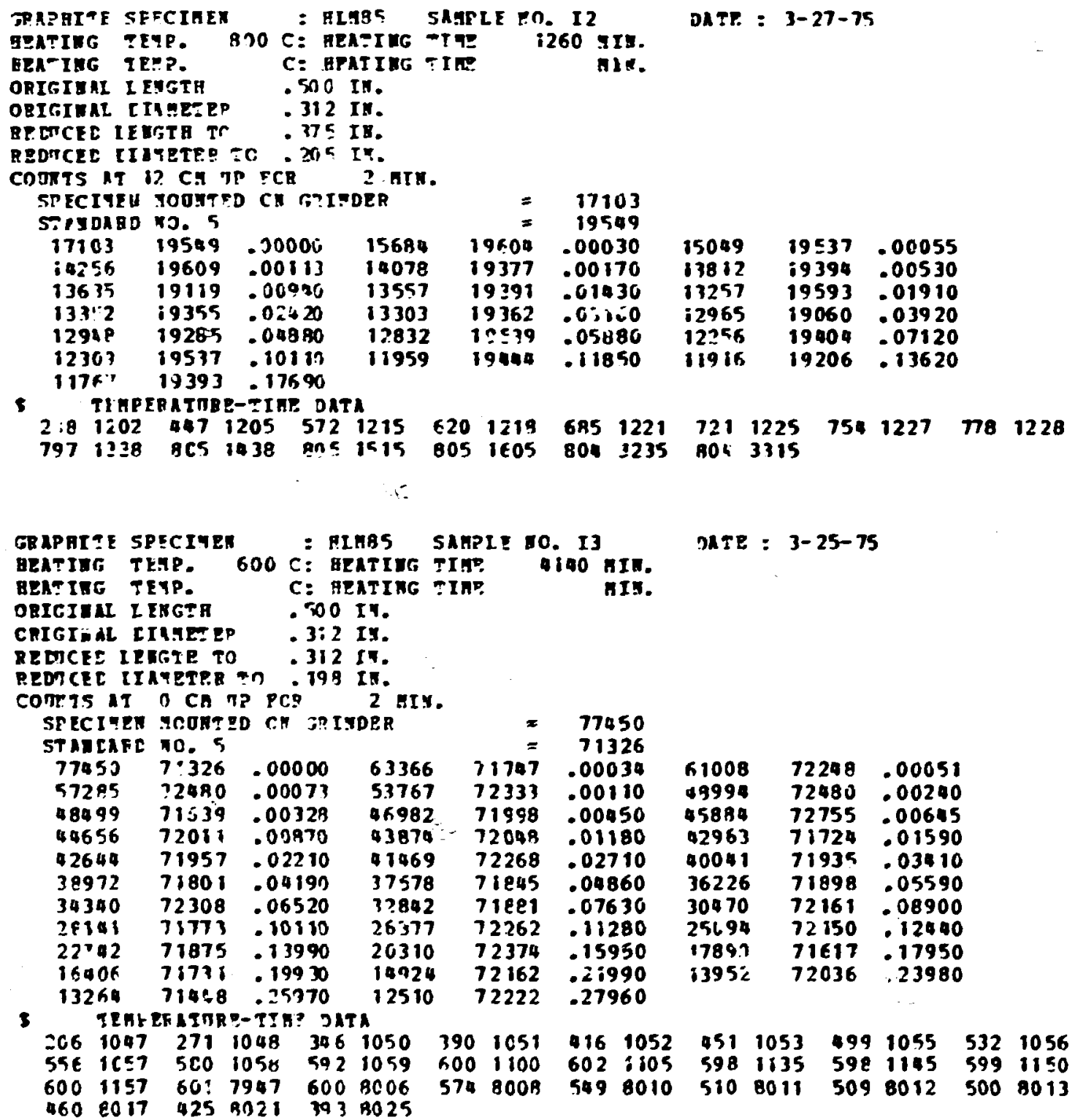




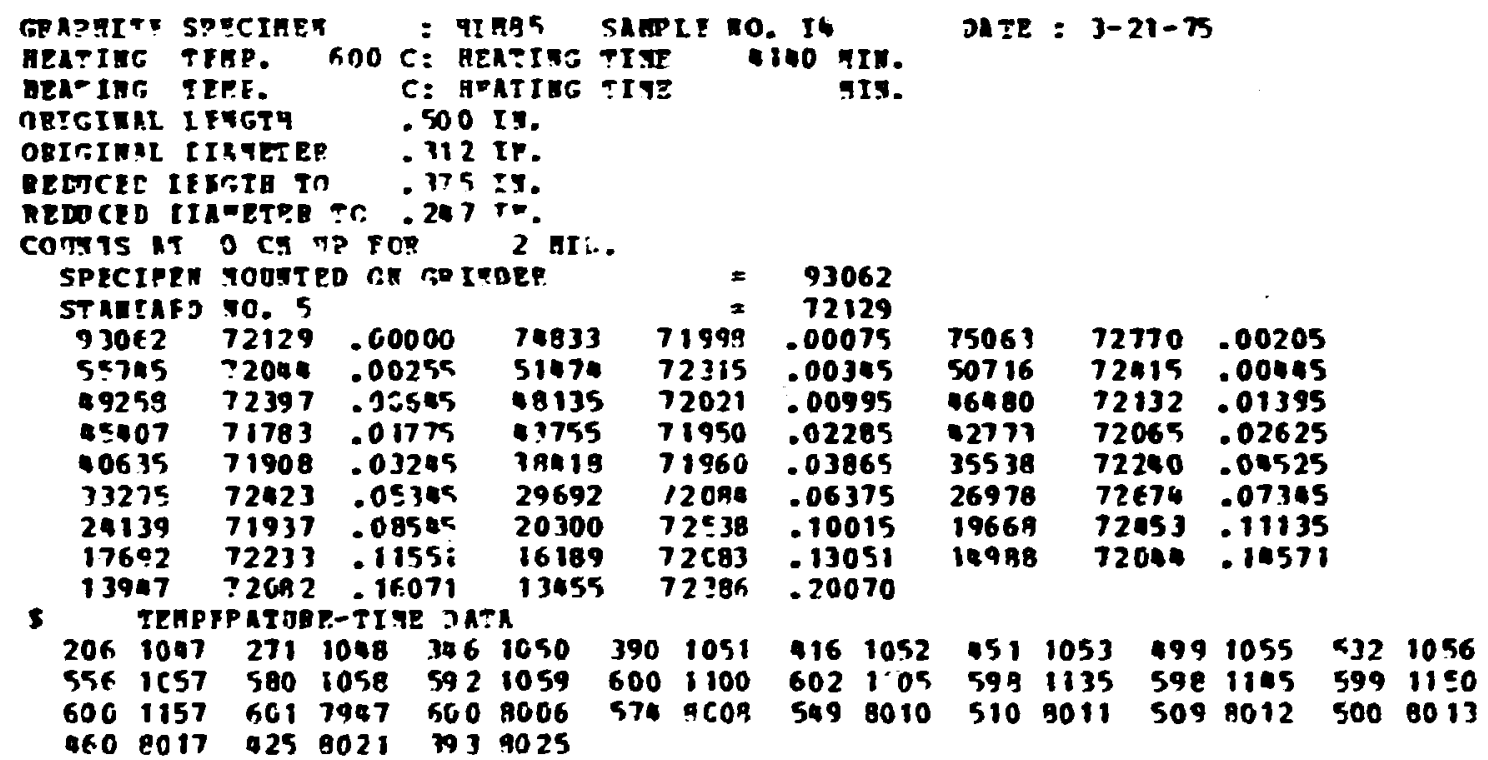

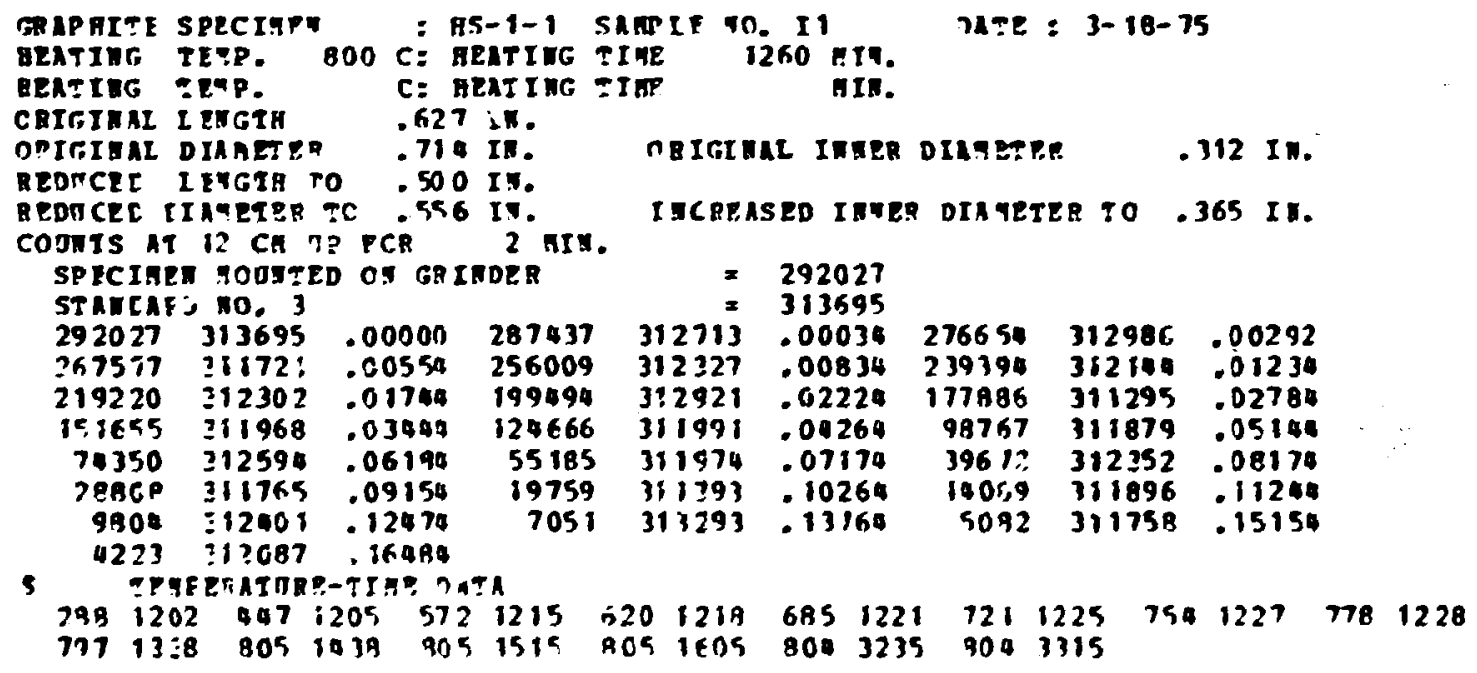




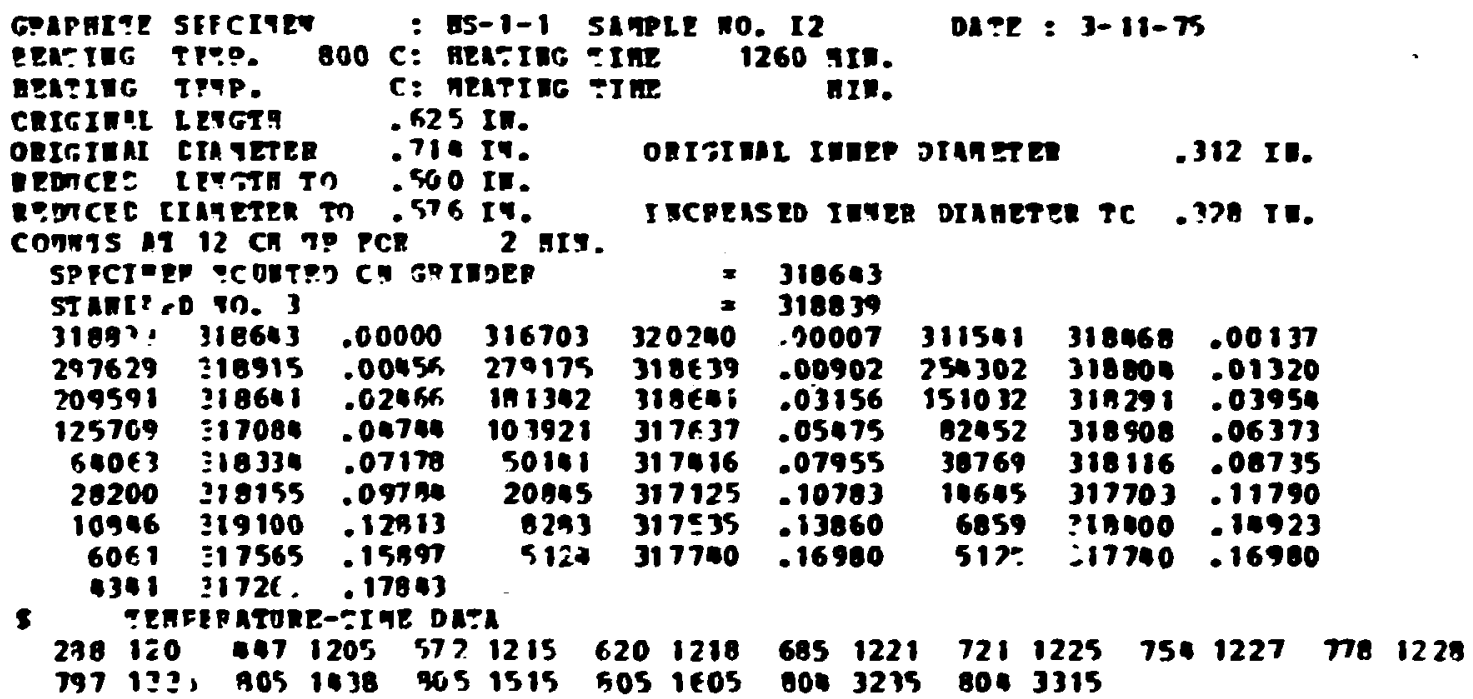




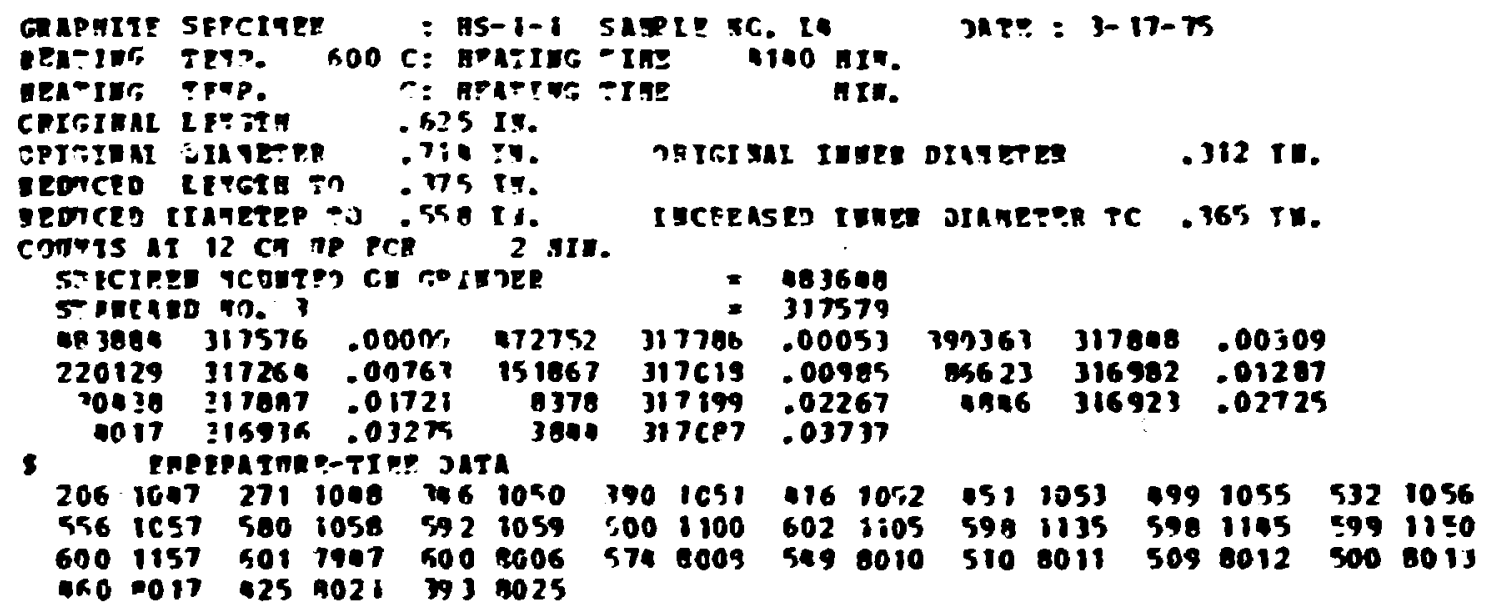

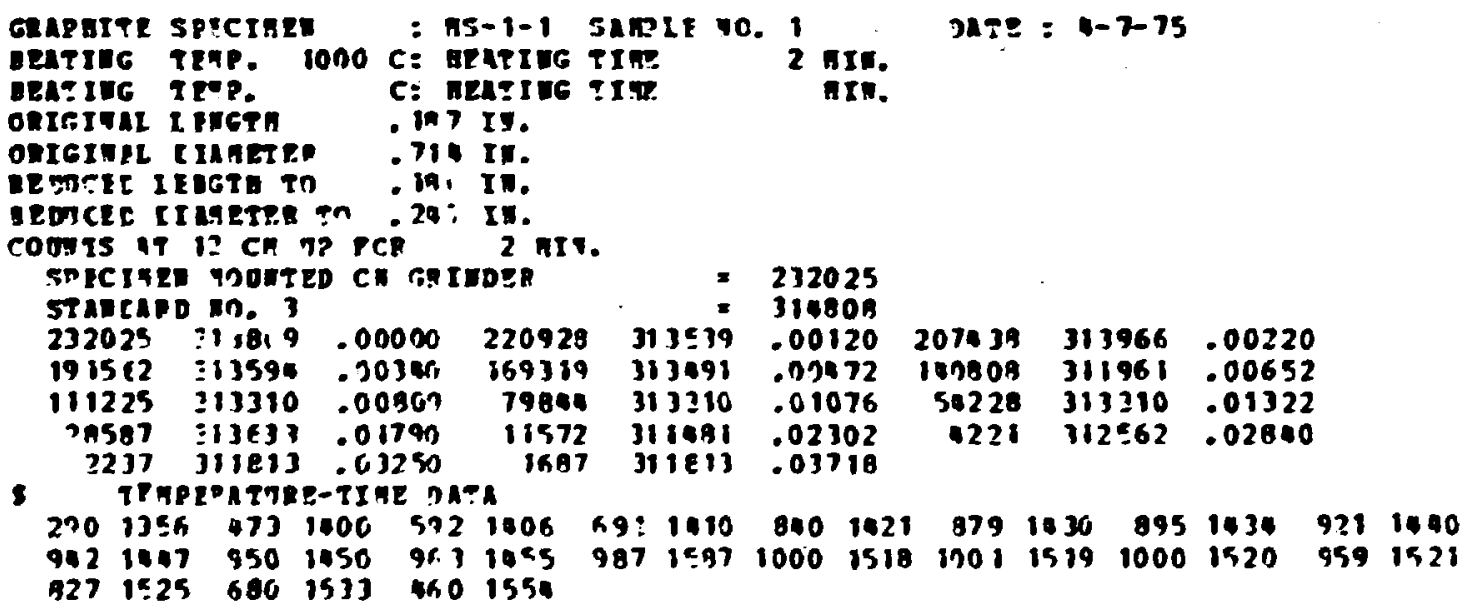




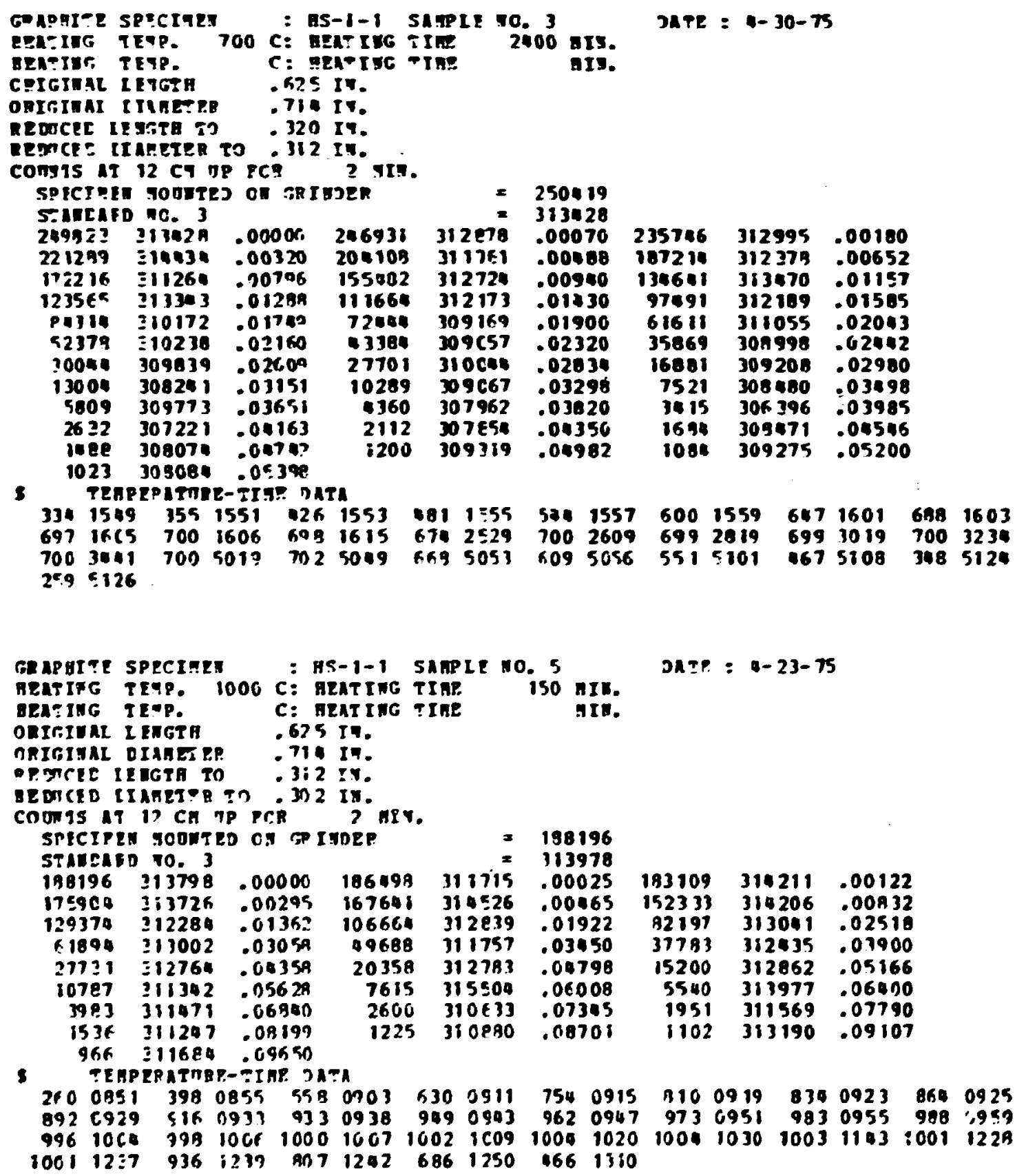




\subsection{Appendix B: Plots of Diffusion Data}

The 36 plots included in this appendix display all of the ${ }^{137} \mathrm{Cs}-$ diffusion data in terus of relative concentration vs both penetration distance (the upper points 0 ) and the square of penetration distance (the lower points $\Delta$ ). The temperature-time data for temperatures greater than $400^{\circ} \mathrm{C}$ are also displayed. Each plot is laoeled accerding tc the type of graphite (ATJ, H-327, H-45I, HLM-85, and HS-1-1) and experiment number. It is apparent that some features of these plots will be difficult to explain. Experiments with the HS graphite are obviously the simplest in appearance; analysis of these data is described in Sect. 4.1. Some of the other experimental data appear to conform to Eq. (16). Included in this category are the following: experiment $7 U$ with the ATJ graphite; experiments $1 U, 2,2 U, 5 C, i U U, 8$, 8IJU, and $9 U \mathrm{U}$ with $\mathrm{H}-327$; and experiments $\mathrm{ID}$ and $1 \mathrm{U}$ with $\mathrm{H}-451$. Some of the other experiments were performed for timas either too short or too long, at the selected temperature, for the data to be conveniently analyzed. 


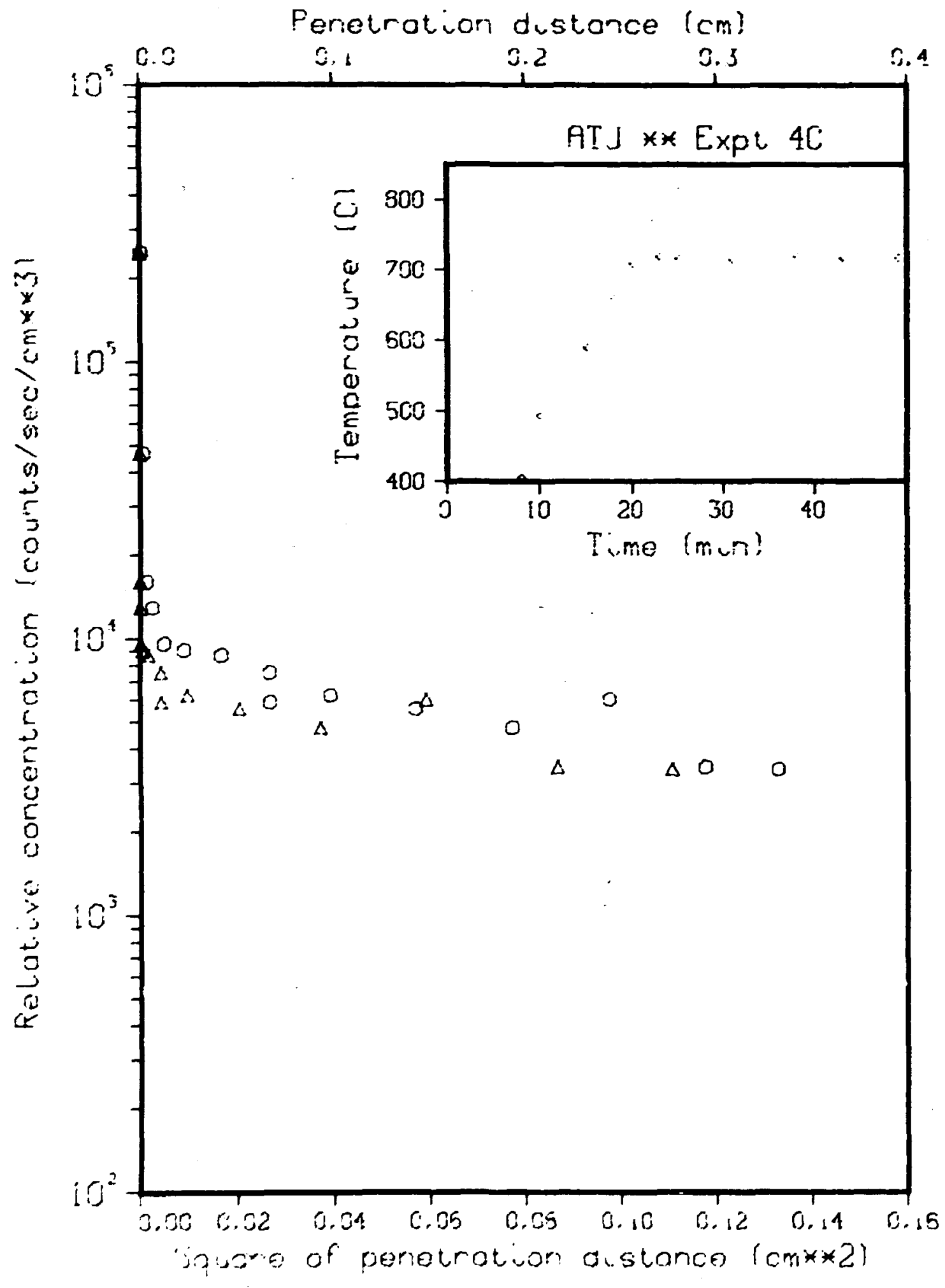


$-85-$

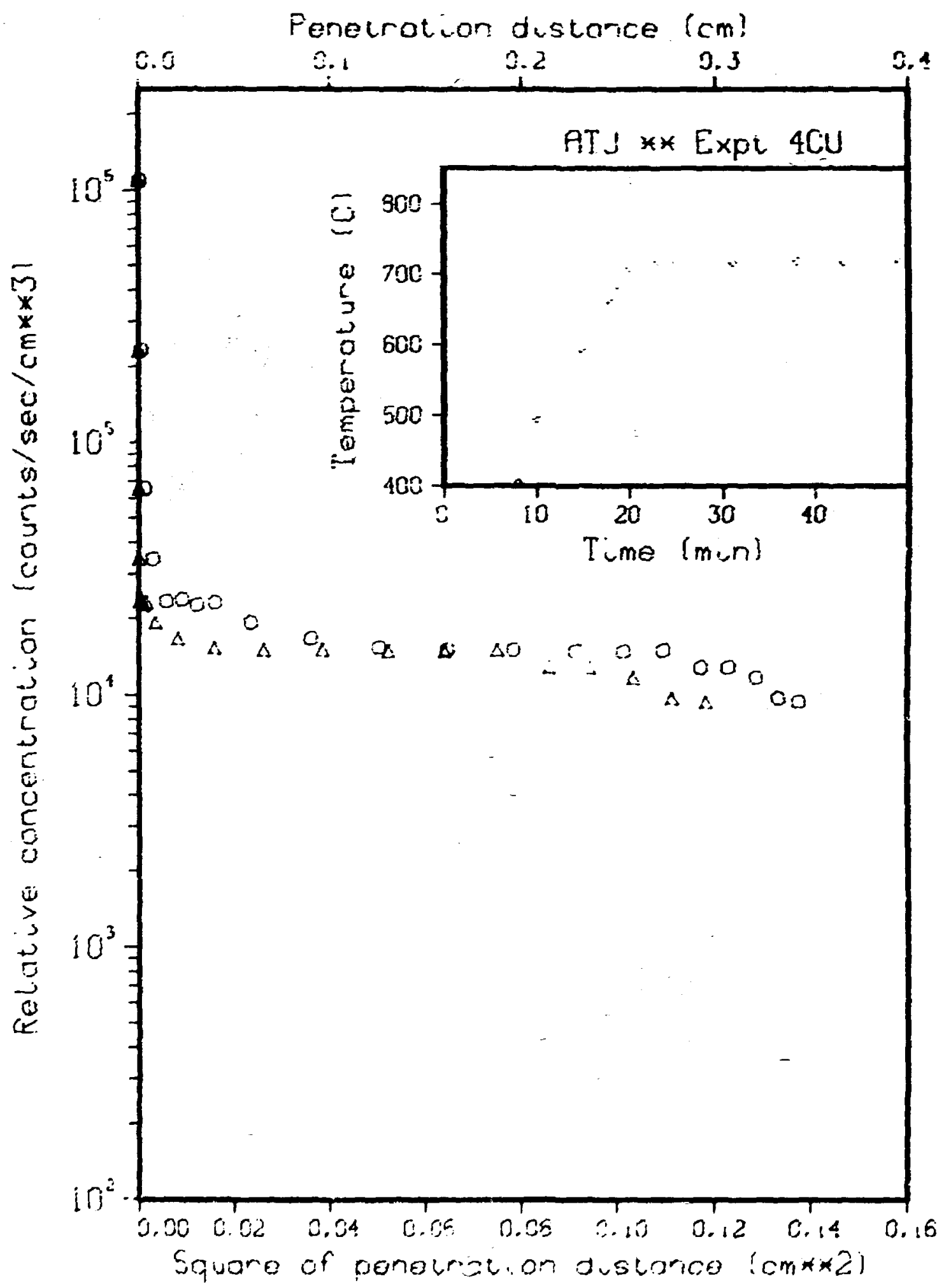




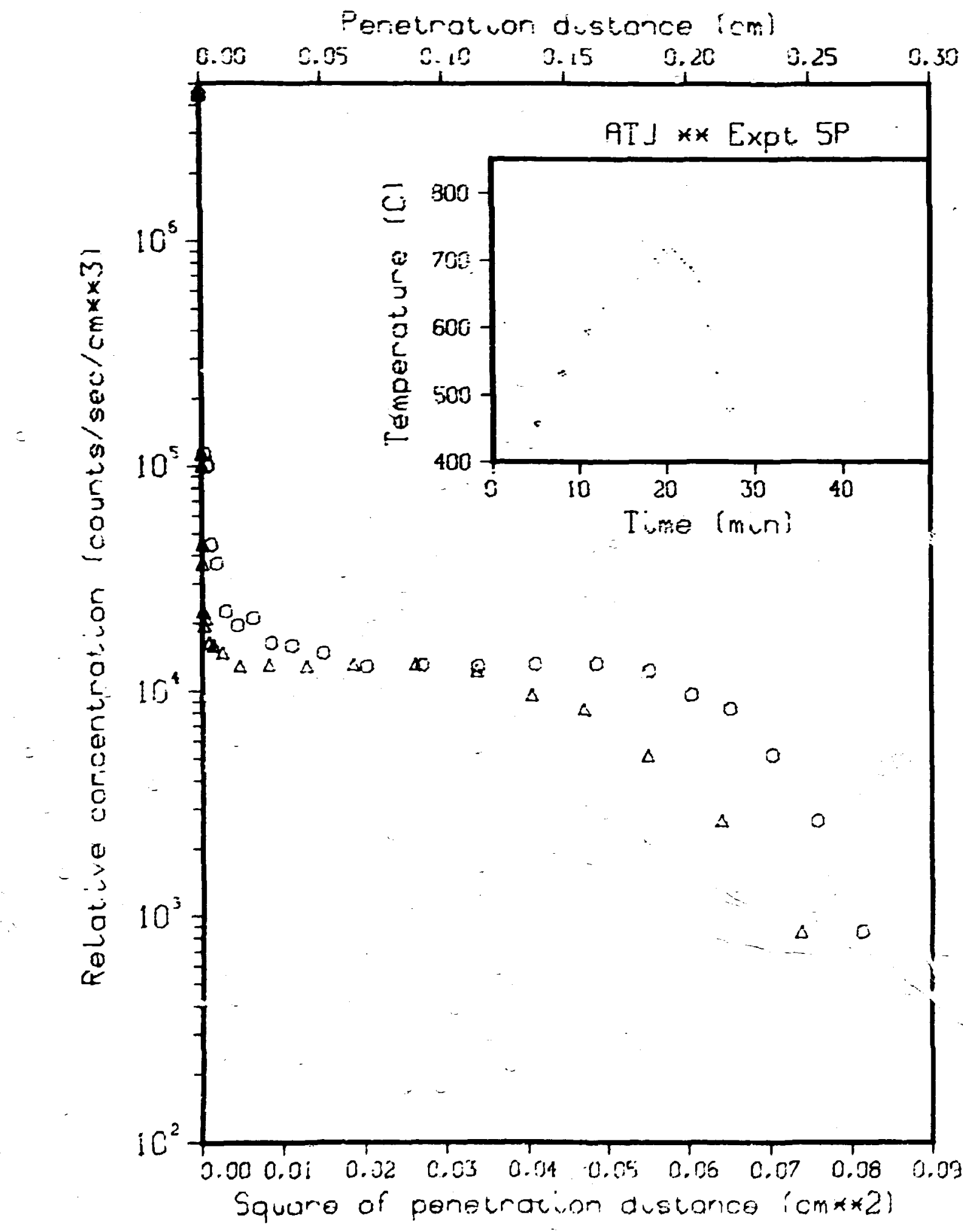




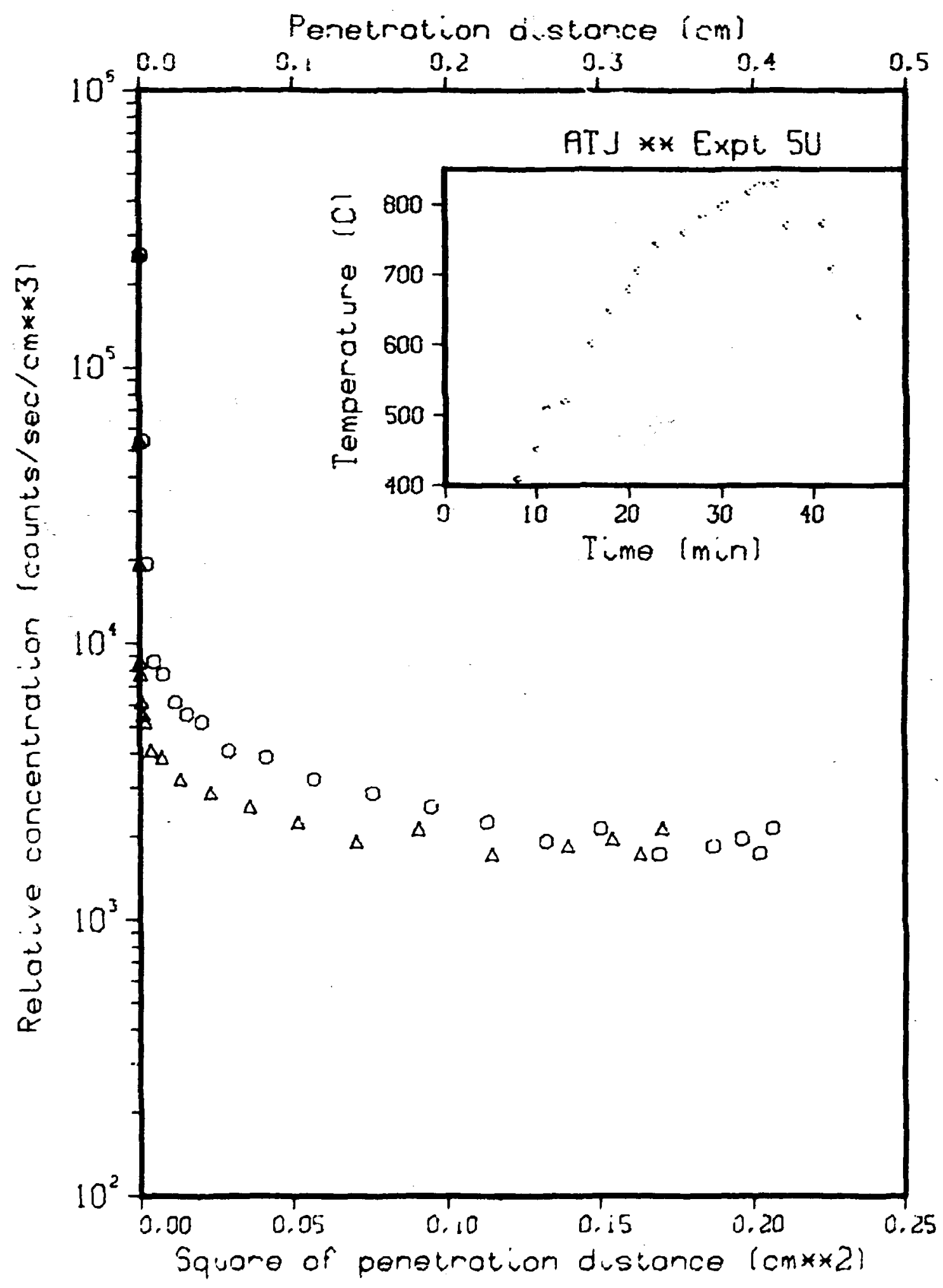




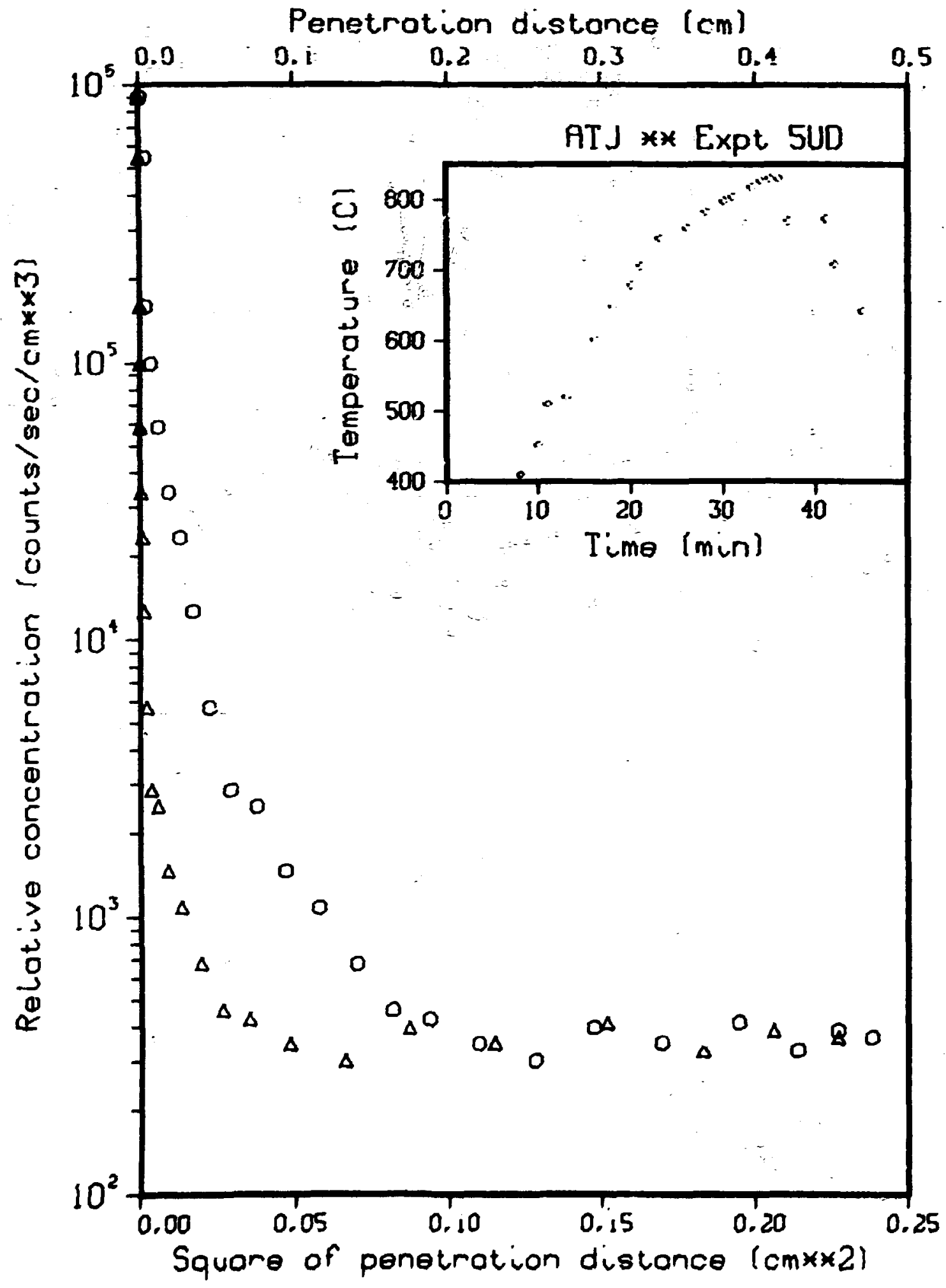




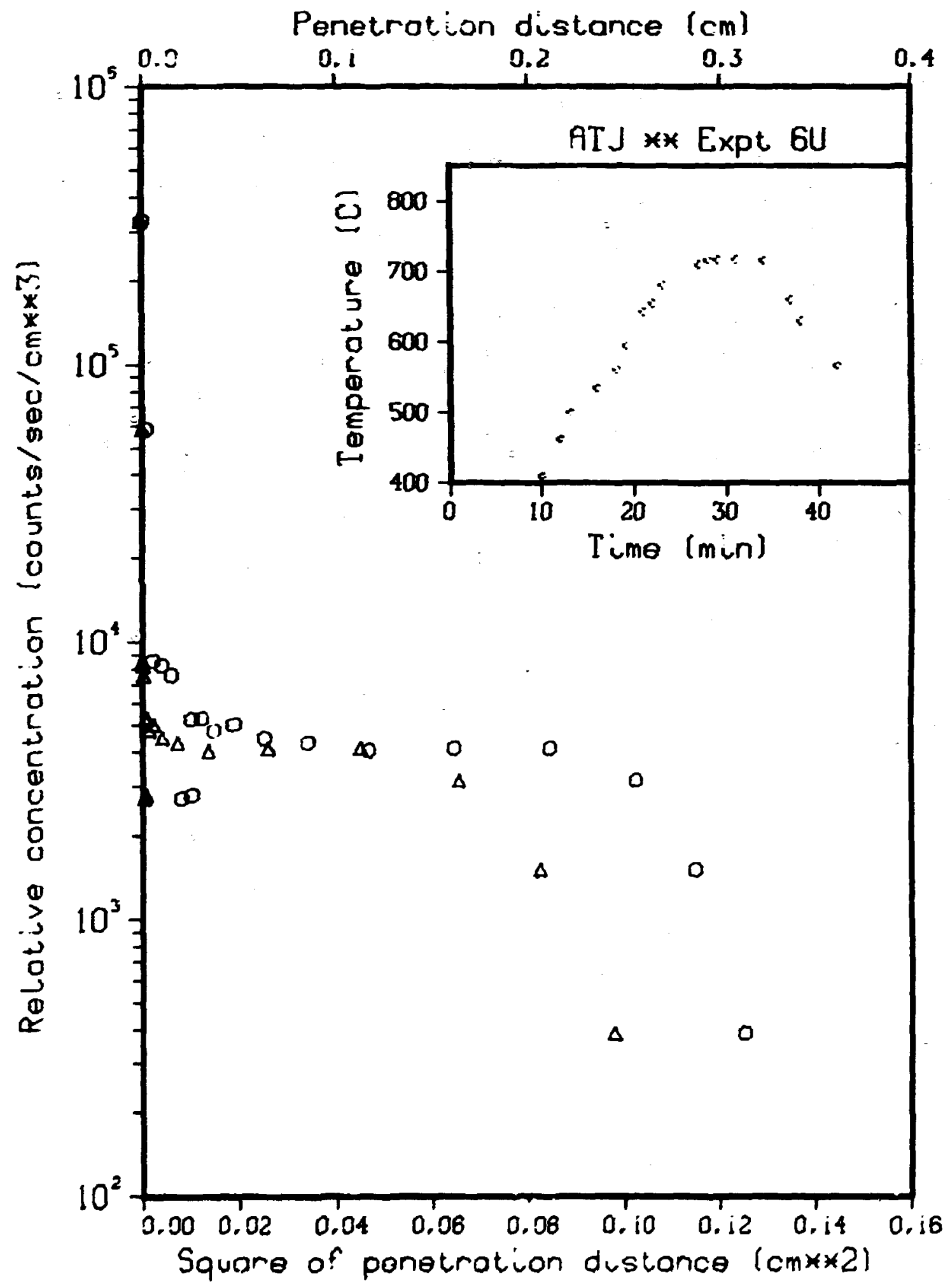




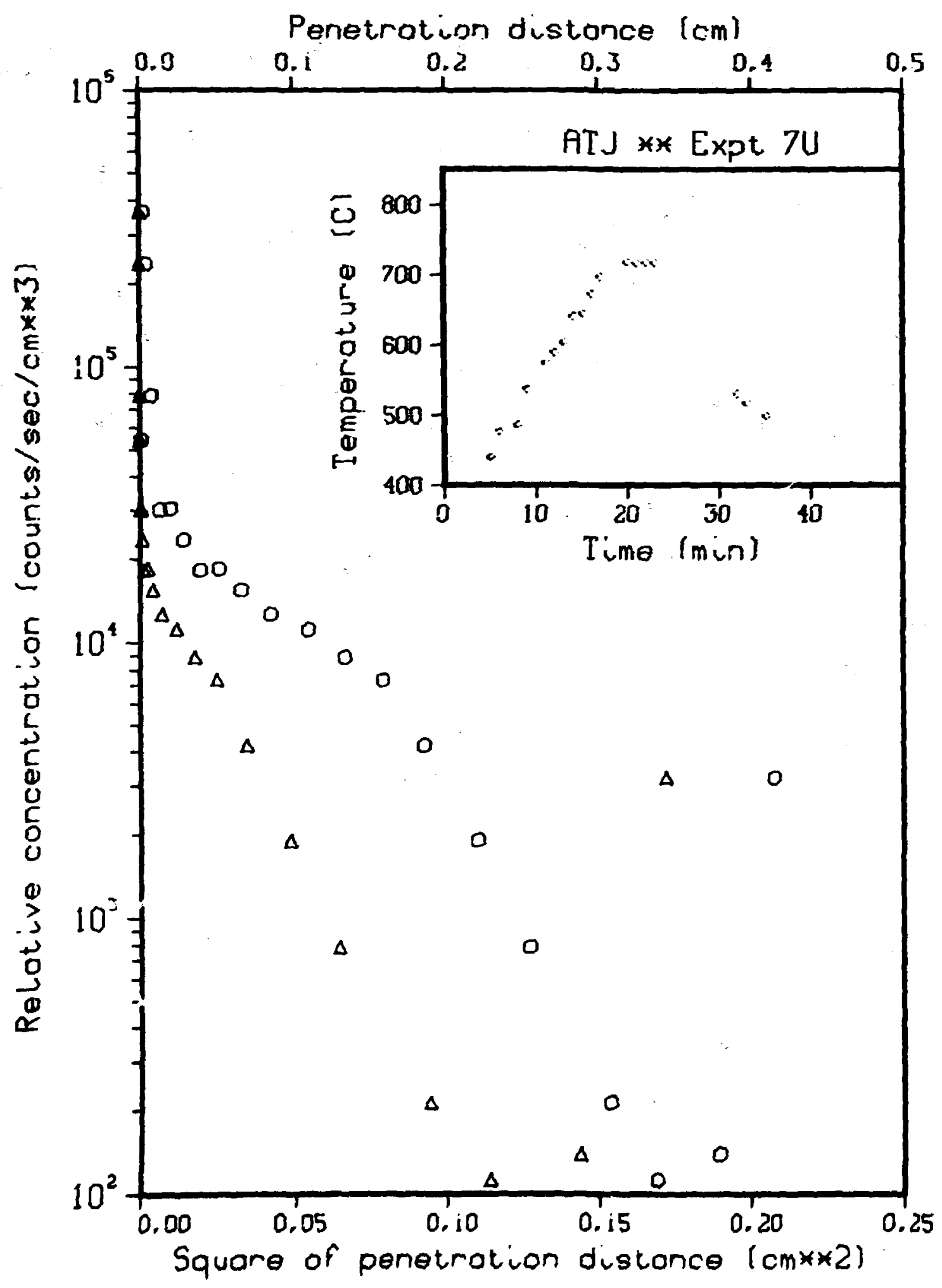




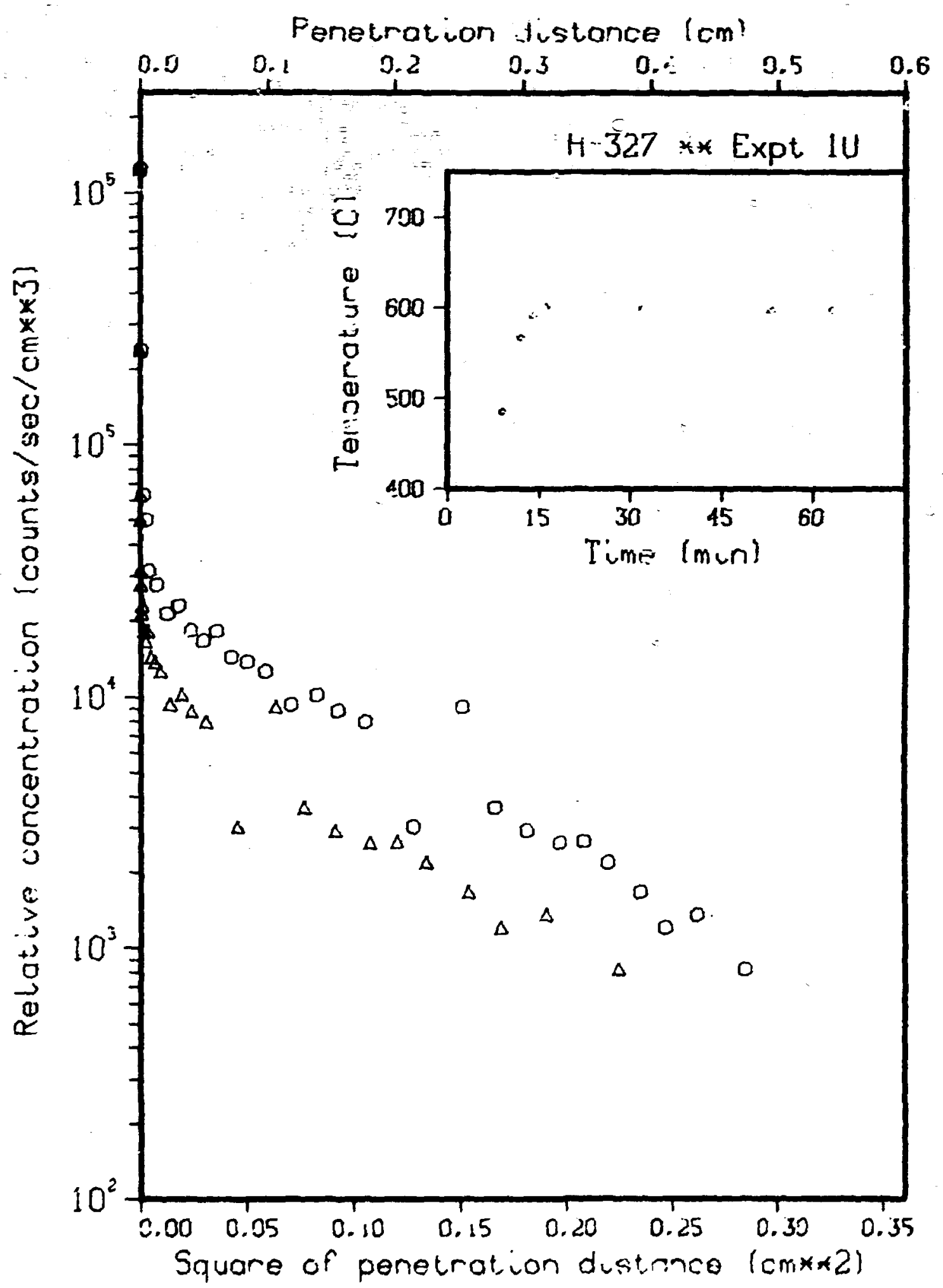




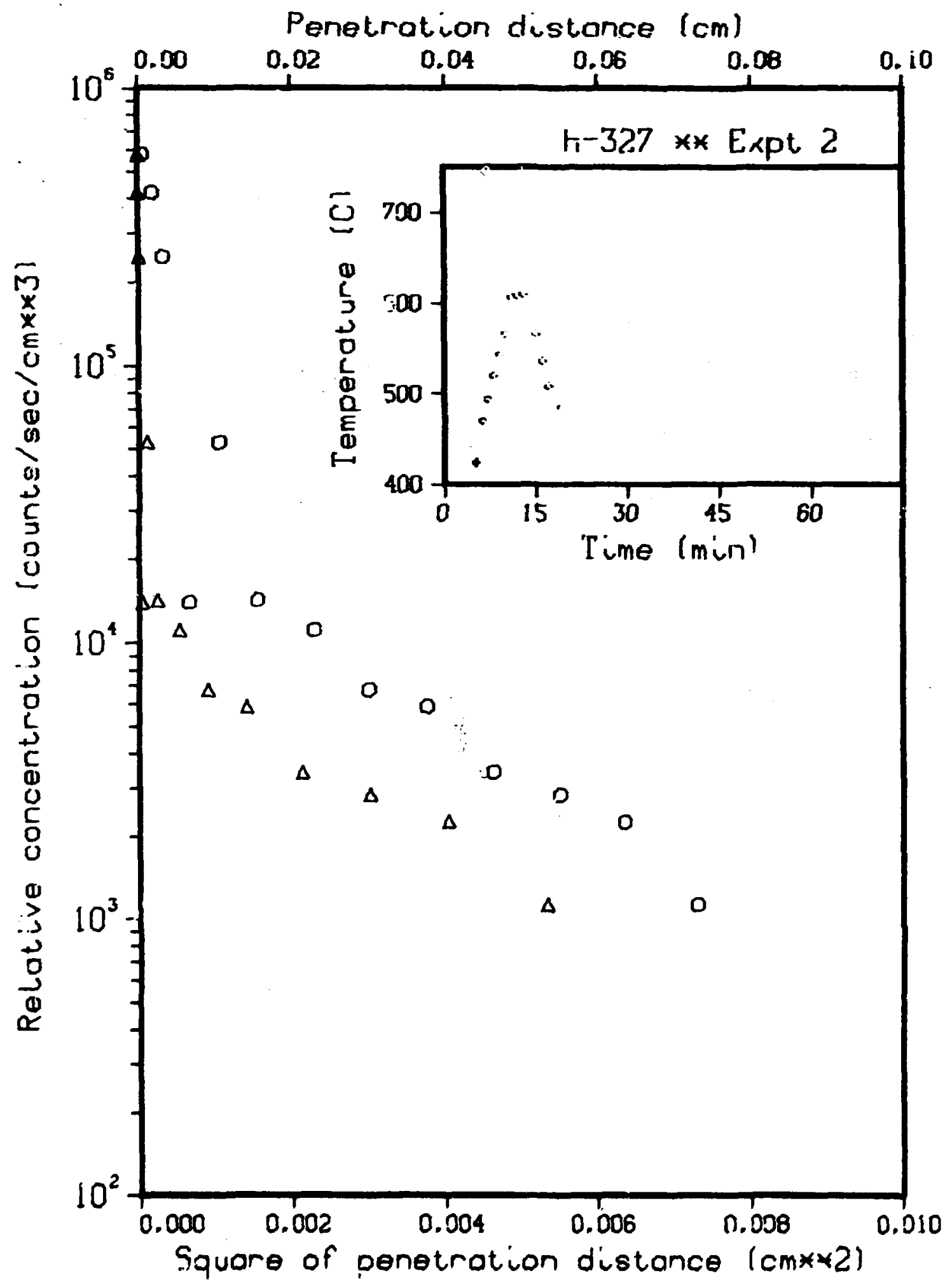




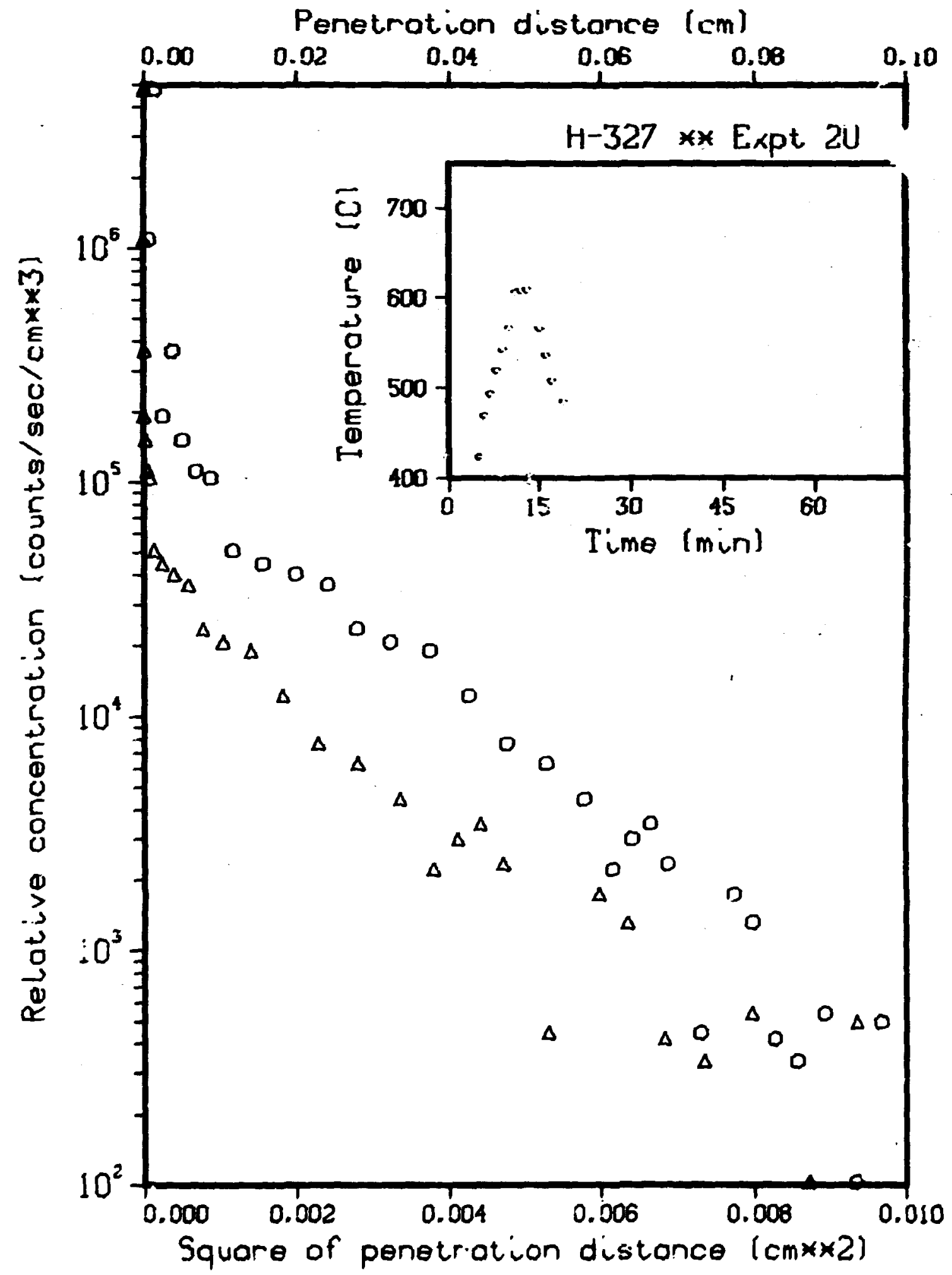




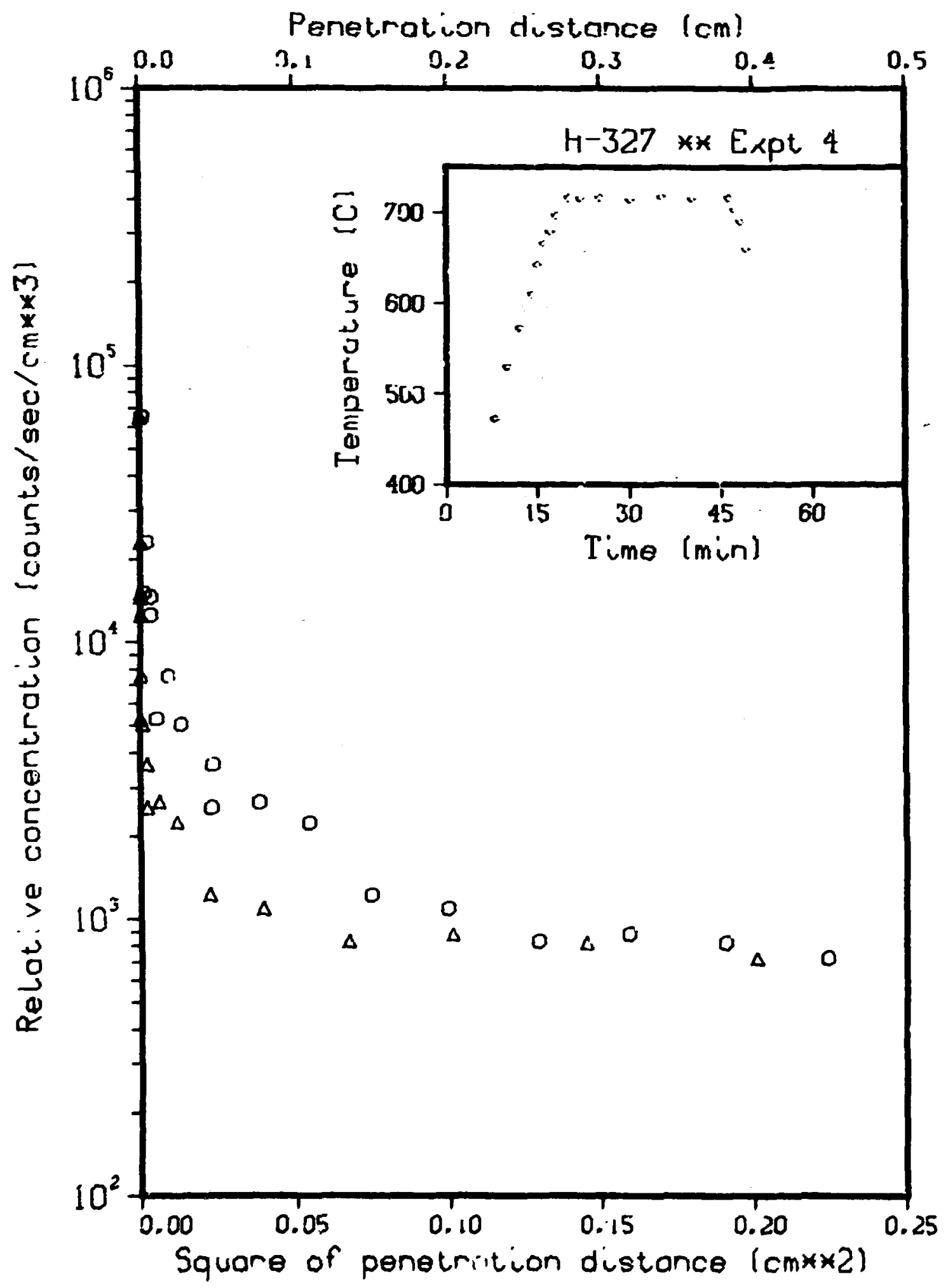




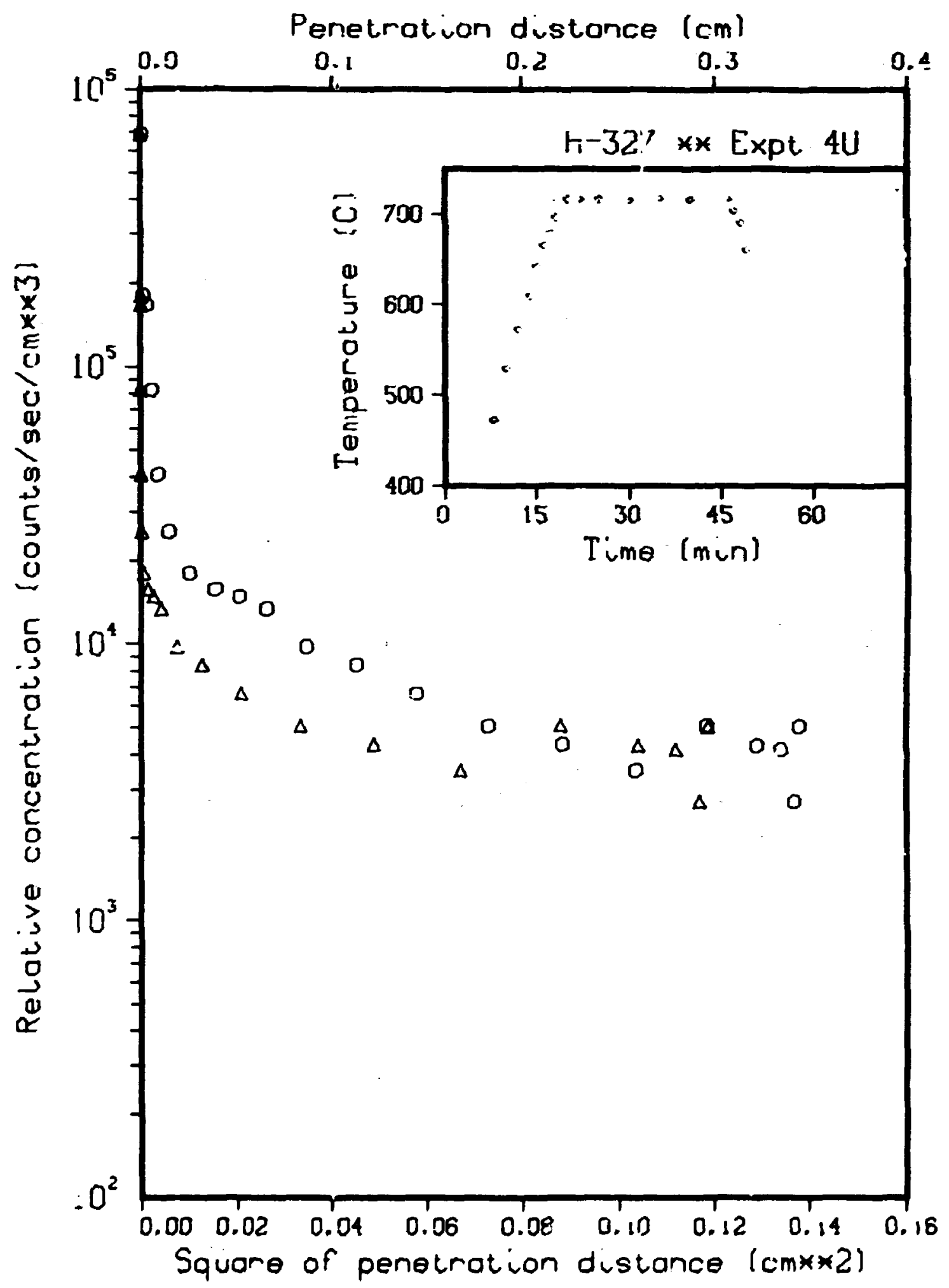




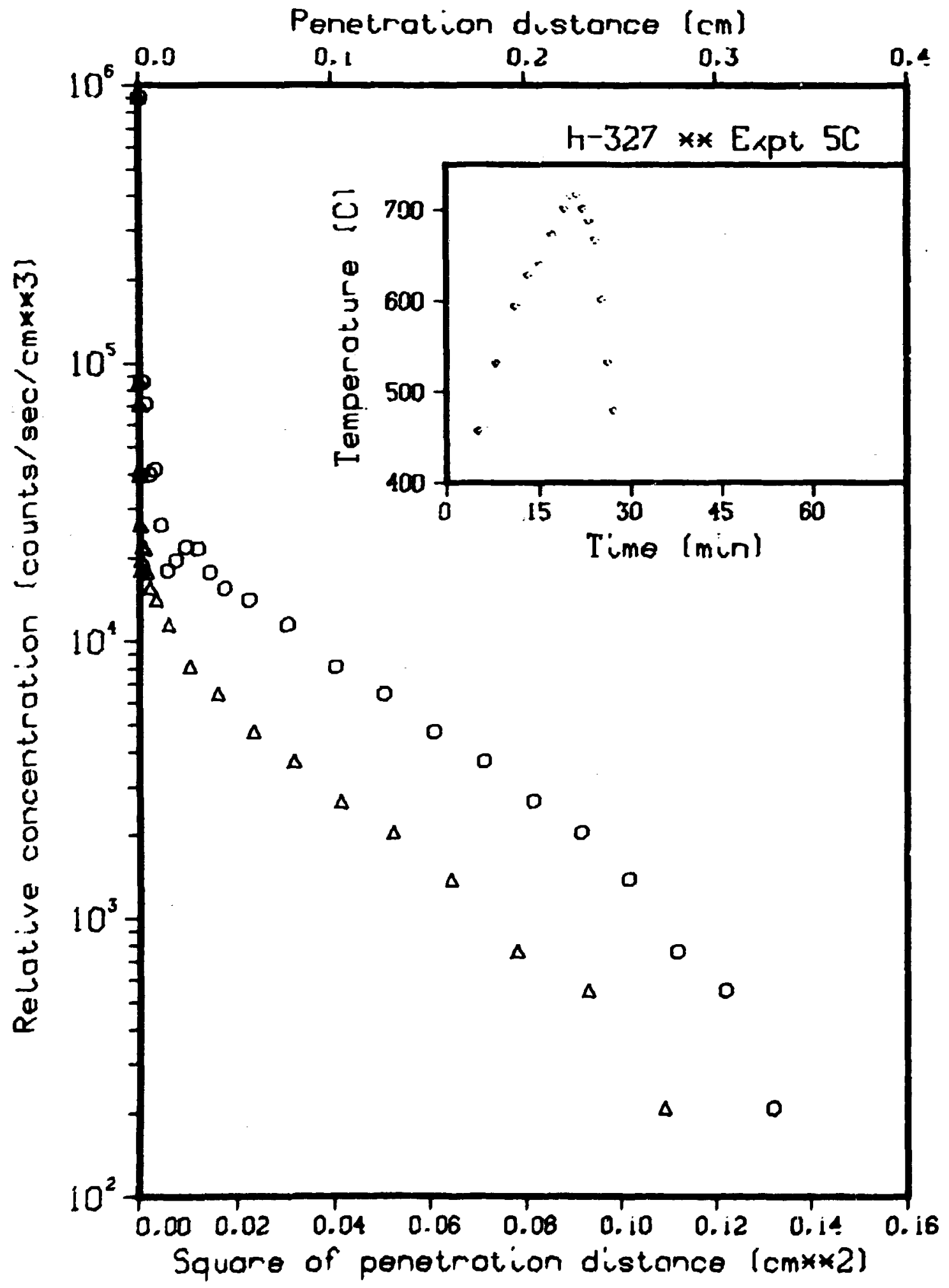




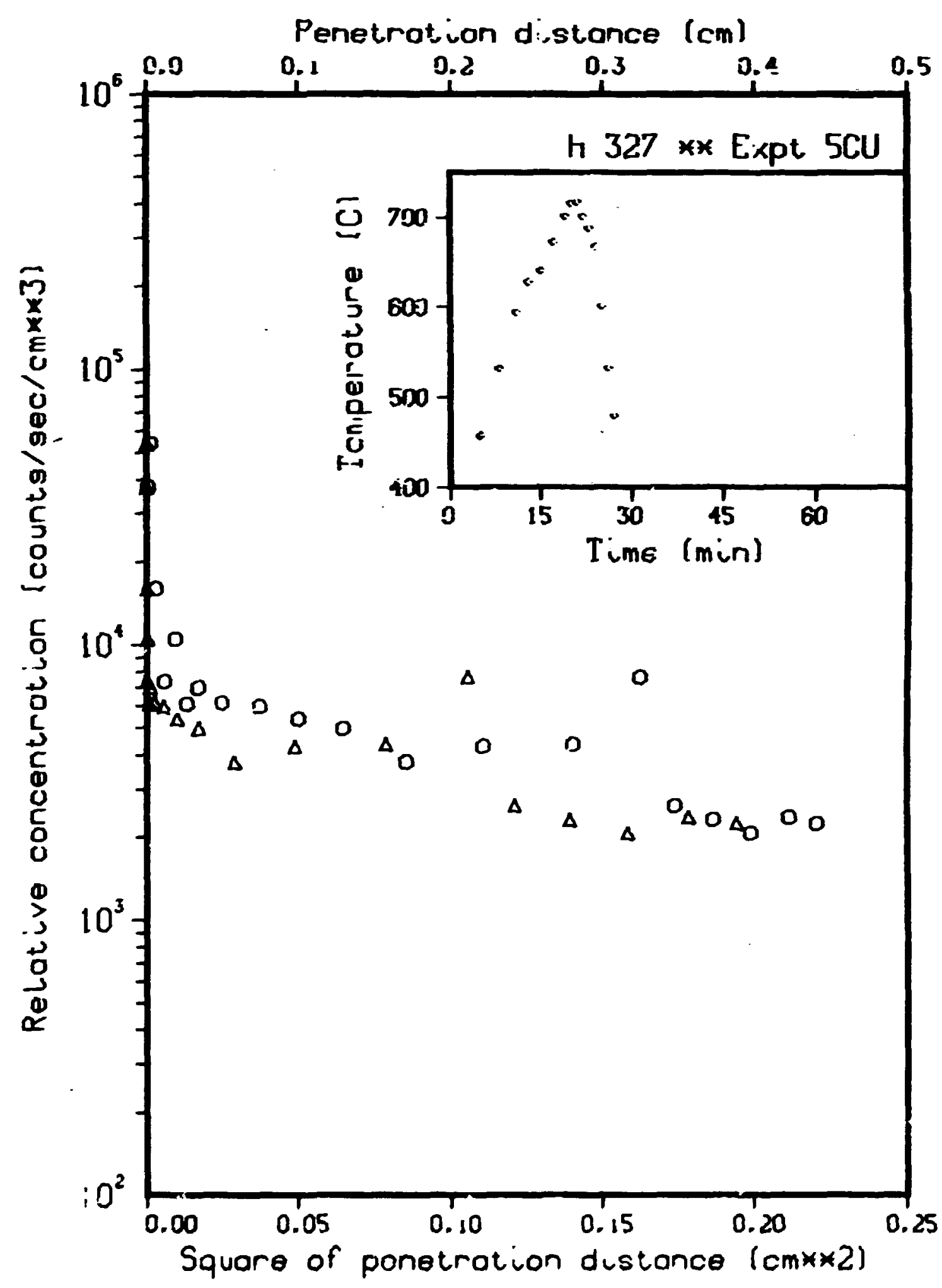




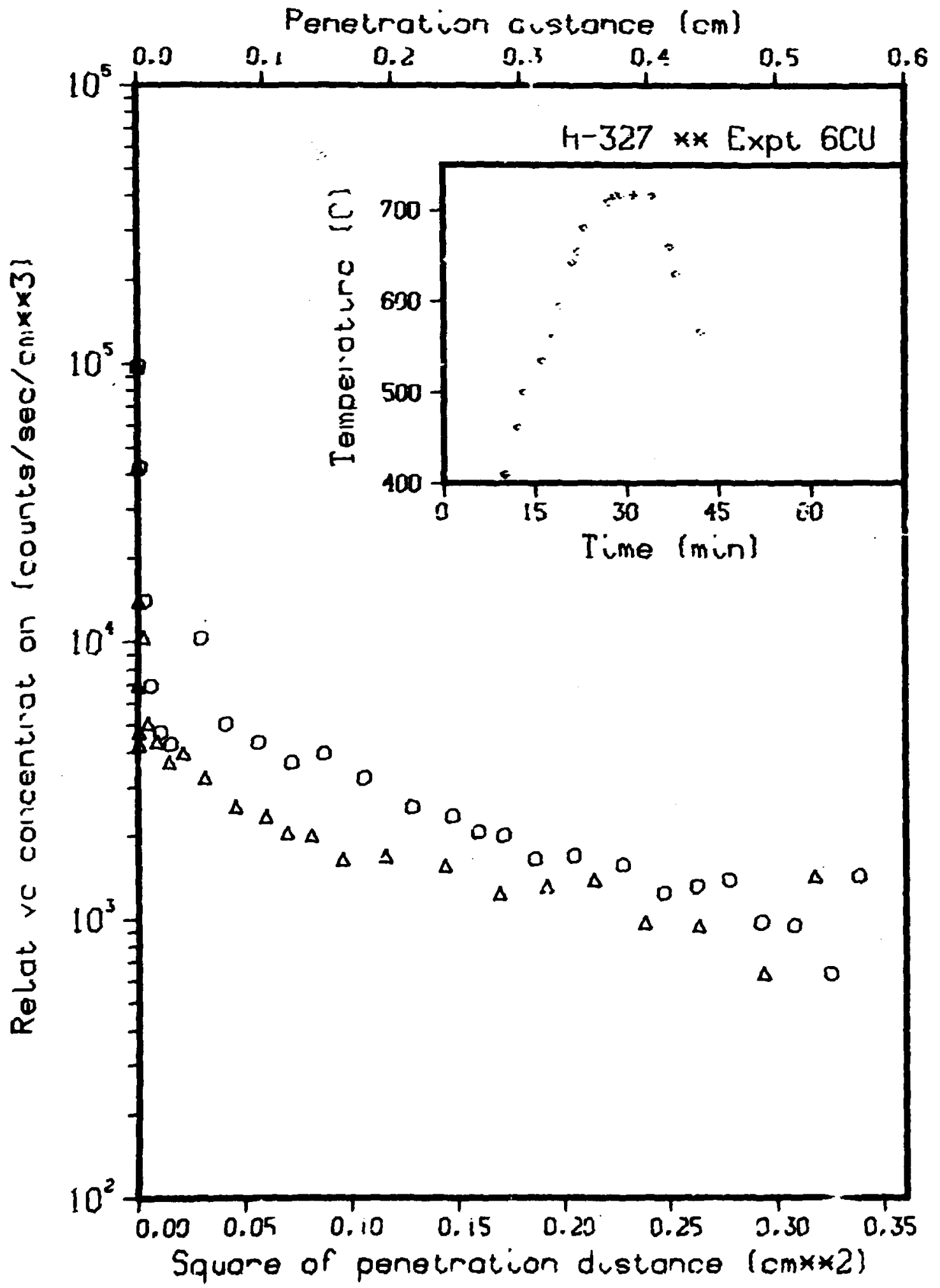




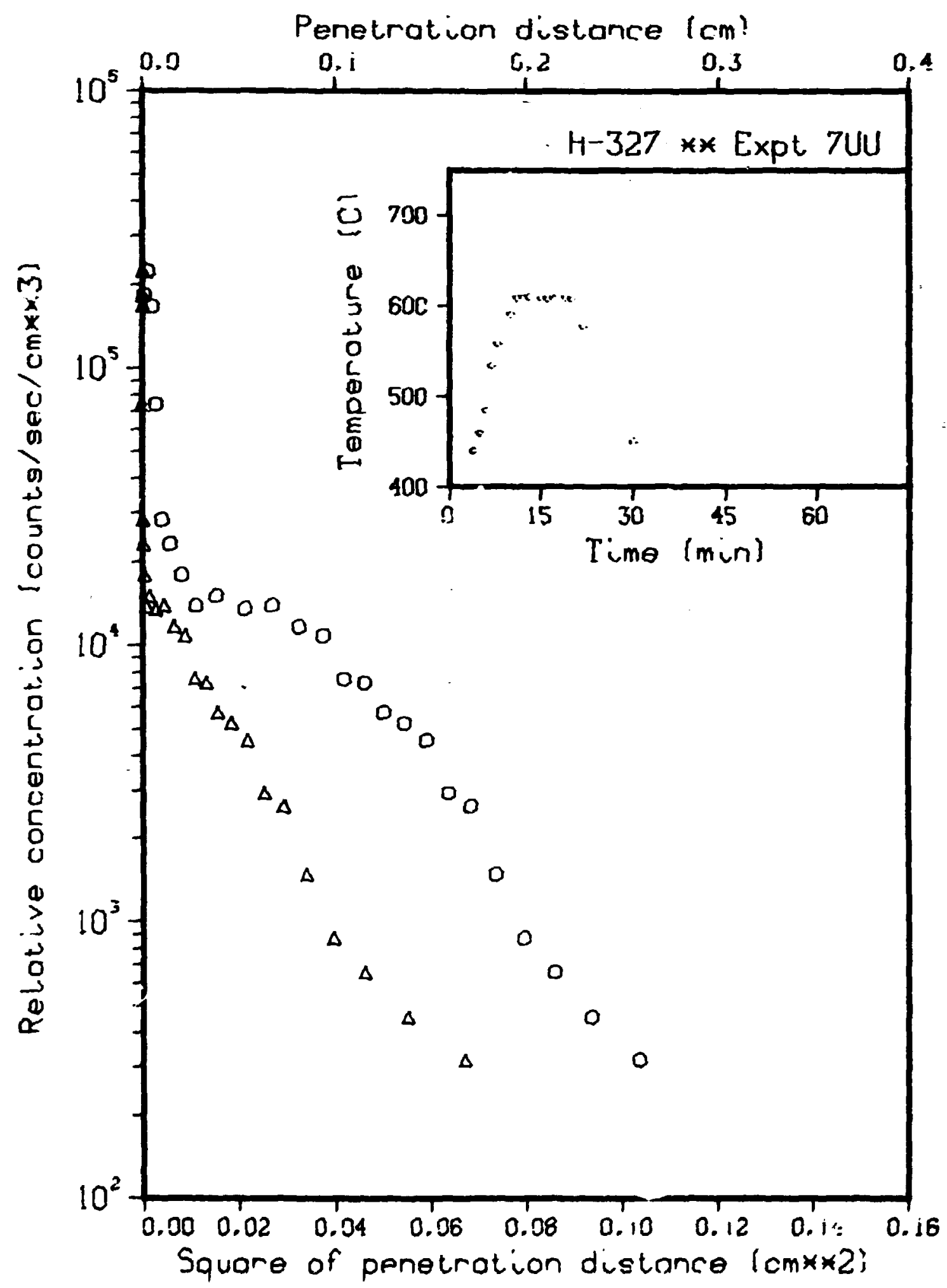




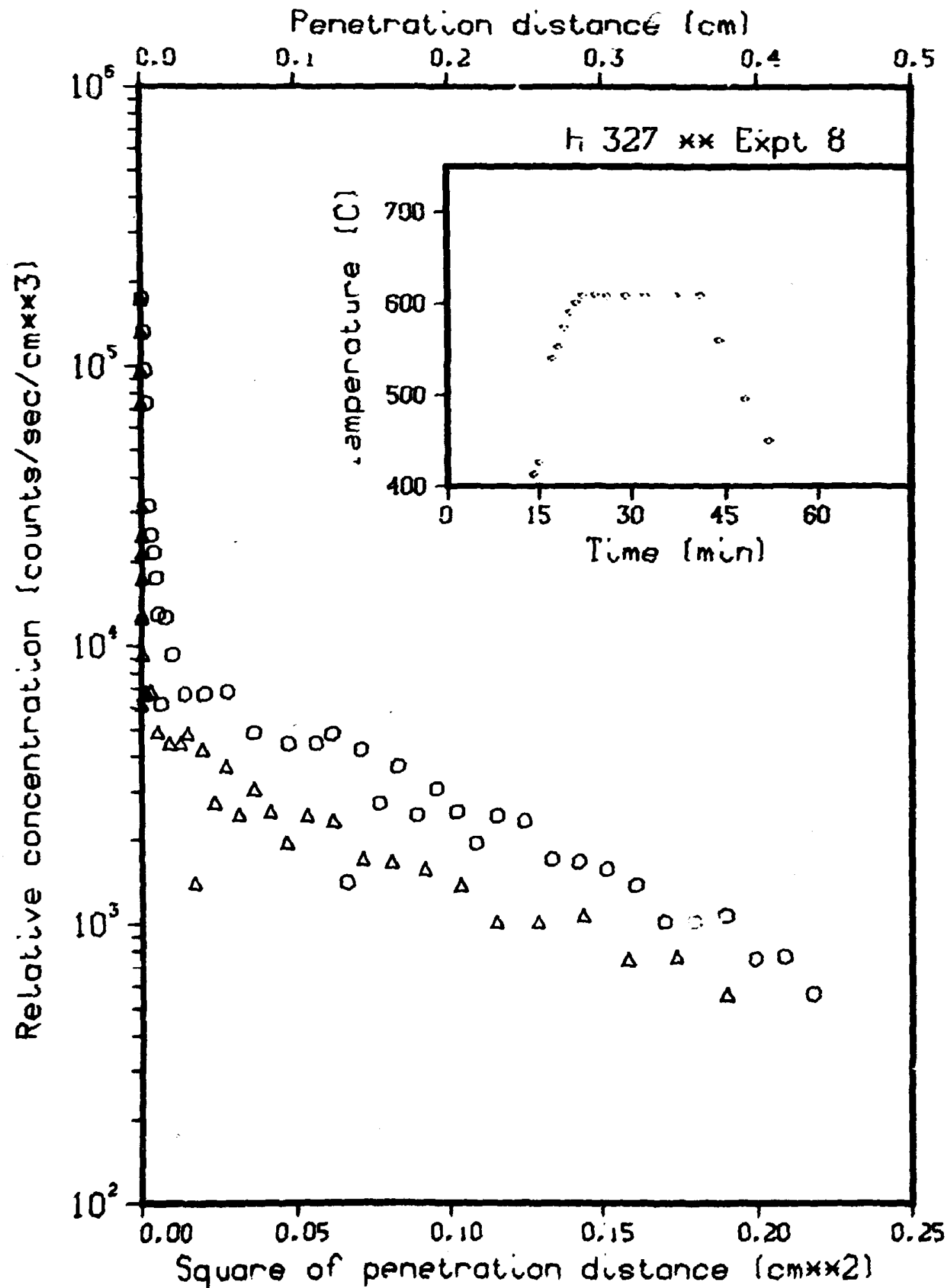




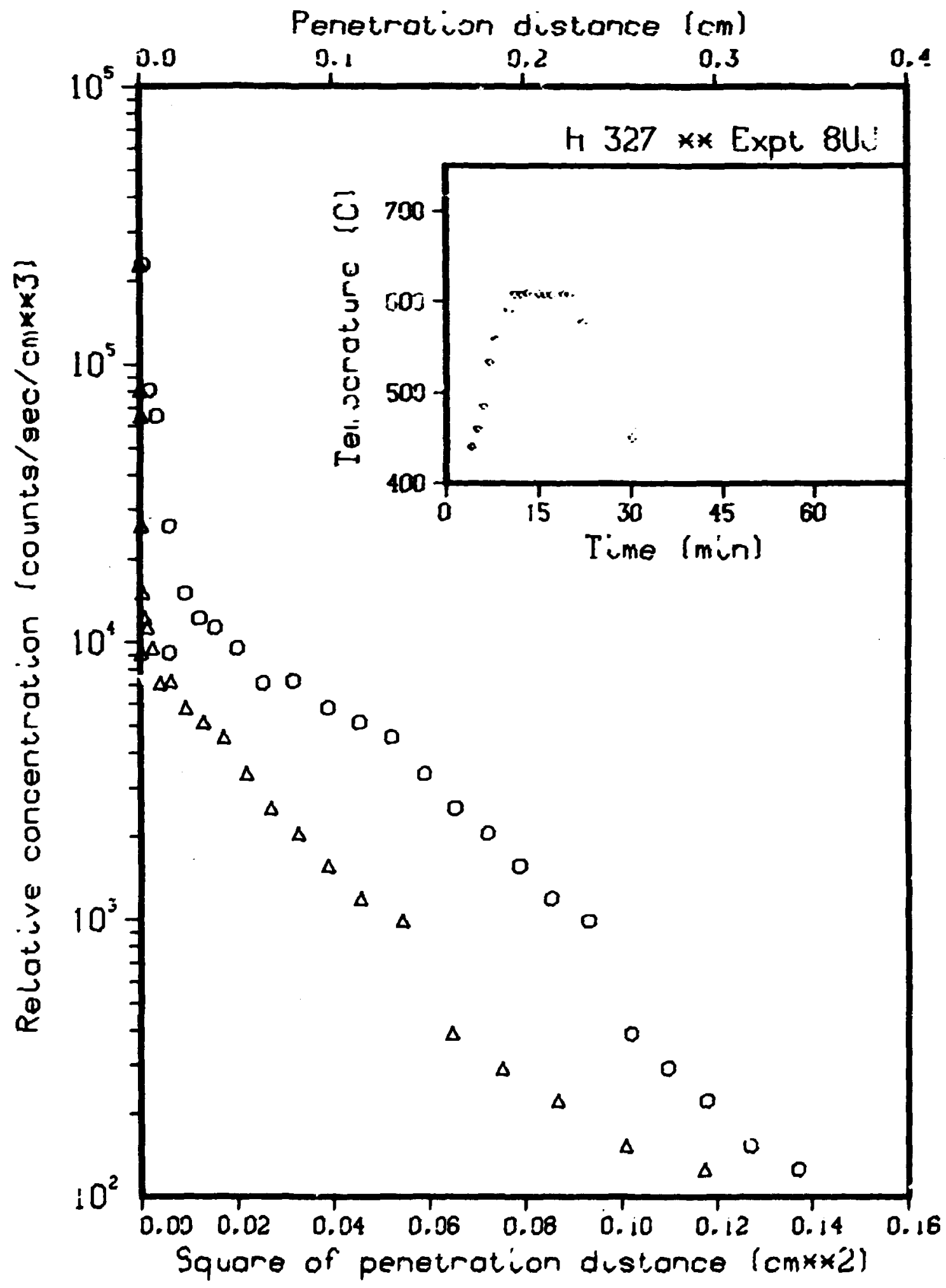




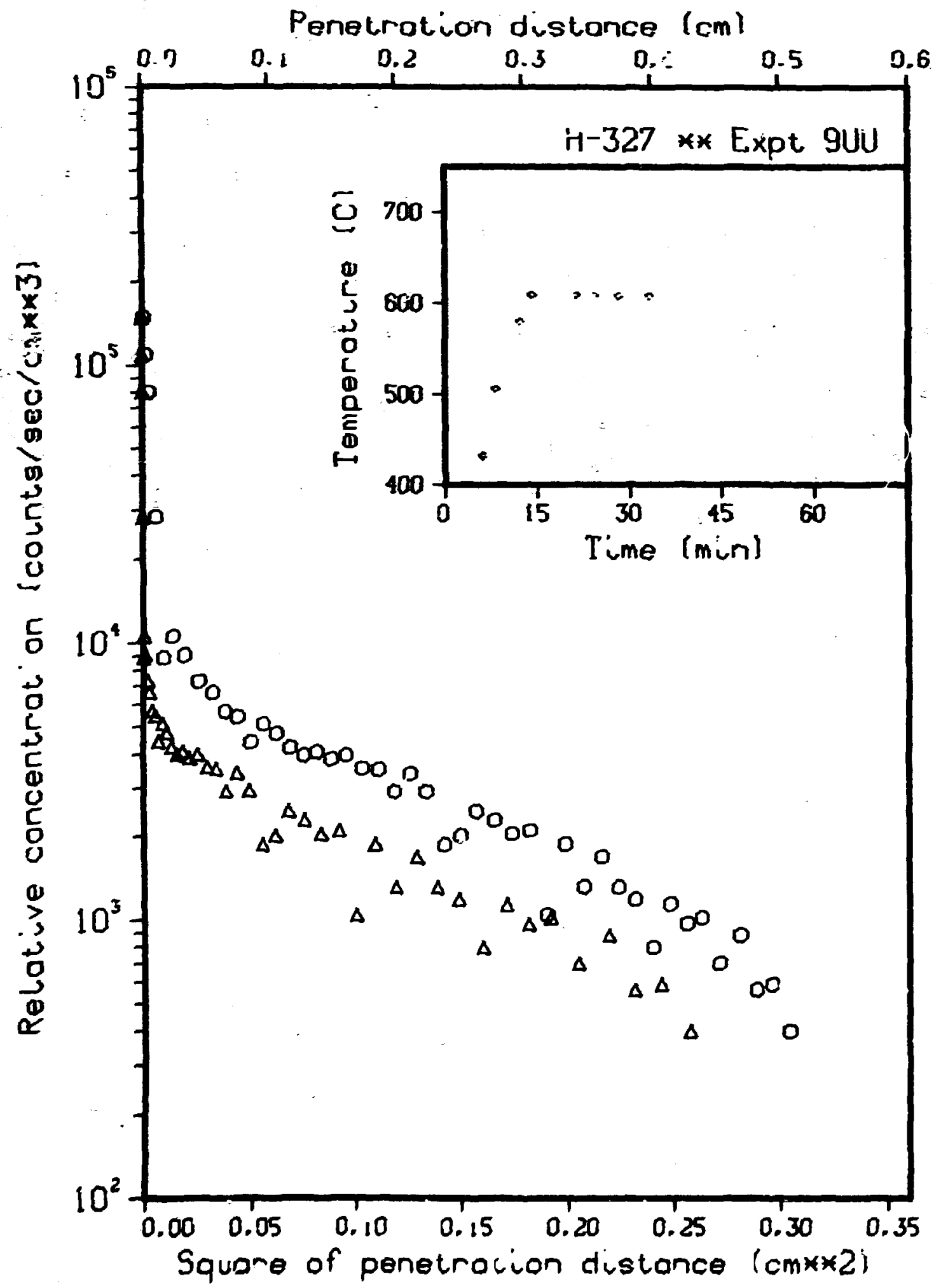




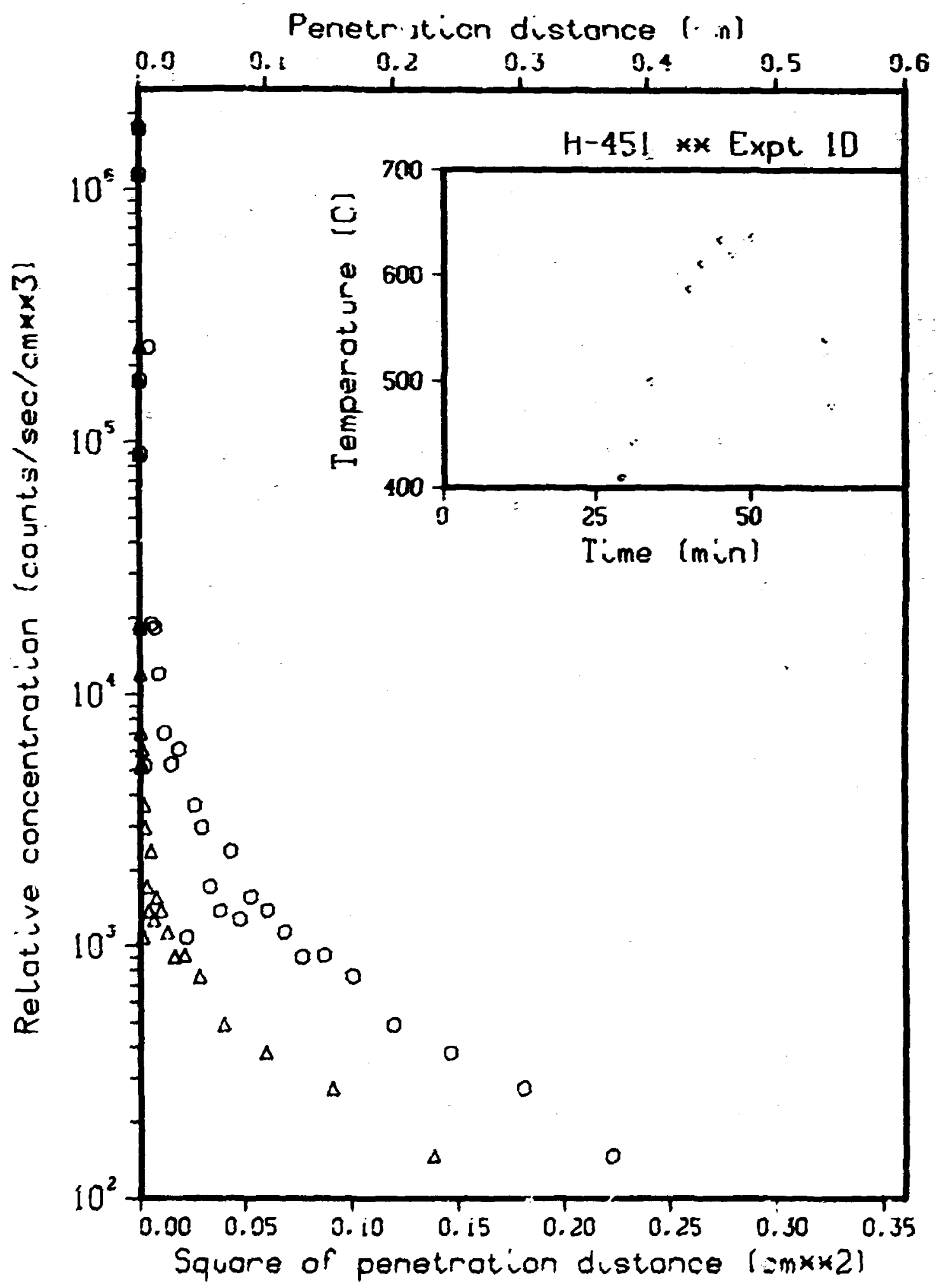




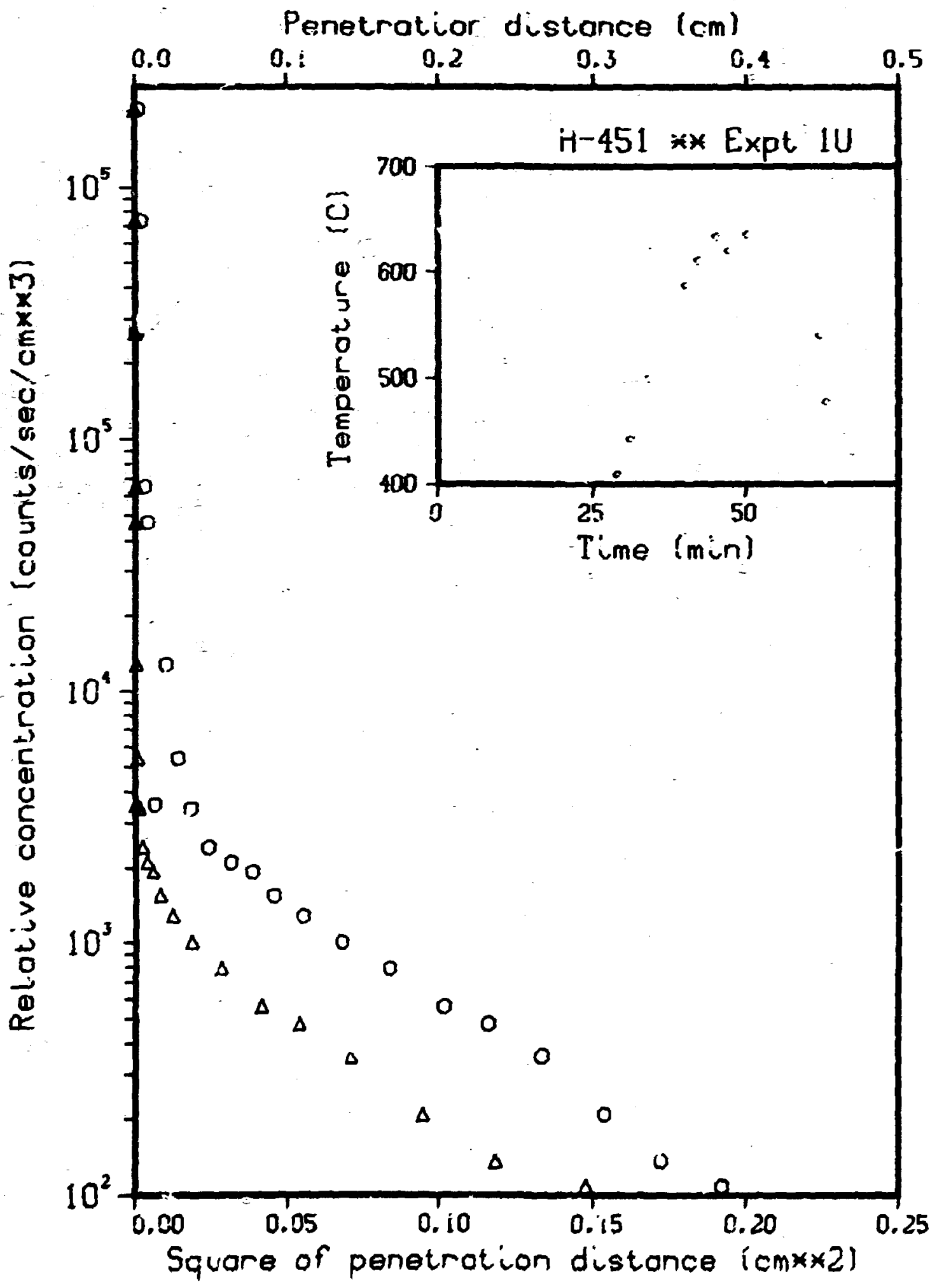




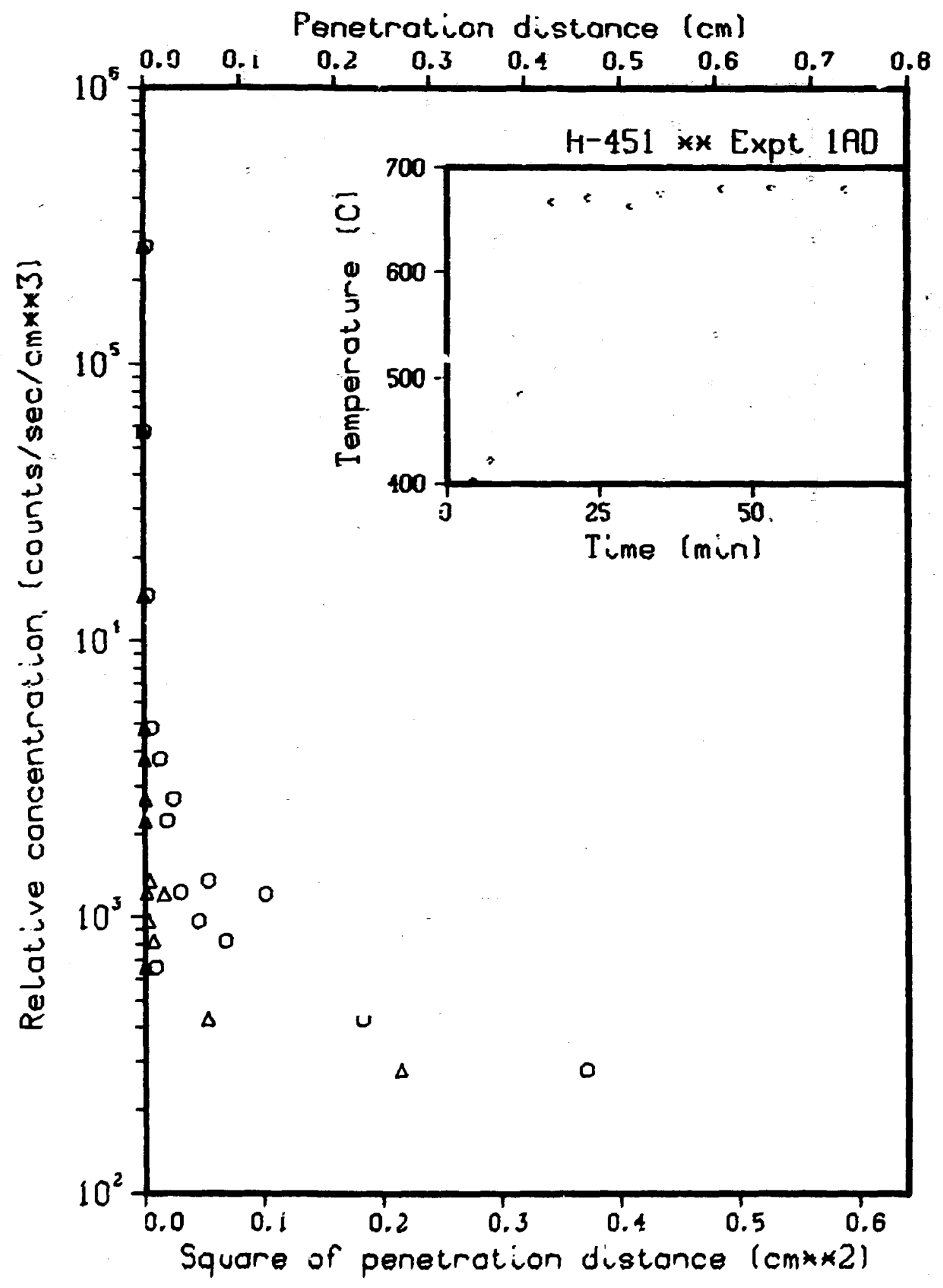




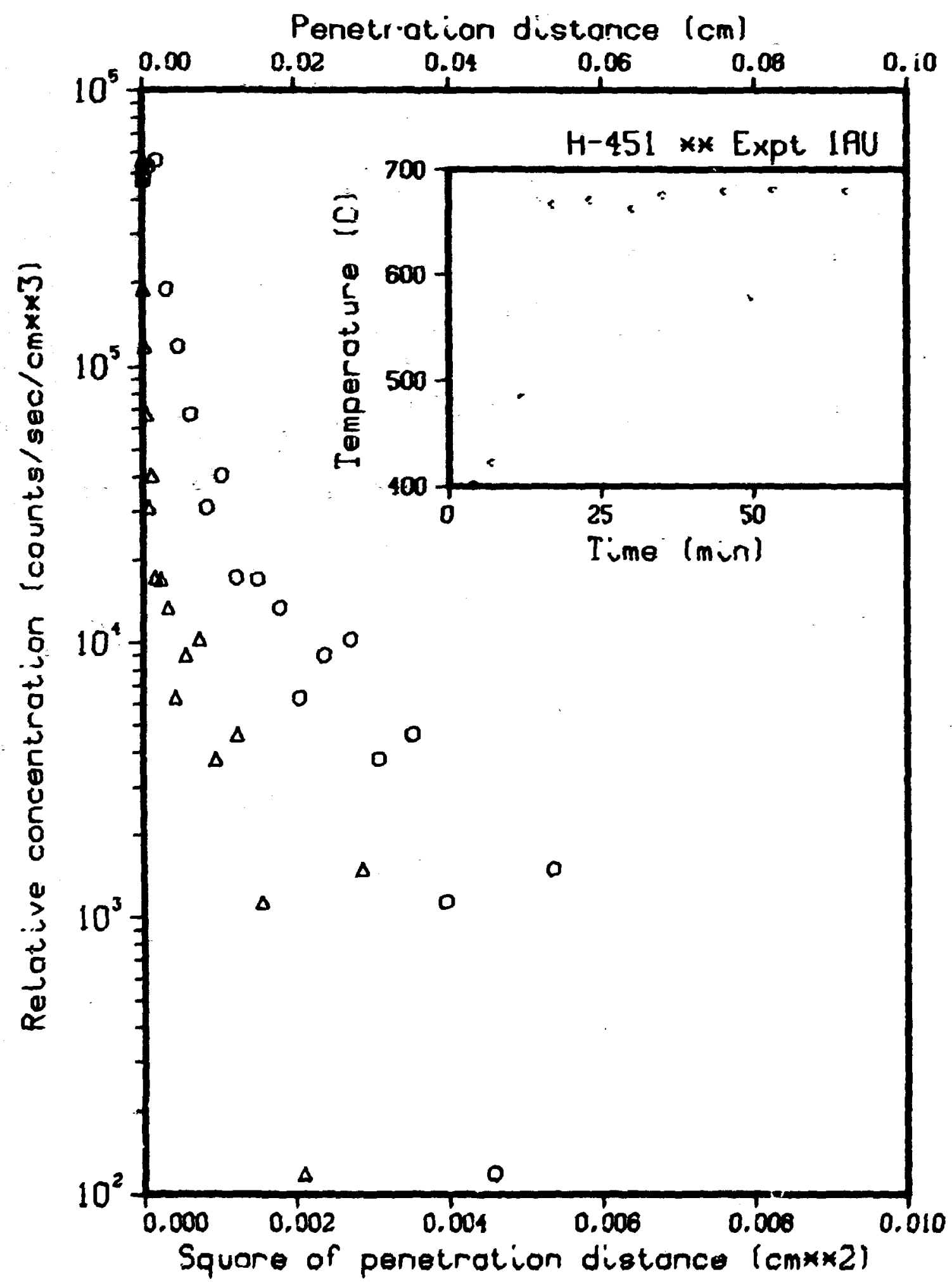


Penetration distance $(\mathrm{cm})$

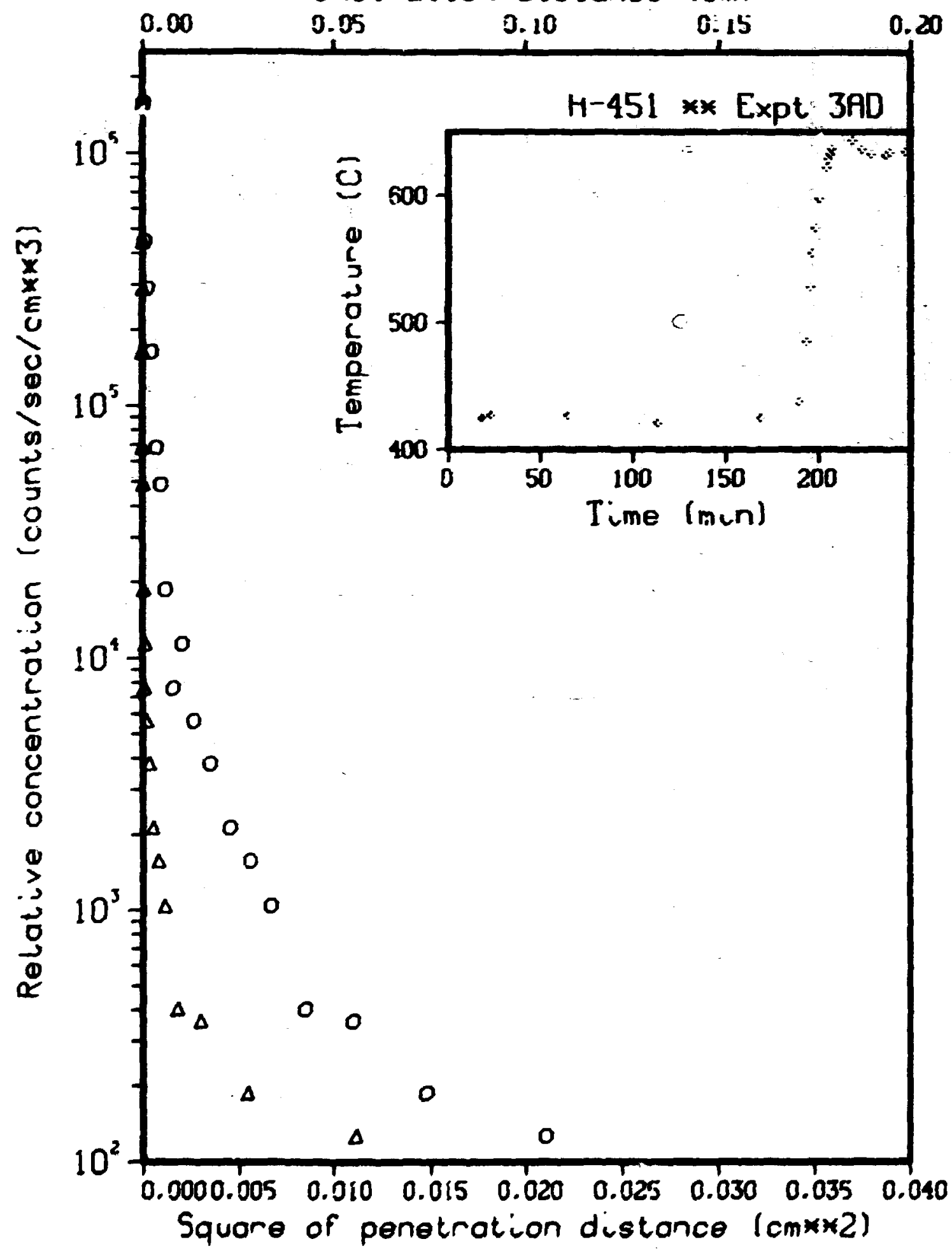




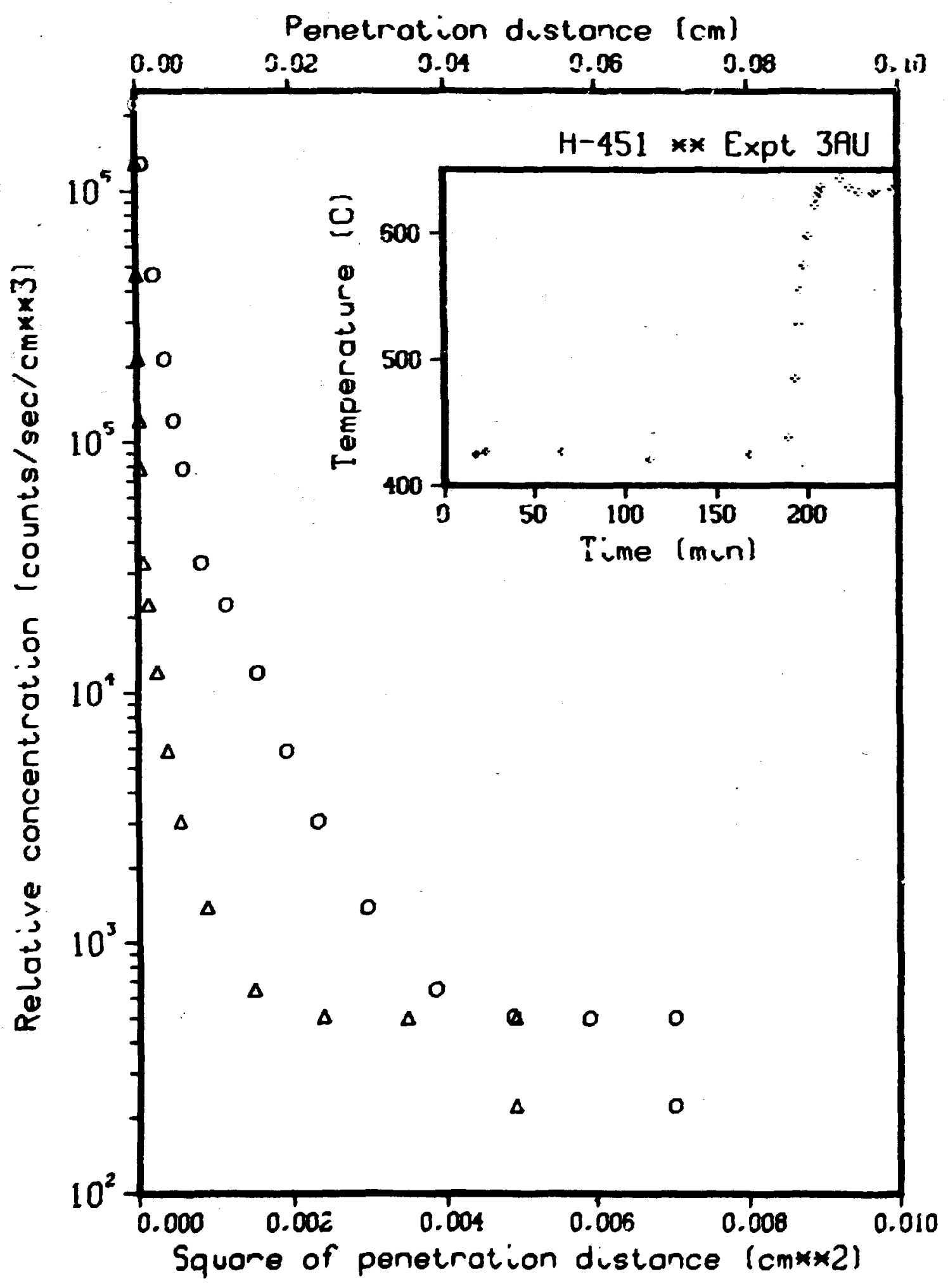


$-109-$

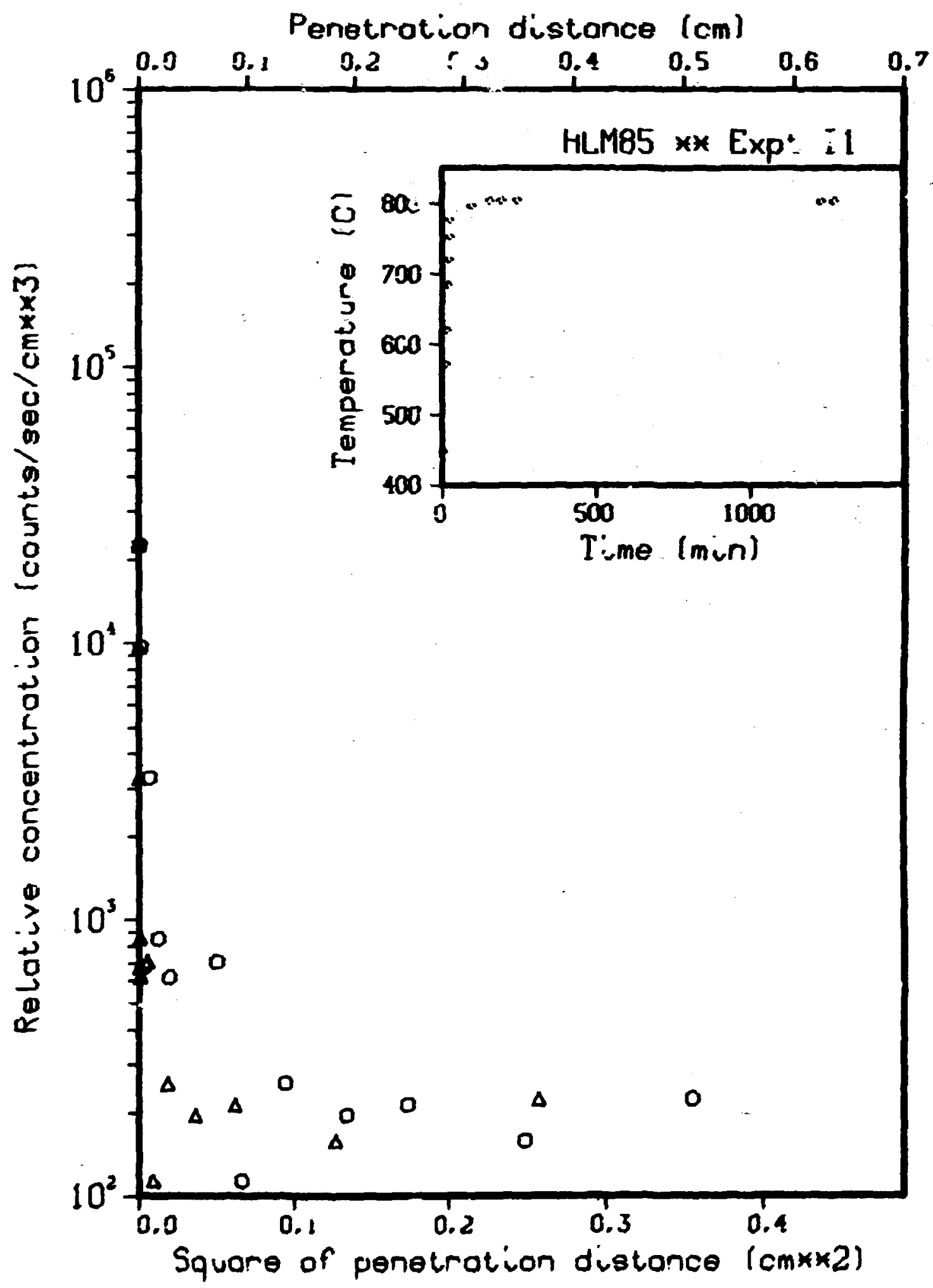




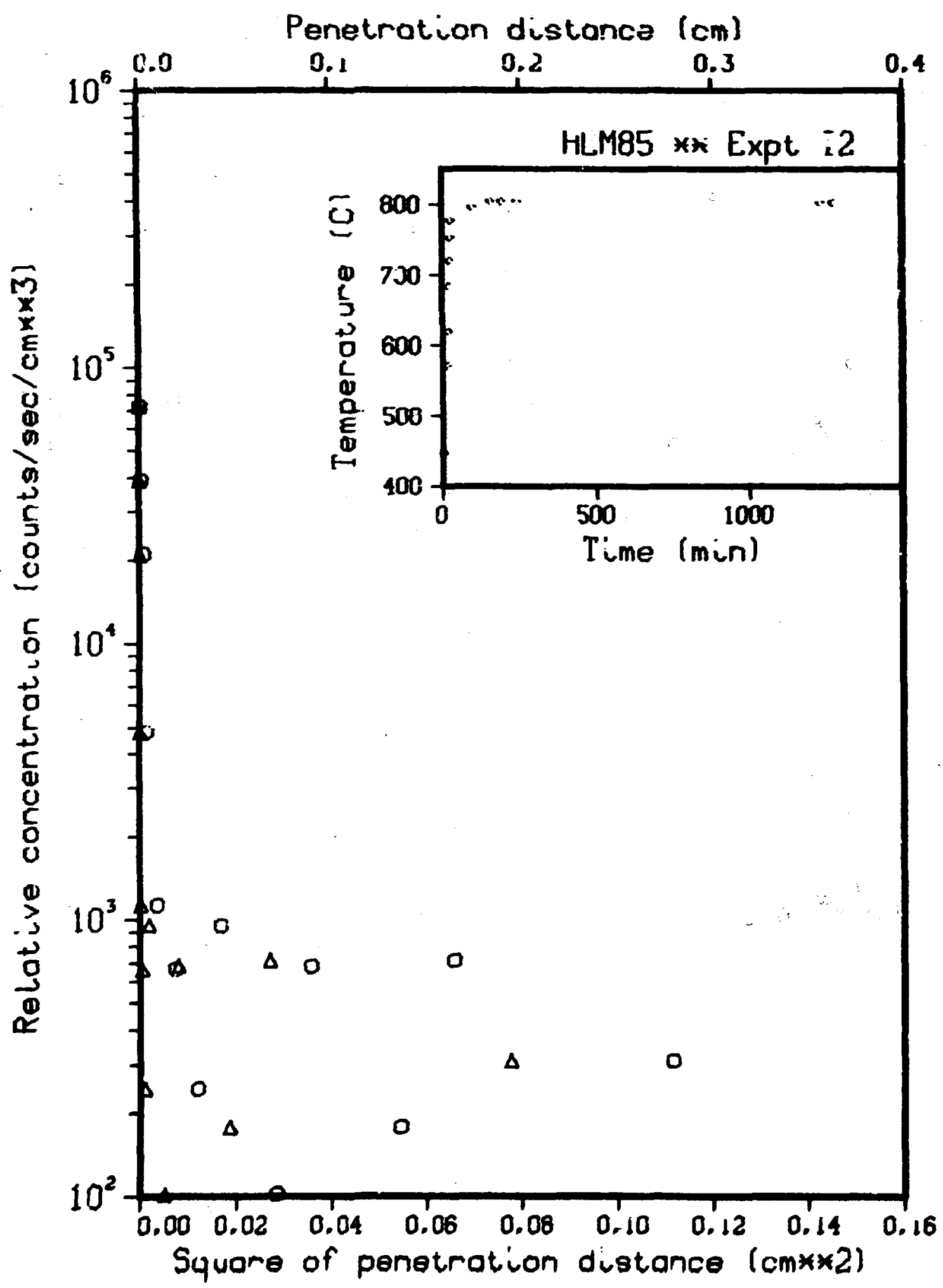




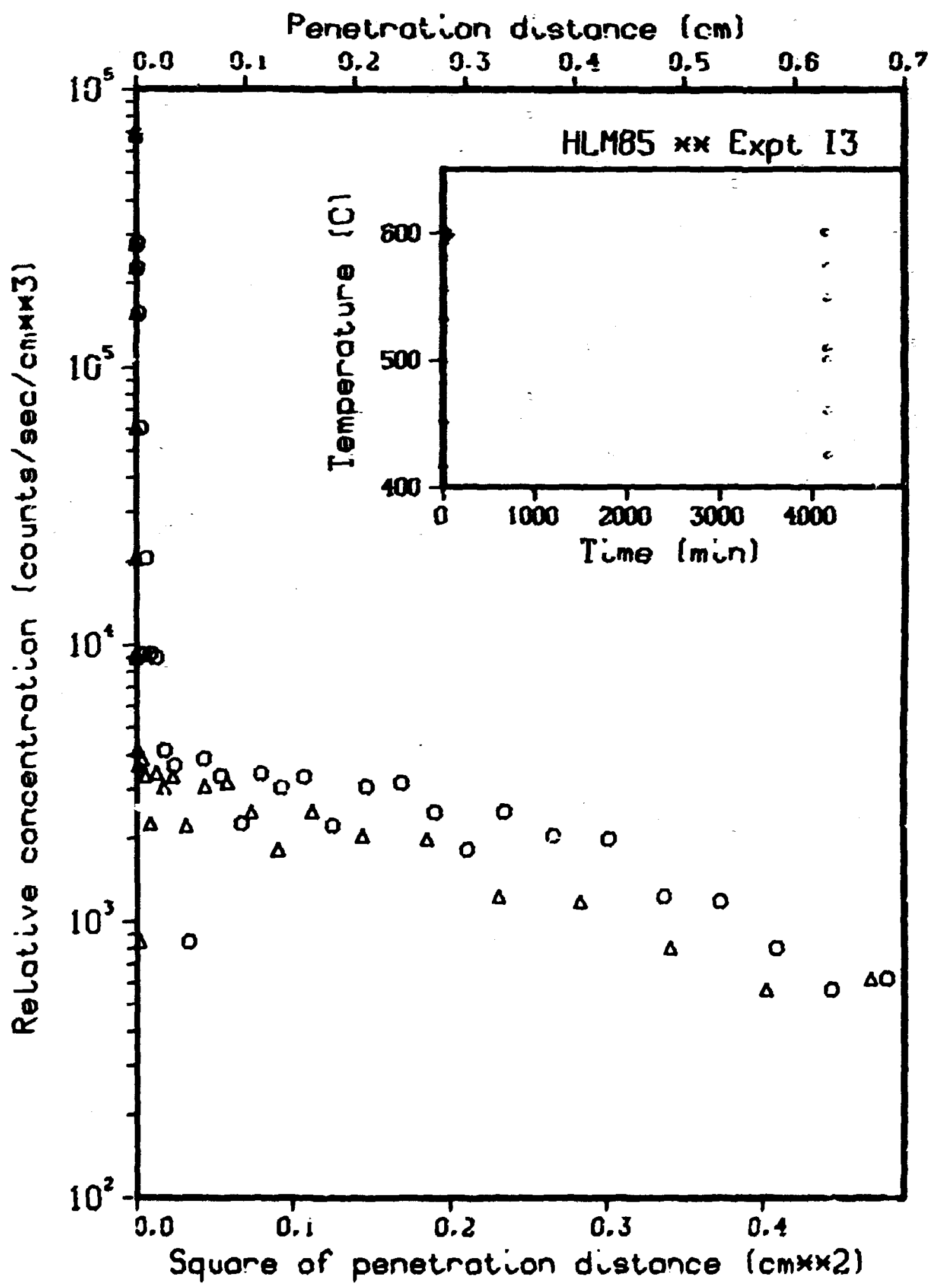




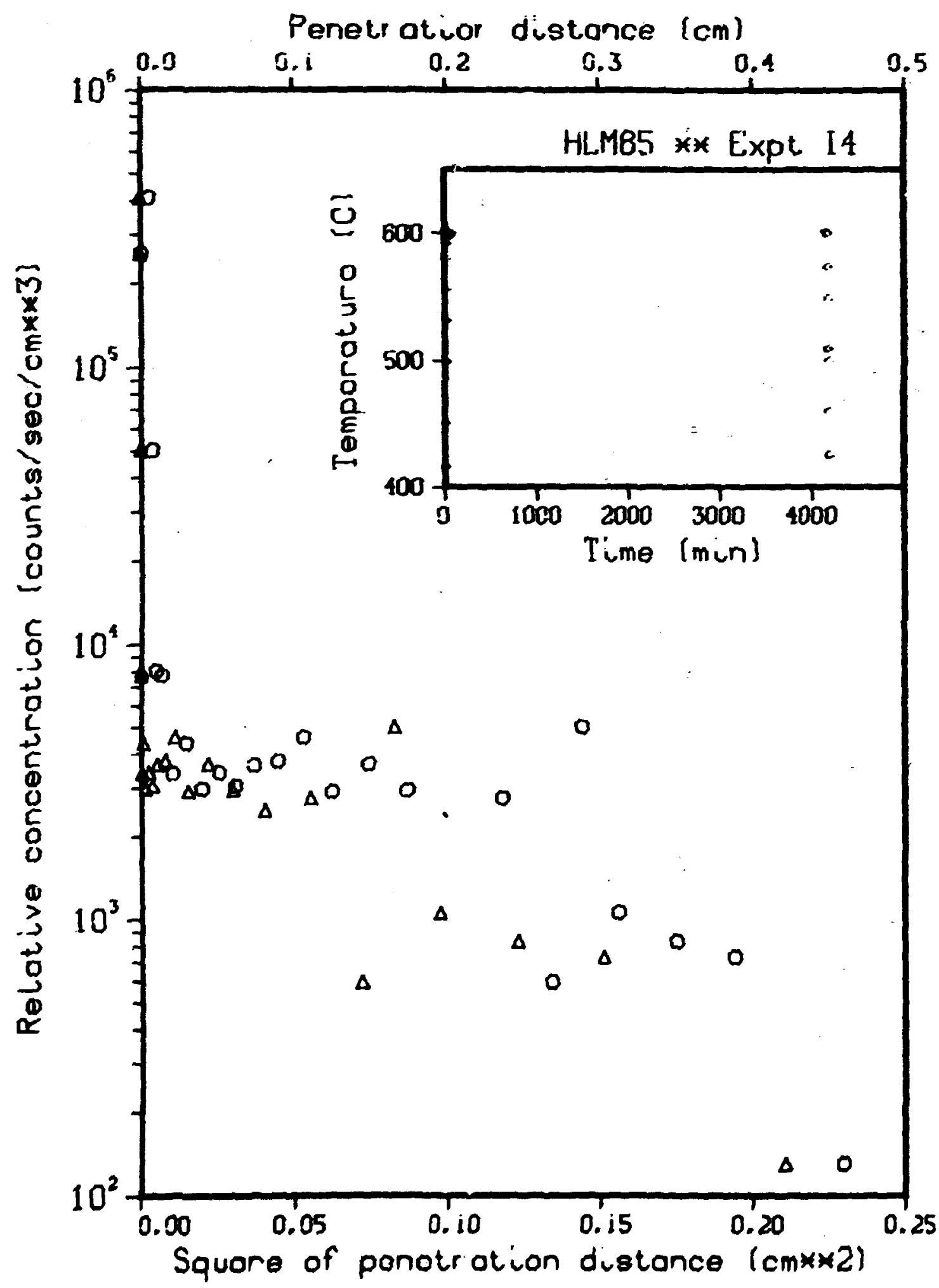




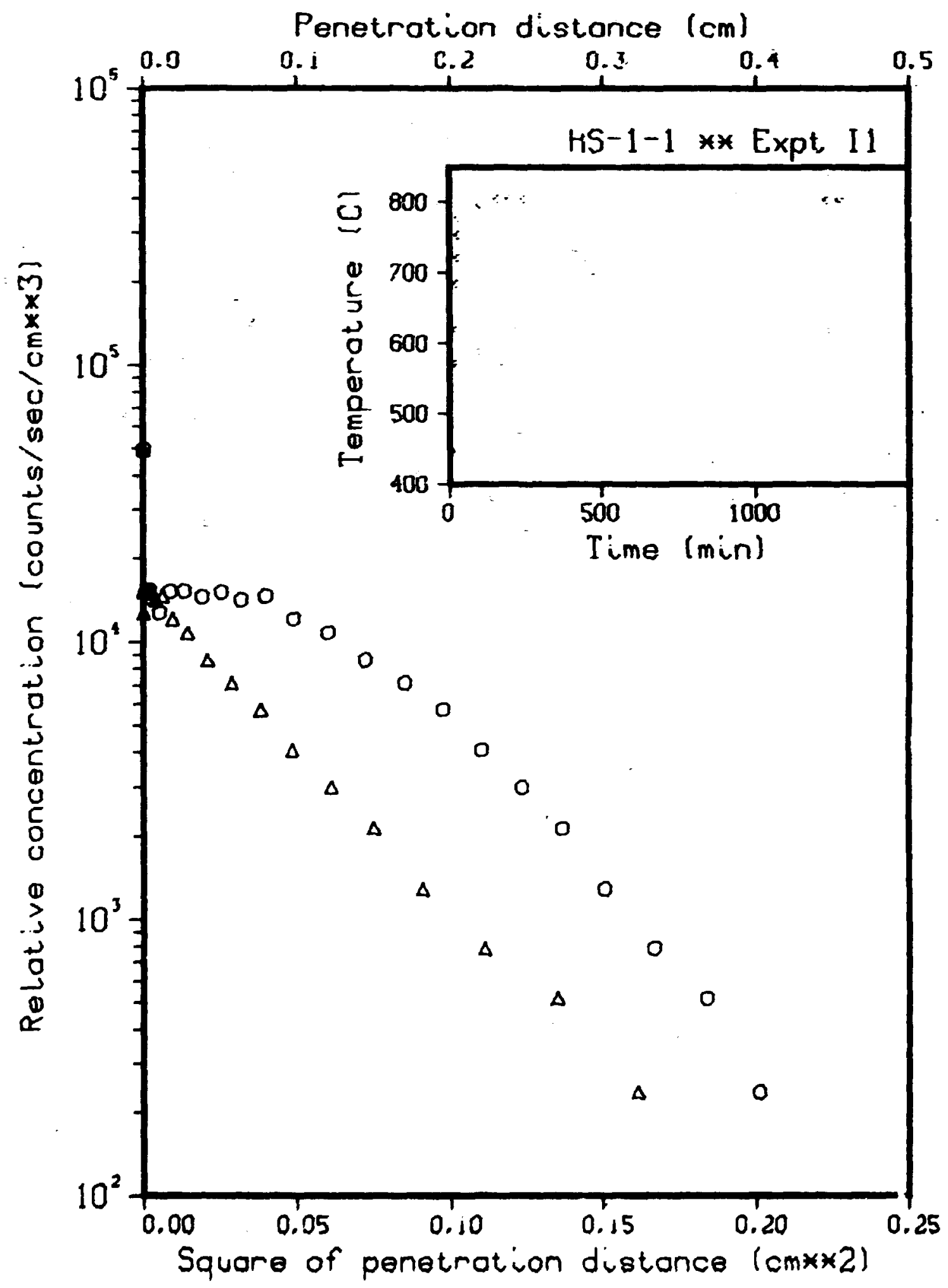




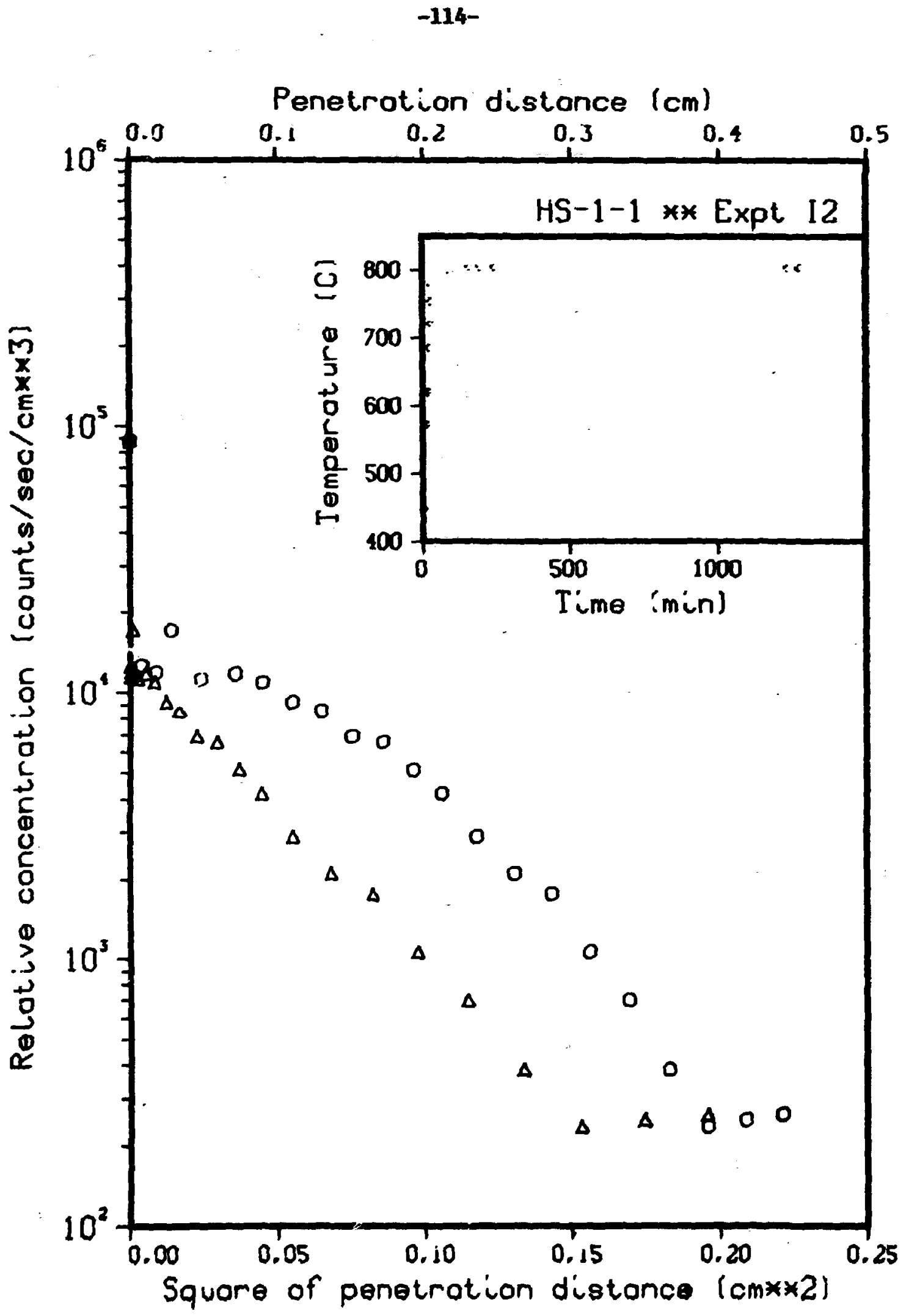


Penetrotion distonce $(\mathrm{cm})$

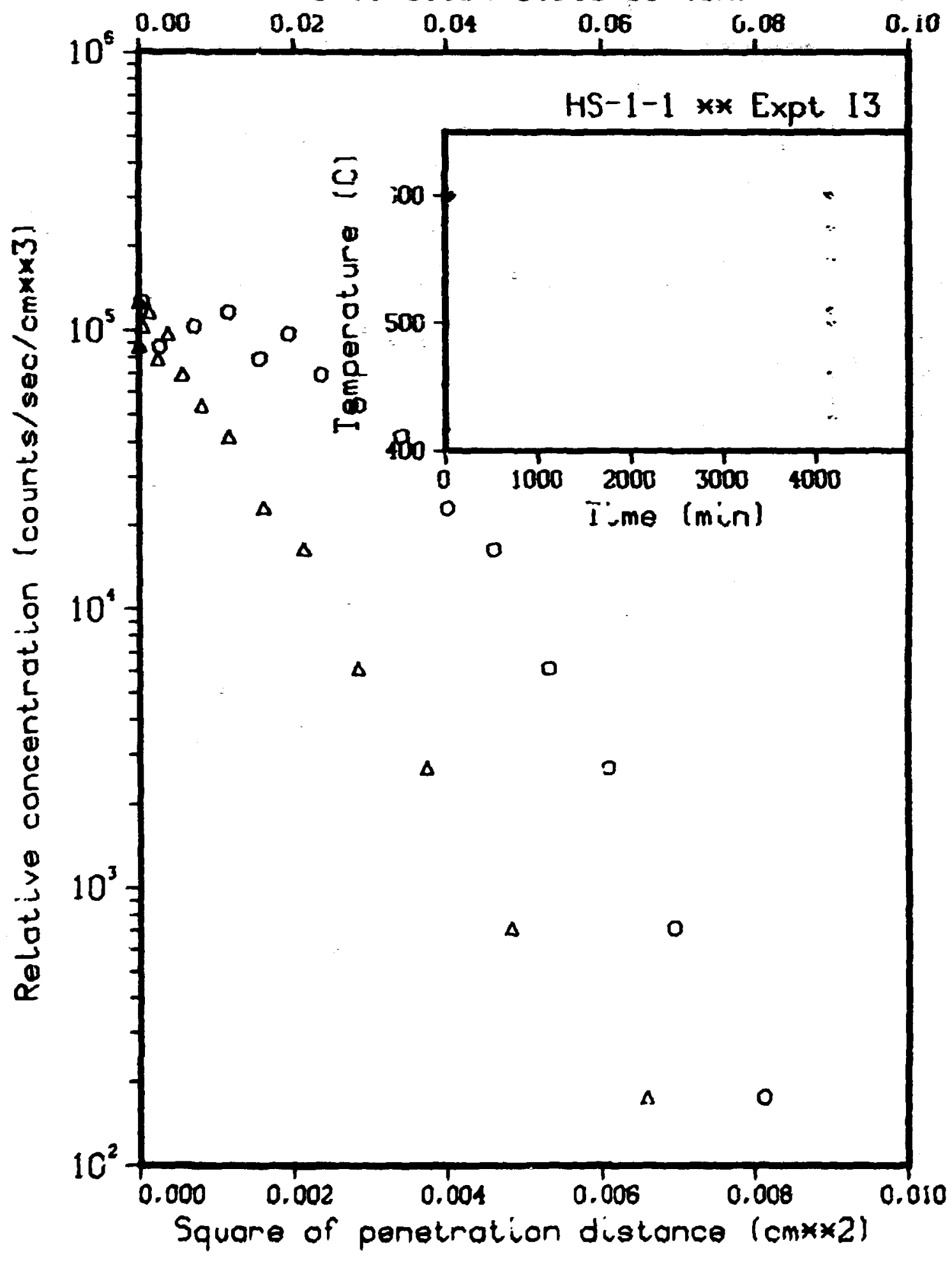




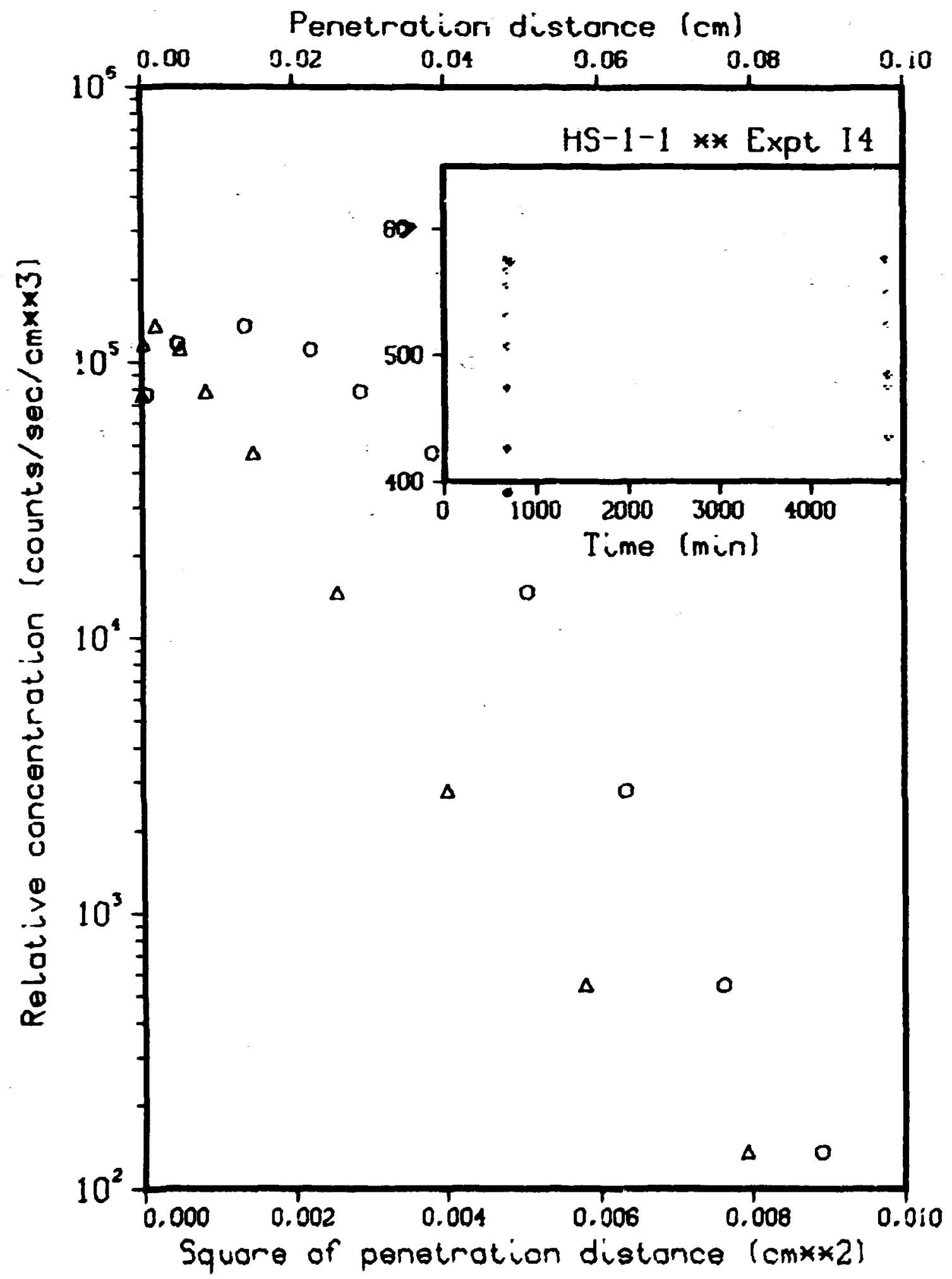




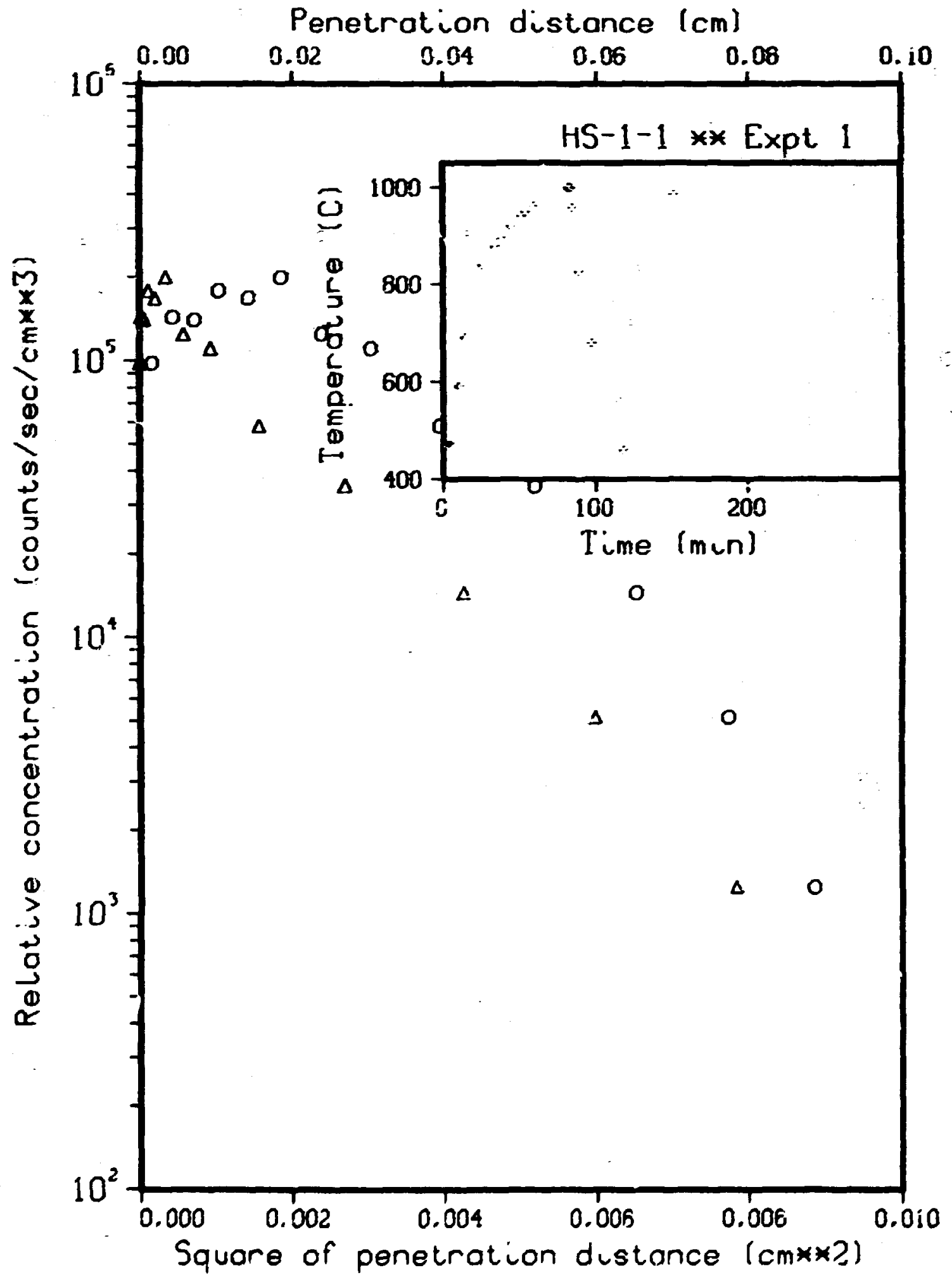




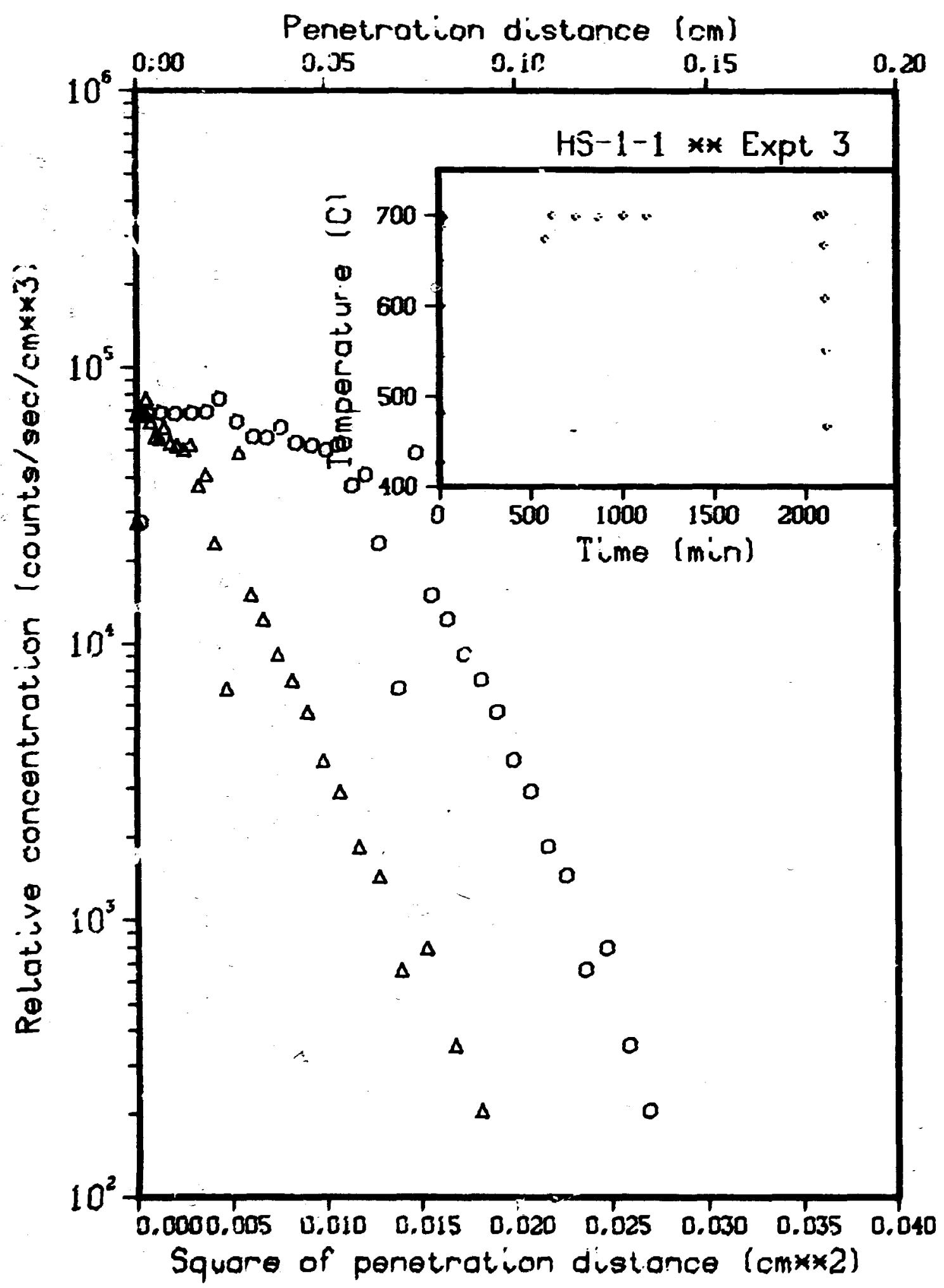




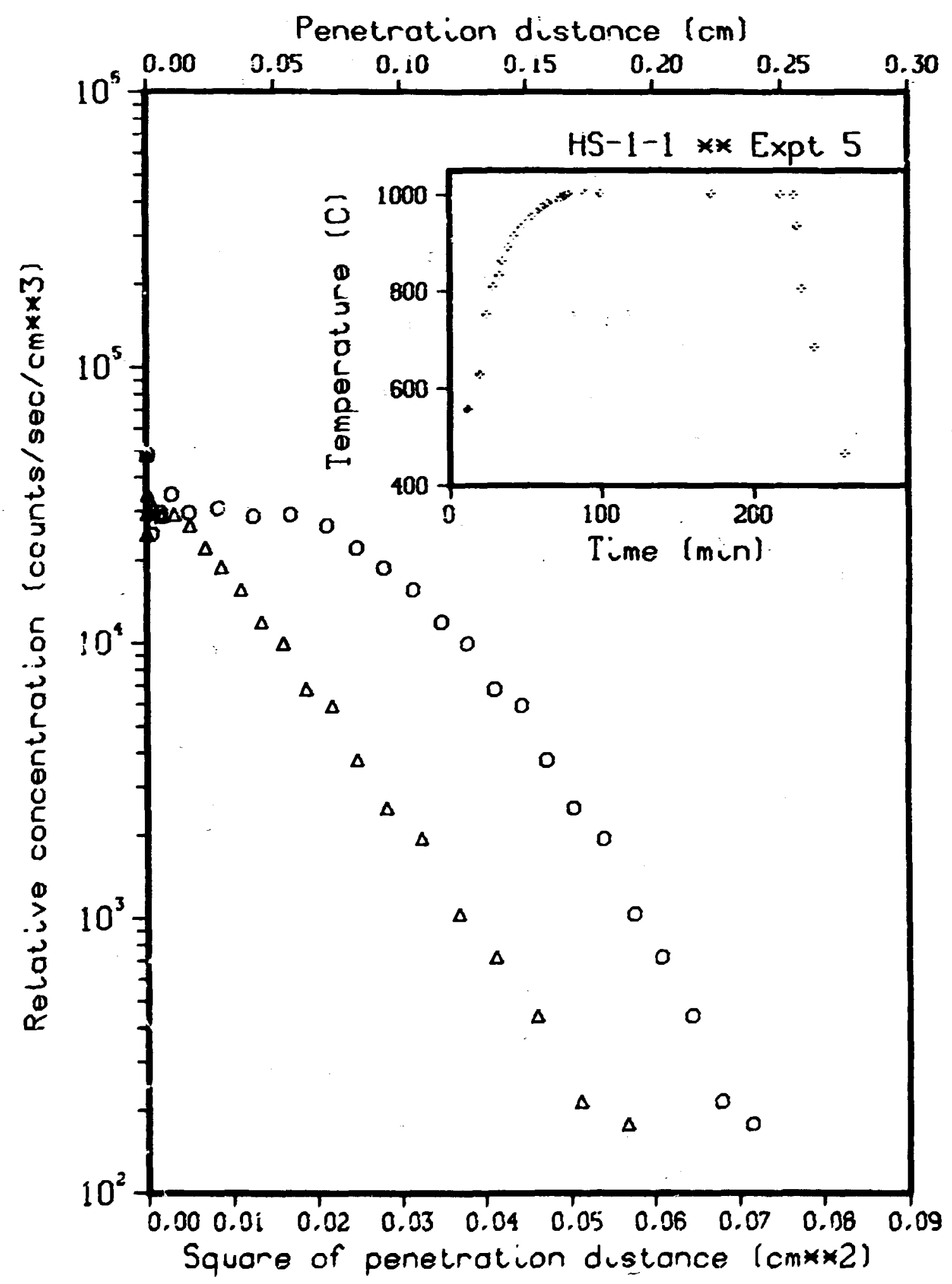


Graphical methods can be used to evaluate the dimensionless variables $u$ and $t$ of Eqs. (16) and (17). Table C.1 1s.sts values of the concentration ratio expressed in Eq. (16), whlle Table C.2 lists values of the fraction remaining of $\mathrm{Eq}$. (17) for the appropriate ranges of $u$ and $\tau$. 
Table c.1. Computed valies of the concentration-rat10 runction ${ }^{2}$ for difrusion with first-order plate-out in an Inrinitely lons medium with an Instantaneous-plane (Impulae) source

\begin{tabular}{|c|c|c|c|c|c|c|c|c|c|c|}
\hline $\mathbf{u}$ & 0.00 & 0.25 & 0.50 & 0.75 & 1.00 & 1.25 & 1.50 & 1.75 & 2.00 & 2.20 \\
\hline $\begin{array}{l}0 \\
0.05 \\
0.10 \\
0.20 \\
0.30 \\
0.40 \\
0.50 \\
0.60 \\
0.70 \\
0.80 \\
1.00 \\
1.20 \\
1.40 \\
1.60 \\
1.80 \\
2.00 \\
2.20\end{array}$ & $\begin{array}{l}1.0000 \\
0.9975 \\
0.9900 \\
0.9608 \\
0.9139 \\
0.8521 \\
0.7788 \\
0.6977 \\
0.6126 \\
0.5273 \\
0.3679 \\
0.2369 \\
0.1409 \\
0.0773 \\
0.0392 \\
0.0183 \\
0.0079\end{array}$ & $\begin{array}{l}1.0000 \\
0.9877 \\
0.9716 \\
0.9285 \\
0.8722 \\
0.8048 \\
0.7292 \\
0.6486 \\
0.5661 \\
0.4947 \\
0.3355 \\
0.2148 \\
0.1271 \\
0.0695 \\
0.0351 \\
0.0164 \\
0.0071\end{array}$ & $\begin{array}{l}1.0000 \\
0.9639 \\
0.9272 \\
0.8515 \\
0.7732 \\
0.6934 \\
0.6132 \\
0.5342 \\
0.4581 \\
0.3865 \\
0.2611 \\
0.1642 \\
0.0959 \\
0.0519 \\
0.0260 \\
0.0121 \\
0.0052\end{array}$ & $\begin{array}{l}1.0000 \\
0.9360 \\
0.8754 \\
0.7633 \\
0.6618 \\
0.5695 \\
0.4858 \\
0.4100 \\
0.3420 \\
0.2816 \\
0.1830 \\
0.1117 \\
0.0637 \\
0.0339 \\
0.0168 \\
0.0077 \\
0.0033\end{array}$ & $\begin{array}{l}1.0000 \\
0.9091 \\
0.8264 \\
0.6821 \\
0.5617 \\
0.4609 \\
0.3763 \\
0.3053 \\
0.2458 \\
0.1960 \\
0.1207 \\
0.0706 \\
0.0390 \\
0.0202 \\
0.0098 \\
0.0044 \\
0.0019\end{array}$ & $\begin{array}{l}1.0000 \\
0.8844 \\
0.7822 \\
0.6118 \\
0.4781 \\
0.3731 \\
0.2905 \\
0.2253 \\
0.1740 \\
0.1336 \\
0.0769 \\
0.0426 \\
0.0225 \\
0.0113 \\
0.0053 \\
0.0023 \\
0.0010\end{array}$ & $\begin{array}{l}1.0000 \\
0.9615 \\
0.7422 \\
0.5509 \\
0.4088 \\
0.3032 \\
0.2247 \\
0.1662 \\
0.1226 \\
0.0902 \\
0.0481 \\
0.0249 \\
0.0125 \\
0.0060 \\
0.0027 \\
0.0012 \\
0.0005\end{array}$ & $\begin{array}{l}1.0000 \\
0.8397 \\
0.7052 \\
0.4973 \\
0.3507 \\
0.2473 \\
0.1743 \\
0.1228 \\
0.0864 \\
0.0607 \\
0.0297 \\
0.0143 \\
0.0067 \\
0.0030 \\
0.0013 \\
0.0005 \\
0.0002\end{array}$ & $\begin{array}{l}1.0000 \\
0.8188 \\
0.6705 \\
0.4495 \\
0.3014 \\
0.2021 \\
0.1355 \\
0.0908 \\
0.0608 \\
0.0407 \\
0.0182 \\
0.0080 \\
0.0035 \\
0.0015 \\
0.0006 \\
0.0002 \\
0.0001\end{array}$ & $\begin{array}{l}1.0000 \\
0.8026 \\
0.6441 \\
0.4149 \\
0.2672 \\
0.1721 \\
0.1109 \\
0.0714 \\
0.0460 \\
0.0296 \\
0.0122 \\
0.0050 \\
0.0020 \\
0.0008 \\
0.0009 \\
0.0001 \\
0.0000\end{array}$ \\
\hline
\end{tabular}

2Bq. (16) In text; values plotted in Fig. 15; $T=\sqrt{k t ;} u=\frac{x}{2} \sqrt{\frac{c}{D t}}$.

${ }^{b} C R=C_{T}(x, t) / C_{T}(0, t)$; includes mohile and imobile fractions. 
4

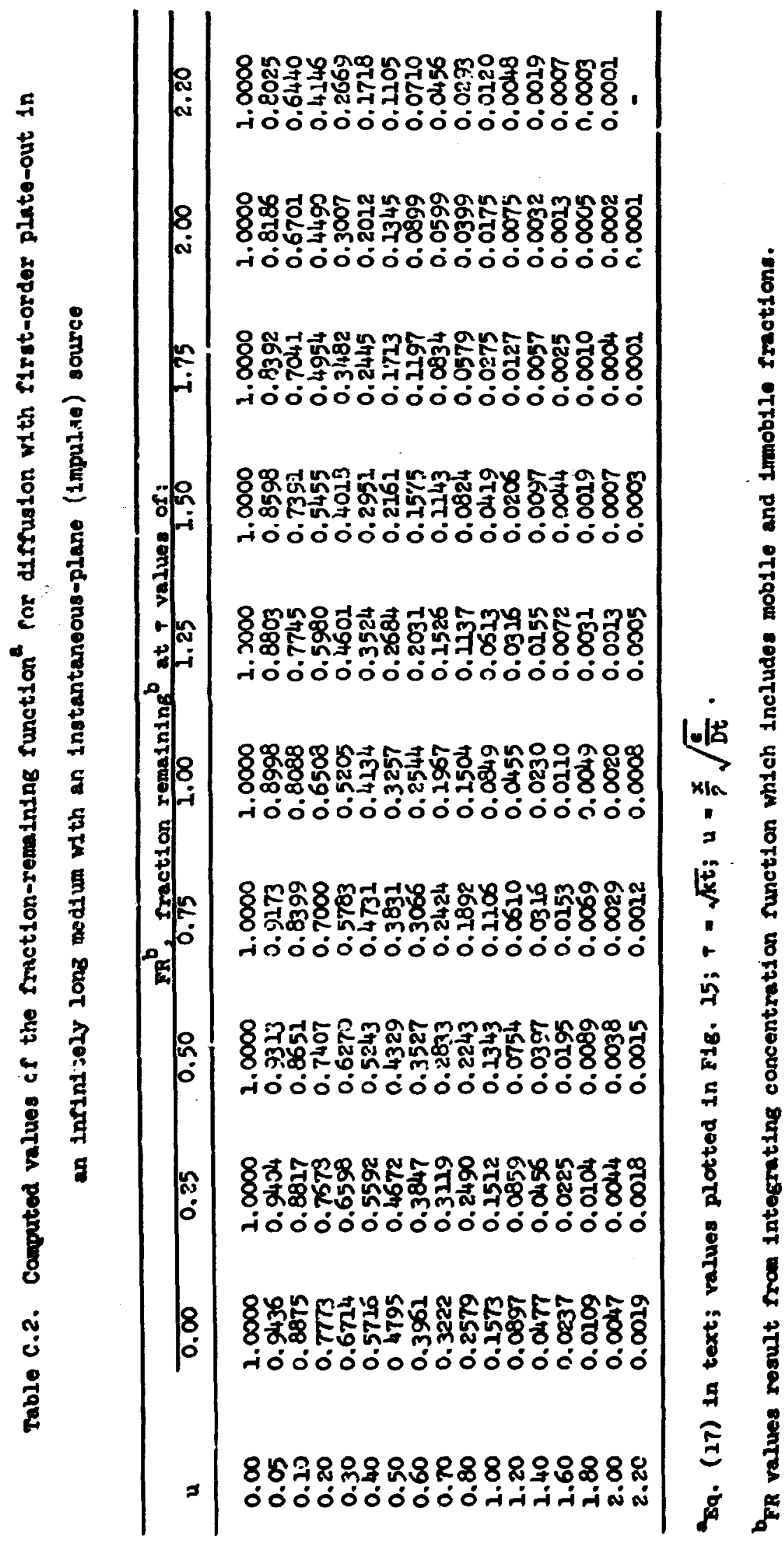




\subsection{Appendix D: Helfu Flow During Bxperiments with H-451 Graphite}

As stated fn Sect. 5.3, heliu flow through the graptite was aaintained during experiments with $\mathrm{B}-451$ for the purpose of testing for vapor-phase transport of cesitu. Figures 21-23 show that no such transport occurred under conditions of these experiments. Helfu flow data are listed in the three tables of this appendix. The first five lines In each table are self-explanatory; data, of which there are two sets per line, are as follows:

FTHIE = the tine required for $10 \mathrm{~cm}^{3}$ of helive (at nearly standard condicions) to flow through the two abutting samples of graphite, s;

PFORE = the fore pressure on the graphite, psig;

PBACK = the back pressure on the graphite, psig;

DELP - the pressure differential across the graphite samples (wre accurate than PrORE-PBACK), torr;

FIDPP = temperature of the graphite at the time of measurenent, ${ }^{\circ} \mathrm{C}$;

THRS = the clock hour at the time of measurement;

TiNS = the clock minute at the time of measurement.

These data are read with format $(2(76 ., 275 ., 276 ., 13,12))$.

Permeabilities calculated from the tabular data are plotted in Figs. D-1, D-2, and D-3 to provide a qualitative view of the tightness with which the graphite was sealed to the 0.006-in.-wall stainless steel tubing (Figs. 8 anc 10).

Therwal cycling in experiment H-451.1 (suples 1D and 10 of Appendixes $A$ and B) was as follows: (1) heat to about $635^{\circ} \mathrm{C}$ for ${ }^{137} \mathrm{C}$. diffusion experinent; (2) $c 001$ to room temperature; (3) rehest to $400^{\circ} \mathrm{C}$ for permeability measurements; (4) $\operatorname{cool}$ to $300^{\circ} \mathrm{C}$, then successively to 200,100 , and $22^{\circ} \mathrm{C}$ for further perweability measurements, as shown in F1g. D-1. It Is apparent that the graphite--stainless steel sesl was relatively tight at 400 and $300^{\circ} \mathrm{C}$ but leaked as the eystem cooled to room temperature. The leak was reduced, or elininated, before the 


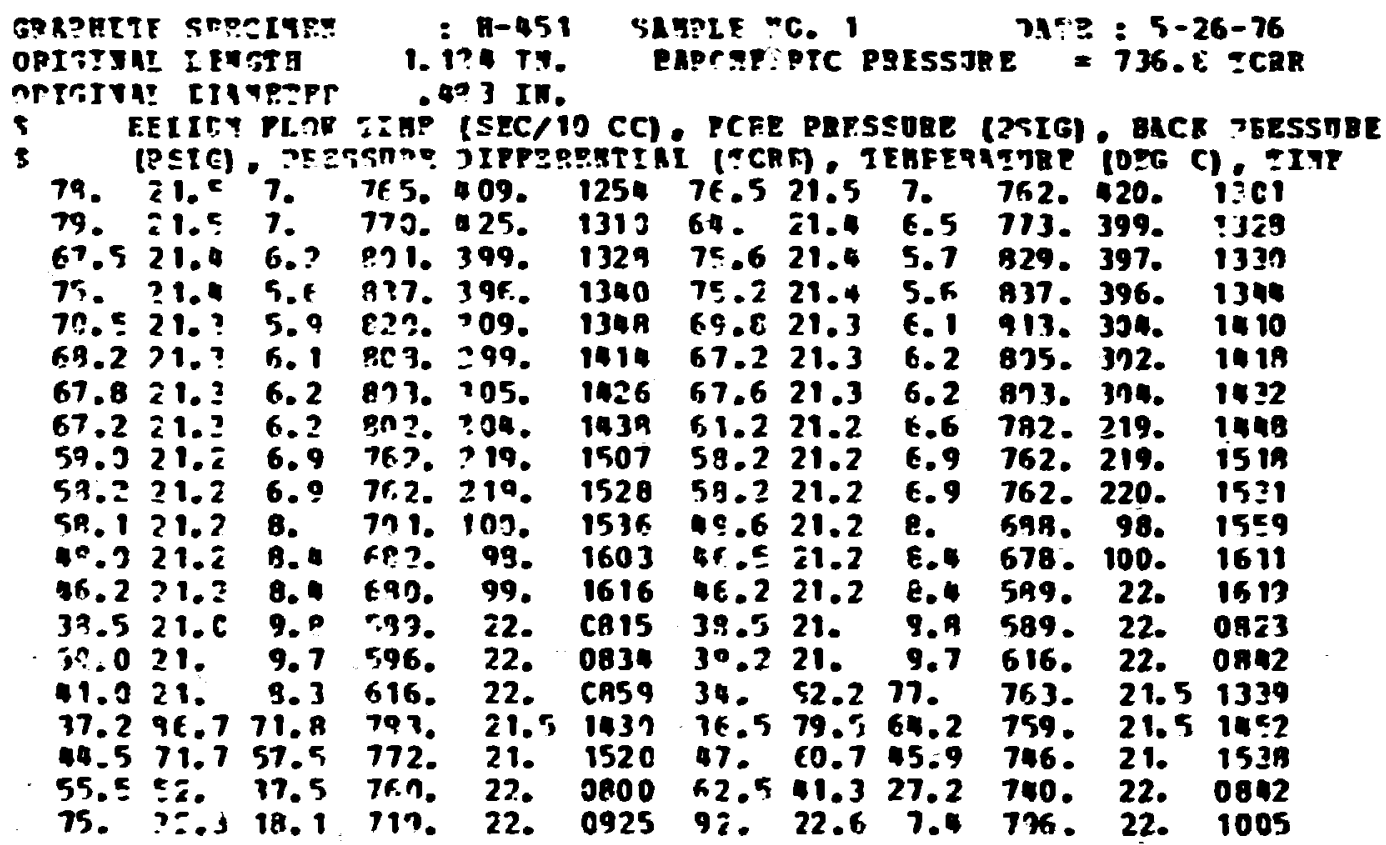

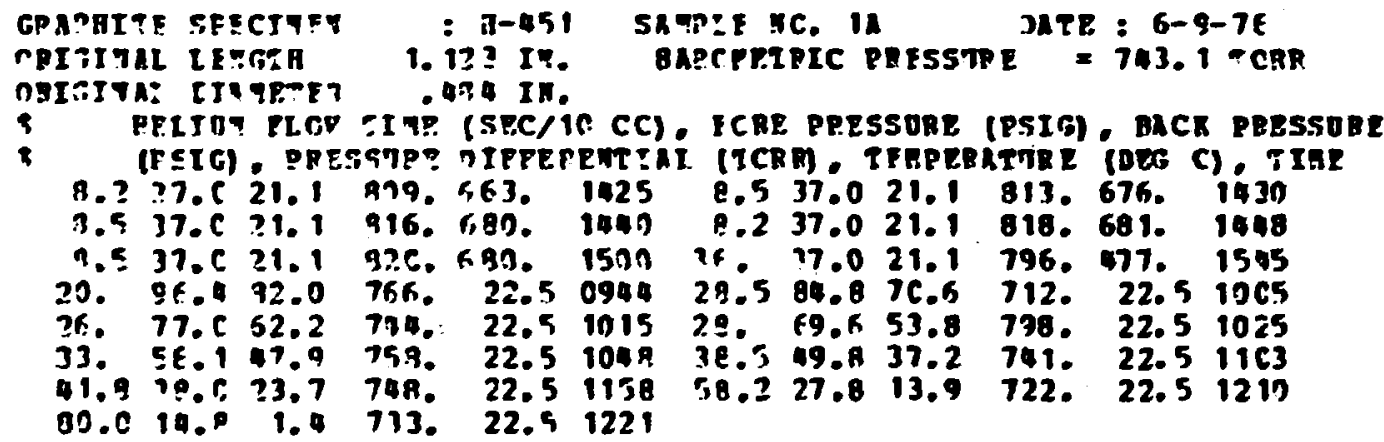

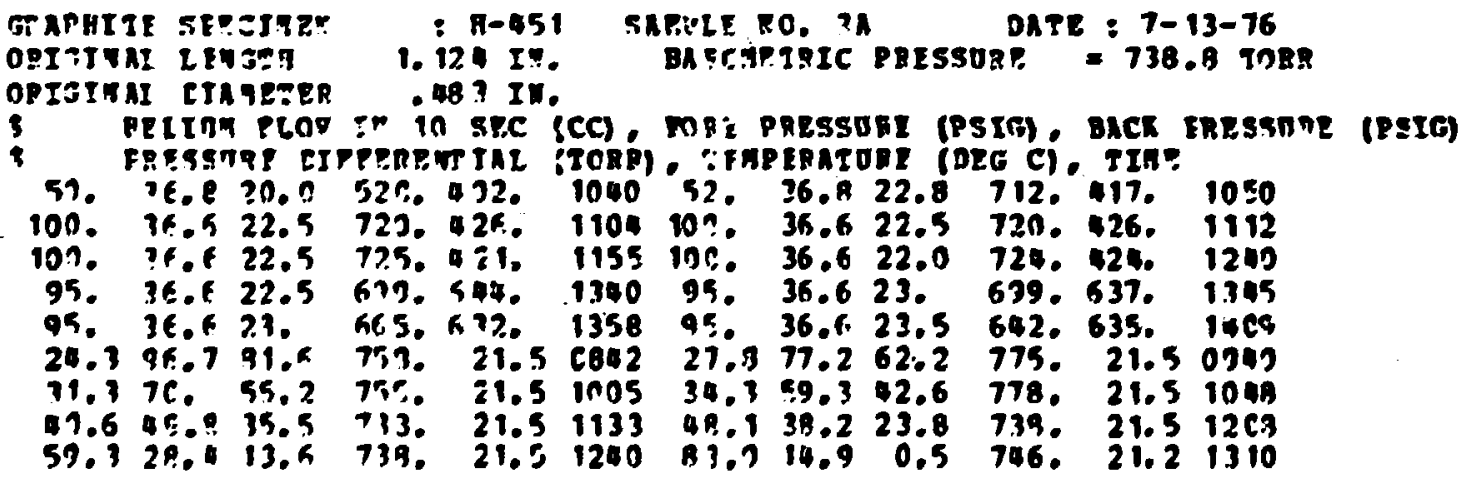




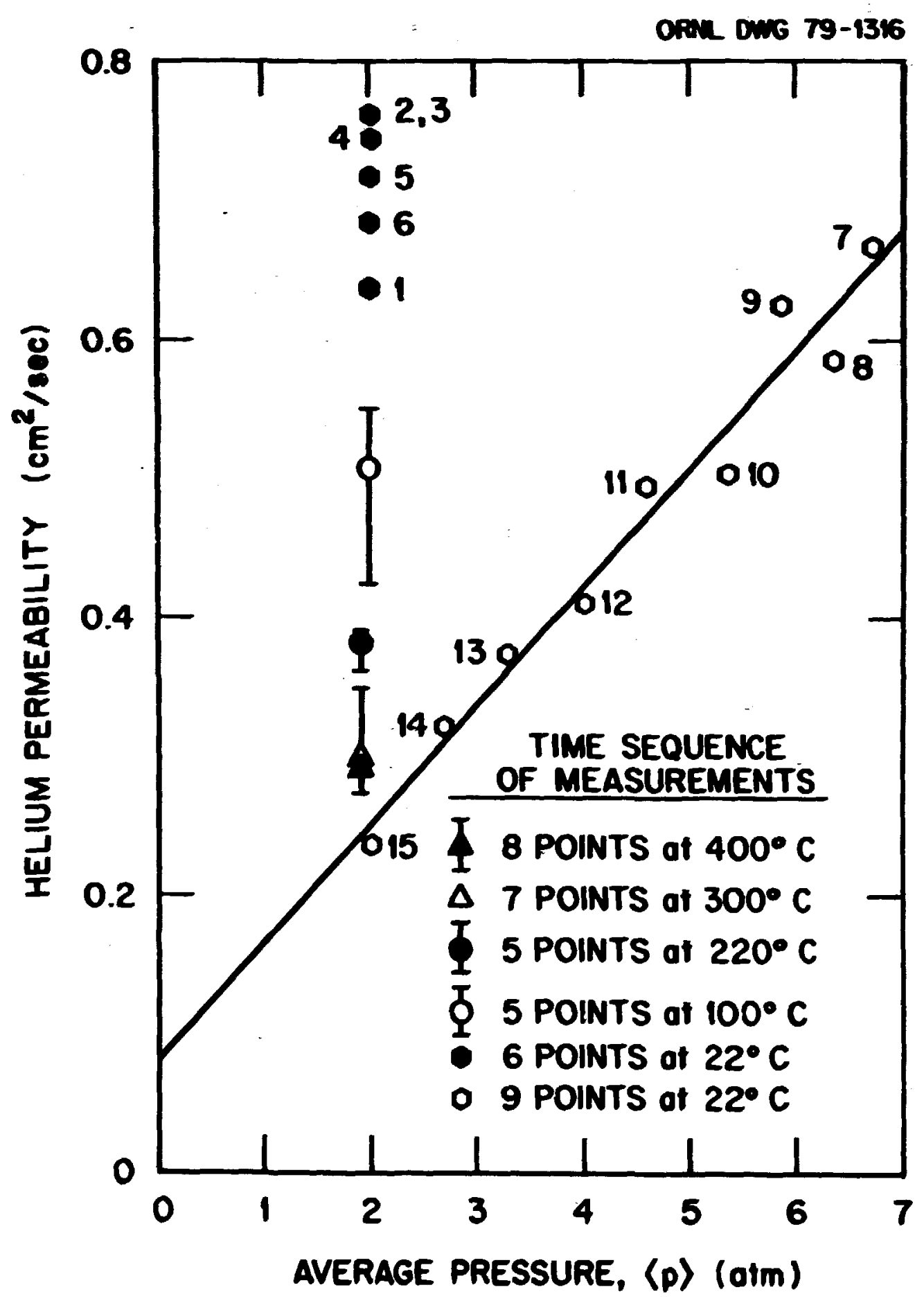

F1g. D-1. Helfum perteabilities measured wth H-451 graphite samples $1 \mathrm{U} / 1 \mathrm{D}$. 


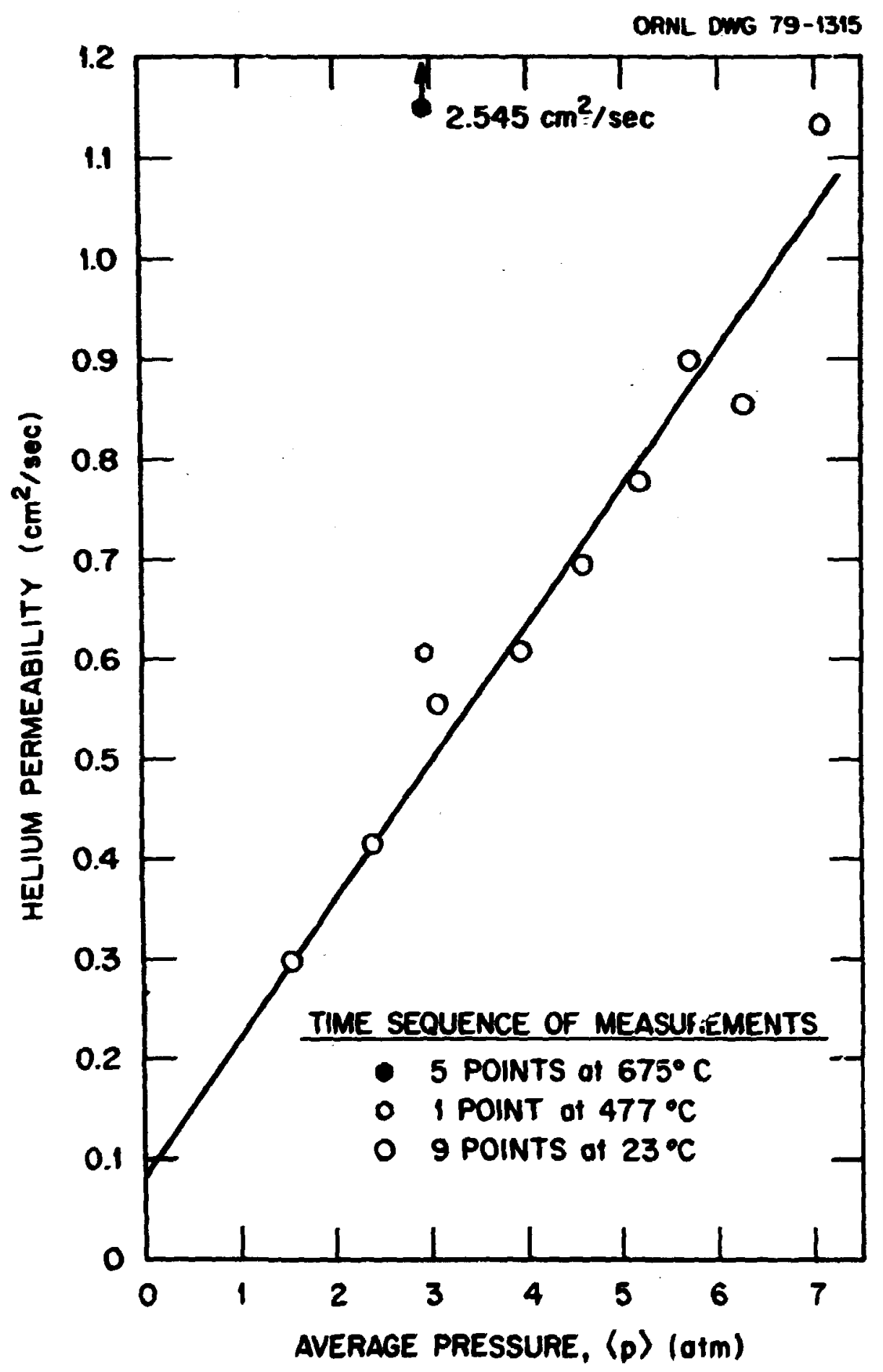

18. D-2. Helium perweablities meseured with H-451 graphite samples 1AU/LD. 


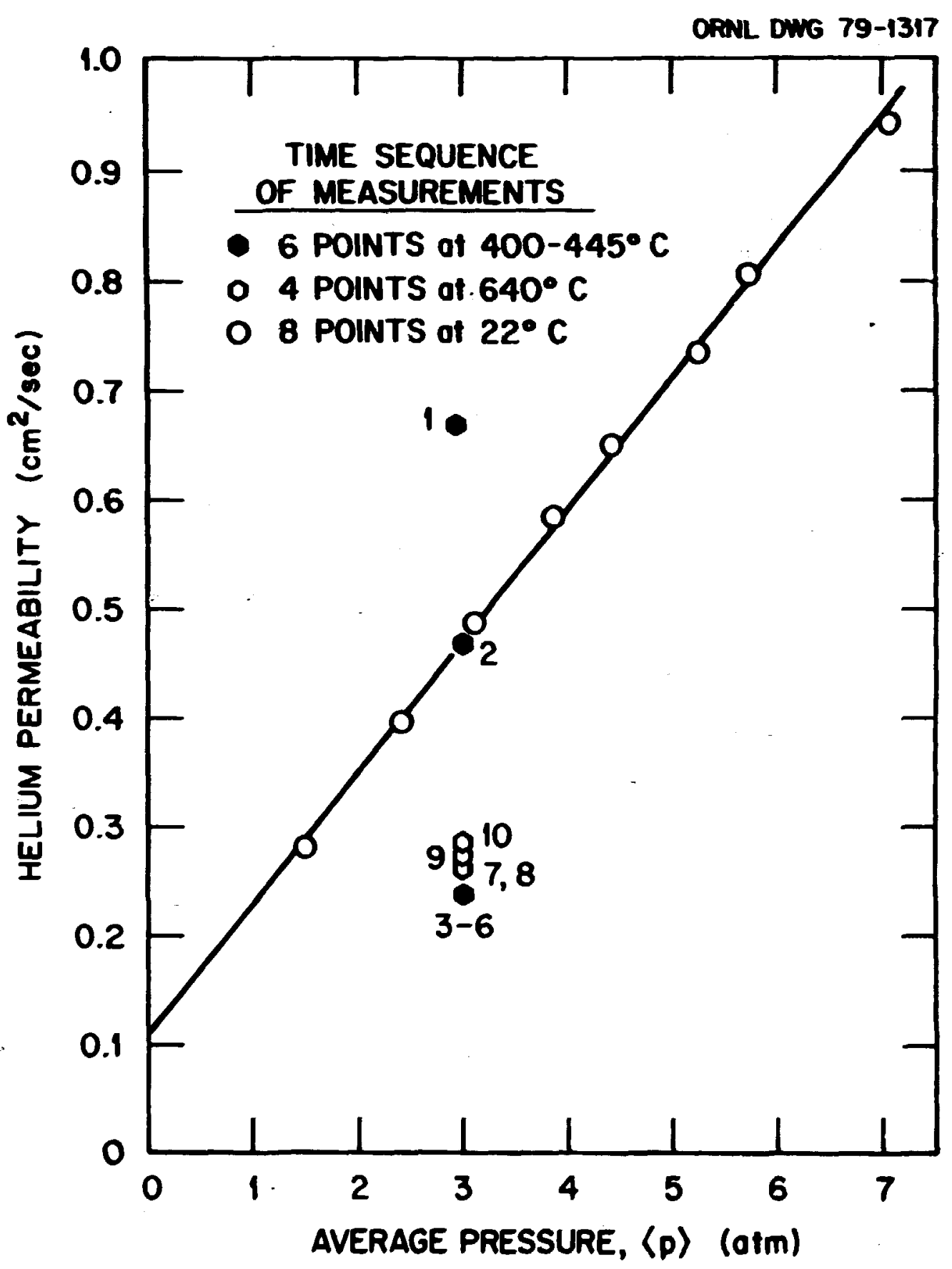

F1g. D-3. Helium permeabilities measured with H-451 graphite samples 3AU/3AD. 
pressure vas increased to 7.2 atm by increasing pressure on the jack (Fig. 8); calculated permeability parameters of the linear least-squares fit are given below. In Fig. D-1, numbers beside points are the orders In wich data vere taken.

Thermal cycling in experiment H-451.1A (saples $1 A D$ and $1 A U$ of Appendixes A and B) was as follous: (1) heat saples to about $675^{\circ} \mathrm{C}$ for ${ }^{137} \mathrm{Cs}$ diffusion experiment, taking permeability data during the time at this temperature; ( 1 ) $\operatorname{cool}$ to $477^{\circ} \mathrm{C}$ and take one set of permeability data; (3) $\operatorname{cool}$ to room temperature and take additional data.

Thermal cycling in experiment $h-451.3 A$ (saples $3 A D$ and $3 A D$ of Appendixes A and B) was as follows: (1) heat samples to $400^{\circ} \mathrm{C}$ and start taking permeability data; (2) continue heating to about $640^{\circ} \mathrm{C}$ for ${ }^{137} \mathrm{Cs}$ diffusion and simultaneously take perweability data; (3) cool to roos temperature to take additional data.

It is not possible to state that no helium bypassed the two graphite samples of each experiment during the times that these were at anneal temperature. The data of Figs. D-1, D-2, and D-3, do, however, suggest that. a significant fraction of the helium did pass through the graphite. This is particularly apparent In Fig. D-3.

Permeability parameters for $21-23^{\circ} \mathrm{C}$ obtained by linear least-squares analysis (the straight lines of Figs, D-1, D-2, and D-3), and referred to Eq. (D-1), are tabulated below. In each heading, the term $\hat{S}()$ is the standard deviation of the quantity in parentheses; $\hat{S}(f i t)$ is the standard deviation of fit of data to the model, namely to the equation

$$
R=D_{2 R}+\left(B_{0} / n\right)\langle p\rangle \text {. }
$$

\begin{tabular}{|c|c|c|c|}
\hline Expt. & $\begin{array}{l}S(f \pm t) \\
\left(\mathrm{cm}^{2} / \mathrm{s}\right) \\
\end{array}$ & $\begin{array}{c}D_{2 K} \pm \hat{s}\left(D_{2 K}\right) \\
\left(\mathrm{cm}^{2} / \mathrm{s}\right) \\
\end{array}$ & $\begin{array}{l}B_{0} / n \pm \hat{s}\left(B_{0} / n\right) \\
\left(\mathrm{cm}^{2} \mathrm{~g}^{-1} \mathrm{~atm}^{-1}\right)\end{array}$ \\
\hline 1 & 0.0286 & $0.0813 \pm 0.0292$ & $0.0853 \pm 0.0061$ \\
\hline IA & 0.0518 & $0.0848 \pm 0.0472$ & $0.1378 \pm 0.0099$ \\
\hline $3 A$ & 0.0096 & $0.1123 \pm 0.0089$ & $0.1196 \pm 0.0020$ \\
\hline
\end{tabular}

